\title{
3D PRINTED PHANTOM TO MIMIC DYNAMIC SOFTENING OF CERVIX DURING PRE-LABOUR
}

By

\author{
Jung Soo Kim \\ BEng, University of Waterloo, 2008 \\ BASc, Ryerson University, 2013
}
A thesis presented to Ryerson University
In partial fulfillment of the
requirements for the degree of
Master of Applied Science
in the Program of
Electrical and Computer Engineering

Toronto, Ontario, Canada, 2016

CJung Soo Kim 2016 


\section{AUTHOR'S DECLARATION}

I hereby declare that I am the sole author of this thesis. This is a true copy of the thesis, including any required final revisions, as accepted by my examiners. I authorize Ryerson University to lend this thesis to other institutions or individuals for the purpose of scholarly research I further authorize Ryerson University to reproduce this thesis by photocopying or by other means, in total or in part, at the request of other institutions or individuals for the purpose of scholarly research. I understand that my thesis may be made electronically available to the public. 
3D printed phantom to mimic dynamic softening of cervix during pre-labour

Master of Applied Science

2016

Jung Soo Kim

Faculty of Engineering and Architectural Science, Electrical and Computer Engineering

Ryerson University

\begin{abstract}
It is thought that through the development of more realistic training models for midwives and obstetricians it may be possible to reduce the overuse of labour induction. To this end we demonstrate a method for creating pneumatically-controlled phantom cervixes using thermoplastic elastomer, filled with a granular material. The maximum spring constant of the phantom cervix was measured to be $10.5 \mathrm{~N} / \mathrm{m}$ at $-20 \mathrm{kPa}$ deflated air (vacuum) and the minimum spring constant measured was $5.3 \mathrm{~N} / \mathrm{m}$ at $20 \mathrm{kPa}$ inflated air. The true stress measured on these elastomeric phantom cervixes indicated a maximum stress of $133 \mathrm{kPa}$ and a minimum stress of $94 \mathrm{kPa}$ at 0.15 strain. Discrimination and threshold tests demonstrated that people can distinguish between the hard and soft states of the phantom. Future work will focus on increasing the softness of these devices.
\end{abstract}




\section{Acknowledgements}

I would like to thank my supervisor, James Smith, for sharing his insight and for his open mindedness and generosity. Thanks to Derek Lobb, an associate professor in the department of obstetrics and gynecology, who allowed us to have access to fresh cervix tissue and providing insights regards to dilation of cervix. Thanks to midwifery people for providing us with constant feedback of the challenges they face with cervix during pre-labour. Thanks to David Dider for inviting us to his lab, Think2Thing, and sharing his insights and capability of 3D printers. Thanks to David Payton from Parker Canada Division for consulting and providing pneumatic system components. Thanks to Jim Koch for helping us with cutting and milling when we built the testing bed. Thanks to Jason Nolan and Urban Energy Center for let us use their 3D printer when we were in rush. Lastly, special thanks to Michelle Luk, Jamil Jivraj, Ronnie Wong and Zafar Sayed, graduate/PhD students, for helping out with everything. 


\section{Contents}

Author's Declaration $\quad$ ii

Abstract iii

Acknowledgements $\quad$ iv

List of Tables $\quad$ vii

List of Figures $\quad$ viii

1.0 Introduction $\quad 1$

1.1 Problem Overview 1

1.2 Methods and Results 2

$\begin{array}{ll}2.0 \text { Literature Review } & 4\end{array}$

2.1 Symptoms $\quad 4$

2.2 Anatomy and Physiology of Cervical Ripening 4

2.3 Cervical Dilation Graph 6

$\begin{array}{ll}2.4 \text { The Bishop Score } & 7\end{array}$

2.5 Mechanical Properties of Cervical Tissue 10

2.6 False Diagnostic and Symptomatic Problems With Preterm Birth 11

2.7 Balloon Dilators and Tractive Force 12

$\begin{array}{ll}2.8 \text { 3D Printer Technology } & 14\end{array}$

2.9 3D Printing Elastomer 14

2.10 Soft Robotics $\quad 15$

2.11 Phantom Cervix: A Biomedical Soft Robot 16

2.12 Ideation of the Phantom Cervix 16

2.13 Testing Platform $\quad 17$

$\begin{array}{ll}3.0 \text { Methods } & 18\end{array}$

$\begin{array}{ll}3.1 \text { Balloon Cervix } & 18\end{array}$

3.2 Design Approach 1: Silicone/Rubber cured Cervix 20

3.2.1 Overview of Lessons Learned 23

3.3 Design Approach 2: 3D Printed Cervix 23

3.4 3D printing a Simplified Cervix Model 26 
3.5 Pneumatic System 32

3.6 Testing platform $\quad 35$

3.7 Force Measurement Device Calibration / Verification 36

3.7.1 Measurement Procedure $\quad 40$

$\begin{array}{ll}4.0 \text { Results } & 42\end{array}$

5.0 Discussion $\quad 56$

$\begin{array}{ll}6.0 \text { Conclusion } & 65\end{array}$

$\begin{array}{ll}\text { Appendices } & 67\end{array}$

$\begin{array}{ll}\text { References } & 87\end{array}$ 


\section{List of Tables}

Table 1: Description of Cervical Dilation ad Effacement 9

$\begin{array}{lr}\text { Table 2: Sample Labels } & 10\end{array}$

Table 3: Materials Used for Curing Process 26

Table 4: Materials Used for 3D Scanning and 3D printing 27

Table 5: Phantom Cervix test for various wall thickness $\quad 27$

Table 6: Durability and Repeatability test with various wall thickness 30

Table 7: Materials Used for Building Pneumatic System 34

Table 8: Materials Used for Building Testing Platform 34

Table 9: Linear Actuator Unit Conversion Table 36

Table 10: Force Sensor Unit Conversion Table 38

Table 11: Force Sensor Reading versus Masses for consistency test 39

Table 12: Average value of the force measurements at the maximum depth of $1.45 \mathrm{~mm}$ on the phantom cervix

Table 13: Maximum Force Measured (g) at different Pressure Level for Sample A of the phantom cervix

Table 14: Maximum Force Measured (g) at different Pressure Level for Sample B of the phantom cervix

Table 15: Maximum Force Measured (g) at different Force exertion point for Sample A of the phantom cervix

Table 16: Maximum Force Measured (g) at different Force exertion point for Sample B of the phantom cervix 53

Table 17: Spring Constant (N/m) and True Stress ( $\mathrm{kPa}$ ) measure for all pressure 


\section{List of Figures}

Figure 1: Average cervical stroma response to uniaxial compression cycles, adapted from [27]

Figure 2: Average cervical stroma response to ramp-relation in (a) unconfined compression and (b) confined compression, adapted from [27]

Figure 3: The cervix balloon prototype (left) and simplified representation (Image Source: Luk, Michelle; Jung, Kim; Lobb, Derek; Smith, James Andrew. A Novel Cervical Model for Use in Obstetrics Simulation Training. Unpublished Manuscript. Ryerson University, 2014).

Figure 4: Particle Jamming

Figure 5: 3D printed mold and inner support for silicone cured cervix

Figure 6: Silicone-Rubber Cured Cervix from 3D printed mold

Figure 7: Motorized two degree of freedom Latex-Rubber Curing platform

Figure 8: Latex-Rubber Cured Cervix

Figure 9: Cervix Tissue sample for 3D scan

Figure 10: 3D scanned Cervix Tissue

Figure 11: 3D model constructed from the 3D scan of Cervix Tissue 25

Figure 12: 3D printed Cervix based on 3D scan of Cervix Tissue 25

Figure 13: Commercial cervix model for medical training purposes 26

Figure 14: Wall Thickness of Upside Down, Cut-open Phantom Cervix Sample 28

Figure 15: 3D Printed Phantom Cervix on 3D printer bed 28

Figure 16: Horizontally sliced Phantom Cervix and Delamination of Phantom Cervix due to support material's drip

Figure 17: 3D Model of the Phantom Cervix on Top, Front, Side and Perspective View 31

Figure 18: Setup of Pneumatic System 33

Figure 19: Schematic of Pneumatic System 33

Figure 20: Testing Platform $\quad 35$

Figure 21: Linear Actuator Unit Conversion Graph 36

Figure 22: Force Sensor Unit Conversion Graph 37

Figure 23: Force Sensor Reading vs. Masses for consistency test 39

Figure 24: CAD cross-sectional diagram of phantom cervix and its measured side $\quad 40$

Figure 25: CAD illustration of the force Sensor testing platform, testing tip and the phantom cervix

Figure 26: Average Force measurement at different pressure for the Inner Side Sample A of the phantom cervix 
Figure 27: Average Force measurement at different pressure for the Center Side Sample A of the phantom cervix

Figure 28: Average Force measurement at different pressure for the Outer Side Sample A of the phantom cervix

Figure 29: Average Force measurement at different pressure for the Inner Side Sample B of the phantom cervix

Figure 30: Average Force measurement at different pressure for the Center Side Sample B of the phantom cervix

Figure 31: Average Force measurement at different pressure for the Outer Side Sample B of the phantom cervix

Figure 32: Average Force measurement at different sides for the $-20 \mathrm{kPa}$ Sample A of the phantom cervix

Figure 33: Average Force measurement at different sides for the $0 \mathrm{kPa}$ Sample A of the phantom cervix

Figure 34: Average Force measurement at different sides for the $20 \mathrm{kPa}$ Sample A of the phantom cervix

Figure 35: Average Force measurement at different sides for the $-20 \mathrm{kPa}$ Sample B of the phantom cervix

Figure 36: Average Force measurement at different sides for the $0 \mathrm{kPa}$ Sample B of the phantom cervix

Figure 37: Average Force measurement at different sides for the $20 \mathrm{kPa}$ Sample B of the phantom cervix

Figure 38: Average Force Measurement of Sample A of the phantom cervix

Figure 40: Discrimination experiment with the phantom cervix and 24 subjects. Subjects were capable of distinguishing between hard and soft states.

Figure 41: Results of the threshold experiment on the phantom cervix with 24 subjects. Subjects were capable of detecting the threshold of change between hard and soft states, with a bias towards higher air pressure (harder cervix).

Figure 42: Average force measurement at different pressure levels (center side) 57

Figure 43: Average force measurement at different pressure levels (inner side) 57

Figure 44: Average force measurement at different pressure levels (outer side)

Figure 45: Spring Constant (N/m) vs. Compression Distance (m) for different stress points of the phantom cervix. The phantom is shown in the upper left as an insert.

Figure 46: Spring Constant (N/m) vs. Compression Distance (m) for different pressure levels of the phantom cervix.

Figure 47: Sigmoid fit for K, Spring constant (N/m) vs. Compression Distance (m) (a) from depth distance 0 to $1.45 \mathrm{~mm}$ (b) from $1.45 \mathrm{~mm}$ to $0 \mathrm{~mm}$ 
Figure 48: 3D view of the Spring Constant (N/m) vs. Compression Distance (m) at all air pressure levels of the phantom cervix.

Figure 49: Average of Axial strain vs. Stress $(\mathrm{kPa})$ of the phantom cervix.

Figure 50: Stress-strain curves of (a) real cervix tissue (graph adapted from [27]) and (b) our phantom cervix. The phantom cervix is up to two orders of magnitude stiffer than real cervix tissue. 


\subsection{Introduction}

Induction of labour is a common procedure yet much of the works relating to vaginal examinations rely on mechanical cervical dilators. This can cause consternation among patients due to the trauma and pain caused by mechanical cervical dilators. In addition, complicating training for obstetricians, gynecologists and midwives alike, mechanical cervical dilators can be obscured by visual feedback, which requires a more tactile approach to determining a patient's dilation level with more ease of use and less bodily trauma [1]. As a result, we built a phantom cervix possible for addressing some of these concerns. A dynamic phantom cervix can provide the basis for future training model for obstetricians and midwives.

Dilation, the opening of the cervix (measured in centimeters), and effacement, the thinning of the cervix (measured in percentage), occur in pregnant woman as labour and delivery get closer [2]. During the stages of pregnancy the cervix may open to about 10 centimeters [3]. As in Smith et al. [4], many practitioners consider dilation as the dominant cervical canal metric for determining progress of labour due to the fact that it is the most convenient to measure. We build on the work of Smith et al. [4] to put forth a cervix modeled using elastomer in order to address concerns of obstetricians, gynecologists and midwives involved in labour induction training. Our work, however, focuses on controlled compliance rather than controlled dilation, in order to eventually develop a training system to improve the ability of practitioners to quantify softness or hardness of the cervix.

In this study, we develop a phantom creation using a low-cost 3D printer to help mimic cervix compliance with the goal of further training obstetricians engaged in the pre-labour phase. The $3 \mathrm{D}$ printed phantom cervix is connected to pneumatic system to change its physical property to stimulate its softening. The phantom could eventually be used along with balloon dilator (catheter) by obstetricians and gynecologists for training purposes. The final phantom cervix is designed as $3 \mathrm{D}$ model with $0.7 \mathrm{~mm}$ wall thickness to provide reliable durability and repeatability and sufficient softness.

\subsection{Problem Overview}

Labour is induced in over $20 \%$ of women in the United States [5]. However, labour dynamics and dynamics of the cervix are still poorly understood. Medical practitioners identify 
dilation levels in a non-accurate manner resulting in poor accuracy. It is reported that dilation measured is approximately $90 \%$ accurate within $1 \mathrm{~cm}$ only if it is measured by a researcher who is classified as a consultant obstetrician with more than 20 years of experience in labour ward care [6]. Other clinicians with less than 20 years' experience have been reported as only $49 \%$ accuracy within $1 \mathrm{~cm}$ in its dilation. This is critical since the reported transition from pre-labour phase to active labour changes with more than a $20 \%$ increase for every increase in its dilation by $1 \mathrm{~cm}$ when cervix dilation is within $3 \mathrm{~cm}$ to $6 \mathrm{~cm}$ [7]. There are also ongoing studies to understand cervix dilation based on ultrasound computerized system [8], but there are not sufficient enough to improve measurement practices.

\subsection{Methods and Results}

This thesis proposes a pneumatic system based phantom cervix to simulate compliance in the pre-labour (latent) phase, before the cervix engages in much effacement or dilation, helping practitioners to study and be trained in a systematic quantifiable scale. In this paper, cervix dilation fixed to be less than $1 \mathrm{~cm}$, indicating that we are examining compliance control, the labour stage. The phantom cervix is created using elastomers and a feedback controlled pneumatic system to change its material property simulating the softening of the cervix during pre-labour process. This work is similar to the development of a complex heterogeneous aortic valve model created using custom shaped elastomer [9] and soft pneumatic actuator systems [10].

One of the common methodologies to create such custom shaped elastomer based models is to create a custom mold and use elastomeric curing material. Such multi-stepped process is not only complicated but also time consuming and not as reproducible to same quality each time. The biggest change of using traditional mold and curing method is that it is very difficult and limited to create hollow shaped models. The proposed phantom cervix will be created taking full benefit of 3D printing technology and print the custom shaped elastomeric model directly from 3D printer. Such process will take less time and easy to reproduce. The challenge is to print the model thin enough to be inflatable and controllable by pneumatic systems while not being vulnerable to break using low-end commercial 3D printers. Thin elastomer based models are already being 3D printed and used as applications such as a water tight sleeve at $0.75 \mathrm{~mm}$ 
thickness [11]. For 3D printed elastomers to be inflatable by pneumatic systems the elastomeric models should be printed at thinner thickness and the limits to 3D printers will be tested.

3D printable elastomeric models with pneumatic systems can be beneficial in many different fields as well. The ceiling of computational evolution has been proposed due to its need of more complex design evolving soft robots with multiple materials [12]. Soft biomimetic robots are in its need of better process for manufacturing its soft robot body fabrication [13], and multilateral fabrication technique [14]. However, the challenge of 3D printing a phantom cervix sample is that wall thickness is very thin and inner side needs to be hollow requiring the support material to be printed to fill inner side. During the design process we encountered a number of challenges in creating our model. The following section describes the anatomy and physiology of cervical ripening and softening of the cervix leading to dilation and effacement; as well as the key technological advancements and barriers respective to $3 \mathrm{D}$ printing technology and applications in biomechanical engineering. Overall, the existing literature provides the methodological basis and proof of concept relative to our phantom cervix model largely on the basis of existing projects currently underway within the Department of Electrical and Computer Engineering at Ryerson University led by Dr. James Andrew Smith. 


\subsection{Literature Review}

Recently, there has been many research produced in recent years pertaining to sonography, fetal fibronectin, and uterine contraction monitoring. These have improved understanding of how preterm labor occurs, however, their use in practice remains uncertain and largely unreliable. As the clinical criteria for diagnosis of pre-term labor remains difficult and often inaccurate, over diagnosis is common [15]. Moreover, the use of cervical length and fetal fibronection in pregnancy is limited to situations where a negative result can avoid unnecessary interventions. Such techniques have improved our understanding of how preterm labor is induced, however, in large measure these techniques have left women at risk because of their inaccuracy for over diagnosis.

\subsection{Symptoms}

Cervical dilation occurs when the os (opening) of the cervix becomes blocked by mucus, which prevents bacteria from entering the uterus during pregnancy. Dilation occurs as the mucus becomes loosened and discharges from the vagina. This may come out as a single entity or in a thick, slowly discharging form. During cervix dilation, however most women will not notice the plug being released. In terms of diagnosis, women who experience dilation in the pre labour phase may require induced dilation by an obstetrician or gynecologist to ensure a safe delivery.

Bloody show is another symptom that the cervix is dilating. The bloody show is typically not bright red, as it usually comes along with the mucus plug and in tones of pink, red and brown. This may continue throughout labour. Women also experience cramping and pain during dilation, similar to the pain experienced during menstruation, though markedly more intense. This pain is caused by the uterus contracting to dilate the cervix in preparation for delivery.

\subsection{Anatomy and Physiology of Cervical Ripening}

The parturition of the fetus allows for delivery, yet a central question in the physiology of gestation is how the mammalian uterus and the cervix function at the anatomic and molecular levels. During gestation the cervix (usually only $2 \mathrm{~cm}$ long), must remain firm and closed through pregnancy to ensure the fetus develops. This ensures the ability of the fetus to survive 
once it is outside the uterus. During gestation the firmness of the uterus must dilate to a diameter size of approximately $10 \mathrm{~cm}$ [16]. The physiologic change from a stiff firm tough tissue to one that is soft and able to dilate has been observed for centuries [16]. It was not until 1947 [17], however, that the fact was observed that the cervix is predominantly a connective tissue made of collagen, which gave credence to scientific evidence related to biochemical and biomechanical relationship of the phenomenal cervical function during gestation.

During the past few decades, our knowledge of cervical function has advanced geometrically. The cause or causes of cervical ripening have increased efforts in recent years to understand dilation as separate and distinct [17]. This has led to various experiments to study the anatomy and physiology of human gestation and parturition respective of anatomical ripening, which we attempt to rectify using a phantom cervix to model softening of the cervix tissue as they pertain to cervical dilation and ripening. We propose a model utilizing particle jamming technology and pneumatic pump system to simulate the dynamic compliance of the cervix during gestation.

Located the caudal and inferior pole of the uterus, the cervix is the cylindrical region of the uterus that protrudes and opens into the vagina. It is bounded at its cephalic end by the internal os and at its caudal end by the external os. Towards the peritoneal (serous membrane that forms the living of the abdominal cavity) the area of the bladder connects to a part of the cervix that protrudes into the vagina called the portiovaginalis. The endocervical canal connects the external os to the internal os. Cervical mucosa is lined with tall columnar epithelium, which have within them several big and branded glands ending at the level of the external os. Finally, the stratified squamous epithelium covers the portiovaginalis and extends into the vagina proper.

However, the anatomy of the cervix changes with age [17]. The stratified squamous epithelium of the vagina may move past the external os into the power portion of the cervix [18]. The morphologic changes, or ripening, occur in gestation before labour begins. These are the result of a complex biochemical process involving many pathways and a rearrangement and realignment of the collagen [19]. This is directly observable via the softening or ripening of the cervix. Ripening that occurs too early in gestation often leads to preterm birth. Alternatively, a firm cervix after full term gestation may contribute to abnormalities during labour and problematic delivery. The anatomical changes responsible for the earliest signs of pregnancy (sometimes as early as one month after conception), are noticeable due to changes in vascularity 
and increased water retention [17]. We develop a phantom cervix using as elastomeric material that is thin enough to change its physical compliance that occurring during gestation and cervical ripening or softening.

\subsection{Cervical Dilation Graph}

The use of a cervical dilation graph identifies patients with abnormal progress in labour and permits early corrective therapy [20]. Ledger first identified and emphasized the simplicity of doing so in 1969 [21]. The use of this graph is based on results from Friedman (1955) [22], Schulman and Ledger (1964) and Friedman and Kroll (1971) (see Fig. 3). According to Ledger and Witting, the progress of labour was judged by plotting cervical dilatation against time. Three patterns of cervical dilatation are recognized: (1) prolonged latent phase-a primigravida still in the latent phase of labour after 12 hours, (2) slow active phase - a rate of cervical dilatation in the active phase of labour of less than $1 \mathrm{~cm}$ per hour, and (3) arrest of active phase - no increase in cervical dilatation over a period of two hours or more in that phase [20]. Such abnormal cervical dilatation patterns helped obstetricians and gynecologists determine therapy. In addition, Ledger and Wiitting found this method possible for clinical evaluation and possible intervention. They determined that the adequacy of the size of the pelvis relative to the size of the fetus and the quality of uterine activity could be evaluated.

Traditionally, a partogram were used to create composite graphical records of key data (maternal and fetal) during labour entered against time on a single sheet of paper [20-24]. In our design, however, we rely on the Friedman curve to study frequency and duration of cervical dilatation by digital examination concerning softening of cervix tissue using a phantom model based on a similar dilation graph/score first developed by Ledger [20]. Accordingly, the use of a partogram permitted early recognition of abnormalities [20-24]. These early studies allowed for further clinical evaluation and intervention, which the present research aims to fulfill. Abnormalities relative to cervical dilation, including the softening of the cervix, are evaluated using the phantom elastomer model on the basis of graphical quantifiable evidence. 


\subsection{The Bishop Score}

The Bishop score is a model used by medical researchers to predict whether induction of labour will be required. Developed by Dr. Edward Bishop in 1964, the system is used to assess the odds of spontaneous preterm delivery using five components of vaginal examination: cervical dilation, cervical effacement, cervical consistency (softening), cervical position, fetal station [25]. According to the Bishop Score, any score above 8 describes a woman most likely to enter a successful vaginal birth. In general, Bishop Scores less than 6 usually require a cervical ripening method and labour induction.

\begin{tabular}{|l|c|c|c|c|l|}
\hline Parameter & \multicolumn{4}{|c|}{ Score } & \multicolumn{1}{c|}{ Description } \\
\hline Position & $\begin{array}{c}\text { Posteri } \\
\text { or }\end{array}$ & Middle & $\begin{array}{c}\text { Anteri } \\
\text { or }\end{array}$ & - & $\begin{array}{l}\text { During the menstrual cycle and labour the } \\
\text { position of the cervix changes. As labour } \\
\text { and gestation evolve, so too does the } \\
\text { position of the cervix that changes and } \\
\text { becomes more anterior and closer to the } \\
\text { opening of the vagina [19]. }\end{array}$ \\
\hline
\end{tabular}




\begin{tabular}{|c|c|c|c|c|c|}
\hline Parameter & \multicolumn{4}{|c|}{ Score } & Description \\
\hline Consistency & Firm & $\begin{array}{l}\text { Mediu } \\
\text { m }\end{array}$ & Soft & - & $\begin{array}{l}\text { The female cervix is generally tough and } \\
\text { resistant to stretching in women before they } \\
\text { have given birth, similar to a balloon that } \\
\text { has never been inflated. After vaginal } \\
\text { delivery, the surface of the cervix becomes } \\
\text { much less rigid and it is this that allows for } \\
\text { easier dilation during gestation and labour, } \\
\text { typically stretching to } 10 \mathrm{~cm} \text { immediately } \\
\text { prior to delivery. Ripening that occurs too } \\
\text { early in gestation often leads to preterm } \\
\text { birth [15-17]. Alternatively, a firm cervix } \\
\text { after full term gestation may contribute to } \\
\text { abnormalities during labour and problematic } \\
\text { delivery [15-17]. The anatomical changes } \\
\text { responsible for the earliest signs of } \\
\text { pregnancy (sometimes as early as one } \\
\text { month after conception), are noticeable due } \\
\text { to changes in vascularity and increased } \\
\text { water retention and overall cervix } \\
\text { consistency [17]. }\end{array}$ \\
\hline Effacement & $0-30 \%$ & $\begin{array}{c}40- \\
50 \%\end{array}$ & $\begin{array}{c}60- \\
70 \%\end{array}$ & $80+\%$ & $\begin{array}{l}\text { Effacement refers to the process whereby } \\
\text { the cervix in preparation for devilry } \\
\text { gradually drops closer to the cervix. This } \\
\text { occurs once the fetus has entered the pelvis, } \\
\text { which will make the cervix gradually soften } \\
\text { and ripen to become thinner. This is often } \\
\text { referred to be obstetricians as 'thinning' and } \\
\text { often this process refers to the procedural } \\
\text { activity of effacement [16]. }\end{array}$ \\
\hline Dilation & closed & $1-2 \mathrm{~cm}$ & $3-4 \mathrm{~cm}$ & $5+\mathrm{cm}$ & $\begin{array}{l}\text { Cervical dilation refers to the opening of the } \\
\text { cervix and the entrance of the uterus during } \\
\text { childbirth. The cervical dilation that } \\
\text { occurs-either naturally or induced by } \\
\text { surgical means-is usually accompanied by } \\
\text { effacement and the thinning or ripening of } \\
\text { the cervix [16-18] }\end{array}$ \\
\hline
\end{tabular}




\begin{tabular}{|c|c|c|c|c|c|}
\hline Parameter & \multicolumn{4}{|c|}{ Score } & Description \\
\hline $\begin{array}{l}\text { Fetal } \\
\text { Station }\end{array}$ & -3 & -2 & $-1,0$ & $\begin{array}{l}+1 \\
+2\end{array}$ & $\begin{array}{l}\text { Fetal station refers to the location of the } \\
\text { head of the fetus in proximity to the ischial } \\
\text { spines. These are located approximately } 3-4 \\
\mathrm{~cm} \text { inside the vagina and are usually not felt } \\
\text { [64]. Medical practitioners envisage where } \\
\text { the ischial spines are and often use them as a } \\
\text { proximity to the fetal station. Negative } \\
\text { numbers mean that the head is further inside } \\
\text { than the ischial spines whereas positive } \\
\text { numbers mean that the head is situated } \\
\text { below the spines [18]. }\end{array}$ \\
\hline
\end{tabular}

Table 1: Description of Cervical Dilation and Effacement. (From [25])

The Bishop's Score assists obstetricians and midwives how to measure the cervical os. It is usually the most important indicator of progression through the various tags of labour. Interpretation of a Bishop's Score of 5 or less suggests that labour is likely to start without induction. The lower the Bishop's Score the less likely induction will be successful. Some sources suggest that only score above 8 are reliable in predicting successful induction [26].

Though it remains important to measure the cervical os many medical practitioners are doing it very poorly, by 'feeling' it and the result varies greatly based on patient experience. The current training is done on rubber made dolls or static rubber cervix with different os size that is far from the actual cervix and the Bishop's Score, not to mention that it is not dynamic. Furthermore, the implementation of a phantom cervix can provide simulation of cervix softening to help study/develop cervical dilation related applications using the Bishop Score.

We propose the use of a phantom cervix created using elastomers and a feedback controlled pneumatic system to change its material properties to simulate softening of the cervix during pre-labour. We prove that creation of custom shaped elastomer based models is widely supported on quantifiable evidence.

We measured the phantom with the exerted force versus the distance it has improved to quantify its softness for variable stress points and pressure level. This can be characterized and compared to the real cervix tissue to mimic its softening process. In this study, the pneumatic system and the linear actuator are feedback controlled. This is consistent with other 
developments in the field of biomedical engineering, such as the complex heterogeneous aortic valve model created using custom shaped elastomer (rubber) to help medical practitioners examine other pneumatic responses such as hypertension [9]. As a result, we developed and tested a phantom cervix specifically engineered to mimic the softening of the cervix during the labour process.

\subsection{Mechanical Properties of Cervical Tissue}

The mechanical property of cervical tissue changes depending on the history of vaginal delivery and current pregnancy status. The result of mechanical compression test performed is shown in the graph below, indicating that women with no previous vaginal delivery, labeled as NPND, are the stiffest and the pregnant specimen, labeled as PCS, are the softest [27]. Women with previous vaginal delivery, labeled as NPPD, are in the middle between NPND and PCS.

\begin{tabular}{ll}
\hline Obstetric history & Abbreviation \\
\hline Non-pregnant: no previous vaginal deliveries & NPND \\
Non-pregnant: previous vaginal deliveries & NPPD \\
Pregnant: taken at time of cesarean section & PCS \\
\hline
\end{tabular}

Table 2. Sample Labels [27]

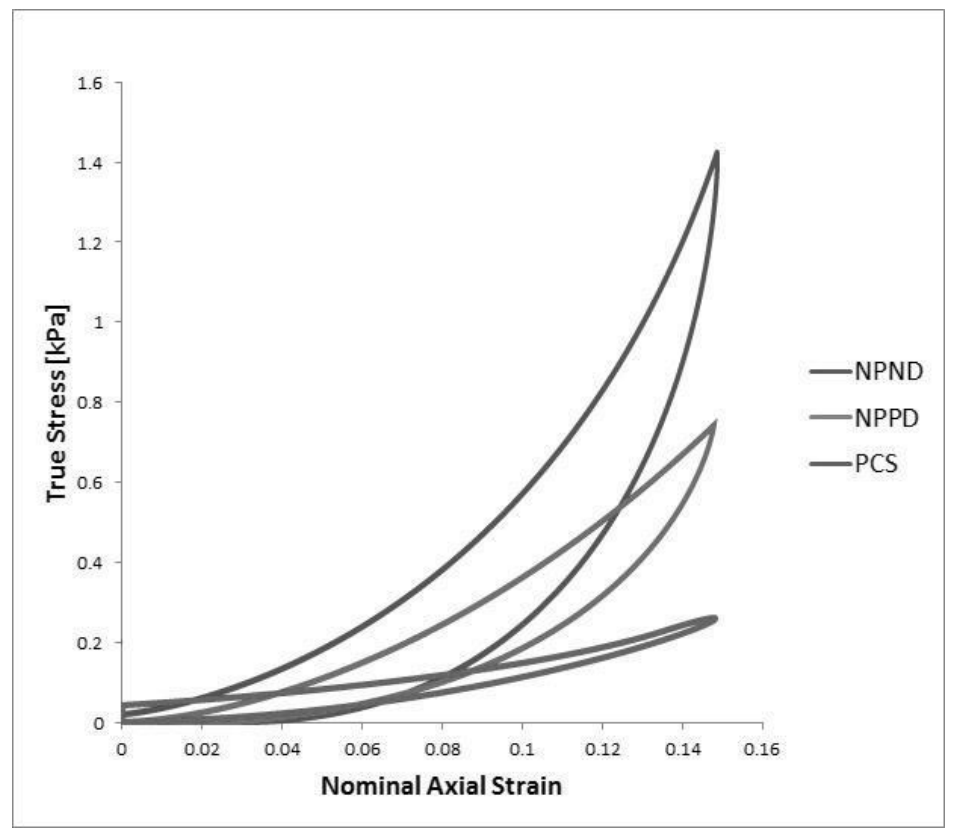

Figure 1. Average cervical stroma response to uniaxial compression cycles, adapted from [27] 


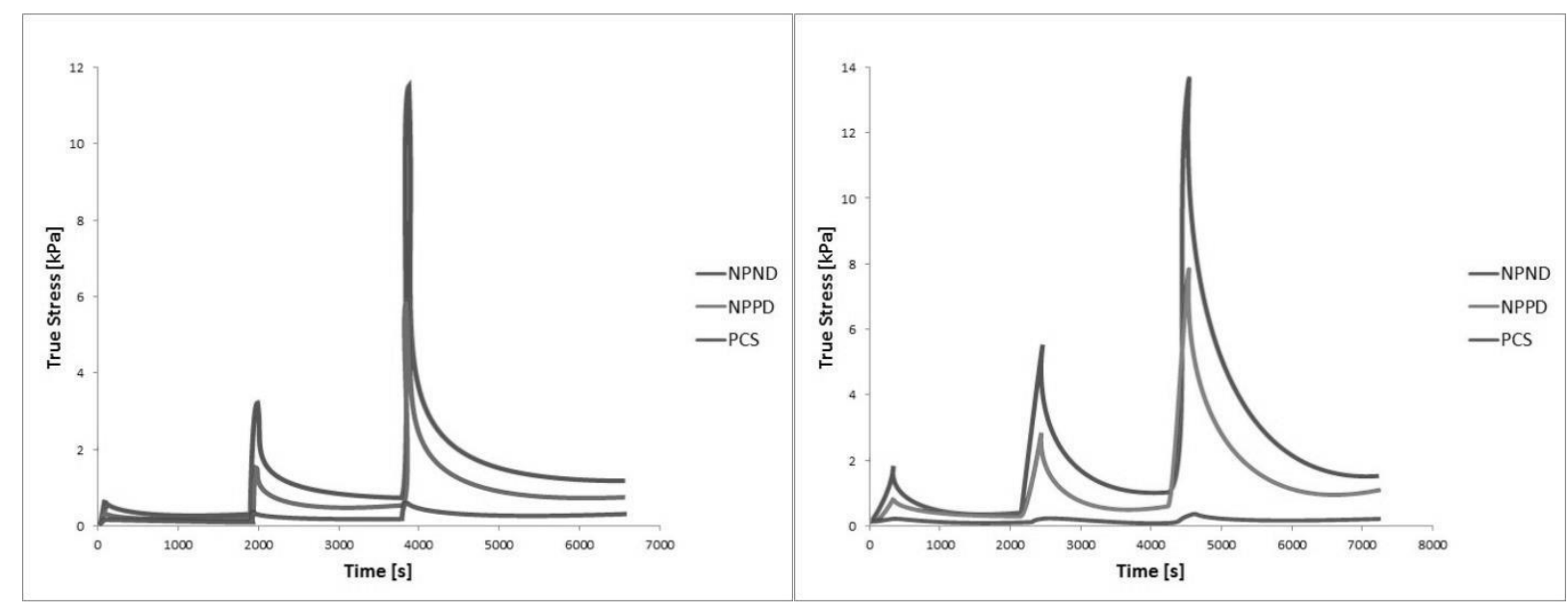

Figure 2. Average cervical stroma response to ramp-relation in (a) unconfined compression and (b) confined compression, adapted from [27]

For unconfined compression, the maximum stress varies between $12 \pm 14 \mathrm{kPa}$ to $0.56 \pm$ $0.64 \mathrm{kPa}$ at the maximum strain of $30 \%$ depending on if the subject is NPND, NPPD or PCS. For confined compression, the maximum stress varies between $14 \pm 17 \mathrm{kPa}$ to $0.28 \pm 0.18 \mathrm{kPa}$ at the maximum strain of 0.15 depending on if the subject NPND, NPPD or PCS [27]. This indicates the mechanical property of cervical tissue can vary significantly from patient to patient.

In Myers et al., it is noted that stress-strain behavior is noticeably nonlinear and it is much stiffer when the tissue is loaded in tension: two orders of magnitude between the corresponding stress levels in tension $(\sim 100 \mathrm{kPa})$ and compression $(\sim 1 \mathrm{kPa})[27]$.

\subsection{False Diagnostic and Symptomatic Problems with Preterm Birth}

The prediction of preterm birth should fulfill established and quantifiable prerequisites. However, it is important that in order to lessen the impact of traditional diagnostic criteria of contradictions and cervical change that cause high false positive rates and those as such medical practitioners should seek to develop educational biomechanical alternatives using soft robotics. This relies on consistent findings within the literature $[15,28]$, which suggests high false positive rates in favor of enhancing evidence based guidelines for management of preterm birth. However, though negative test results are difficult to avert, planned intervention including 
routine recommendations of reduced activity for women with multiple gestations, act as widely accepted practices despite the lack of support data.

Nonetheless the false diagnosis and relative inaccuracy of current models is cause for concern. Early detection of preterm labour is difficult because initial symptoms may seem mild and may occur in normal pregnancies. Approximately $40 \%$ of preterm births follow preterm labour and 35\% result from preterm prematurely ruptured membranes [28]. The remaining $25 \%$ are due to medical or obstetric conditions such as hypertension, antennal hemorrhage, or intrauterine growth restriction [28]. In terms of addressing the symptomatic problems with preterm birth, traditional criteria identify cervical dilation as $3 \mathrm{~cm}$ or more, effacement at $80 \%$ of more and/or membrane rupture, frequency uterine contractions, and bleeding [28]. However, these thresholds are both sensitive and difficult to objectively quantify as obstetricians rely on physical examination, and the rate of false positive diagnosis rises to as much as $40 \%$ [28]. As a result, other means have been sought after to help obstetricians and gynecologists accurately identify pre-term labour.

Tests such as digital and ultrasonic examinations of the cervix have been used to identify dilation and effacement [29]. Other tests have examined biochemical markers of preterm labour in blood, saliva and cervicovaginal secretions [29]. However, in large measure these diagnostic tools vary in accuracy and performance. The predictive value of any tests always varies according to population, which refers to not only the demographical characteristics or historical risk factors connected to preterm birth, but also, most importantly: the presence or absence of clear symptoms that are difficult to measure with accuracy and reliability. It is possible that with better training models diagnostic accuracy could be improved - and it is envisioned that future models of our 3D-printed cervix could fulfill that role.

\subsection{Balloon Dilators and Tractive Force}

Contemporary models of the catheter balloon dilator originate from designs developed during the nineteenth century [30,31]. At its core, there are two principal methods for dilation: direct and indirect. Direct involves a device placed in the endocervical canal and expands the canal through laterally applied force [32]. However, this method is generally no longer performed during labour induction because it presents a host of potential problems including the 
risk of infection due to the insertion of foreign objects in the endocervical canal [33]. The indirect method involves a balloon placed in the extra-amniotic space above the interior os of the cervix, as shown in Smith's simplified cervix model that engaged an internal reaction in the cervix, similar to that seen during normal pre-labour allowing the cervix to efface (thin) and dilate (open) [4]. This method has proven it possible to use for to be applied by the balloon to the interior os even when external traction, as a result of the balloon filling the extra amniotic space and thereby moving the force from the amniotic sac to the interior os [4].

Fully controllably devices for cervical dilation such as balloon dilators have been used in recent biomedical technologies because they combine traditional mechanical devices with several new features that give medical practitioners full process control in all of the phases of cervical dilation [34]. Creation of custom shaped elastomer based models is widely explored in the existing literature. In biomedical engineering, complex heterogeneous aortic valve models have been created using custom shaped elastomer [9], whilst soft pneumatic actuators can be created that allow medical practitioners confidence of continuous control [10].

When using the balloon dilator, the amount of tractive force varies from none [35] to "minimal" [36] to about .5 kg (approximately $5 \mathrm{~N}$ ) and upwards [1] but in much of the existing literature it is often not directly specified [1]. In Smith et al., the experimental set up brought together multi organ simulators, complete with the phantom baby, to which load cells on the actuators detected force applied by a balloon dilator or direct manipulation. Extending from the end of the lumen to the woman's thigh, the tractive force is difficult to measure and provides several practical challenges for systematic methods for measuring force. Often, a woman in labour can wait several hours [37] for labour to occur naturally. While the time can vary widely, from a half-an-hour [38] to ten hours [40] or more, the general consensus suggests that six hours is an acceptable upper limit before attempting intervention [40].

In Smith in et al [4], dilation was studied in relation to the amount and duration of tractive force responsive to the cervix. The system was built using load cells on the actuators to detect force to simulate dilation. However, unlike in Smith et al. [4], phantom model using 3D printed elastomeric phantom connected to a pneumatic system simulates softening of the cervix.

To better understand the forces applied by balloon dilators we are looking to create a model by which they can be tested, in a way that mimics the dynamics of the actual cervix. While we do not carry out such tests presently, the work presented here could be used to develop 
future dilators or the training by which they are used. The phantom cervix can help obstetricians and gynecologists in educational capacities to develop less traumatic alternatives in relation to the induction of labour and predictions of early pre-term birth.

\subsection{D Printer Technology}

3D printing has been widely adopted by a number of professionals in diverse fields and areas including in machines, engineering, robotics, design houses, workshops and models. Initially, 3D printing technology was prohibitively expensive but costs have dropped and integration with complementary CAD [41] and visualization technologies have accelerated its adoption, especially in fields like Biomedical Engineering, where it is combined with diagnostic imaging technologies.

\subsection{D Printing Elastomer}

One method for using a custom shaped elastomer based model is done by curing material to create a custom mold using a 3D printer [10]. However, undertaking custom shaped elastomer models requires multistep and complicated processes. Recent works on soft technologies have used elastomers that today play a vital role in developing new biomechanical actuation technology. The use of elastomer has played a leading role in the development of soft robotics 3D printed that can move, deform their body, and modulate different biological systems [42].

Soft technologies have greater benefited from the use of elastomer as a primary material by providing: (i) safer and more dynamic interactions are currently available with conventional robotics; (ii) adaptive behaviors that use mechanical intelligence and are therefore more utility for medical applications. The ability of researchers to simplify the controllers needed for physical interaction has assisted obstetricians in developing cheaper and simpler robotic components using elastomer [10]. In the future, medical practitioners appear pounced to engineer hybrid soft robotic systems for medical interventions by combining biocompatible soft materials

like elastomer to tissue engineered cells [43]. This is likely to create a high degree of convergence with 3D printing that brings together disparate fields such as mechanical 
engineering, bioengineering, materials science and medicine. The use of elastomer in 3D printing is at the forefront of soft robotics able to treat cervical dilation during latent (pre) labour.

\subsection{Soft Robotics}

Soft robotics developed in part with the need to develop dramatically less invasive and harmful biomechanics. The manufacture of soft robotics along with 3D printing developed hand in hand. Using a standard filament 3D printer, artificial robot muscles can today be directly printed that are air powered, able to squeeze into tight spaces or environments [44]? Soft-bodied robots and shadow robotics have been used as solutions to a number of medical and biological challenges. They are promising because they bring together $3 \mathrm{D}$ printing to align different materials with a rigid core and a soft exterior [44].

Soft robotics takes lessons from biology to focus on mechanical qualities of materials more amenable to the human body. Soft components provide several advantages to rigid electromagnetic materials (i.e. magnets, copper and steel) or plastics [42]. Traditionally, conventional robots were designed to be rigid and as such their ability to articulate the body structure of humans proved rather elusive. Recent developments in biotechnology have coevolved with changes in 3D printing technology. Today, soft materials are now used to provide optimized manipulation of pneumatic muscles [42]. These technologies help minimize the force requires to cause deformation and are made of low-modulus materials (such as elastomers). Silicone rubber is a popular choice for biomimetic fabrication today due to its wide spread availability and low relative cost [42].

Additionally, the pneumatic manufacture of soft robotics is used often in walking robots that require layers of silicone elastomers containing embedded chamber that can be pressurized by fluid on air. Through careful design of chamber size, wall thickness, and geometry, selective inflammation and deflation of these cavities can produce a variety of walking gaits [43]. In addition, with the development of pumps and valves, as well as reliable power supply that are compatible with highly deformable body structures, there is now more possibility than ever before in utilizing soft robotics to construct comparatively complex embedded pneumatic networks capable of high resolution, detailed, and distributed movements [42]. However, one of the biggest challenges remaining in the development of soft robotics is designing flexible 
actuation systems amenable to high forces, in order to replicate the functionality of muscles in the animal body [42].

\subsection{Phantom Cervix: A Biomedical Soft Robot}

A phantom cervix is necessary to simulate cervical softening to help obstetrician to train themselves (since it is not possible to train them enough on real patients) as simulators have proven relative complex and cost intensive.

For example, using patented haptic response technology, the SIMone Childbirth Birthing Simulator/Manikin is a device currently on the market that gives medical practitioners a unique training experience, which received the 2011 EU Robotics Technology Transfer Award [45]. The price of the simulator is $\$ 49,400$ USD. Inside the simulator is a fetal head with the sagittal suture and fontanels for determining the position and approach of the head.

The simulator provides a high degree of realism and is developed specifically with an audio/visual interface to monitor information on the progress of birth. Additionally, the monitoring software gives medical practitioners useful information on the both and allows training in intervention both through the use of medication and the use of performing dilation and effacement procedures. It includes a 19" flat screen monitor with an easy to use Touch Screen, displays an exact image of the position and rotation of the fetal head within the maternal pelvis.

\subsection{Ideation of the Phantom Cervix}

As the development of a dynamic cervix model targeting training applications is without precedent, there are no standardized design methodologies. As such, the development has followed an exploratory trajectory focused on frequent ideation as well as experimental validation of manufacturing and testing. Smith et al. first initialized an active cervix phantom for labour induction training [5]. Its design reduces the dimensionality plane model of the cervix simulating dilation. Unlike the model built by Smith et al., which is modeled using Smooth-On EcoFlex silicone and four Firgelli L16 actuators that provide the dilation force, the phantom cervix described in this thesis is created using 3D printing technology and an active pneumatic 
system to stimulate softening of cervix. Similarly, our model uses actuators to detect force and help medical practitioners prepare for induction or augmentation of labour more accurately. In Section 3 we will describe the iterative design process that led to our 3D printed cervix models in more detail.

\subsection{Testing Platform}

The pneumatic system connected phantom sample will be placed on a testing platform with built-in force sensor on top and liner slider on the bottom to lift the sample plate. The outer frame of the platform was built with MicroRax, miniature strudel aluminum t-slot framing and bracket system useful because it provides a handy base for different sized projects. The compact and rugged framing system is ideal for use in machines, engineering, robotics, design houses, workshops and models. The testing platform has been used as a basis for prototyping functional devices that contains circuit boards [46]. In terms of assembly, the MicroRax has also been used because of its adaptability to 3D printed components [47]. 


\subsection{Methods}

We propose the use of a phantom cervix created using elastomers and a feedback controlled pneumatic system to change its material properties to simulate softening of the cervix during pre-labour. This method builds on several existing principals in the biomechanical engineering literature [4] [11]. We prove that creation of custom shaped elastomer based models is widely supported on quantifiable evidence.

Our method measures the phantom with exerted force versus the distance it has improved to quantify its softness for variable stress points and pressure level. This can be characterized and compared to the real cervix tissue to mimic softening processes. In this study, our methods use a pneumatic system to control feedback. This is consistent with other developments in the field of biomechanical engineering found in the existing literature [4] [11]. As a result, our method develops on and tests a phantom cervix specifically engineered to mimic the softening of the cervix during the labour process, suitable for use by obstetricians, midwives and gynecologists.

\subsection{Balloon Cervix}

Producing a phantom cervix model that can dynamically change its physical property is complex and difficult. To change its physical property by inflating and deflating the grain filled model using pneumatic system, the model has to be made with elastomeric material that is thin enough to expand and shrink its size. The original approach was performed on a donut shaped balloon as a proof of concept. 


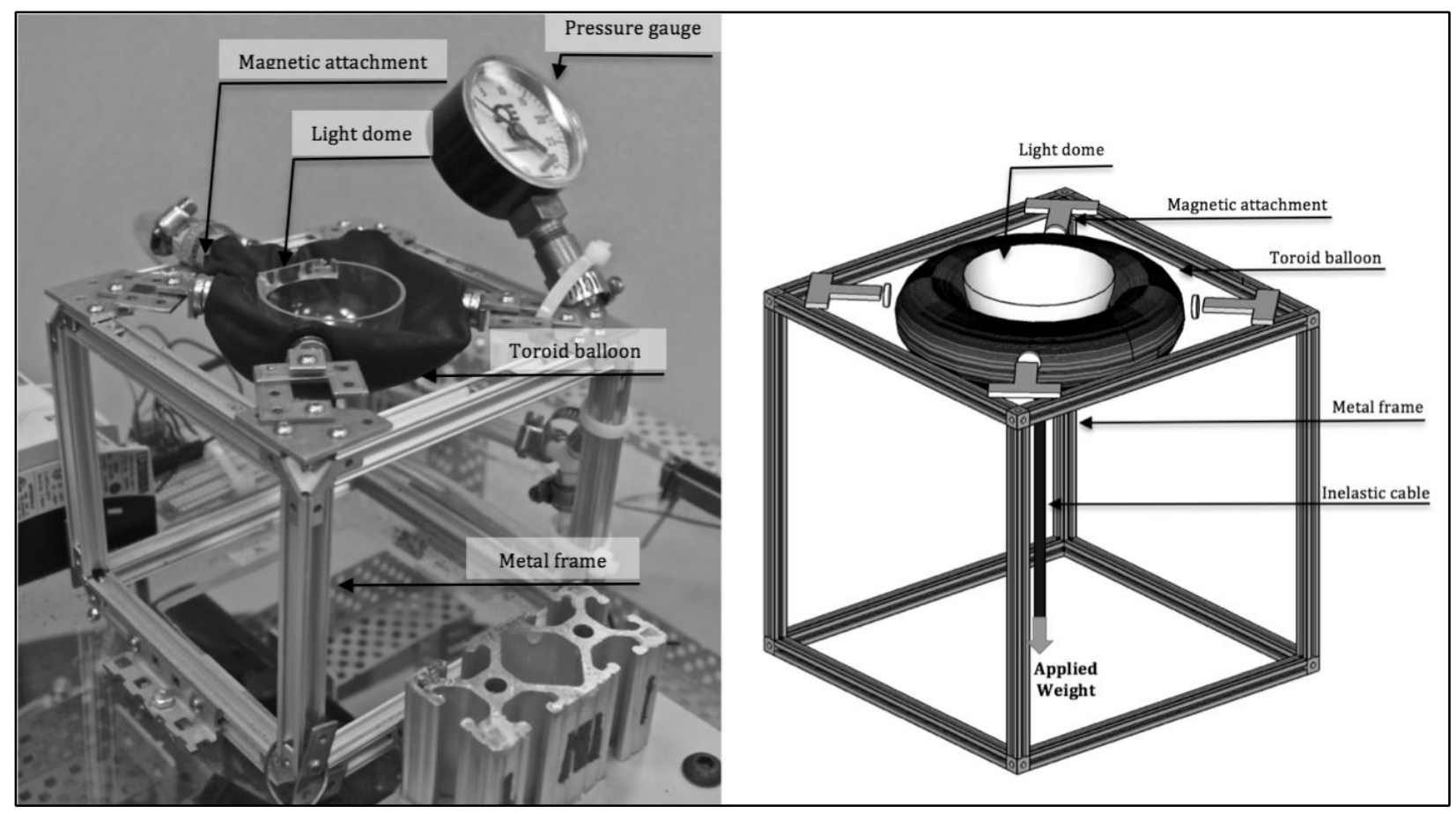

Figure 3: The cervix balloon prototype (left) and simplified representation (Image Source: Luk, Michelle; Jung, Kim; Lobb, Derek; Smith, James Andrew. A Novel Cervical Model for Use in Obstetrics Simulation Training. Unpublished Manuscript. Ryerson University, 2014).

We utilize a very similar same methodology to that performed by Luk, Kim and Lobb [48]. In it, we use a balloon based cervix model that uses particle jamming technology and a pneumatic pump system to simulate the dynamic compliance of the cervix. Figure 2 shows the model which uses non-porous, flexible toroid-shaped Qualatex 16" Latex balloon loosely packed with dry factory-ground Melitta Arabica packaged coffee. The balloon was secured via a metal frame that had four evenly spaced magnets attached onto the frame and four dimes secured onto the corresponding inside layer of the balloon. A small, light dome with an inelastic cable was placed on top of the inner circle of the toroid such that a mass could be suspended from the cervix balloon. Dynamic compliance of the cervix was achieved through the adaptation of pneumatic participle jamming technology. We used the Sparkfun ROB-10398 pneumatic pump. The pump was fastened to the opening of the balloon to vary the vacuum pressure inside the cervix balloon. In accordance with the principals of particle jamming, the coffee grains flowed at atmospheric pressure, while excess interstitial fluid (i.e., air) was present, but formed into a compact and stiff solid when a vacuum was applied to remove the fluid. 


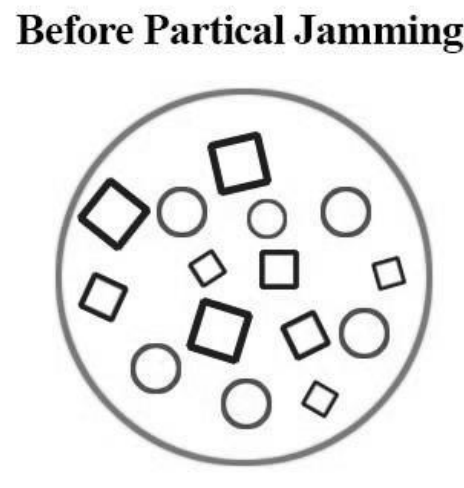

After Particle Jamming

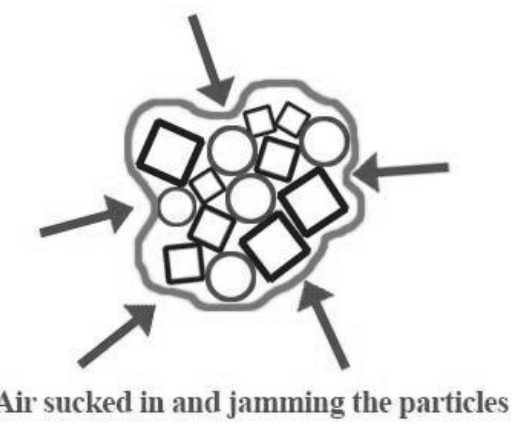

Figure 4: Particle Jamming

After observing that applying pneumatic system to grain filled elastomeric material can change its property, the challenge has become in creating a phantom cervix that coincides with the real cervix's size and its shape. As mentioned before, the outer wall has to be elastomeric in order to expand and shrink in its shape while the inside of the model has to be hollow for the grains to be filled and the air to flow.

\subsection{Design Approach 1: Silicone/Rubber cured Cervix}

3D Printing the mold posed a unique problem. Following discussions with Think2Thing's David Didur we observed that it was possible to construct a silicone/rubber cured cervix [49]. The first approach taken was the traditional way of creating custom shaped elastomeric material using molds and silicone/silicone-rubber curing method. The mold and a thin breakable inner support were created using a 3D printer, the LulzBot TAZ 4. The mold and inner support was printed in ABS (Acrylonitrile Butadiene Styrene) Ecoflex Series. The Ecoflex rubber was selected due to its versatility and ease of use. The rubbers are mixed 1A:1B by weight of volume and cured at room temperature with negligible shrinkage. This allowed our mold to be of low viscosity that is also skin safe and certified by an independent laboratory to ISO 10993-10, Biological evaluation of medical devices. The material itself is very soft, strong and stretchy. It can be stretched many times to its original size without rearing and will rebound to its original form with minimum distortion. 
Dragon Skin silicone rubber was chosen as another material to form the cervix mold cast. The Dragon Skin series is a high performance platinum cured liquid silicone useful in a variety of different applications. When the silicone is poured into the thin gap between the mold and the inner support and the inner support, a mold was cast illustrated in the figure below.
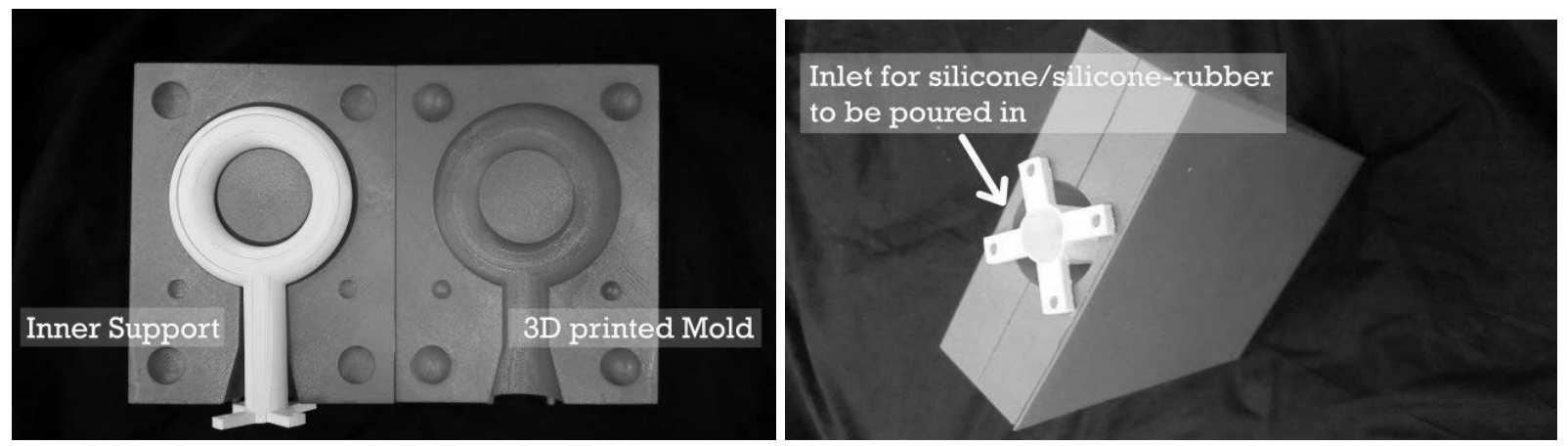

Figure 5: 3D printed mold and inner support for silicone cured cervix

The test result of silicone cured model was disappointing in terms of its consistency in its wall thickness, durability and repeatability. The wall thickness was inconsistent resulting in different rate in the change of its physical property when air was pumped into the model for inflation. Also, it was easily ripped resulting in difficulties on its durability and repeatability. The curing of the silicone took 8 hours on average. The silicone cured model is shown in the figure below.

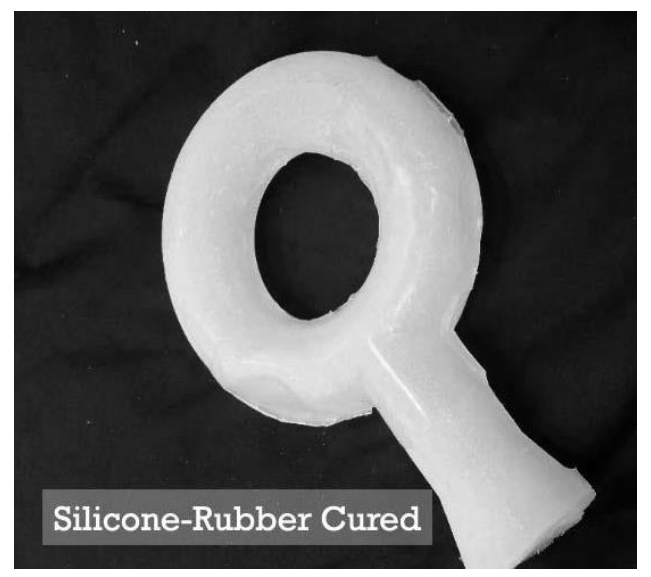

Figure 6: Silicone-Rubber Cured Cervix from 3D printed mold

The second approach was using latex rubber instead of silicone. Instead curing in the mold, liquid latex rubber was poured directly onto the inner support. The inner support was mounted on a motorized shaft which consists of 2 degree of freedom. 


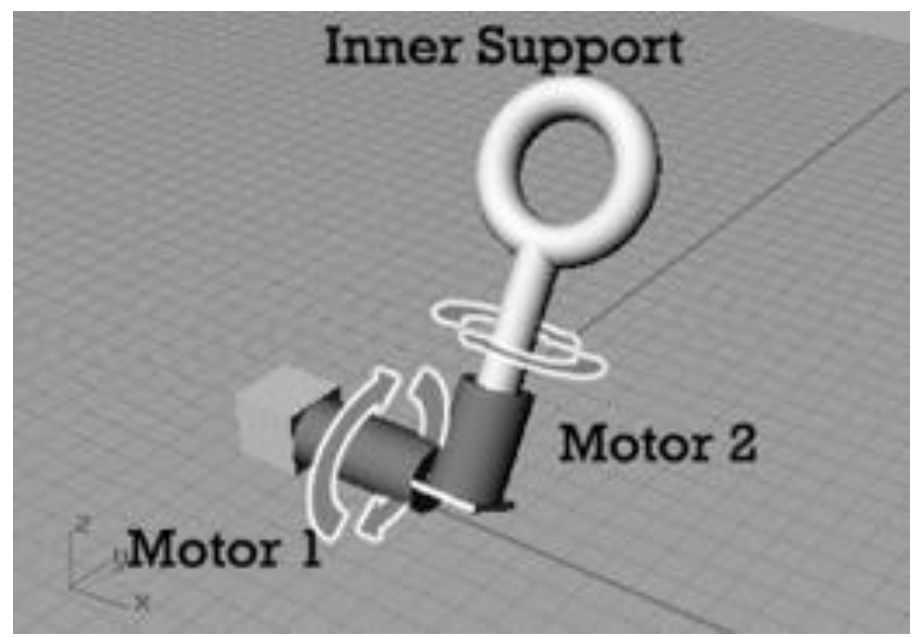

Figure 7: Motorized 2 Degree of Freedom Latex-Rubber Curing platform

The shaft spins at constant speed, motor 1 providing vertical spin and horizontal spin. The speed of the motor needs to be calibrated according to stickiness of the liquid latex rubber, allowing consistent flow of the rubber as it spins resulting in uniform distribution of the latex rubber over its surface. For this case, the motor was set to $1 / 3$ rotation/second. Such system allows liquid rubber to flow around the donut shaped inner support while it is being cured allowing it to cure in relatively consistent wall thickness. The average curing time was 10 hours. The resultant rubber model is shown in the figure below.

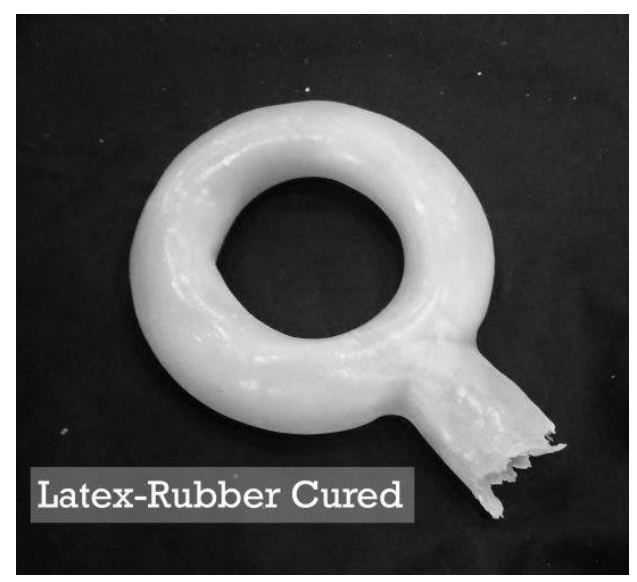

Figure 8: Latex-Rubber Cured Cervix

When the air was supplied to the model the rubber model was much more durable compared to the silicone model. However, the rate of inflated surface was still uneven, although the wall thickness was much more even than silicone model. The biggest downside of rubber model was 
that it is deformed after inflation and never returns to its original shape resulting in poor repeatability.

\subsubsection{Overview of Lessons Learned}

Overall, we observed that the test result of silicone cured model was disappointing both in terms of its consistency and wall thickness, durability and repeatability. As a result, the wall thickness inconsistently changed at a different rate when air was pumped into the model for inflation. This model was also tearing and ripping quite easily, resulting in irreparable damage to the model, which made durability and repeatability less viable in the silicone cured model.

Conversely, the rubber model performed significantly better. The rubber model allowed for greater consistency during the pumping stage of the experiment, which made the model much more amenable to periodic use. The downside in using the rubber model, however, was that the rate of inflated surface was still uneven. In comparison to the silicone model, the wall thickness was much more evenly dispersed. The main drawback of the rubber model was that it deformed after inflation. This caused problems and poor repeatability.

\subsection{Design Approach 2: 3D Printed Cervix}

3D printers allow us to print hollow models by using support materials which can be dissolved and washed out after the print is finished. The minimum layer thickness varies depending on the 3D printer but a typical mid-level printer can print within $0.1 \mathrm{~mm}$ accuracy. A medium-end 3D printer, the Lulzbot Taz 4, was used to print the cervix phantom and its

minimum layer thickness at $0.05 \mathrm{~mm}$. The filament used was a 3.00mm 3D Filament ABS White (Acrylonitrile Butadiene Styrene) thermoplastic filament is a premium grade material that is well suited for more detailed and demanding 3D prints. It was selected because of its standardization and low cost. The $3.00 \mathrm{~mm}$ 3D ABS filament has been repeatedly tested on various machines for flow consistency and print quality; from name brand printers to homemade ones, the consistently round diameters provide optimum flow through the extruder nozzle. 
To ensure that our simplified 3D printed model was qualitatively representative of actual cervix tissue, a 3D scan of the real cervix tissue was captured immediately after hysterectomy. 3D scan was captured using NextEngine 3D scanner. The figures below show cervix tissue, 3D scan of the cervix tissue, 3D model of the scan and 3D printed cervix using ABS (Acrylonitrile Butadiene Styrene) material.

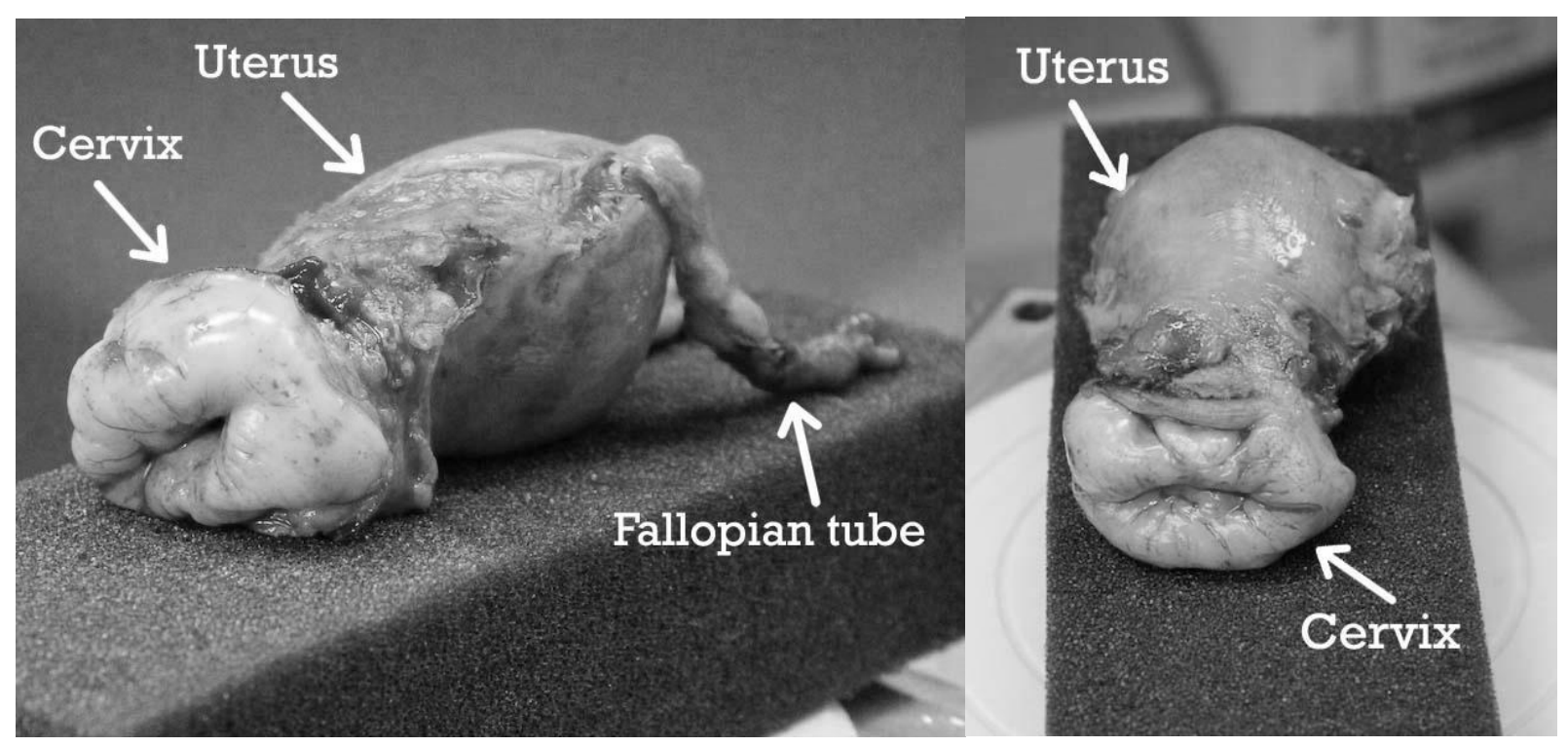

Figure 9: Cervix Tissue sample for 3D scan

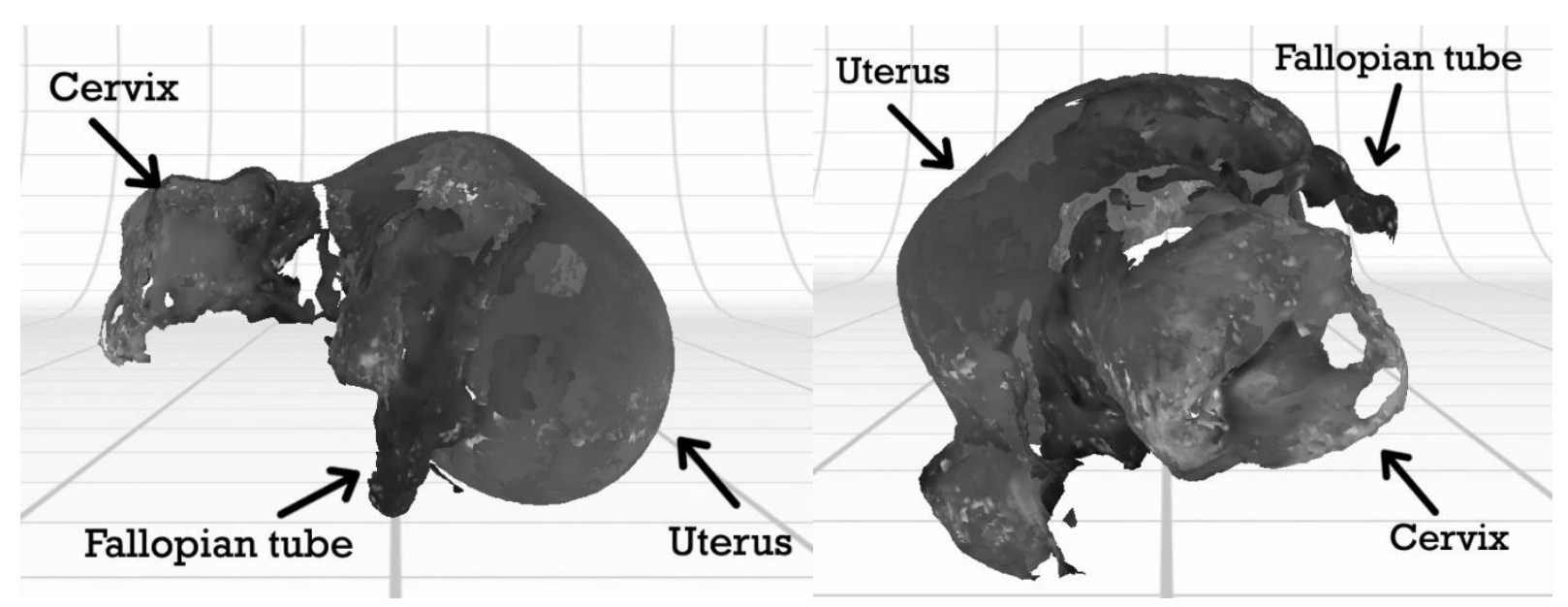

Figure 10: 3D scanned Cervix Tissue 


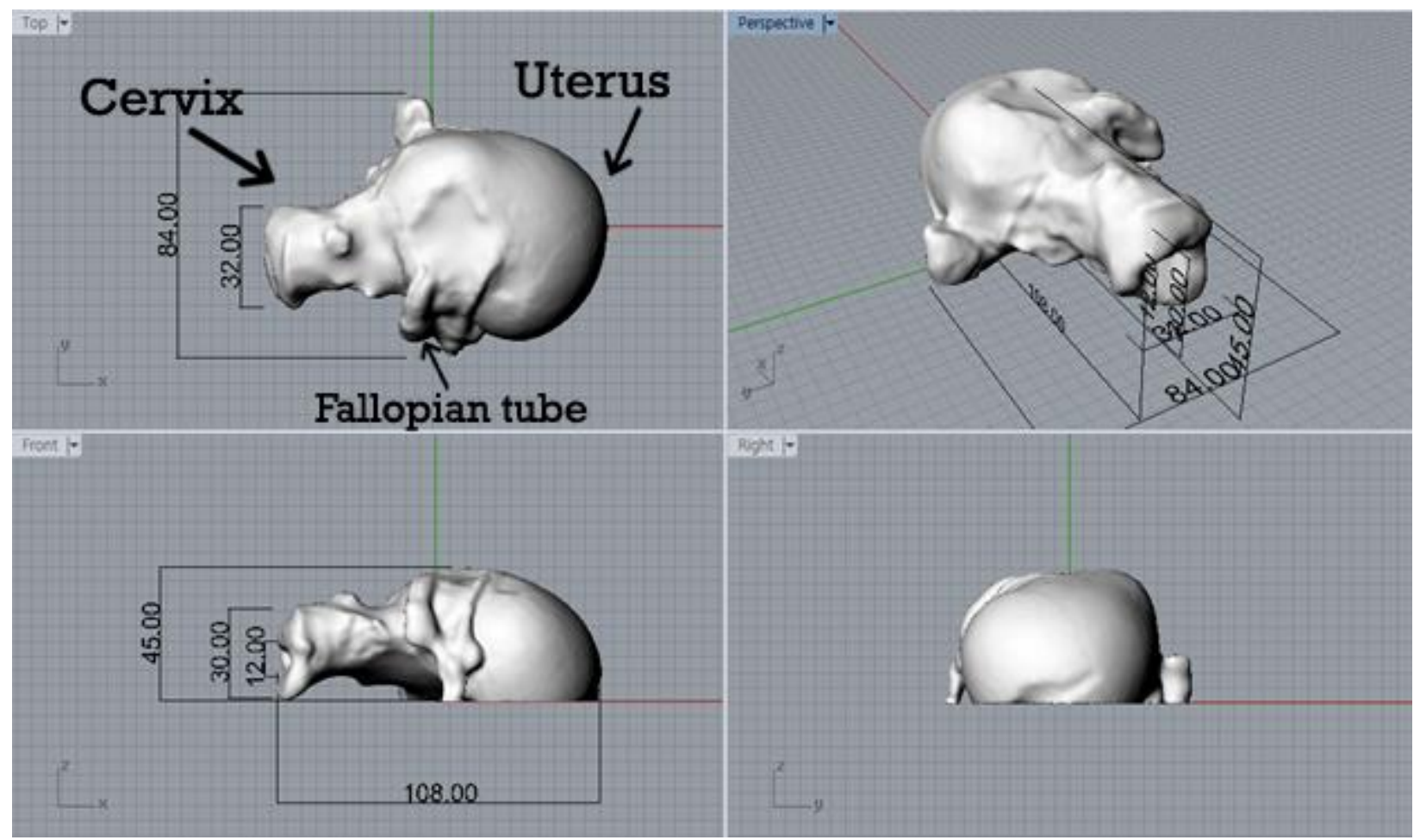

Figure 11: 3D model constructed from the 3D scan of Cervix Tissue (mm)

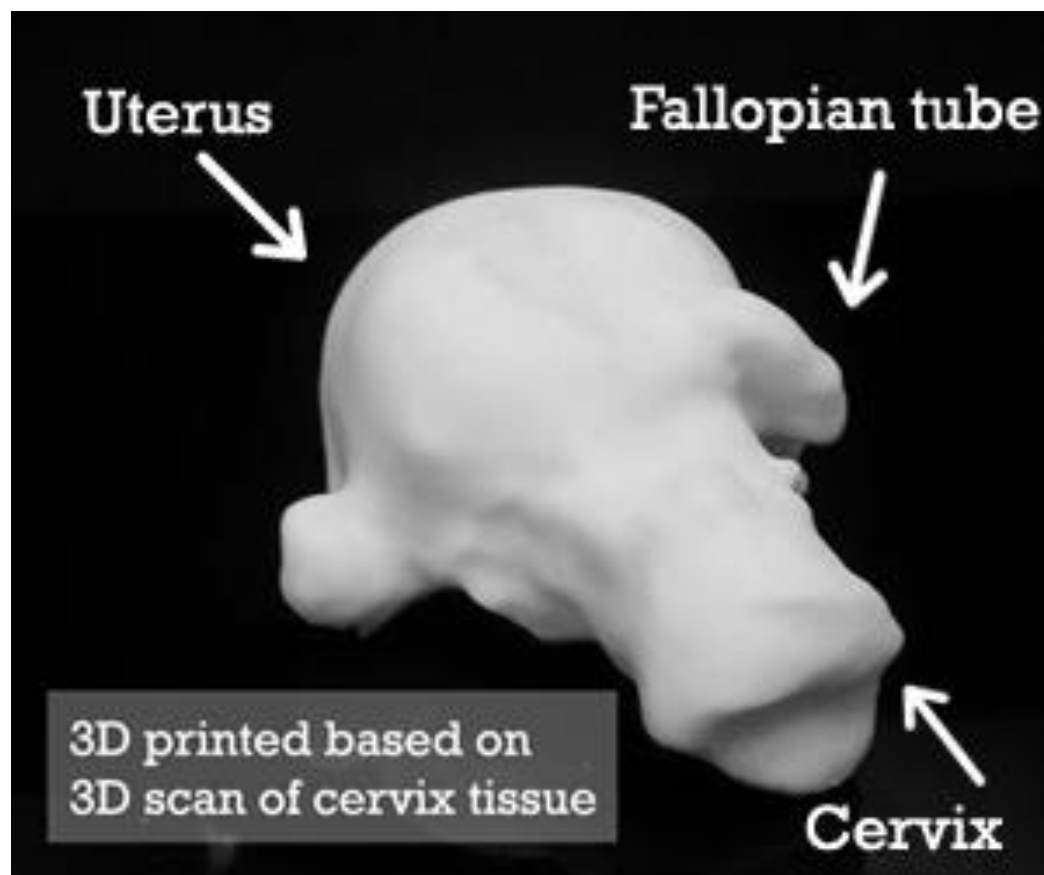

Figure 12: 3D printed Cervix based on 3D scan of Cervix Tissue

From the 3D scan of the cervix tissue and its 3D printed model, the basic shape of the phantom model was determined to be that of a torus, similar to the solid commercial silicone 
cervix model shown in Fig. 11. The outer diameter of the phantom model needs to be in the range of $30 \mathrm{~mm}$ to $40 \mathrm{~mm}$ with inner diameter to be less than $5 \mathrm{~mm}$ to represent the pre-labour phase.

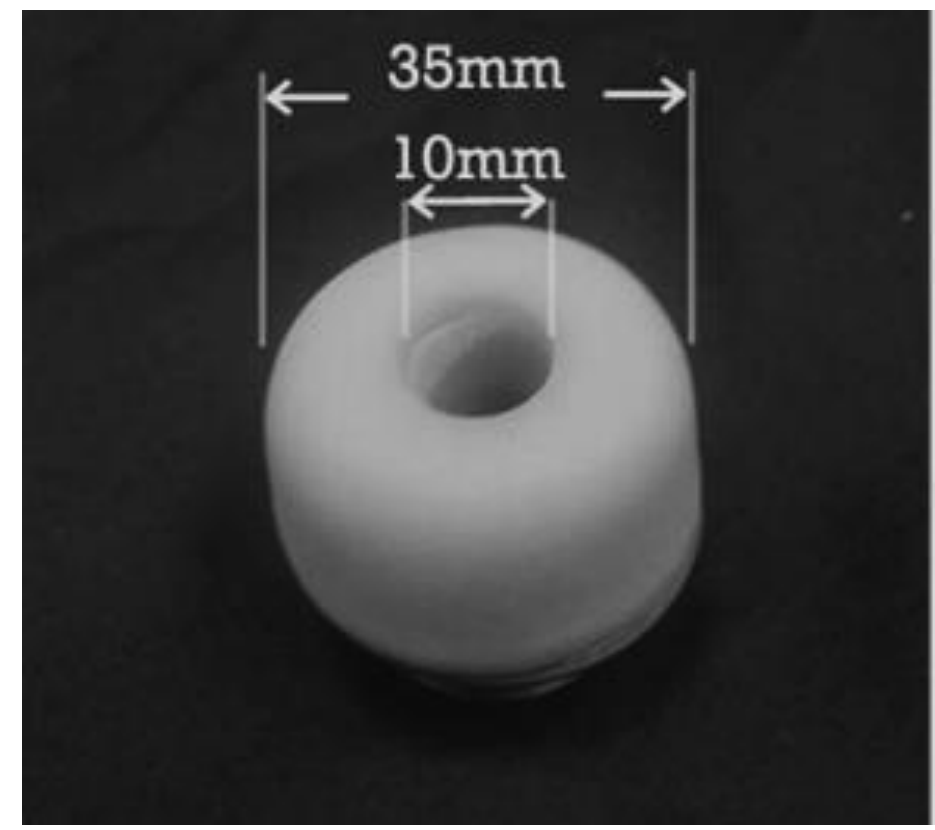

Figure 13: Commercial cervix model for medical training purposes

\subsection{D printing a Simplified Cervix Model}

Due to cost and viability, the phantom cervix was printed with ninja flex elastomeric filament, as this material was inexpensive and performed relatively better than other available materials. It is strong and durable and can also be used conjointly with our water soluble PVA filament. The materials used in this project are shown in the table below.

\begin{tabular}{|c|c|c|}
\hline & \multicolumn{2}{|c|}{ Curing } \\
\hline Type & Silicone & Latex \\
\hline Part Number & $\begin{array}{l}\text { Eco-flex10, } \\
\text { DragonSkin }\end{array}$ & Liquid Later Rubber (Mold Craft) \\
\hline Reason & Movie Industry material & Cost \\
\hline Seller & Smooth-on & Burma Rubber \\
\hline
\end{tabular}

Table 3: Materials Used for Curing Process 


\begin{tabular}{|c|c|c|c|c|c|}
\hline & 3D Scan & \multicolumn{3}{|c|}{ 3D print } \\
\hline Type & Scanner & Printer & Solid filament & $\begin{array}{c}\text { Elastomer } \\
\text { filament }\end{array}$ & Support filament \\
\hline $\begin{array}{c}\text { Part } \\
\text { Number }\end{array}$ & $\begin{array}{c}\text { NextEngine 3D } \\
\text { Scanner }\end{array}$ & $\begin{array}{c}\text { Lulzbot TAZ 4 } \\
\text { 3D printer }\end{array}$ & ABS Filament - & Ninjaflex - & PVA Filament - \\
& FHITE 3.0mm & $\begin{array}{c}\text { FIRE red } \\
3.0 \mathrm{~mm}\end{array}$ & NATURAL 3.0 mm \\
\hline Reason & Cost, Well- & Cost, & Cost, Durability & Cost, Viability & Dissolvable in water \\
& reviewed & Well-reviewed & & & \\
\hline Seller & NextEngine & Lulzbot & Filaments.ca & Fennel drive & Filaments.ca \\
\hline
\end{tabular}

Table 4: Materials Used for 3D Scanning and 3D printing

The thickness of the phantom cervix is limited to be thin and soft, mimicking the softness of the real cervix tissue. This was done to conform to the pneumatic test. Also, because the cervix had to be thick enough to change its physical property by inflating and deflating with the pneumatic system, the minimum printable thickness needed to be tested. Various wall thicknesses of the phantom printed are described in Table 4.

\begin{tabular}{|c|c|c|c|c|}
\hline $\begin{array}{c}\text { Wall Thickness } \\
(\mathrm{mm})\end{array}$ & $\begin{array}{c}\text { Softness compared to real } \\
\text { cervix tissue }\end{array}$ & Inflation & Deflation & Printing Success \\
\hline$>1.2$ & Too stiff & No & No & Success \\
\hline 1.2 & Stiff & No & Yes & Success \\
\hline 1.0 & Medium & Yes & Yes & Success \\
\hline 0.8 & Soft & Yes & Yes & Success \\
\hline 0.5 & Soft & Yes & Yes & Success \\
\hline$<0.5$ & - & - & - & Unable to print \\
& & & & (Too thin) \\
\hline
\end{tabular}

Table 5: Phantom Cervix test for various wall thicknesses 
Wall thickness above $1.0 \mathrm{~mm}$ was too stiff compared to the real cervix tissue and wall thickness below $0.5 \mathrm{~mm}$ was unable to be printed due to its printer limitation. The samples of phantom cervix model with thickness ranging from $0.5 \mathrm{~mm}$ to $1.0 \mathrm{~mm}$ with $0.1 \mathrm{~mm}$ wall thickness variation were printed multiple times to test its durability and repeatability.

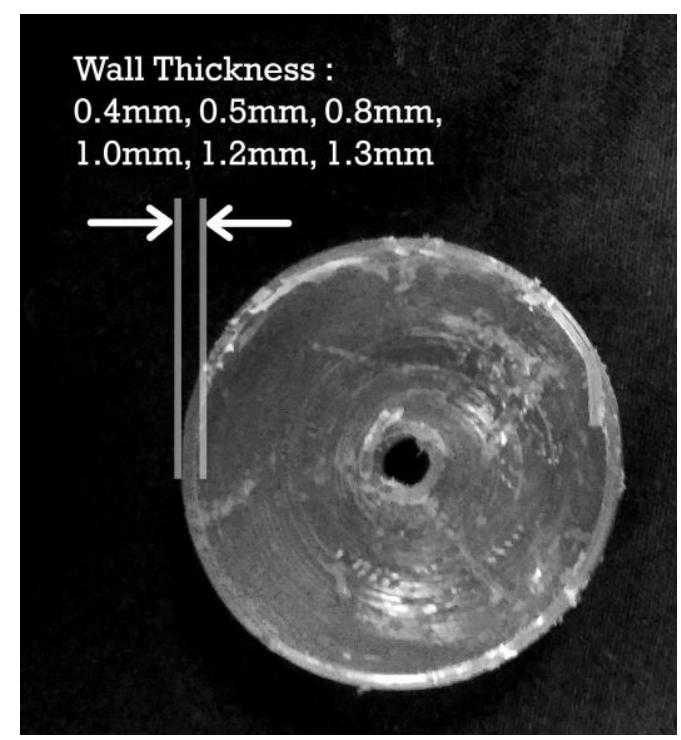

Figure 14: Wall Thickness of Upside Down, Cut-open Phantom Cervix Sample

The challenge of 3D printing a phantom cervix sample is that wall thickness is very thin and inner side needs to be hollow requiring the support material to be printed to fill the inner side.

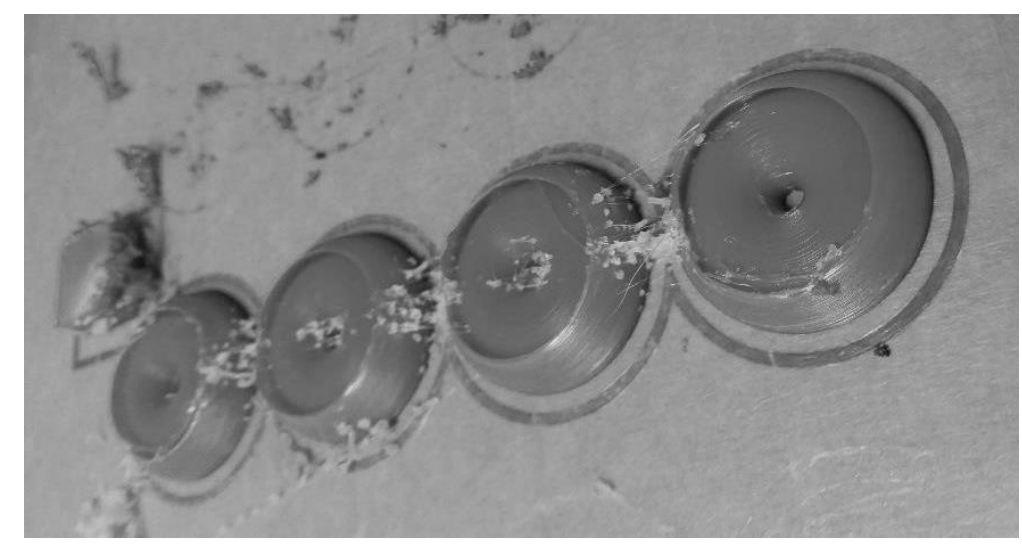

Figure 15: 3D Printed Phantom Cervix on 3D printer bed

Polyvinyl alcohol filaments were used as support material as this material is watersoluble and therefore removable afterwards. 3D printers print 3D models one layer at a time 
requiring elastomeric filament and support material is mounted on a dual head and be swapped to print both materials as required within a layer before it moves on to print the next layer. To create a quality print, it is necessary to calibrate the printer very carefully to level the printing bed and dual head, filaments extrusion rate, extruder temperature. The extruder temperature was set to 210 degrees for Ninjaflex and 220 degrees for PVA on the Lulzbot Taz4 printer. CURA is used for its slicing program to convert the 3D model into printable gcode. The general setup was set to provide the highest quality possible [See Appendix A]; Setting the printer speed slow to minimize the drips and the minimum layer thickness for the finest details. However, even with a perfectly calibrated setup the drip of each extruder is unavoidable during the frequent material swaps. 3D printing technology is based on melting the filaments to print the filaments in liquid form. The typical recommended temperature is 220 degrees - 230 degrees for Ninjaflex and 190 degrees to 220 degrees for PVA. Since the extruder temperature cannot be cooled instantly, there is always a bit of drip when swapping between two extruder heads.

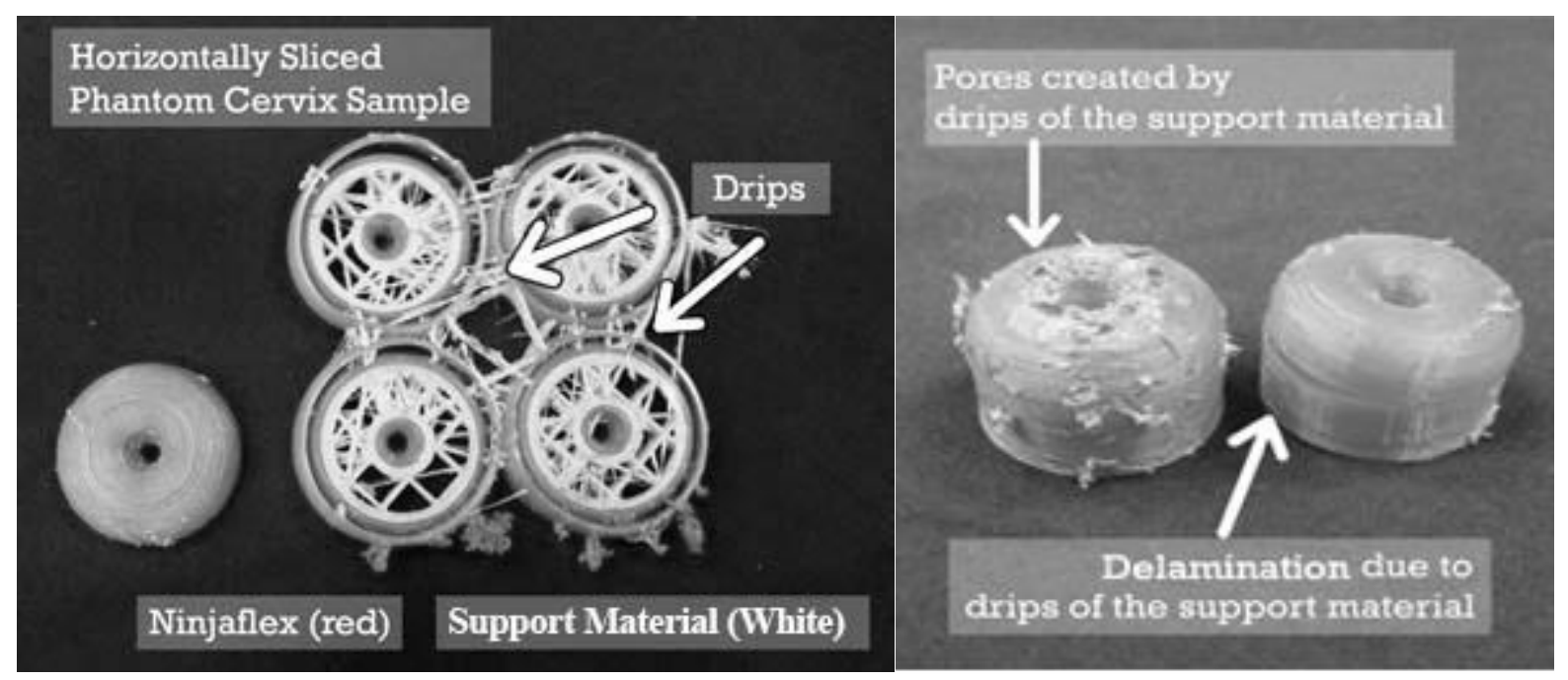

Figure 16: Horizontally sliced Phantom Cervix and Delamination of Phantom Cervix due to support material's drip

To create our model, the outer wall has to be thin enough and air-tight to apply pneumatic system. This is a critical problem since the little drips of support material gets in between the Ninjaflex layer and creates small pores that can jeopardize the air-tightness of the phantom cervix model.

This limits the lower boundary of its wall thickness and restrains its durability and repeatability. 5 samples at each thickness was printed and tested for its durability and repeatability when it is inflated and deflated. The maximum of 20 runs have been tested for each 
of maximum inflation of $20 \mathrm{kPa}$ and maximum deflation of $-20 \mathrm{kPa}$. The samples that could not reach $20 \mathrm{kPa}$ or $-20 \mathrm{kPa}$ due to the pores were considered as a failed sample. The maximum and minimum pressure from $20 \mathrm{kPa}$ to $-20 \mathrm{kPa}$ was chosen based on the result from previous model developed with Luk [48], that the jamming technology within such range provide sufficient hardness/softness we desire.

\begin{tabular}{|c|c|c|c|c|c|c|}
\hline Wall Thickness (mm) & 1.0 & 0.9 & 0.8 & 0.7 & 0.6 & 0.5 \\
\hline Number of Samples Tested & 5 & 5 & 5 & 5 & 5 & 5 \\
\hline Number of Failed Samples at First Attempt & 0 & 0 & 0 & 1 & 4 & 5 \\
\hline Number of Repeated Deflation before Failure & 20 & 20 & 20 & 20 & 20 & 16 \\
\hline Number of Repeated Inflation before Failure & 20 & 20 & 20 & 20 & 8 & 2 \\
\hline
\end{tabular}

Table 6: Durability and Repeatability test with various wall thicknesses

Most of the samples with $0.5 \mathrm{~mm}$ thickness and $0.6 \mathrm{~mm}$ failed. There were number of pores spotted on the outer wall of the sample. They were unable to reach the maximum inflation of 20 $\mathrm{kPa}$. However, they were able to reach the maximum deflation of $-20 \mathrm{kPa}$ for most even some pores were present. Most of the sample with $0.7 \mathrm{~mm}$ thickness succeeded the test and able to repeat more than 20 times.

The final phantom cervix is designed as a 3D model with $0.7 \mathrm{~mm}$ wall thickness to provide reliable durability and repeatability and sufficient softness. The phantom cervix is a torus shape with an outer diameter of $30 \mathrm{~mm}$, inner diameter of $4 \mathrm{~mm}$ and height of $8.5 \mathrm{~mm}$. The bottom layer is $2 \mathrm{~mm}$ providing thick rigid surface that would not be affected by inflation or deflation of the model. The 3D model of phantom cervix is illustrated in the figure below. 


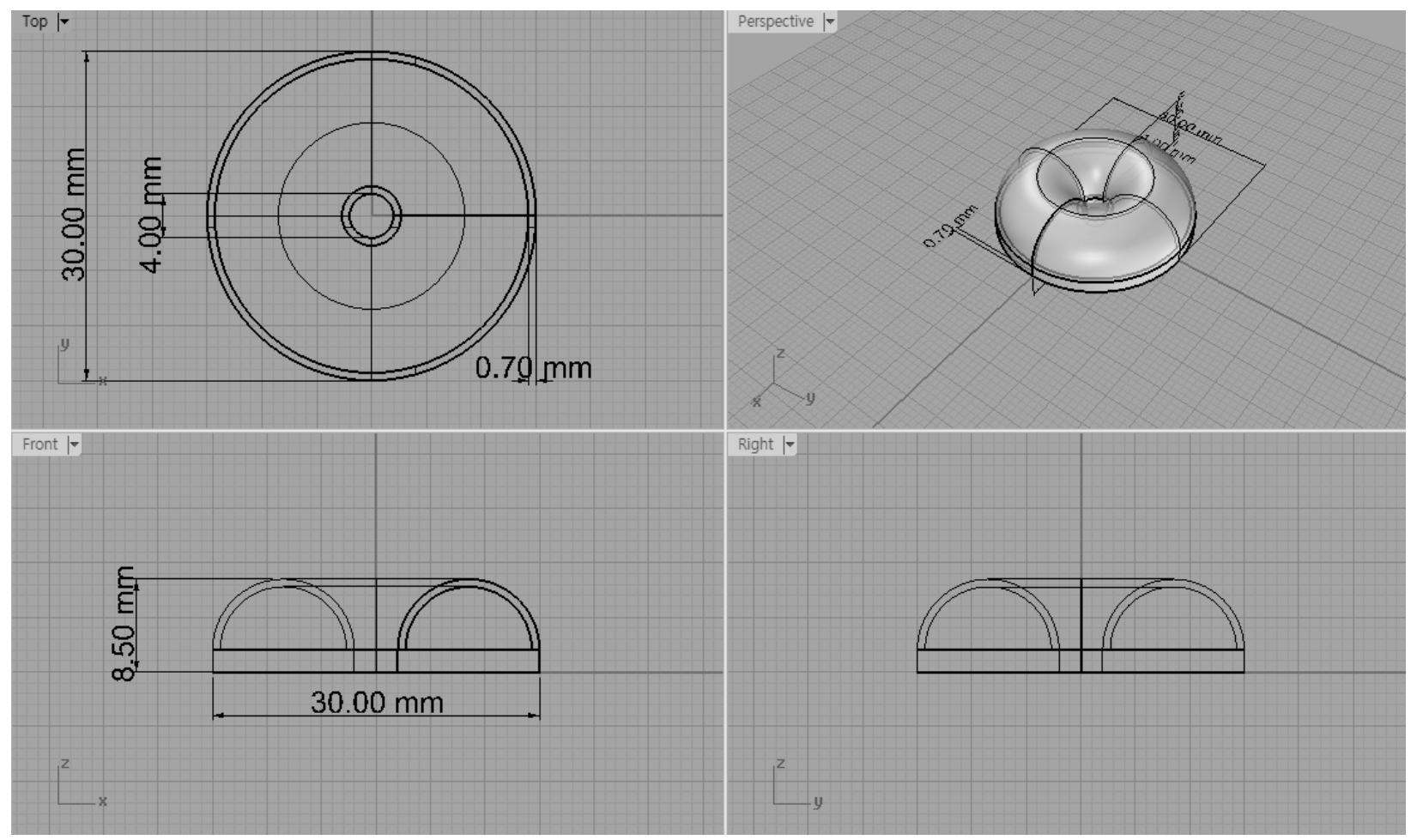

Figure 17: 3D Model of the Phantom Cervix on Top, Front, Side and Perspective View

The bottom layer has a $2 \mathrm{~mm}$ diameter hole. This is the inlet for water to dissolve the support material inside and outlet for the dissolved support material to be removed later.

3D printer was calibrated very carefully and the printing setting was optimized for the best quality print. The layer height for the print was set at $0.1 \mathrm{~mm}$ for the most detail. The speed settings of the printer head for travel speed, bottom layer speed, outer shell speed and inner shell speed was set as $20 \mathrm{~mm} / \mathrm{s}$, a very slow speed to provide the best print quality. The dual extrusion switch amount and retraction amount were set at larger value than typical default setting. This allows the filaments to be retracted more when the filaments are swapped and therefore minimizes the dripping effect. The average print time for each sample was less than 2 hours. Ninjaflex filament was used 0.45 meters or 4 grams and support material was used 0.23 meters or 2 grams per sample print.

Once the phantom cervix is printed using Lulzbot Taz4 with Ninjaflex, it is sunk in water tank for 12 hours allowing the support materials to be dissolved. The dissolved support material can be easily removed and cleaned. 
After it is cleaned, it is fully filled with coarsely-ground Melitta Arabica coffee beans. The hole on the bottom layer is used to fill the phantom cervix with grains after support materials have been cleaned. $2.10 \mathrm{~g}$ of coarsely ground coffee beans are filled in all the samples of the phantom cervix.

\subsection{Pneumatic System}

After the grains filled the sample, silicone-tube is then connected into the hole providing air path for the pneumatic system to control its internal air flow. The pneumatic system is supplied with Parker's pump, valve and Freescale Pressure sensors connected to Freedom Board KL25z providing feedback control. The pump is BTC IIS Dual head - High pressure or Vacuum pump operating at maximum voltage of $12 \mathrm{~V}$ and maximum pressure of $50 \mathrm{psig}(344 \mathrm{kPa})$. The valve is Parker's $\mathrm{X}$-valve, $8 \mathrm{~mm}$ Solenoid valve operating at $3 \mathrm{~V}$ for maximum operating pressure difference of 6 psi $(41 \mathrm{kPa})$. The pump is PWM controlled to supply different pressure level and the valve is open - close valve with no step control. The pump consists of 1 outlet for inflation and 1 inlet for deflation. Both outlet and inlet have to be open all the time for either of inflation or deflation to occur while both outlet and inlet has to be connected to the phantom sample to control its pressure level by dynamically controlling inflation and deflation. To deliver such

mechanism, 4 valves were connected to the pump and the phantom sample in a setup similar to H-bridge logic. The figure below illustrates its H-bridge like valve setup. 


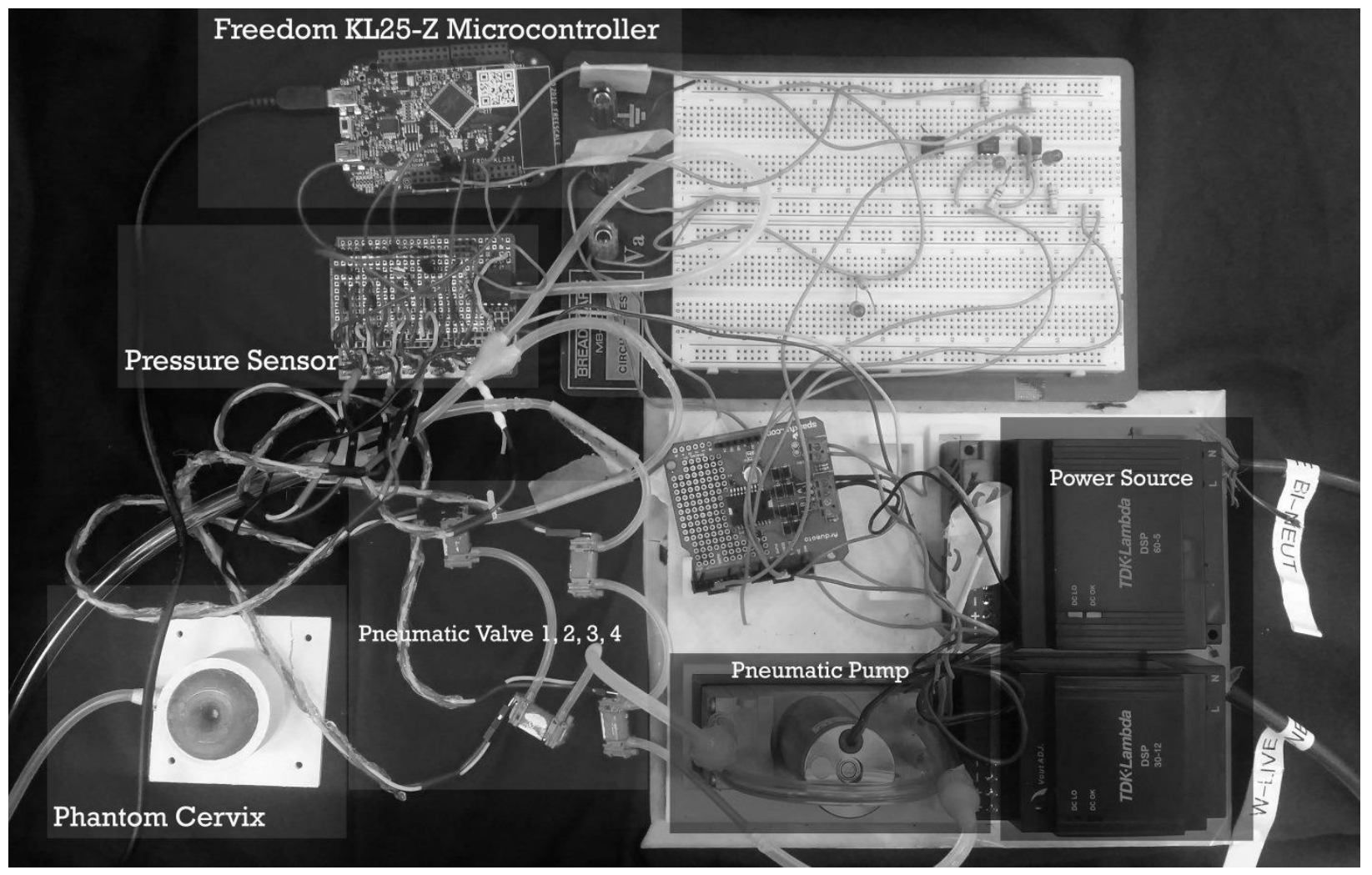

Figure 18: Setup of Pneumatic System

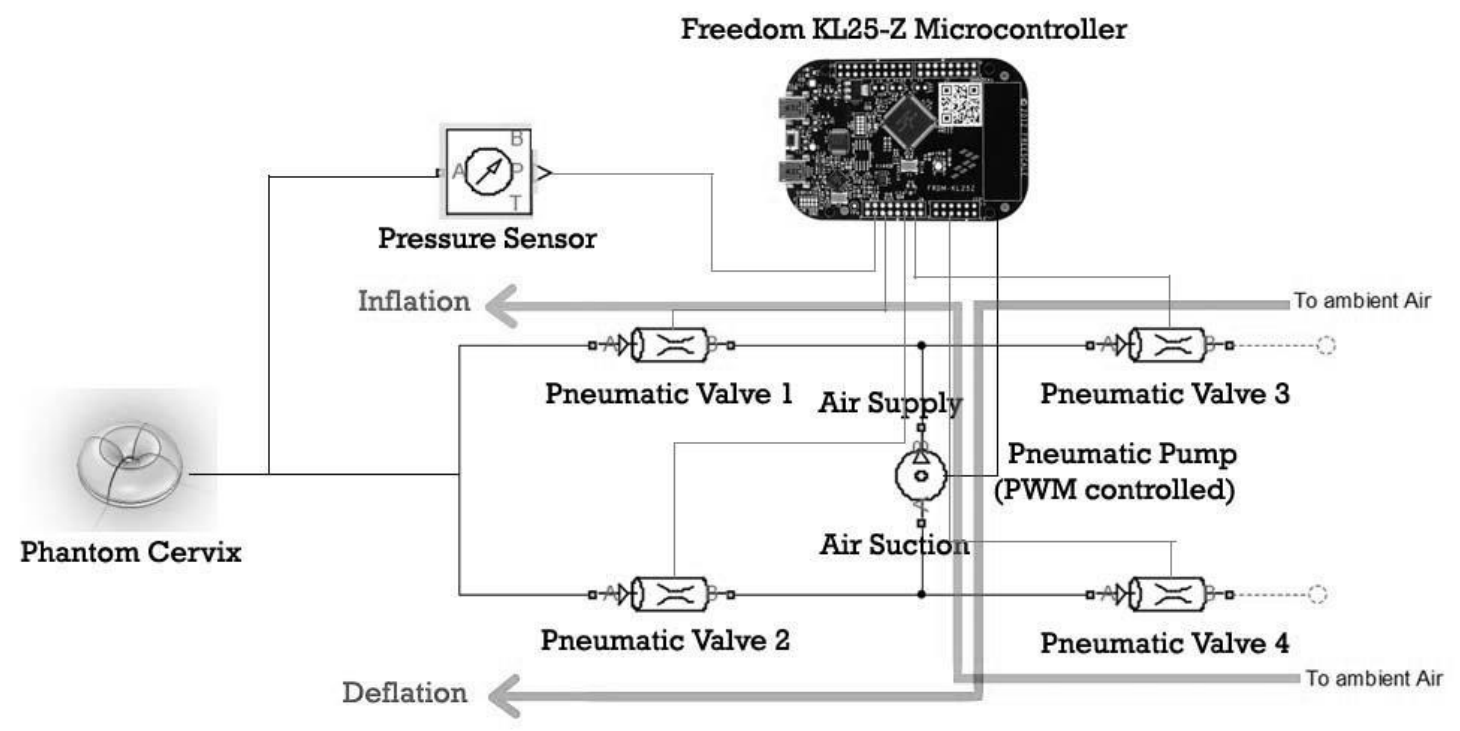

Figure 19: Schematic of Pneumatic System

By opening valve 1 and valve 3 while closing valve 2 and 3, the ambient air will be supplied to phantom cervix resulting in inflation of the phantom cervix. By opening valve 2 and 
3 while closing valve 1 and 4, the air will be sucked out resulting in deflation of the phantom cervix. The amount of the air supplied by the pump is controlled by adjusting PWM value from the microcontroller based on the pressure sensor reading creating a feedback control. Required parts to setup the pneumatic system and the testing platform illustrated in the next section are shown in the table below.

\begin{tabular}{|c|c|c|c|c|}
\hline \multirow{2}{*}{ Type } & $\begin{array}{c}\text { Micro } \\
\text { Controller }\end{array}$ & Pump & Valve & $\begin{array}{c}\text { Silicone-Pressure } \\
\text { Sensor on Chip }\end{array}$ \\
\hline $\begin{array}{c}\text { Part } \\
\text { Number }\end{array}$ & Arduino & $\begin{array}{c}\text { BTC IIS Dual Head- High } \\
\text { Pressure }\end{array}$ & $\begin{array}{c}\text { X-valve, 8mm } \\
\text { solenoid valve }\end{array}$ & MPXV7025DP \\
\hline Reason & $\begin{array}{c}\text { Cost, Easy } \\
\text { Setup }\end{array}$ & $\begin{array}{c}\text { Inflation/Deflation, } \\
\text { Required precision/power }\end{array}$ & Cost & Cost, \\
\hline Seller & Arduino & Parker & Parker & Freescale \\
\hline
\end{tabular}

Table 7: Materials Used for Building Pneumatic System

\begin{tabular}{|c|c|c|c|c|}
\hline \multirow{2}{*}{ Type } & \multicolumn{4}{|c|}{ Testing Platform } \\
& $\begin{array}{c}\text { Micro } \\
\text { Controller }\end{array}$ & $\begin{array}{c}\text { Exterior } \\
\text { Structure }\end{array}$ & Linear Actuator & Force Sensor \\
\hline Part & Arduino & MicroRax & Miniature Linear Motion & Force Sensor 3138- \\
Number & & $10 \mathrm{~mm} \times 10 \mathrm{~mm}$ & Series L16 & S-type \\
\hline Reason & Cost, Easy & Cost, Rigid, & Cost, & Cost, \\
& Setup & Easy Setup & Required precision & Required precision \\
\hline Seller & Arduino & MicroRax & Firgelli Technologies & Phidgets Inc \\
\hline
\end{tabular}

Table 8: Materials Used for Building Testing Platform 


\subsection{Testing platform}

The pneumatic system connected phantom sample will be placed on a testing platform with built-in force sensor on top and liner slider on the bottom to lift the sample plate.

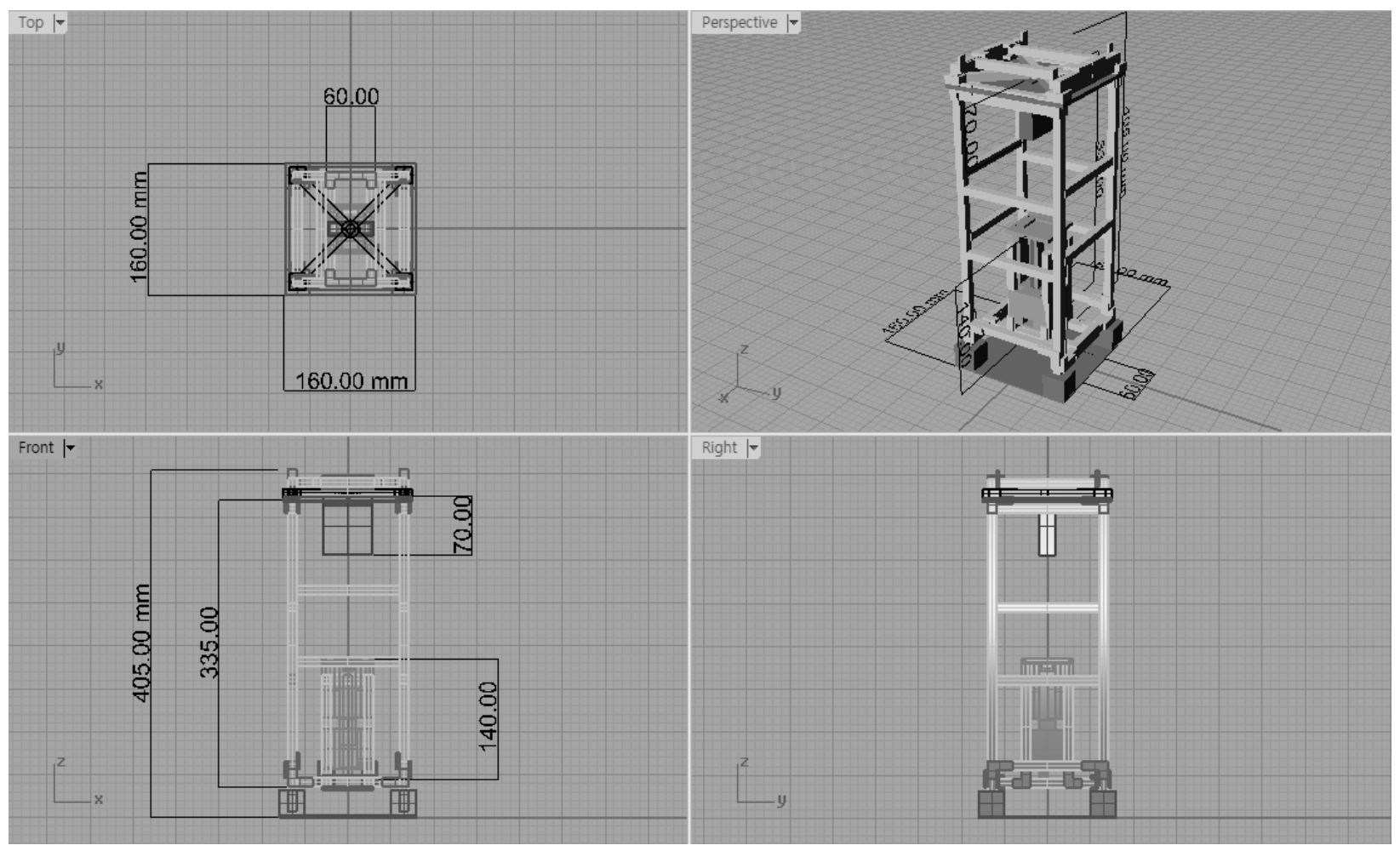

Figure 20: Testing Platform

The figure above illustrates its testing platform built. The grey colored structure is the outer frame built with MicroRax. The brown colored structure represents 3D printed ABS parts to support its inner part to fit. The blue colored structure is also 3D printed ABS parts to fit linear actuator to travel in straight line following MicroRax rail. The sample is placed on top of the blue colored structure. The red colored structure is the Firgelli Technologies' linear actuator, Miniature Linear Motion Series L16. Its operating voltage is $12 \mathrm{~V}$ and maximum travel distance of $50 \mathrm{~mm}$ with $0.3 \mathrm{~mm}$ positional accuracy. The green colored structure represents the Phidgets Inc.' force sensor, 3138 - S-Type Load Cell (0-100kg). Its operating voltage is $5 \mathrm{~V}$ and maximum capacity is $100 \mathrm{~kg}$. The precision is $0.02 \%$ of full scale measure. The force sensor and the linear actuator are connected to Arduino Uno to measure its value and control its movement 
with feedback control. Such system will provide accurate, quantifiable data regards to its displacement and tactile force exerted.

\subsection{Force Measurement Device Calibration / Verification}

The linear actuator and the force sensor were calibrated and their ADC (Analog to Digital Conversion) value captured by Arduino Uno board with ATmega328p chip was measured as following. Arduino board contains 6 channels, 10 bit-analog to digital converter mapping input voltages from 0 to $5 \mathrm{v}$ to 0 to 1023 . Since the linear actuator outputs its position from 0 to $12 \mathrm{~V}$ range, voltage divider was used to scale linear actuator's output range to analog to digital conversion input range.

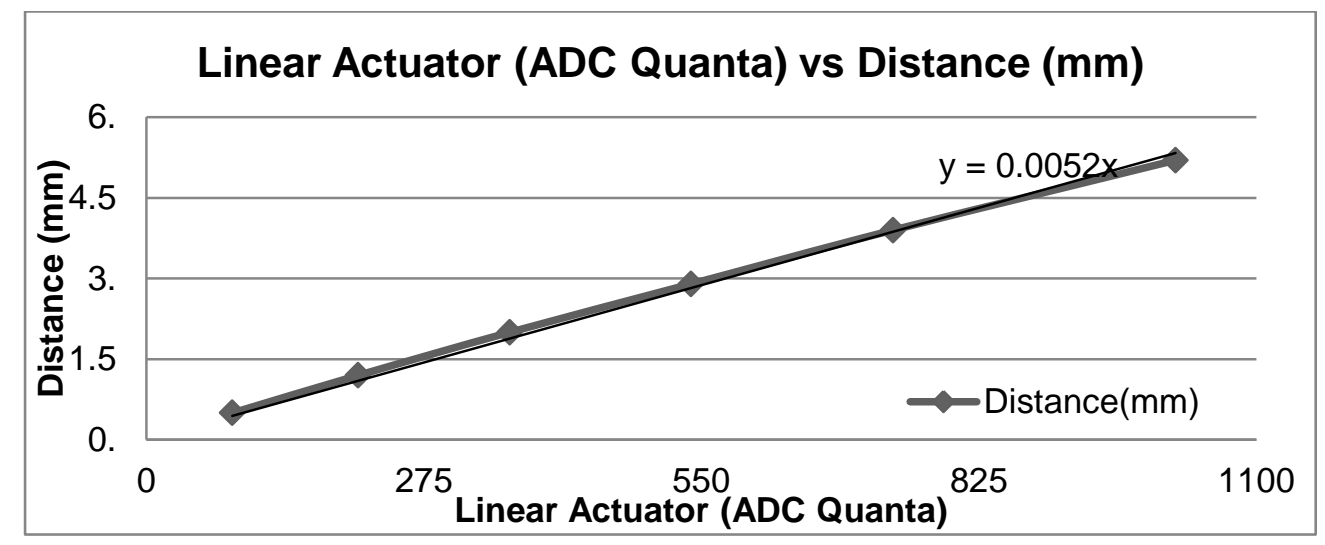

Figure 21: Linear Actuator Unit Conversion Graph

\begin{tabular}{|c|c|c|c|}
\hline Linear Actuator Reading (ADC Quanta) & Distance (mm) & Calculated (mm) & Error (mm) \\
\hline 85 & 0.5 & 0.45 & 0.05 \\
210 & 1.2 & 1.09 & 0.11 \\
360 & 2 & 1.87 & 0.13 \\
540 & 2.9 & 2.81 & 0.09 \\
740 & 3.9 & 3.85 & 0.05 \\
1020 & 5.2 & 5.30 & 0.10 \\
\hline
\end{tabular}

Table 9: Linear Actuator Unit Conversion Table 
For the linear actuator, the unit conversion factor from ADC bits to distance in $\mathrm{mm}$ is calculated as 0.0052 and the equation becomes

Distance $(\mathrm{mm})=0.0052 \times$ ADC Quanta

The error of calculating the distance based on the conversion factor of 0.0052 and ADC Quanta is less than $<0.128 \mathrm{~mm}$.

The ADC reading has error rate of +- 10 quanta and it represents

Error rate $(\mathrm{mm})=0.0052 \times(+-10$ quanta $)=+-0.052 \mathrm{~mm}=+-52 \mathrm{um}$

Accumulated maximum error for the linear actuator is

$0.128 \mathrm{~mm}+0.052 \mathrm{~mm}=0.170 \mathrm{~mm}=170 \mathrm{um}$

For the force sensor, the operating voltage of the sensor is the same as the voltage range for the analog to digital convertor input therefore the force sensor output was fed in directly to 10-bit analog to digital convertor on Arduino board.

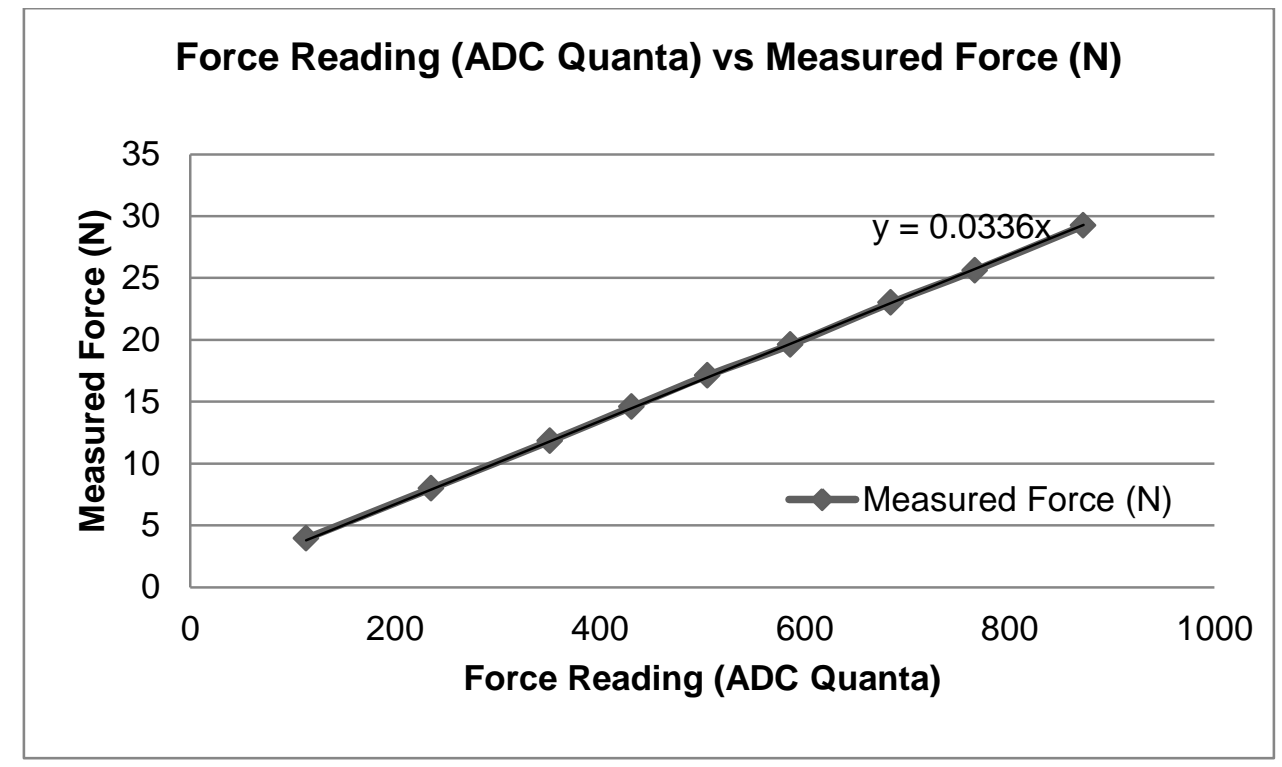

Figure 22: Force Sensor Unit Conversion Graph 


\begin{tabular}{|cccc|}
\hline $\begin{array}{l}\text { Force Sensor } \\
\text { Reading (ADC } \\
\text { Quanta) }\end{array}$ & $\begin{array}{l}\text { Measured } \\
\text { Force (N) }\end{array}$ & $\begin{array}{c}\text { Calculated } \\
(\mathrm{N})\end{array}$ & Error (N) \\
\hline 113 & 3.94 & 3.8 & 0.15 \\
235 & 7.98 & 7.9 & 0.08 \\
351 & 11.81 & 11.79 & 0.02 \\
431 & 14.58 & 14.48 & 0.1 \\
505 & 17.12 & 16.97 & 0.15 \\
586 & 19.6 & 19.69 & 0.09 \\
684 & 22.99 & 22.98 & 0.01 \\
766 & 25.61 & 25.74 & 0.12 \\
872 & 29.23 & 29.3 & 0.07 \\
\hline
\end{tabular}

Table 10: Force Sensor Unit Conversion Table

A similar approach has been taken for the force sensor. The force reading was measured with high precision scale in grams and compared to ADC Quanta captured by Arduino Uno Board. The unit conversion rate is calculated as 3.4237 resulting in a force conversion equation

Force Measured $(\mathrm{g})=0.0336 \times$ ADC quanta

The error of calculating the force measurement based on the conversion factor of 0.0336 and ADC quanta is less than $<0.15 \mathrm{~N}$.

Considering the ADC reading error rate of +- 10 quanta, the error tolerance for the force measurement becomes

Error rate $(\mathrm{N})=0.0336 \times(+-10$ quanta $)=+-0.336 \mathrm{~N}$

Accumulated maximum error of the Force Sensor is

$0.15 \mathrm{~N}+0.336=0.486 \mathrm{~N}$

To check the consistency and verify there is no hysteresis effect on the force sensor itself, another test was performed. Force sensor reading was recorded as known masses were loaded in the increment ranging from $500 \mathrm{~g}$ to $1 \mathrm{~kg}$. The measurements were compared with the force sensor reading as the loaded masses are unloaded in the decrement of the same increment used in loading. The graph and table below illustrates the recorded force sensor reading. 


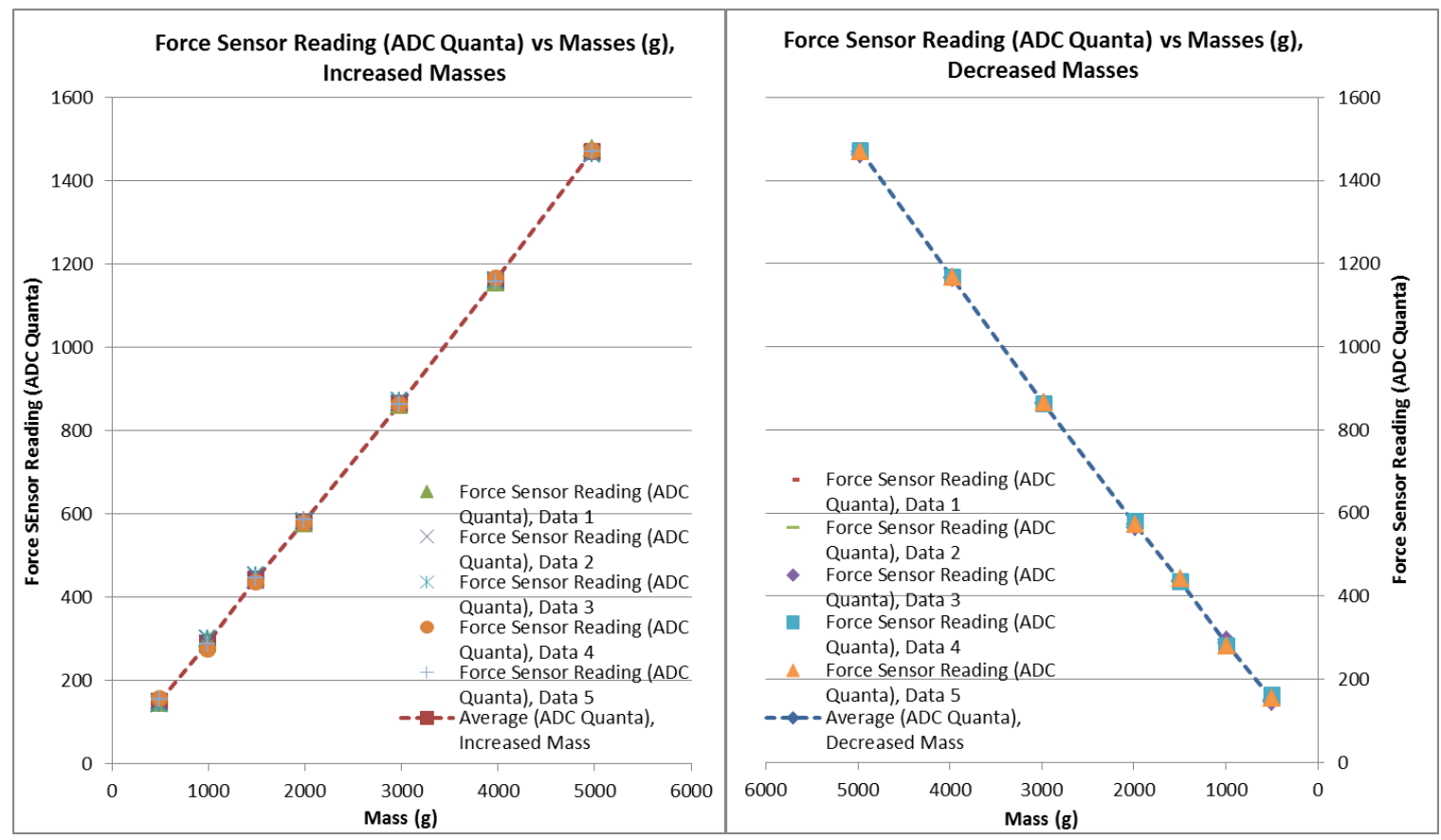

Figure 23: Force Sensor Reading vs. Masses for consistency test

\begin{tabular}{|cc|ccccc|c|}
\hline \multirow{2}{*}{ Mass(g) } & Measured Force & \multicolumn{5}{|c|}{ Force Sensor Reading (ADC Quanta) } & Average (ADC \\
& $(\mathrm{N})$ & Data 1 & Data 2 & Data 3 & Data 4 & Data 5 & Quanta) \\
\hline 498 & 4.88538 & 144 & 150 & 142 & 156 & 155 & 149.4 \\
996 & 9.77076 & 298 & 288 & 302 & 275 & 286 & 289.8 \\
1489 & 14.60709 & 442 & 438 & 452 & 436 & 445 & 442.6 \\
1988 & 19.50228 & 575 & 580 & 582 & 578 & 585 & 580 \\
2979 & 29.22399 & 860 & 866 & 872 & 862 & 863 & 864.6 \\
3974 & 38.98494 & 1155 & 1162 & 1158 & 1167 & 1156 & 1159.6 \\
4972 & 48.77532 & 1478 & 1465 & 1462 & 1472 & 1470 & 1469.4 \\
3974 & 38.98494 & 1172 & 1158 & 1165 & 1168 & 1167 & 1166 \\
2979 & 29.22399 & 869 & 865 & 863 & 862 & 865 & 864.8 \\
1988 & 19.50228 & 569 & 577 & 565 & 580 & 572 & 572.6 \\
1489 & 14.60709 & 436 & 420 & 438 & 435 & 441 & 434 \\
996 & 9.77076 & 288 & 292 & 294 & 281 & 279 & 286.8 \\
498 & 4.88538 & 152 & 140 & 146 & 161 & 155 & 150.8 \\
\hline
\end{tabular}

Table 11: Force Sensor Reading versus Masses for consistency test

Each comparison was performed 5 times and the resultant graph for increased masses and decreased masses show consistent linear force sensor reading. The difference in its reading between the incremented masses and decremented masses are within $2 \%$. 


\subsubsection{Measurement Procedure}

In order to perform force measurement experiments on phantom cervix, the phantom was placed on the sample place holder as shown in figure 24 . The sample plate then moved up from 0 $\mathrm{mm}$ depth to $1.45 \mathrm{~mm}$ and moved back to $0 \mathrm{~mm}$, providing force exertion on the sample at maximum depth of $1.45 \mathrm{~mm}$. The force measurement was sampled for 25 points over the distance of $2.9 \mathrm{~mm}$ (from $0 \mathrm{~mm}$ to $1.45 \mathrm{~mm}$ and back from $1.45 \mathrm{~mm}$ to $0 \mathrm{~mm}$ ). The force measurements of the sample were repeated for 9 different states varied with 3 different stress points and 3 pressure levels. Each simulation for a state was run 10 times for 2 samples and the average was taken as the result.

\section{A. Pressure Levels}

The pressure of the sample was controlled to be $-20 \mathrm{kPa}$ (deflation), $0 \mathrm{kPa}$ and $20 \mathrm{kPa}$ (inflation). The pressure level was feedback controlled with error rate of +- $0.4 \mathrm{kPa}$. At each pressure level, the force measurement of the sample was measured.

\section{B. Stress Points}

The position of sample placed on the sample plate was changed to exert the force on different stress points of the cervix sample. The force sensor exerted its force on inner side, center side and outer side of the sample. Each side was $2 \mathrm{~mm}$ apart in their distance as demonstrated in the diagram below.
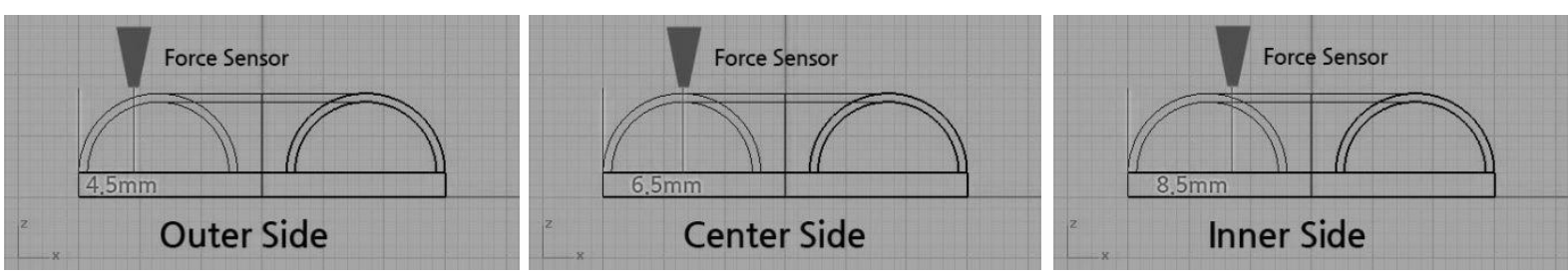

Figure 24: CAD cross-sectional diagram of Phantom Cervix and its measured side 


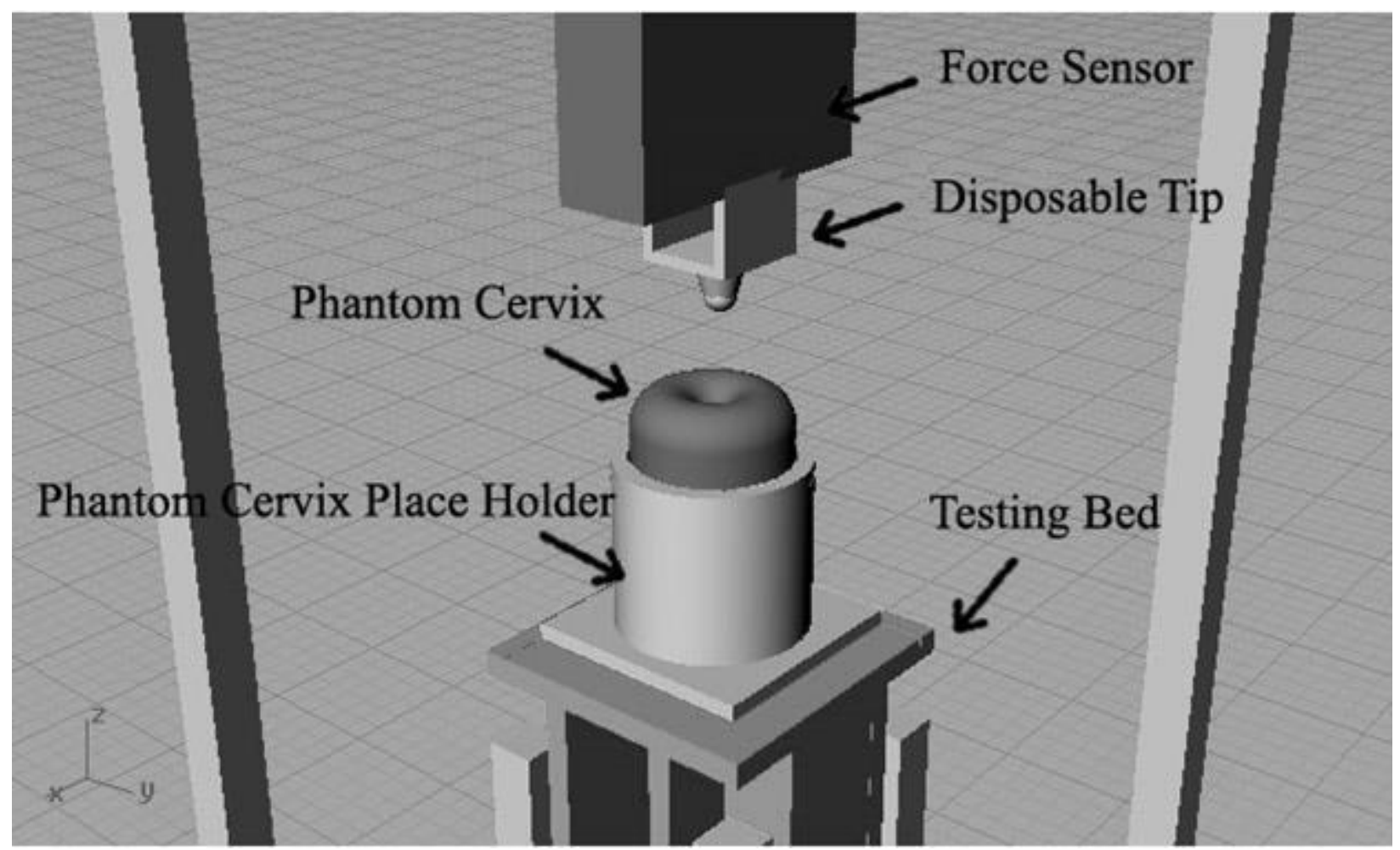

Figure 25: CAD illustration of the force sensor testing platform, testing tip and the phantom cervix. 


\subsection{Results}

The force exerted on a phantom cervix and the compression distance is measured while the phantom is placed on the testing bed moving from $0 \mathrm{~mm}$ to maximum depth of $1.45 \mathrm{~mm}$ and back to $0 \mathrm{~mm}$. The same measurement is performed for different force exertion point on inner side, center side and outer side of the phantom cervix at $-20 \mathrm{kPa}$ deflation pressure, $0 \mathrm{kPa}$ atmospheric pressure and $20 \mathrm{kPa}$ inflation pressures. For each set, the data was collected over 10 trials for 2 samples (Appendix B) and the average value is calculated. The purpose of this test is to observe the change in its physical property and quantify its physical property. The final result is presented in force $(\mathrm{N})$ against depth distance $(\mathrm{mm})$. The result is represented in the table below.

\begin{tabular}{|c|c|c|}
\hline \multicolumn{3}{|c|}{ Average result of all the trials measured at maximum depth of $1.45 \mathrm{~mm}$} \\
\hline \multirow{2}{*}{ Pressure (kPa) } & Pressure (kPa) & Force (N) measured at maximum depth of $1.45 \mathrm{~mm}$ \\
\hline \multirow{3}{*}{-20} & Inner & 13.17 \\
& Center & 16.20 \\
& Outer & 10.94 \\
\hline \multirow{3}{*}{0} & Inner & 11.31 \\
& Center & 13.65 \\
& Outer & 9.23 \\
\hline \multirow{2}{*}{20} & Inner & 10.07 \\
& Center & 11.25 \\
& Outer & 8.58 \\
\hline
\end{tabular}

Table 12. Average value of the force measurements at the maximum depth of $1.45 \mathrm{~mm}$ on the phantom cervix.

Discrimination experiment and threshold experiment has been performed to 24 subjects as well to observe how people perceive the change of its physical property and test the ability to distinguish "hard" and "soft" state of the phantom cervix. 


\section{Sample A for different pressure}

The force measurements for each side of the sample A phantom cervix illustrate a trend as its pressure changes. At $-20 \mathrm{kPa}$, deflation, the force was measured to be the highest and at 20 $\mathrm{kPa}$, inflation, the force was measured to be the lowest for all sides of the sample. This indicates that the phantom cervix experiences the most force exerted when it is deflated and experiences the least force exerted when it is inflated.

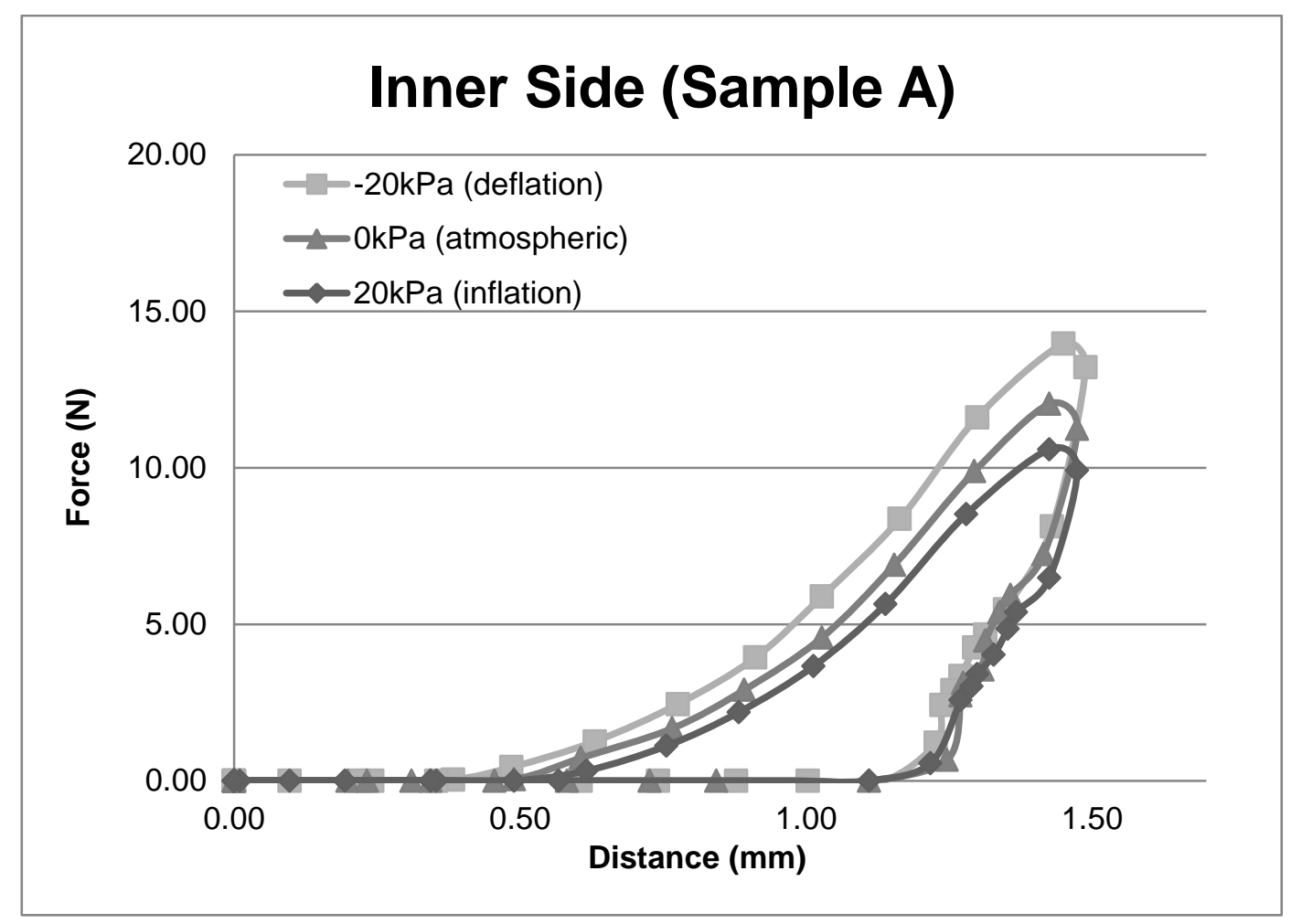

Figure 26: Average Force measurement at different pressure for the inner side Sample A of the phantom cervix. 


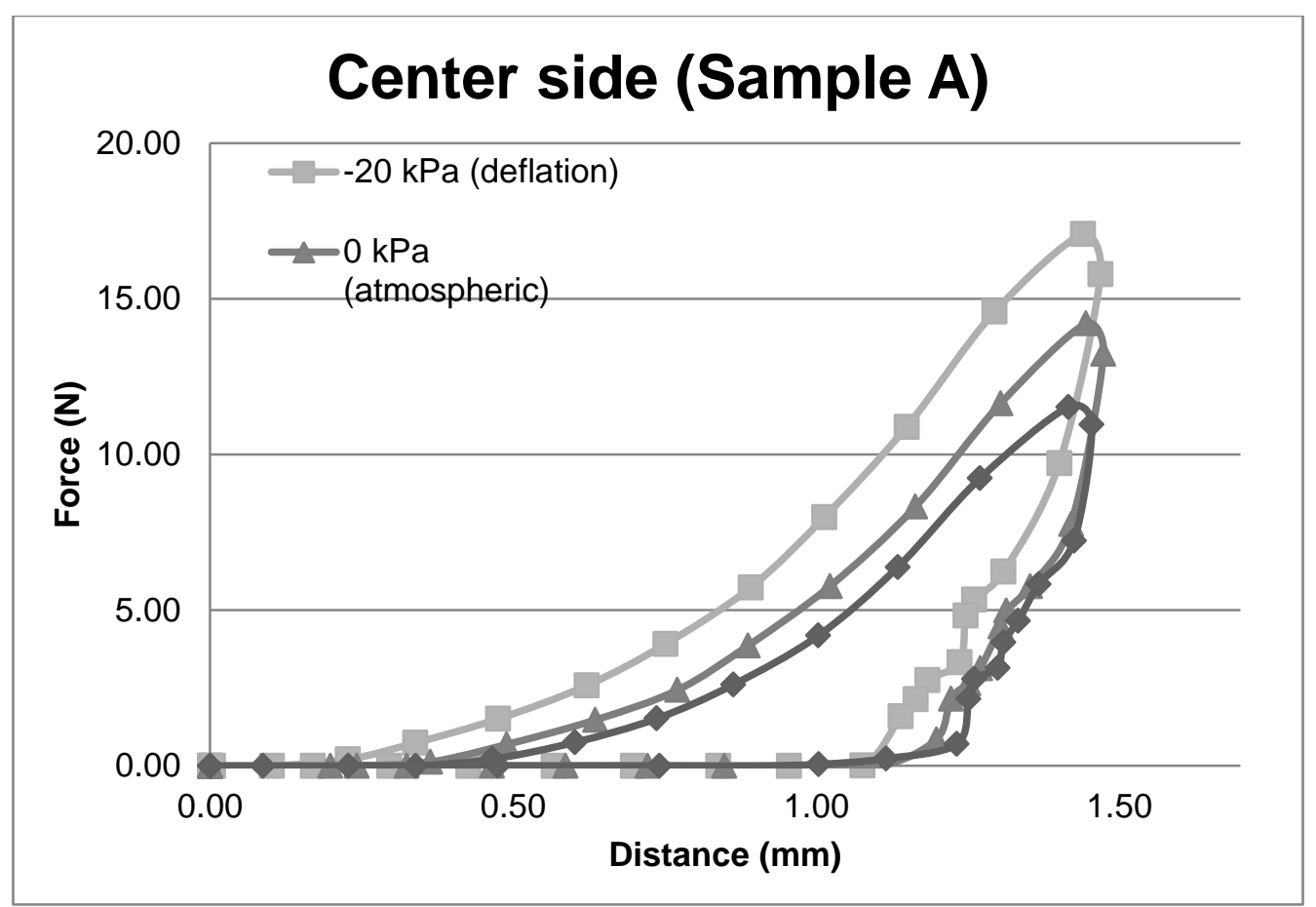

Figure 27: Average Force measurement at different pressure for the center side Sample A of the phantom cervix.

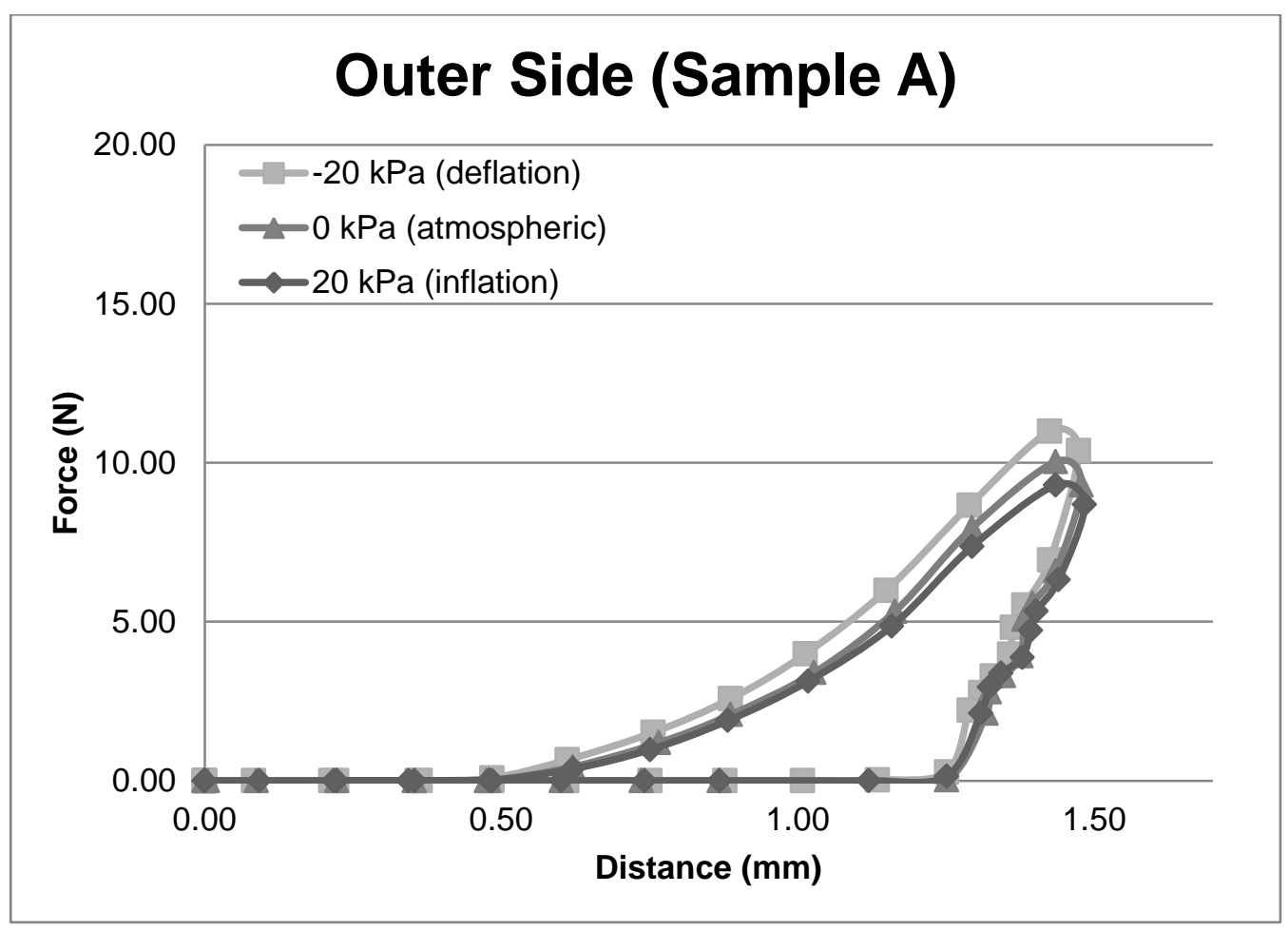

Figure 28: Average Force measurement at different pressure for the outer side Sample A of the phantom cervix. 


\begin{tabular}{|c|c|c|}
\hline \multicolumn{3}{|c|}{ Sample A } \\
\hline & Pressure $(\mathrm{kPa})$ & Maximum Force measured $(\mathrm{N})$ \\
\hline \multirow{3}{*}{ Inner Side } & -20 (deflation) & 13.96 \\
\hline & 0 (atmospheric) & 12.04 \\
\hline & 20 (inflation) & 10.59 \\
\hline \multirow{3}{*}{ Center Side } & -20 (deflation) & 17.08 \\
\hline & 0 (atmospheric) & 14.21 \\
\hline & 20 (inflation) & 11.53 \\
\hline \multirow{3}{*}{ Outer Side } & -20 (deflation) & 11.00 \\
\hline & 0 (atmospheric) & 10.03 \\
\hline & 20 (inflation) & 9.30 \\
\hline
\end{tabular}

Table 13: Maximum Force Measured (N) at different pressure level for Sample A of the phantom cervix. 


\section{Sample B for different pressure}

The force measurements for each side of the sample B phantom cervix illustrates consistent trend with sample A. The sample at $-20 \mathrm{kPa}$ deflated pressure experiences the more force exerted compared to other pressure levels and the sample at $20 \mathrm{kPa}$ inflated pressure experiences the least force exerted for the same depth distance.

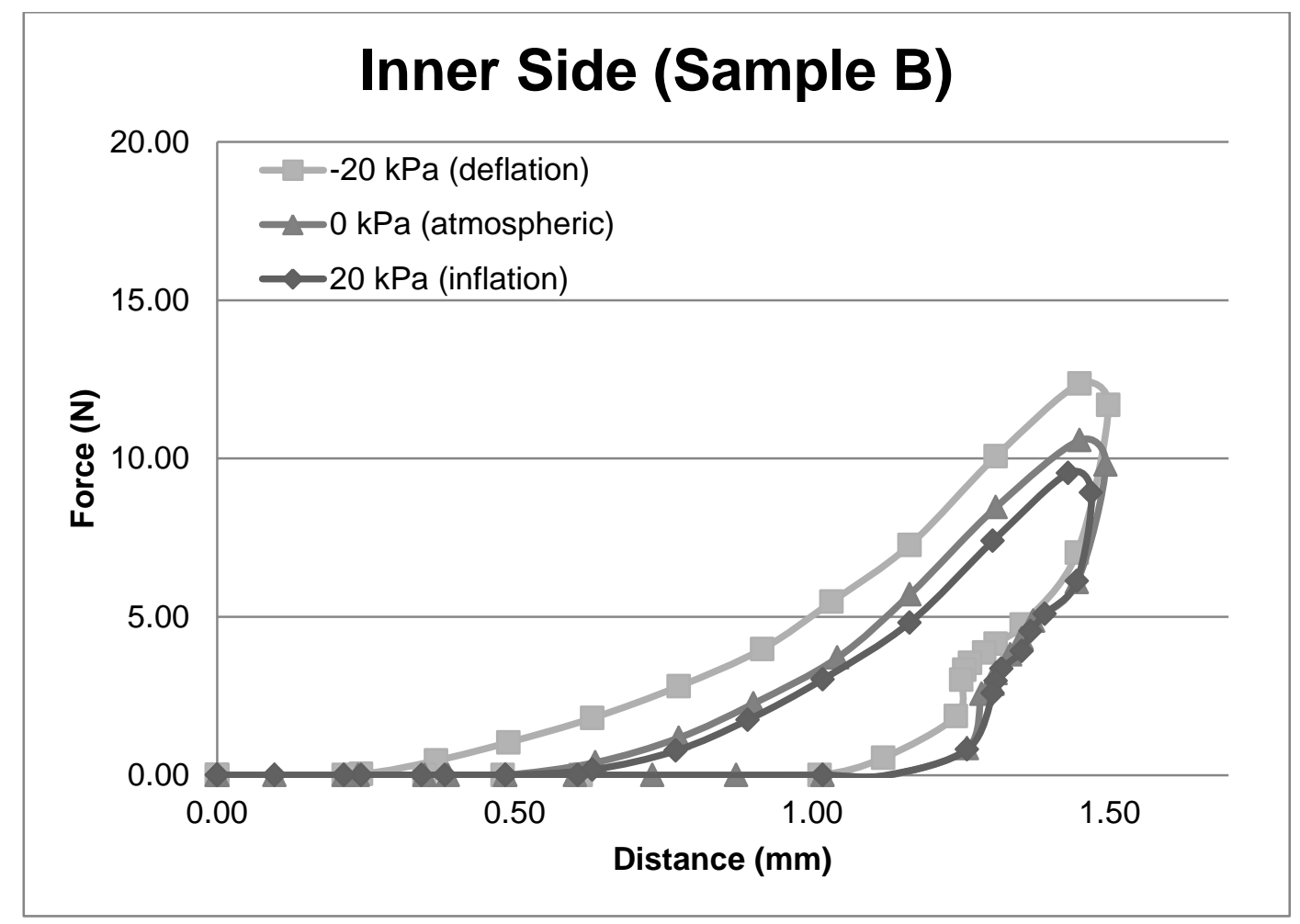

Figure 29: Average Force measurement at different pressure for the inner side Sample B of the phantom cervix. 


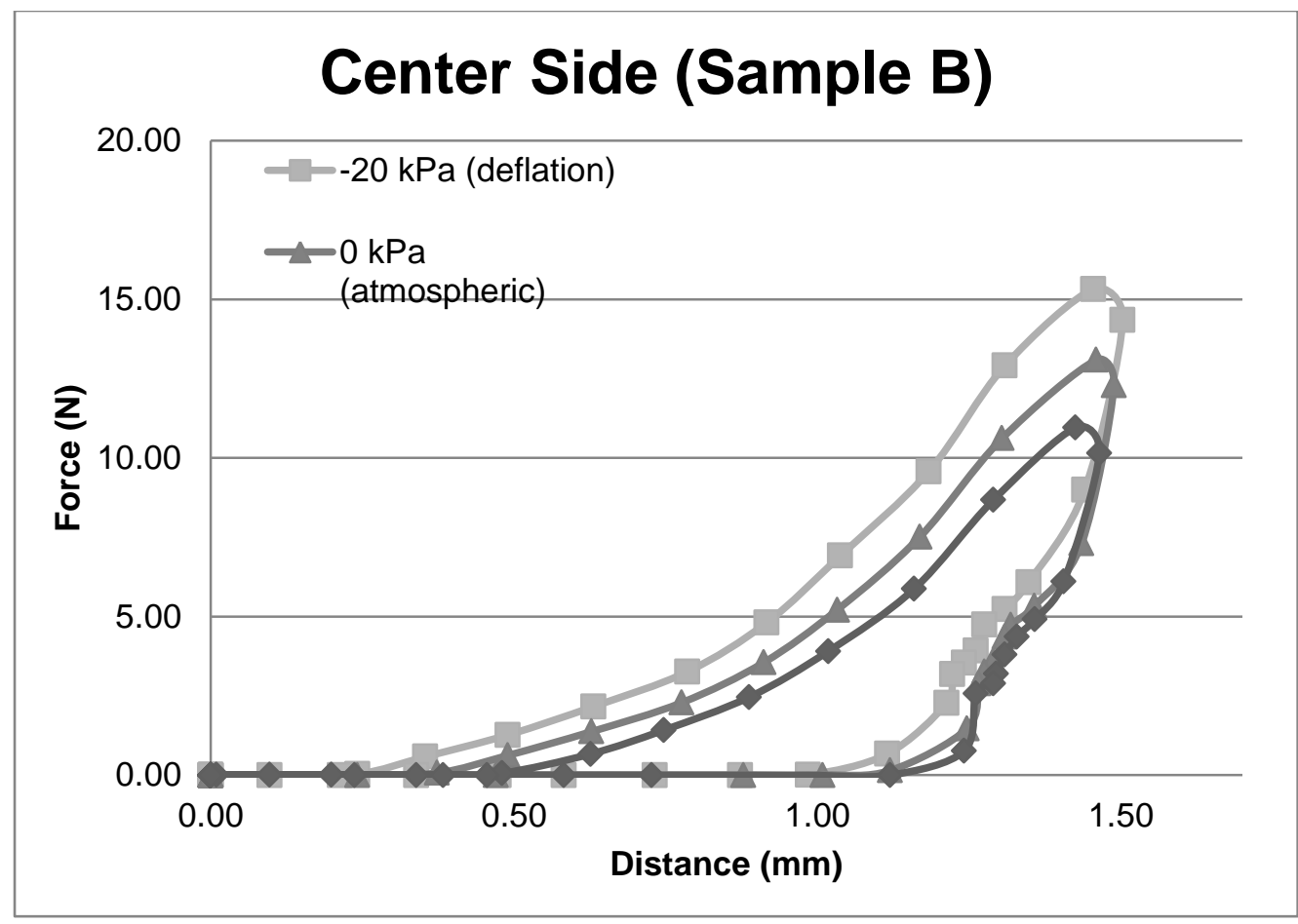

Figure 30: Average Force measurement at different pressure for the center side Sample B of the phantom cervix.

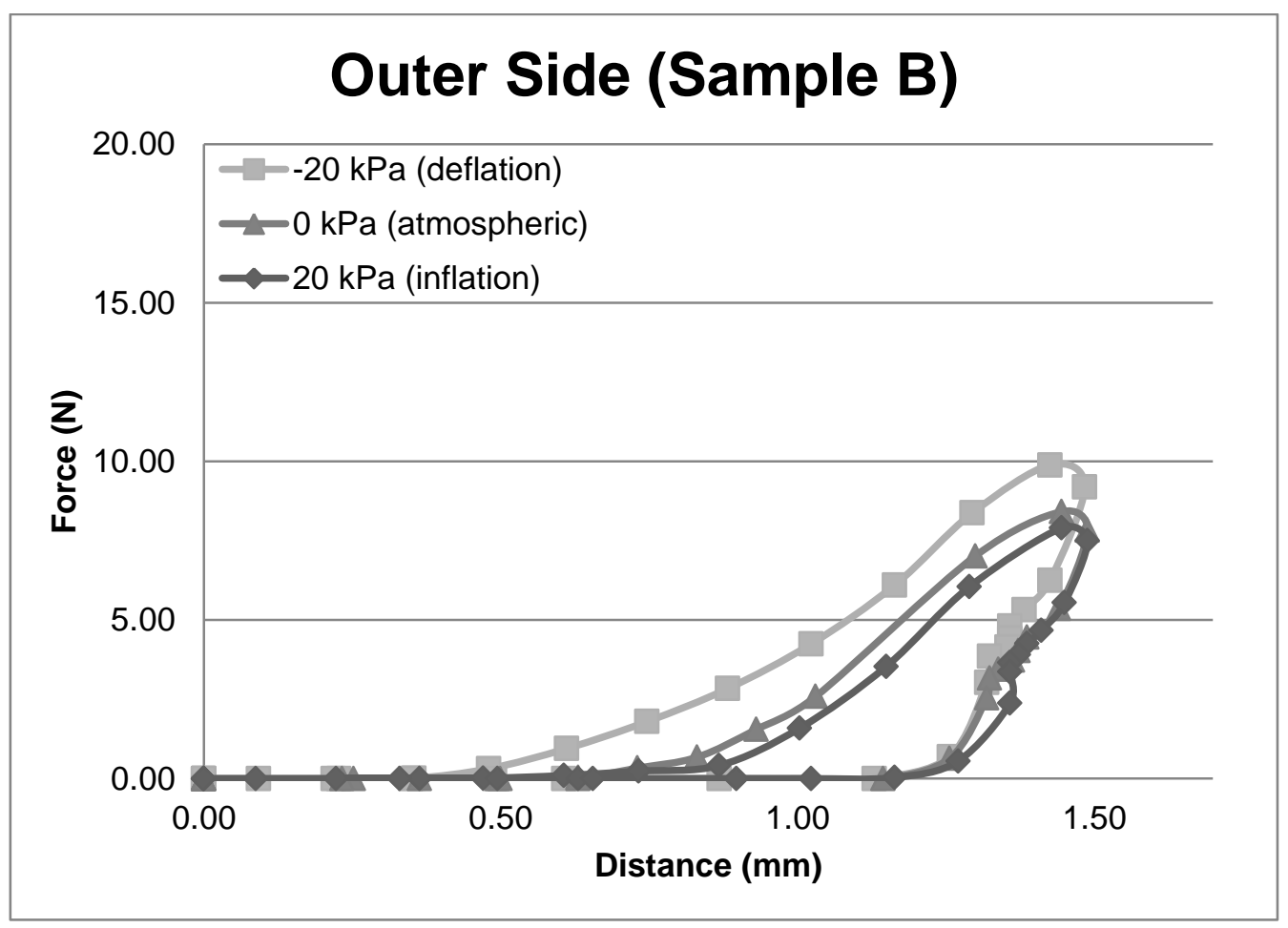

Figure 31: Average Force measurement at different pressure for the outer side Sample B of the phantom cervix. 


\begin{tabular}{|r|r|r|}
\hline & \multicolumn{2}{|c|}{ Sample B } \\
\hline & Pressure (kPa) & Maximum Force measured (N) \\
\hline Inner Side & 0 (atmospheric) & 12.37 \\
& 20 (inflation) & 10.58 \\
\hline \multirow{3}{*}{ Center Side } & 0 (atmospheric) & 9.54 \\
& 20 (inflation) & 15.32 \\
& -20 (deflation) & 13.09 \\
Outer Side & 0 (atmospheric) & 10.96 \\
& 20 (inflation) & 9.89 \\
& & 8.42 \\
\hline
\end{tabular}

Table 14: Maximum Force Measured (N) at different pressure level for Sample B of the phantom cervix.

\section{Sample A for different stress points}

The graphs below are illustrated to show the trend of its force measurement for different sides of the sample. The graph is based on the same data point collected as above, but re-graphed for each air pressure level for each sample instead of for each side. 


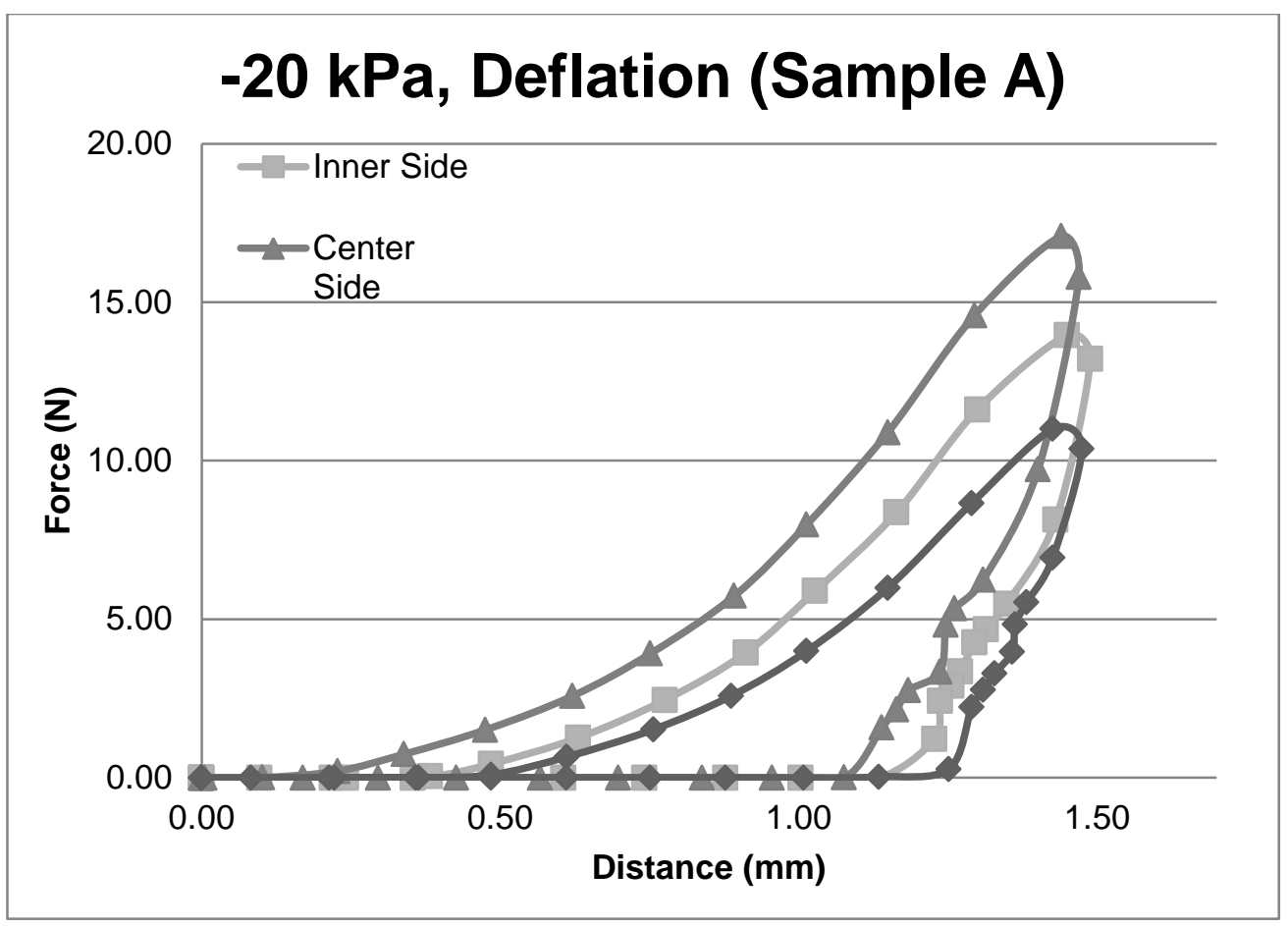

Figure 32: Average Force measurement at different sides for the $-20 \mathrm{kPa}$ Sample A of the phantom cervix.

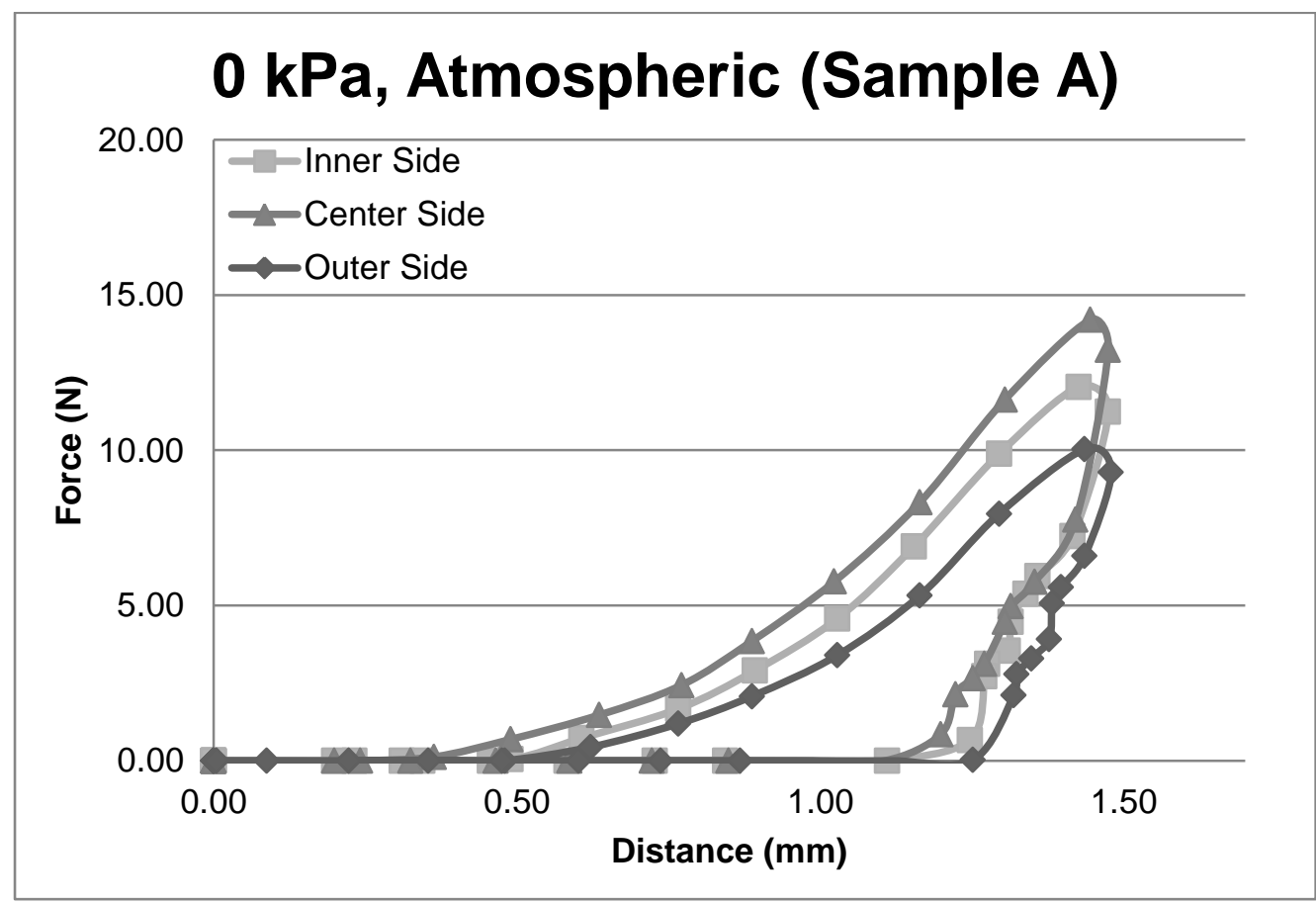

Figure 33: Average Force measurement at different sides for the $0 \mathrm{kPa}$ Sample A of the phantom cervix. 


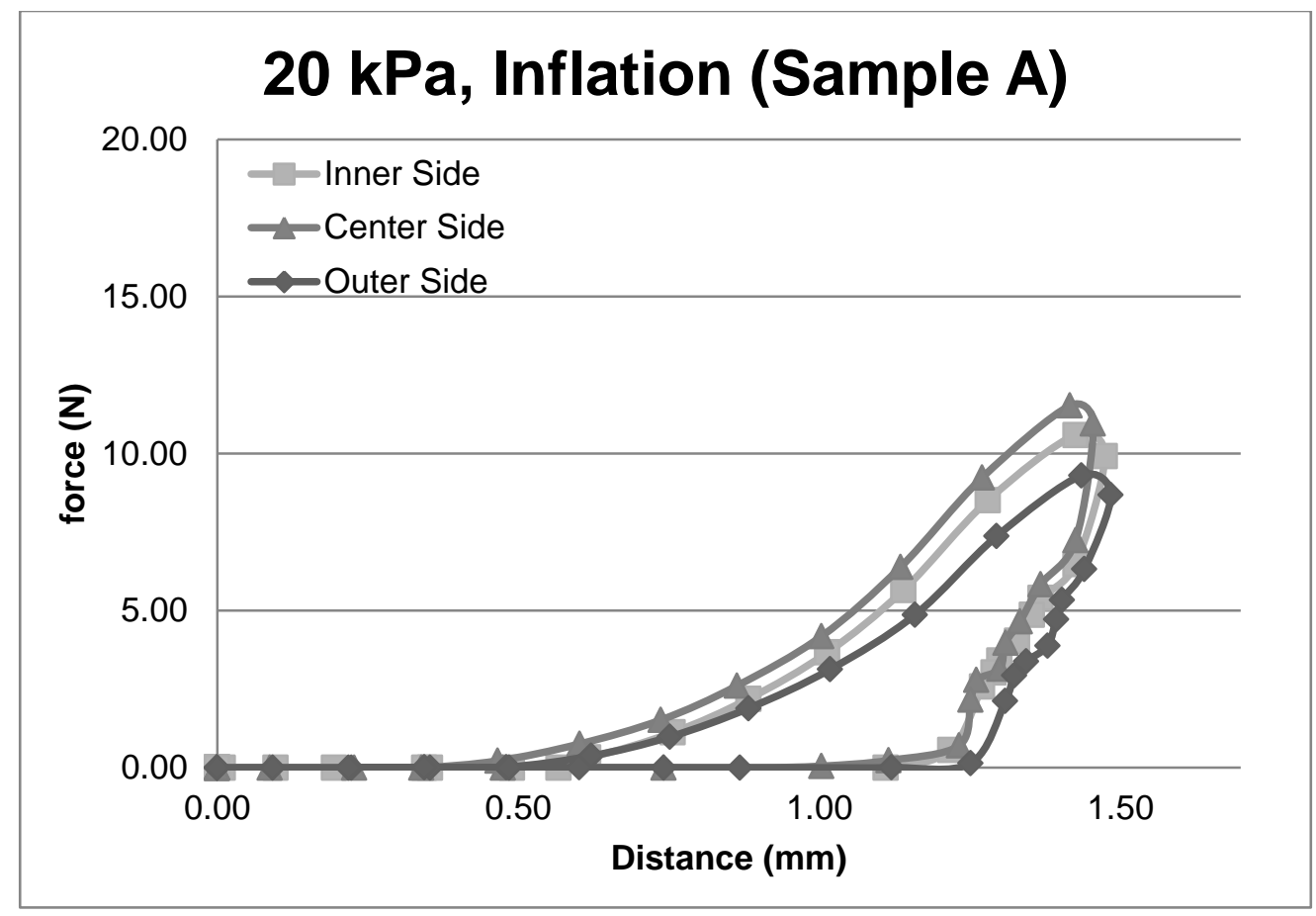

Figure 34: Average Force measurement at different sides for the $20 \mathrm{kPa}$ Sample A of the phantom cervix.

\begin{tabular}{|c|r|r|}
\hline \multicolumn{2}{|c|}{ Sample A } \\
\hline Pressure $(\mathrm{kPa})$ & Pressure $(\mathrm{kPa})$ & $\begin{array}{c}\text { Maximum } \\
\text { Force measured } \\
(\mathrm{N})\end{array}$ \\
\hline-20 & Inner & 13.96 \\
& Center & 17.08 \\
& Outer & 11.98 \\
\hline 0 & Inner & 12.04 \\
& Center & 14.21 \\
& Outer & 10.03 \\
\hline 20 & Inner & 10.59 \\
& Center & 11.53 \\
& Outer & 9.24
\end{tabular}

Table 15: Maximum Force Measured (N) at different force exertion point for Sample A of the phantom cervix. 
The center side demonstrates higher force measured value for each inflated, deflated and atmospheric pressure compared to the inner side and the outer side. The center side has the most amounts of grains accumulated and therefore the stiffness increases the most as more deflation is present. Also, the inner side of the sample is stiffer than the outer side for all air pressure levels. This can be due to its circular geometry, where the inner side has higher stress compared to the outer side.

\section{Sample B for different stress points}

Sample B illustrates similar trend as seen in sample A. The center side has higher force measured compared to the other sides for all inflated, deflated and atmospheric pressure levels. Again, inner side is stiffer than the outer side due to its geometry.

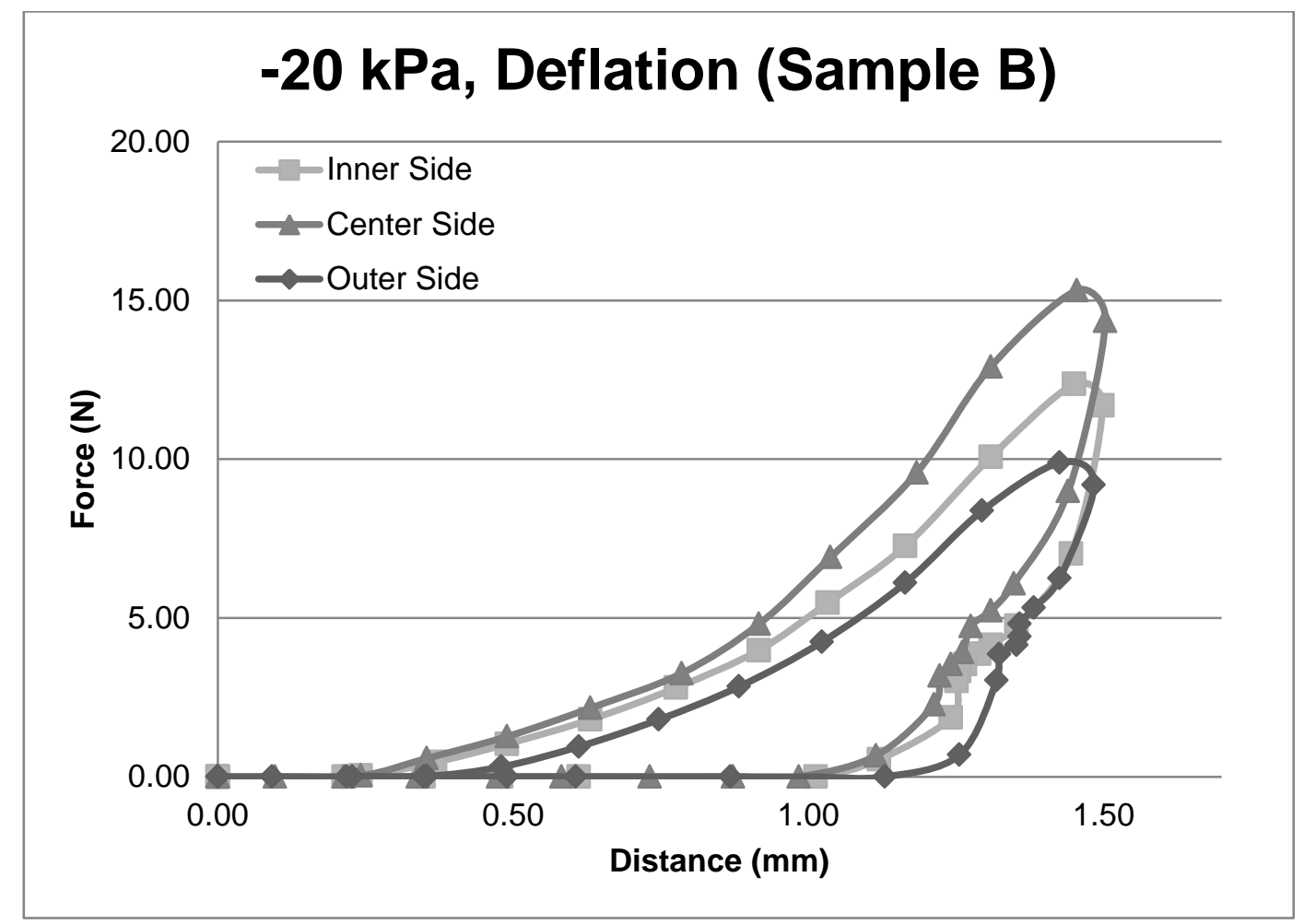

Figure 35: Average Force measurement at different sides for the $-20 \mathrm{kPa}$ Sample B of the phantom cervix. 


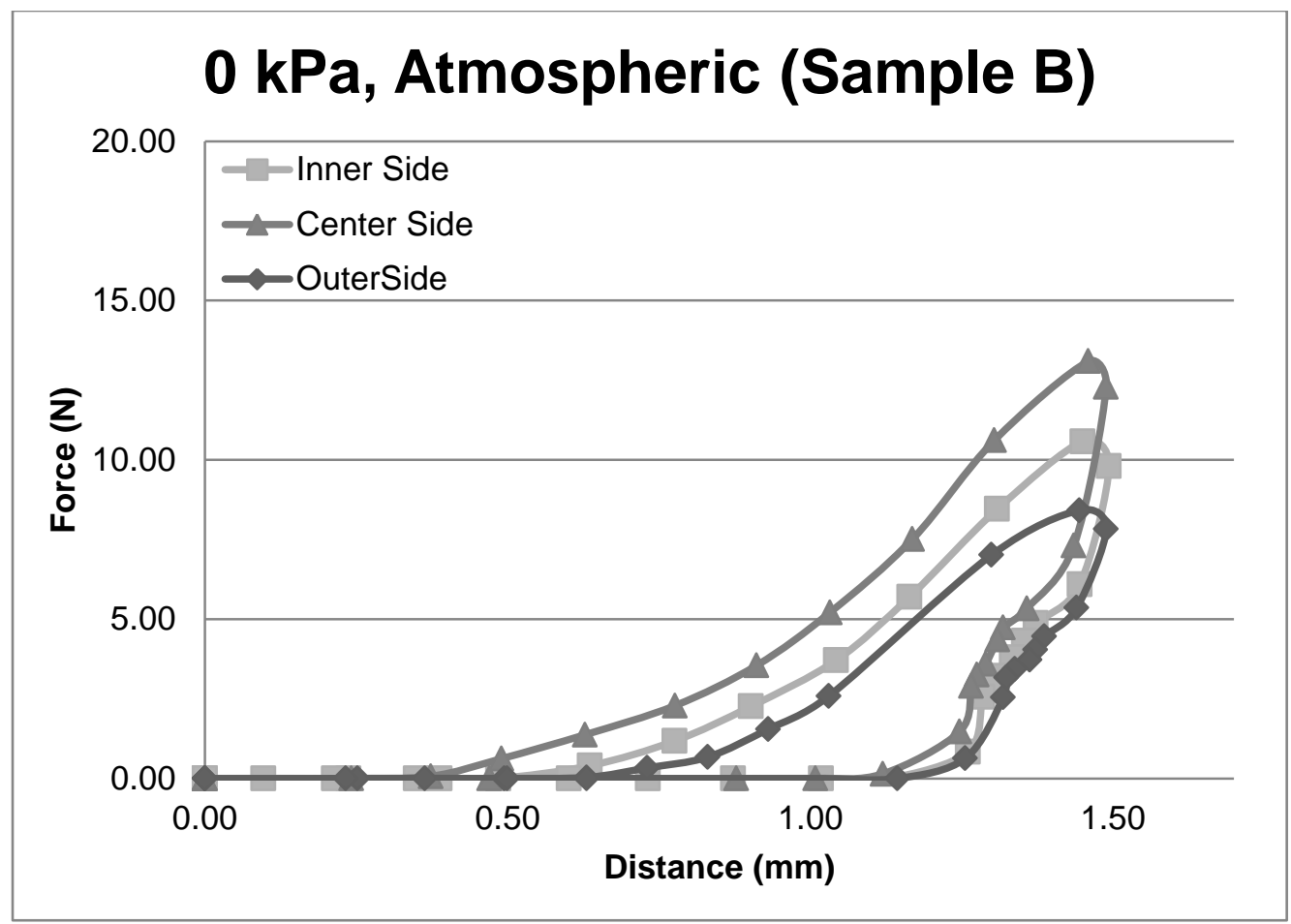

Figure 36: Average Force measurement at different sides for the $0 \mathrm{kPa}$ Sample B of the phantom cervix.

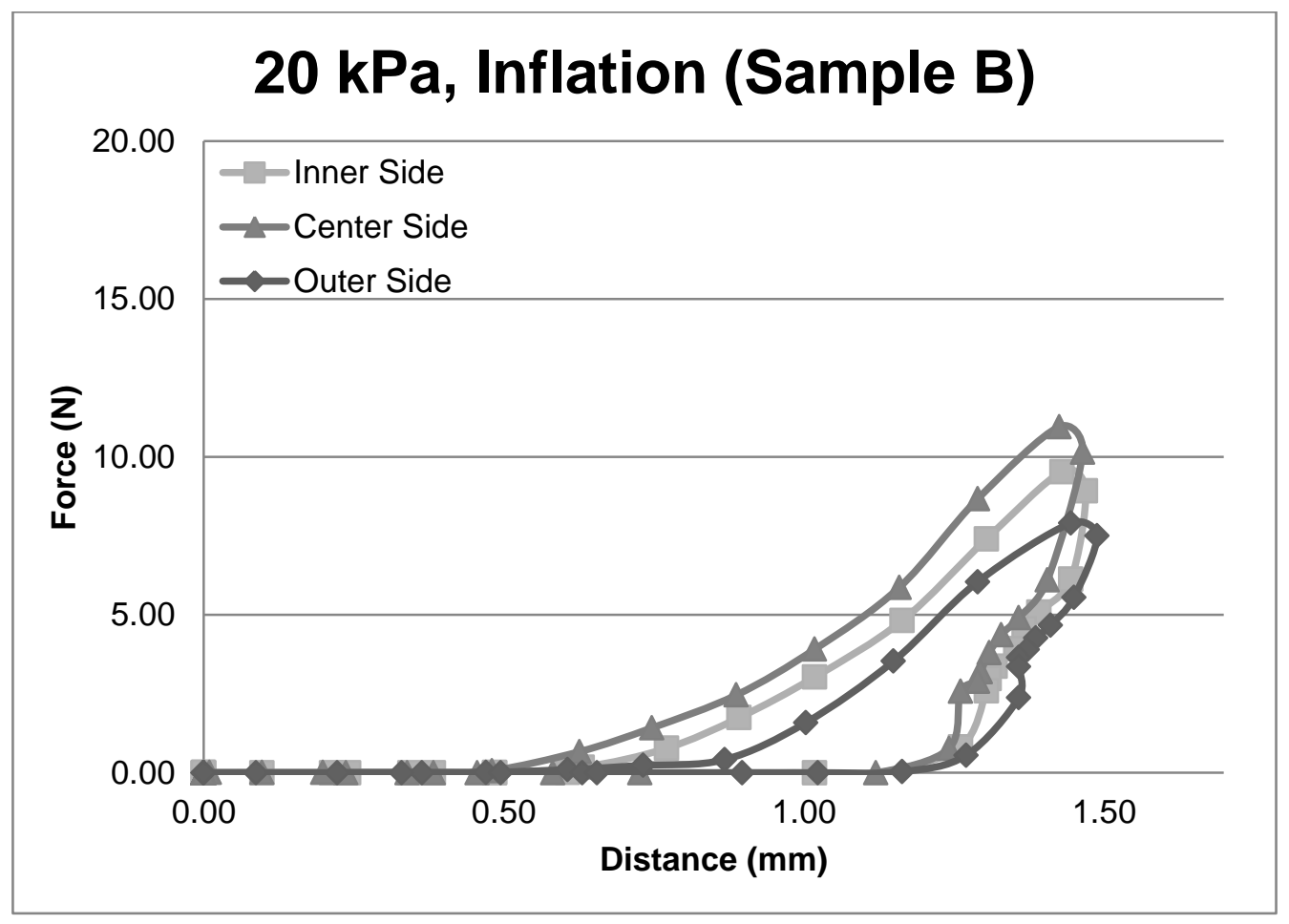

Figure 37: Average Force measurement at different sides for the $20 \mathrm{kPa}$ Sample B of the phantom cervix. 


\begin{tabular}{|c|c|c|}
\hline \multicolumn{2}{|c|}{ Sample B } \\
\hline \multirow{2}{*}{ Pressure $(\mathrm{kPa})$} & Pressure $(\mathrm{kPa})$ & Maximum Force measured (N) \\
\hline \multirow{2}{*}{20} & Inner & 12.37 \\
& Center & 15.32 \\
\hline \multirow{2}{*}{0} & Outer & 9.89 \\
\hline & Inner & 10.58 \\
& Center & 13.09 \\
\hline & Outer & 8.42 \\
\hline
\end{tabular}

Table 16: Maximum Force Measured (N) at different Force exertion point for Sample B of the phantom cervix.

The graphs below illustrate all the force measurements put together in a graph for each sample.

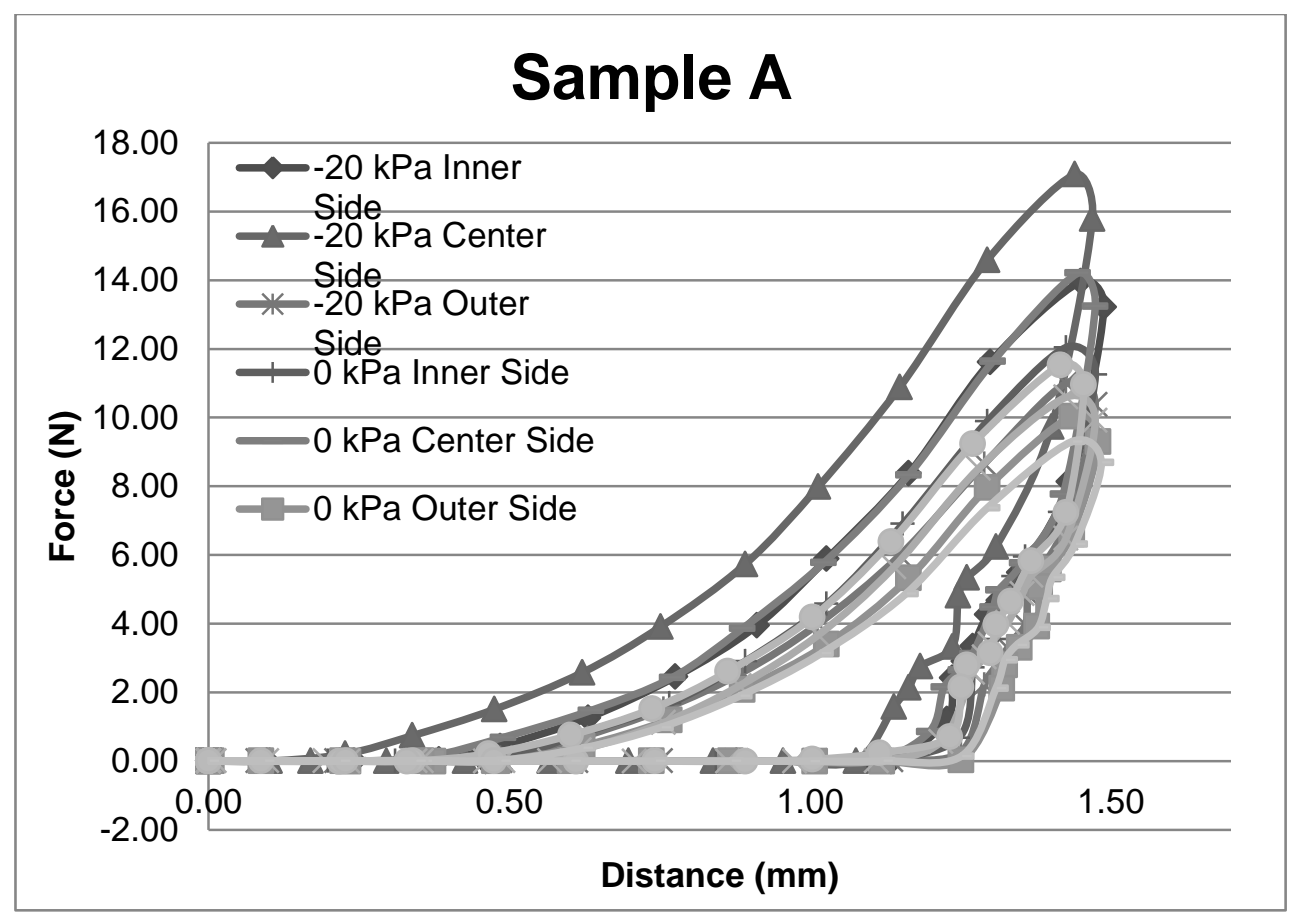

Figure 38: Average Force Measurement of Sample A of the phantom cervix. 


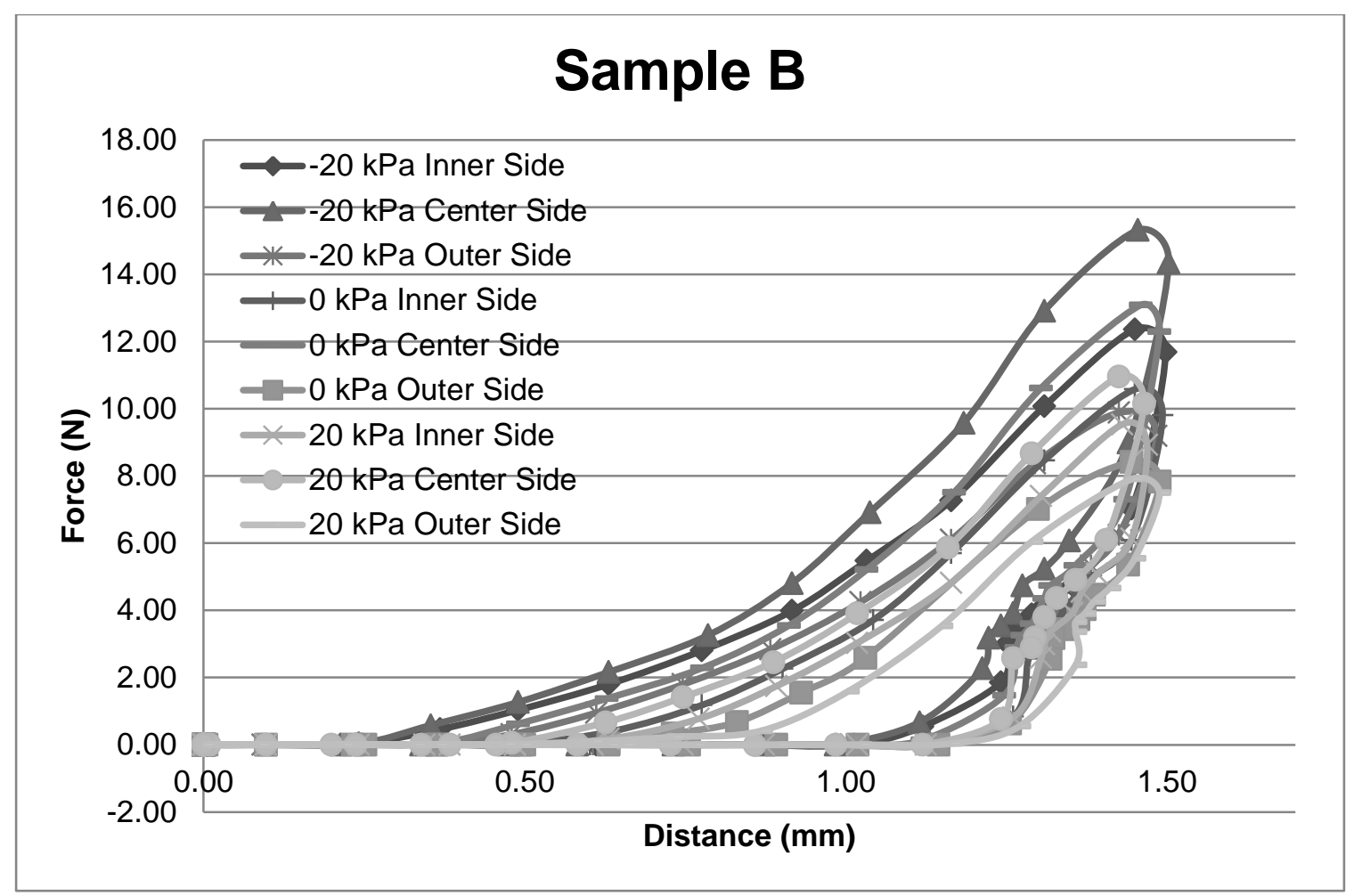

Figure 39: Average Force Measurement of Sample B of the phantom cervix.

As it is seen in the graphs above, the amount of force exerted on the phantom cervix changes depends on its air pressure level and the position of force exerted. More force is exerted as it gets stiffer as the deflated pressure increases and less force is exerted as the inflated pressure increases. The force being exerted on the center side is the stiffest and on the outer side is the softest. Both trends are consistent in both samples A and B.

\section{Discrimination Experiment}

The phantom cervix was presented in randomized trials with either "hard" (-20 kPa) or "soft" $(20 \mathrm{kPa})$ and asked to discriminate between these two states. Total of 24 subjects were collected. The stimulation response matrix shows specificity of $70.83 \%$, sensitivity of $100 \%$, false alarm of $29.17 \%$ and miss of 0 . 


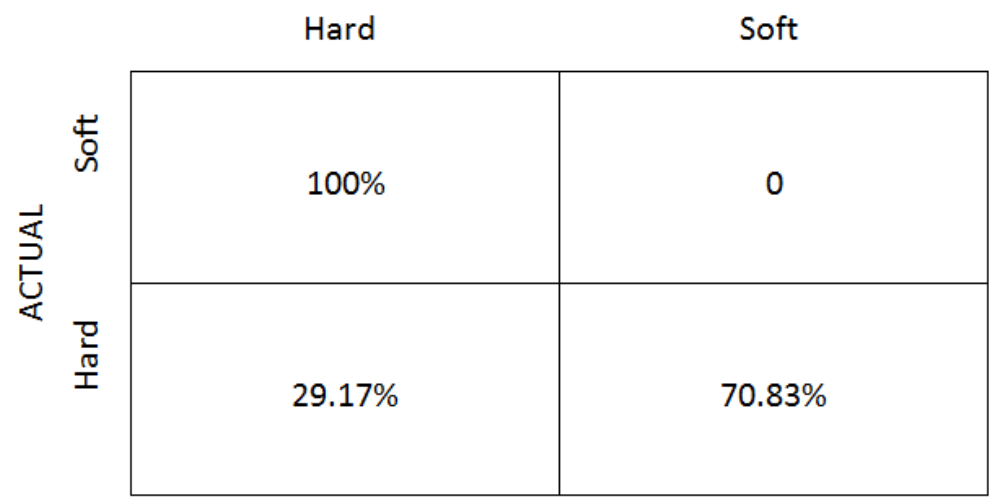

Figure 40: Discrimination experiment with the phantom cervix and 24 subjects. Subjects were capable of distinguishing between hard and soft states.

This result indicates that subjects were capable of distinguish between 'hard' and 'soft' state of the phantom's physical property change as the inner pressure was controlled. False alarm of $29.17 \%$ indicates that 'soft' state was not as distinguishable as 'hard' state.

\section{Threshold Experiment}

The inner pressure of the phantom cervix varied from $-20 \mathrm{kPa}$ to $20 \mathrm{kPa}$ gradually and asked to identify when the subjects perceived it as "soft". The average threshold determined to be $10.6 \mathrm{kPa}$.

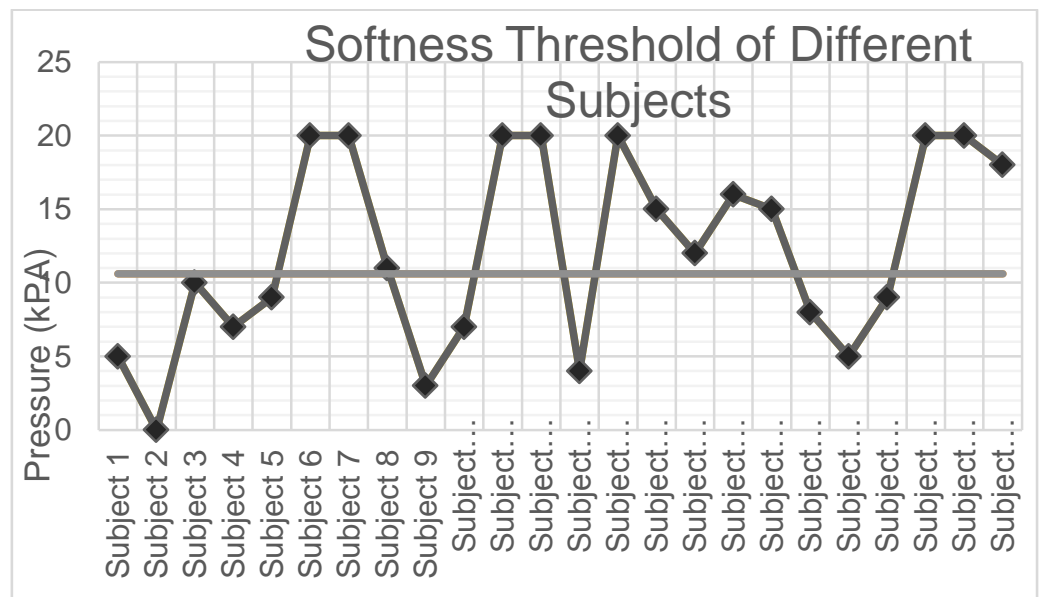

Figure 41: Results of the threshold experiment on the phantom cervix with 24 subjects. Subjects were capable of detecting the threshold of change between hard and soft states, with a bias towards higher air pressure (harder cervix). 


\subsection{Discussion}

Taking the average value of all the measurements using the force platform described in Section 3.6 and 3.7, the maximum force measurement at the maximum depth of $1.45 \mathrm{~mm}$ is observed as $16.2 \mathrm{~N}$ at the center side of the phantom cervix at $-20 \mathrm{kPa}$ deflated pressure. The minimum force measurement at the maximum depth of $1.45 \mathrm{~mm}$ is observed as $8.58 \mathrm{~N}$ at the outer side of the phantom cervix at $20 \mathrm{kPa}$ inflated pressure. The result observed in both samples demonstrates that $-20 \mathrm{kPa}$ deflated pressure experienced the highest force exertion and $20 \mathrm{kPa}$ inflated pressure experienced the least force exertion. For the same inner pressure, the center side of the phantom cervix is observed to be the stiffest and the outer side of the phantom cervix is observed to be the softest. The center side has the most amounts of grains accumulated and therefore the stiffness increases the most as more deflation is present. Also, this can be due to its circular geometry, where the inner side has higher stress compared to the outer side, delivering different stress level on different exertion points.

To verify the physical property change as the pressure changes, we determined its spring constant $(\mathrm{N} / \mathrm{m})$ change and true stress $(\mathrm{kPa})$ at 0.15 strain. The result is shown as below.

\begin{tabular}{|c|c|cc|}
\hline \multirow{2}{*}{ Pressure $(\mathrm{kPa})$} & Pressure $(\mathrm{kPa})$ & $\begin{array}{c}\text { Spring Constant }(\mathrm{N} / \mathrm{m}) \\
\text { measured at maximum } \\
\text { depth of } 1.45 \mathrm{~mm}\end{array}$ & $\begin{array}{c}\text { True Stress }(\mathrm{kPa}) \\
\text { measured at 0.15 strain }\end{array}$ \\
\hline \multirow{3}{*}{-20} & Inner & 7801.68 & 128.22 \\
& Center & 9548.97 & 164.39 \\
\cline { 2 - 4 } 0 & Outer & 6195.88 & 106.65 \\
\hline \multirow{3}{*}{20} & Inner & 6568.90 & 107.71 \\
& Center & 8256.70 & 135.21 \\
& Outer & 5258.94 & 89.37 \\
\hline & Inner & 6072.49 & 94.23 \\
& Center & 6928.97 & 110.43 \\
\hline
\end{tabular}

Table 17. Spring Constant $(\mathrm{N} / \mathrm{m})$ and True Stress $(\mathrm{kPa})$ measure for all pressure 


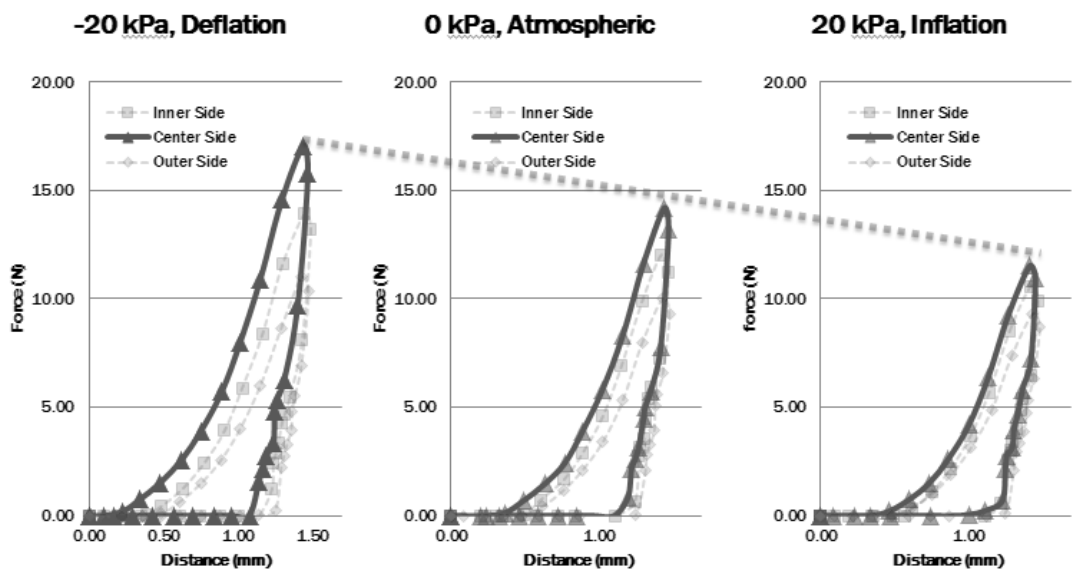

Figure 17: Average Force measurement at different pressure levels (Center Side)

Figure 42: Average force measurement at different pressure levels (center side)

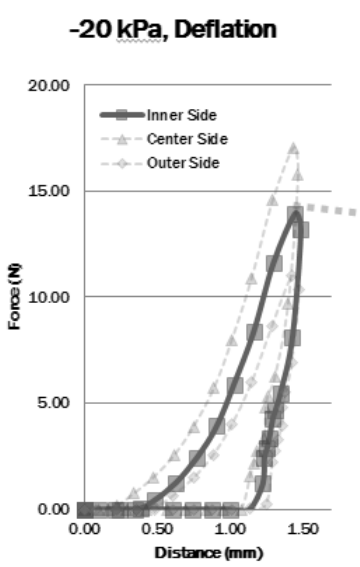

$\mathbf{0 ~ k P a , ~ A t m o s p h e r i c ~}$

$20 \mathrm{kPa}$, Inflation

Figure 18: Average Force measurement at different pressure levels (Inner Side)

Figure 43: Average force measurement at different pressure levels (inner side)
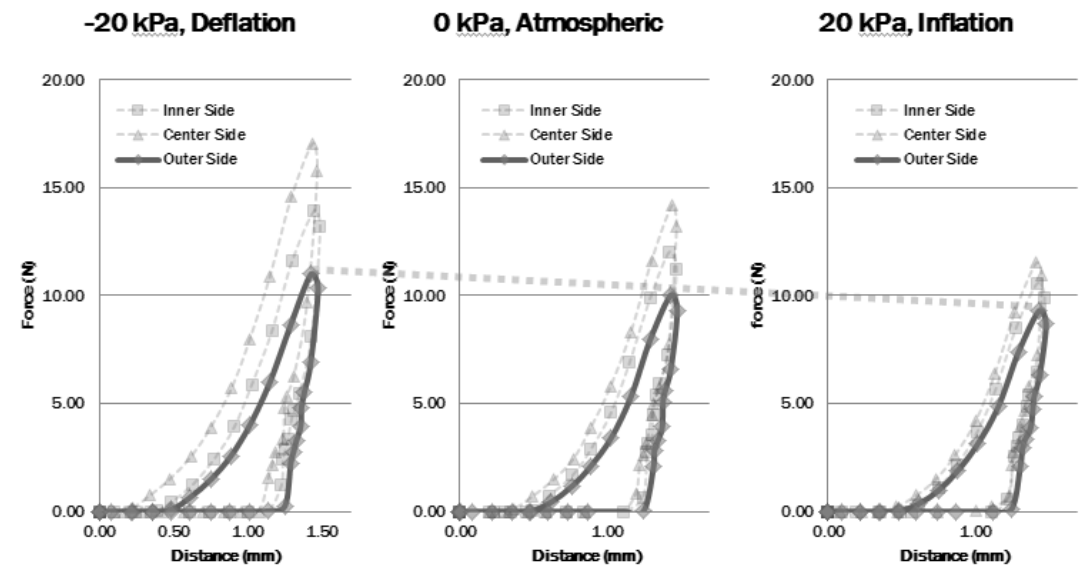

Figure 19: Average Force measurement at different pressure levels (Outer Side)

Figure 44: Average force measurement at different pressure levels (outer side) 
To observe it physical property change, the spring constant was determined based on Hooke's Law equation, Force $(F)=$ Spring Constant $(K) \times$ Distance $(X)$. By rearranging the equation, it becomes Spring Constant $(\mathrm{K})=$ Force $(\mathrm{F}) /$ Distance $(\mathrm{X})$. The spring constant was calculated based on the average value of force measured of all three sides of inner, center and outer side for inflated, deflated and atmospheric pressure level. The spring constant for each compression distance is shown in Figure 45 and Figure 46 for different stress points and different pressure levels.
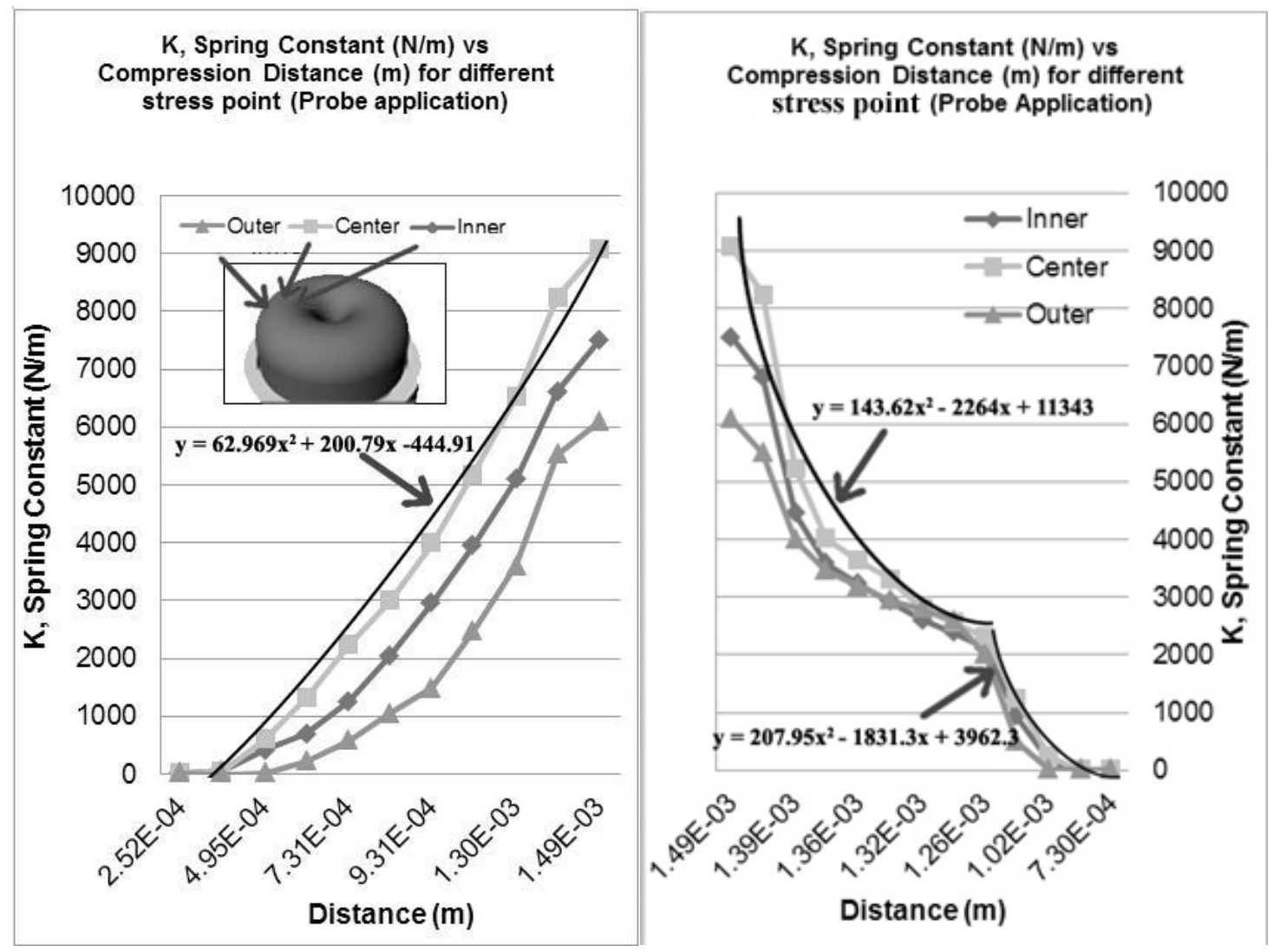

Figure 45: Spring Constant (N/m) vs. Compression Distance (m) for different stress points of the phantom cervix. The phantom is shown in the upper left as an insert. 


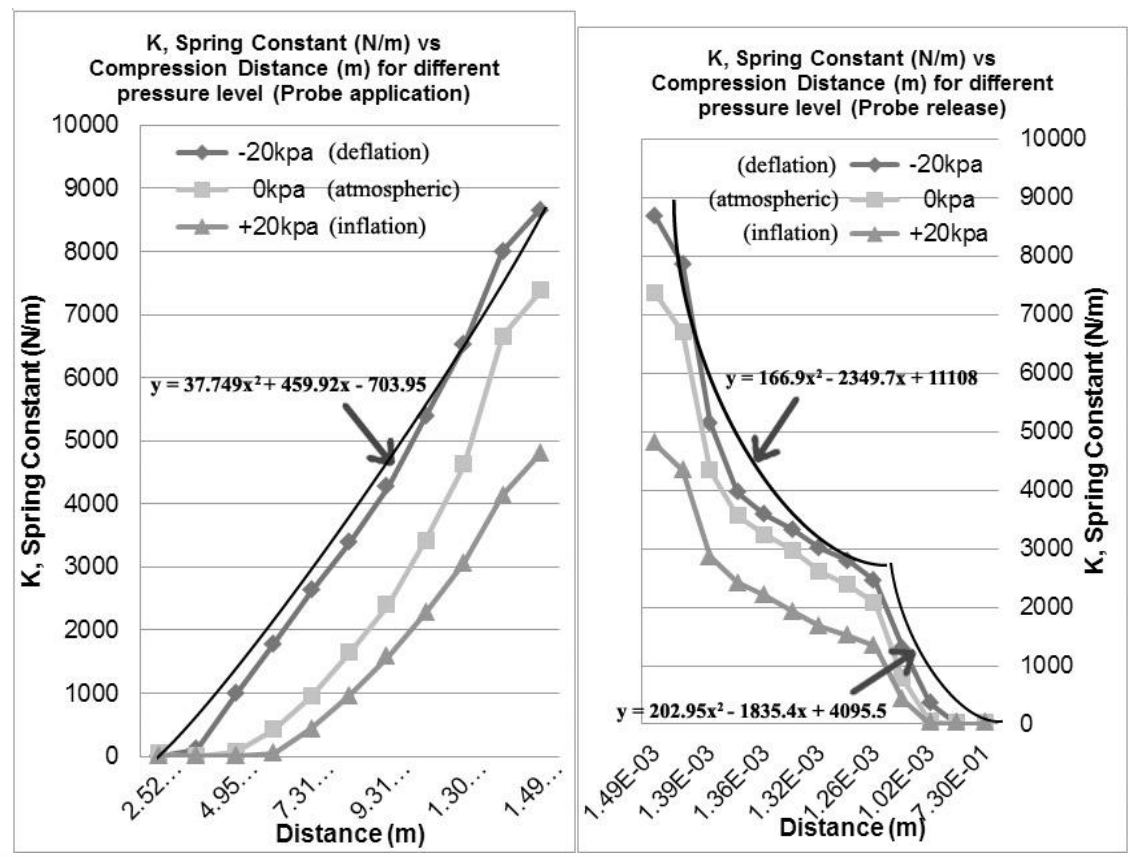

Figure 46: Spring Constant (N/m) vs. Compression Distance (m) for different pressure levels of the phantom cervix.

Deflated pressure level at $-20 \mathrm{kPa}$ was found to have the highest spring constant value for all the compression distance indicating that it has the stiffest physical property. Inflated pressure level at $+20 \mathrm{kPa}$ demonstrates the lowest spring constant value for all the compression distance, indicating it has the softest physical property.

The spring constant calculation shows consistent result to the previous discussions that deflated pressure level at $-20 \mathrm{kPa}$ has the stiffest physical property and the inflated pressure level at $+20 \mathrm{kPa}$ has the softest property. For each pressure level, the center side of the phantom cervix has the stiffest physical property and the outer side of the phantom cervix has the softest physical property. The experimental result illustrates that physical properties of the phantom cervix can vary from the maximum spring constant as $10.5 \mathrm{~N} / \mathrm{m}$ at $-20 \mathrm{kPa}$ deflated pressure and the minimum spring constant measured as $5.3 \mathrm{~N} / \mathrm{m}$ at $20 \mathrm{kPa}$ inflated pressure. Accordingly, this variation we observed throughout all depth distance, illustrating $5.2 \mathrm{~N} / \mathrm{m}$ spring constant variation on average.

The curve fittings in Figure 45 and Figure 46 demonstrate simple trends of the spring constant change. It is fitted with second order polynomials. However it shows discontinuities and substantial difference in some of the data points. 

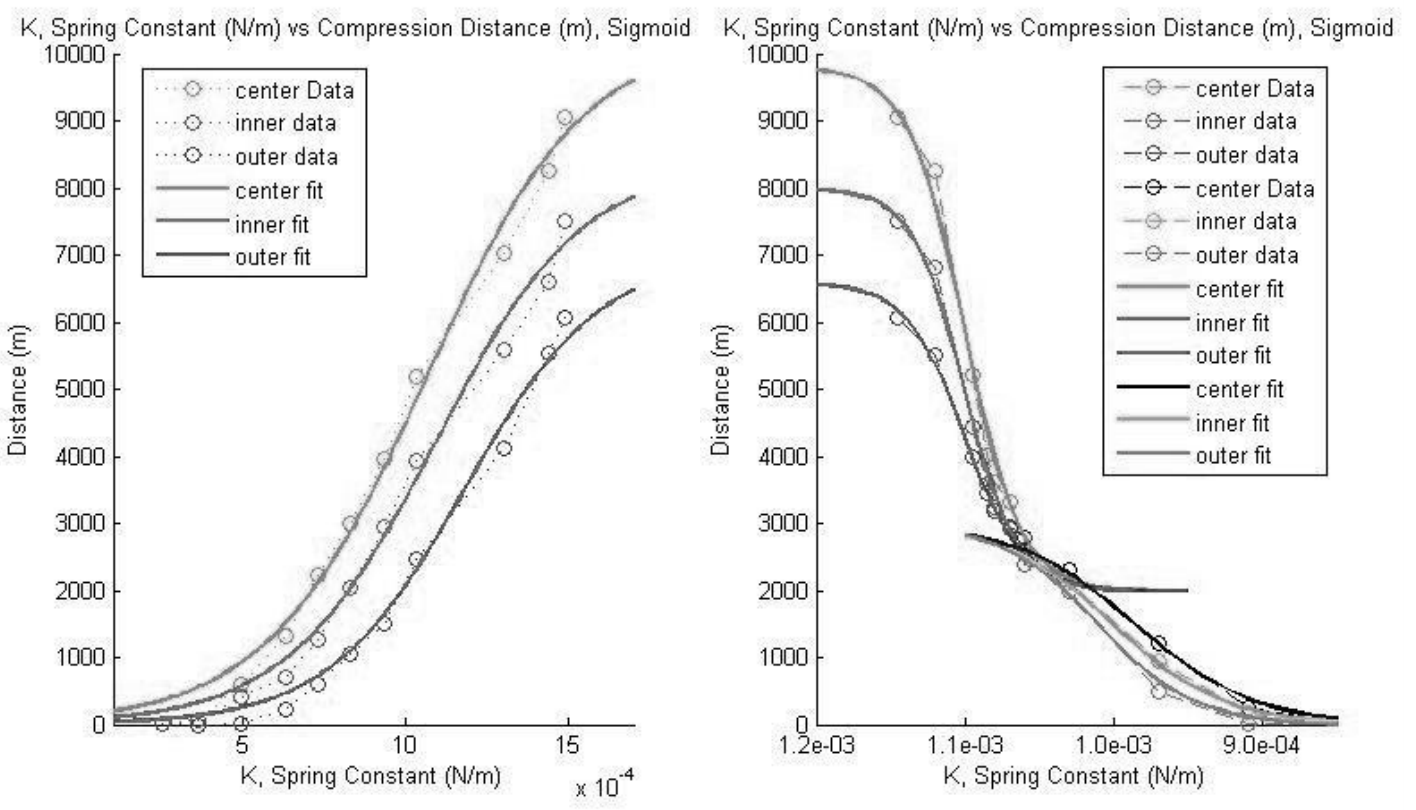

Figure 47: Sigmoid fit for K, Spring constant (N/m) vs. Compression Distance (m) (a) from depth distance 0 to $1.45 \mathrm{~mm}$ (b) from $1.45 \mathrm{~mm}$ to $0 \mathrm{~mm}$

It is more clear to observe the difference and the change in its physical property if the sigmoid fit is applied to the graph of spring constant $(\mathrm{N} / \mathrm{m})$ again compression distance $(\mathrm{m})$. This provides more continuous formulation for the fit and much closer fit to actual data. It is prominent that the trend is not linear. An interesting observation is that there is hysteresis effect present in Figure 41 (a), showing dramatic change in its sigmoid fit. Since it was tested that the force sensor itself does not have hysteresis effect, it can be observed as the hysteresis effect is coming from the phantom model itself which is also observable in real cervix tissue. 


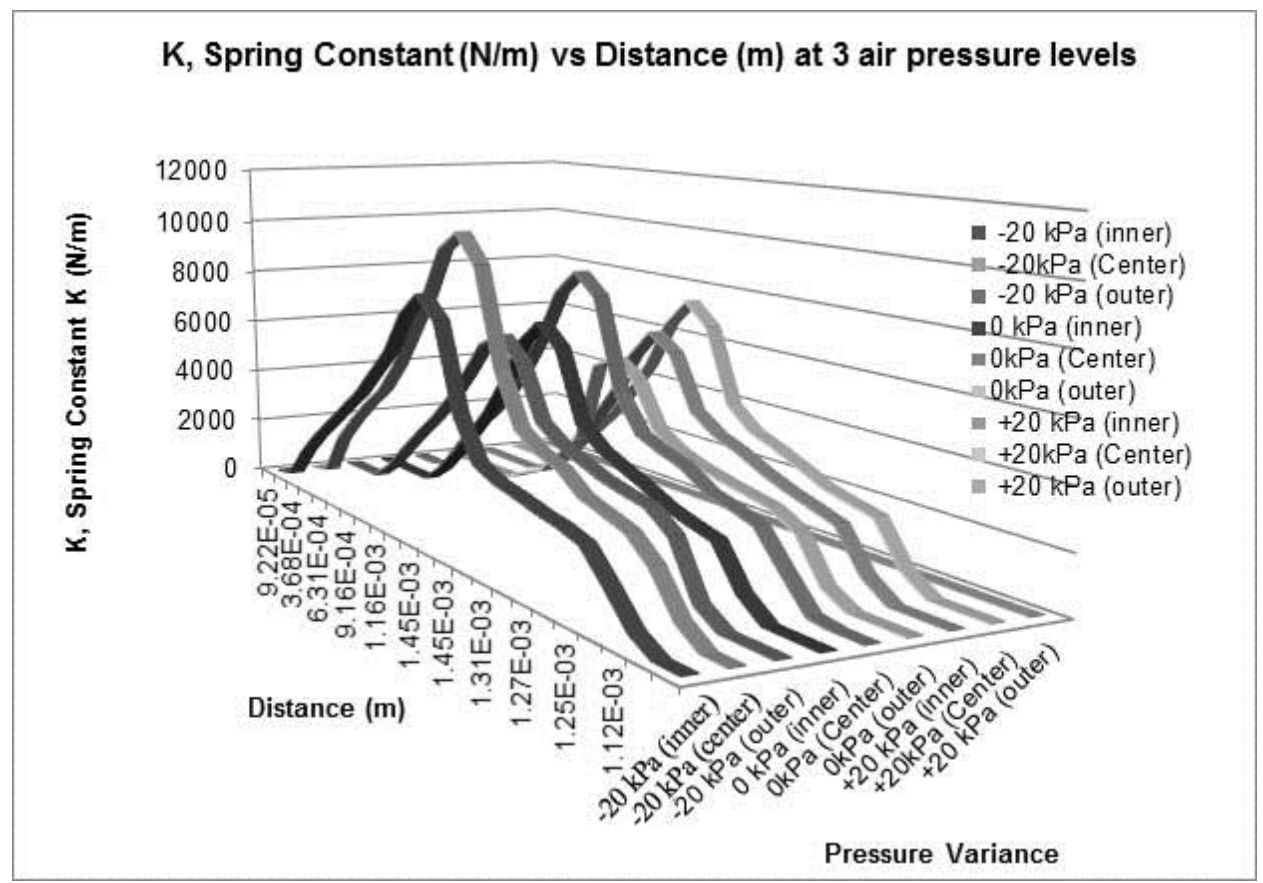

Figure 48: 3D view of the Spring Constant (N/m) vs. Compression Distance (m) at all air pressure levels of the phantom cervix.

All 9 trends for the different pressures of $-20 \mathrm{kPa}, 0 \mathrm{kPa}$ and $20 \mathrm{kPa}$, and different force exertion points on inner side, center side and outer side is illustrated in Figure 48. The continuity and difference of the change in their spring constant is more evident and visual. The deflection in its trend reflects more prominent visualization of its hysteresis effect as well. 


\section{Strain versus Stress}

The data is re-plotted in strain versus stress $(\mathrm{kPa})$. The stress is calculated based on the equation Stress $(\mathrm{kPa})=$ Force $(\mathrm{N}) / \operatorname{Area}\left(\mathrm{m}^{2}\right)$ and the strain is calculated based on the equation Strain $=$ Change in distance $(\mathrm{m}) /$ Original distance $(\mathrm{m})$.

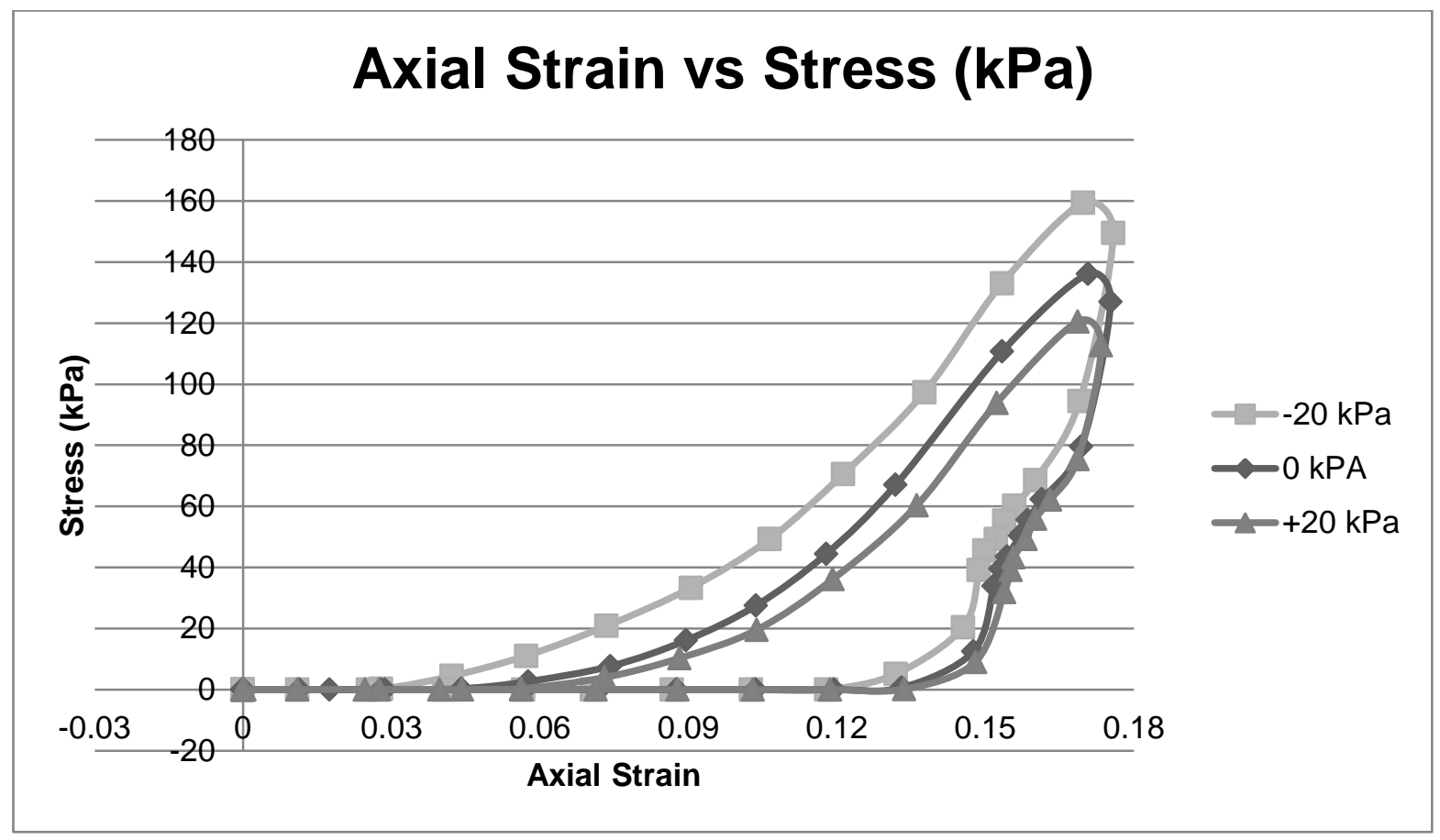

Figure 49. Average of Axial strain vs. Stress $(\mathrm{kPa})$ of the phantom cervix.

At the strain of 0.15 , the experimental result illustrates that physical properties of the phantom cervix can vary from the maximum stress measured as $133 \mathrm{kPa}$ and the minimum stress measured is $94 \mathrm{kPa}$.

Comparing to the mechanical testing result suggested by Myers et al. [27], the phantom cervix illustrates the similar nonlinear relationship of stress-strain and hysteresis effect observed. However, the phantom cervix shows much higher true stress compared to real cervical tissue. 


\section{True Stress (kPa) of real cervix tissue vs phantom cervix}
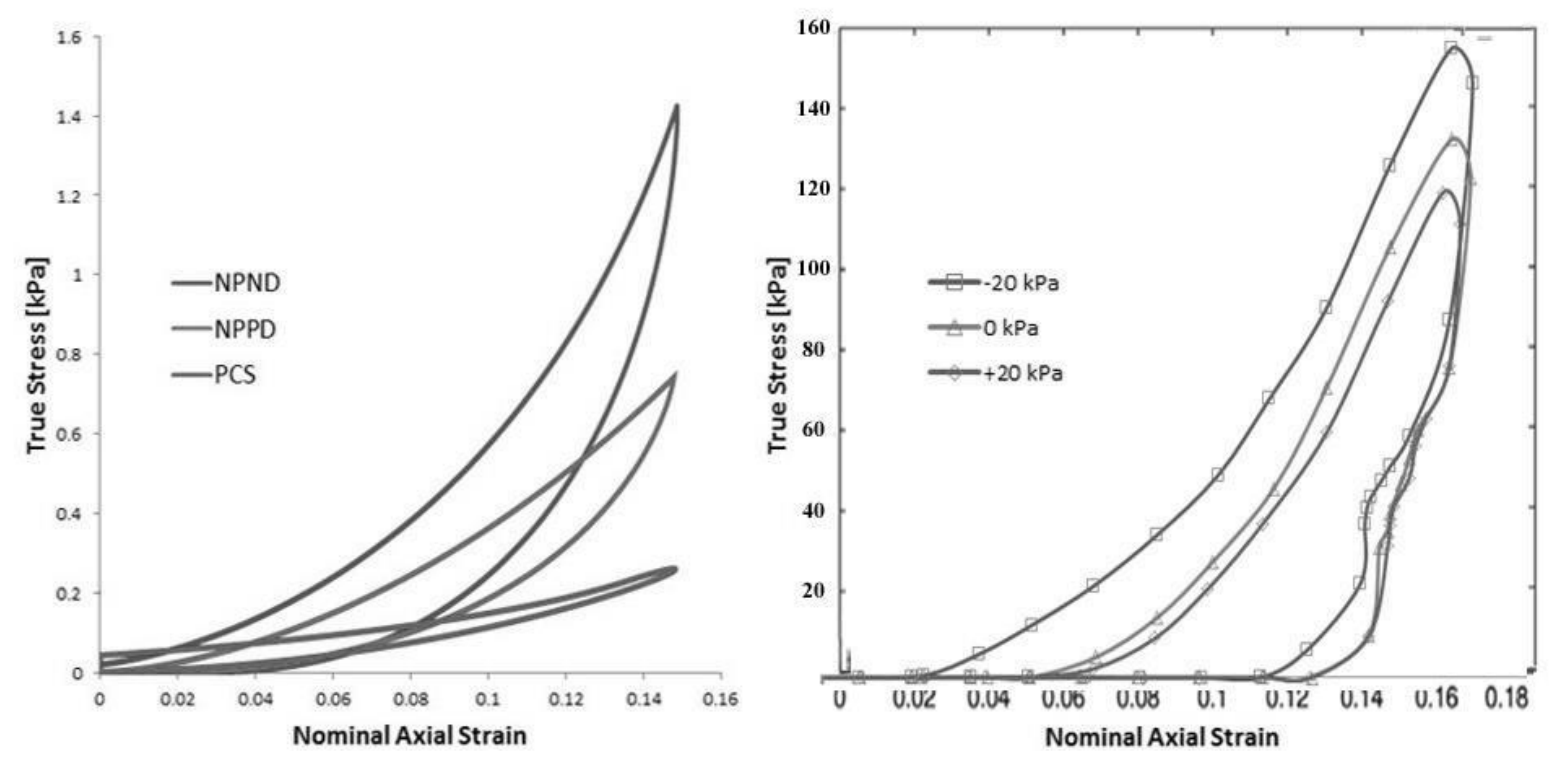

Figure 50. Stress-strain curves of (a) real cervix tissue (graph adapted from [27]) and (b) our phantom cervix. The phantom cervix is up to two orders of magnitude stiffer than real cervix tissue.

The vertical axes ranges from 0 to $1.6 \mathrm{kPa}$ in Figure 50 (a) and it ranges form 0 to $160 \mathrm{kPa}$ in Figure 50 (b). There are two orders of magnitudes difference observed between the true stress level measured in the phantom cervix $(\sim 100 \mathrm{kPa})$ and the real cervix tissue $(\sim 1 \mathrm{kPa})$ in Myers et al [27]. This indicates that phantom cervix is much stiffer than the real cervix tissue. Therefore, the design effort must be expanded on implementing softer solution.

According to the discrimination experiment and threshold experiment, subjects were still able to distinguish between 'hard' and 'soft' state of the phantom cervix. However, the false positive rate of $29.17 \%$ and high threshold of $10.6 \mathrm{kPa}$ in the full range from $-20 \mathrm{kPa}$ to $20 \mathrm{kPa}$ illustrates that it is harder to distinguish 'soft' state and suggests that the phantom cervix is not soft enough.

Our methods confirm the results that a phantom cervix using elastomer and a feedback controlled pneumatic system can be used to measure pressure levels and stress points. This holds the potential, in future design to give feedback to medical practitioners involved in the labour 
and child birth process by providing dynamic change in its physical property. We provide, through this work, baseline controlled compliance results, setting the stage for future designs. 


\subsection{Conclusion}

This thesis examines the process of developing and testing a pneumatically-controlled model of the cervix with the purpose of eventually creating more accurate labour training models for midwives and obstetricians. After examining other manufacturing methods we selected 3D printing technology and pneumatic system as appropriate technology for modeling a pneumatically-controlled cervix during the pre-labour phase. Our model ultimately revealed that the elastomeric filaments performed significantly better than that of the latex or silicone models. As such, we propose the use of elastomeric filaments in future models because they allow for greater control and repeatability. In future studies, different 3D printed elastomers and other compliant materials could be validated with using the testing platform we developed.

To simulate the variable softening of cervix during pre-labour phase, this research shows how the usefulness of pneumatic control of the 3D printed cervix filled with granular material capable of inducing a jamming effect. The stiffness of the cervix upon applied force was tested for the controlled inner pressure ranging from $-20 \mathrm{kPa}$ (deflation) to $20 \mathrm{kPa}$ (inflation), which helped ensure that our research complied with maximum compression of $1.45 \mathrm{~mm}$ depth, the maximum spring constant measured is $10.5 \mathrm{~N} / \mathrm{m}$ at $-20 \mathrm{kPa}$ deflated pressure and the minimum spring constant measured is $5.3 \mathrm{~N} / \mathrm{m}$ at $20 \mathrm{kPa}$ inflated pressure. This shows that the phantom cervix can be controlled to change its spring constant, changing its stiffness to simulate the cervix softening. We showed when force was applied to its maximum depth there is a hysteretic effect observed and controlling air pressure is less effective in changing its physical property -with only $0.4 \mathrm{~N} / \mathrm{m}$ change in its spring constant.

The discrimination test was performed by asking subjects to distinguish between "soft" and "hard" states of the phantom cervix as the change of its physical property was presented randomly. It resulted in $70.83 \%$ specificity, $100 \%$ sensitivity, $29.17 \%$ false alarm and $0 \%$ miss. This shows that the change in its physical property is clearly distinguishable by people. The threshold experiment was performed as well by observing when people acknowledge the transition from 'hard' to 'soft' state when the phantom cervix changes its physical property gradually from hardest to softest. The average threshold is determined to be $10.6 \mathrm{kPa}$ in the range from $-20 \mathrm{kPa}$ to $20 \mathrm{kPa}$.

The true stress variation observed at 0.15 strain ranged from $77 \mathrm{kPa}$ to $133 \mathrm{kPa}$, which

also demonstrates the ability to change its physical property substantially. However the 
magnitude of the stress is larger by two orders of magnitude difference compared to the mechanical property of the real cervix tissue $(\sim 1 \mathrm{kPa})$ suggested in Myers et al. [27]. This result is consistent with the discrimination test and threshold value determined, suggesting that the phantom cervix needs to improve to be softer in the future.

Our results suggest that this approach to creating a dynamic cervix model using 3D printer technology and pneumatic control has the potential for the development of softer controllable versions that could be used to help obstetricians, midwives and medical practitioners during their training.

We provide, through this work, baseline controlled compliance results, setting the stage for future designs. Future work could encompass probing of an actual cervix in order to validate the compliance levels of the phantom cervix. This would help ensure physiological correctness and enhanced human feedback and testing with medical practitioners. Finally, integration could be made between dilation and effacement since this research only focused on the softening of the cervix. 
Appendix A: 3D scanner, 3D printer and CURA Calibration Setup

\begin{tabular}{l|l|} 
Quality \\
\hline Layer height (mm) \\
Shell thickness (mm) \\
Enable retraction \\
Fill \\
\hline Bottom/Top thickness (mm) \\
Fill Density (\%) \\
Speed and Temperature \\
Print speed (mm/s) \\
Printing temperature (C) \\
2nd nozzle temperature (C) \\
Bed temperature (C) & 220 \\
\hline
\end{tabular}

\section{Support}

Support type

Platform adhesion type

Support dual extrusion

\begin{tabular}{|l|}
\hline Everywhere \\
\hline Brim \\
\hline Second extruder \\
\hline
\end{tabular}

\section{Dual extrusion}

Wipe\&prime tower

Ooze shield

\section{$\sqrt{\square}$}

Filament

Diameter (mm)

Diameter $2(\mathrm{~mm})$

Flow (\%)
Machine

Nozzle size $(\mathrm{mm})$

0.35

\section{Retraction}

Speed $(\mathrm{mm} / \mathrm{s})$

Distance $(\mathrm{mm})$

25

Dual extrusion switch amount (mm)

2.0

16.5

\section{Quality}

Initial layer thickness (mm)

Initial layer line width (\%)

Cut off object bottom ( $\mathrm{mm}$ )

Dual extrusion overlap (mm)

\begin{tabular}{|l|}
\hline 0.2 \\
\hline 125 \\
\hline 0.0 \\
\hline 0 \\
\hline
\end{tabular}

\section{Speed}

Travel speed (mm/s)

Bottom layer speed $(\mathrm{mm} / \mathrm{s})$

Infill speed $(\mathrm{mm} / \mathrm{s})$

Outer shell speed $(\mathrm{mm} / \mathrm{s})$

Inner shell speed $(\mathrm{mm} / \mathrm{s})$

\begin{tabular}{|l|}
\hline 20 \\
\hline 20 \\
\hline 0 \\
\hline 20 \\
\hline 20 \\
\hline
\end{tabular}

Cool

Minimal layer time (sec) 15

Enable cooling fan

\section{Cura Calibration Setup}




\begin{tabular}{|c|c|c|c|c|c|}
\hline & 3D Scan & \multicolumn{3}{c|}{ 3D print } \\
\hline Type & Scanner & Printer & Solid filament & $\begin{array}{c}\text { Elastomer } \\
\text { filament }\end{array}$ & Support filament \\
\hline $\begin{array}{c}\text { Part } \\
\text { Number }\end{array}$ & $\begin{array}{c}\text { NextEngine 3D } \\
\text { Scanner }\end{array}$ & $\begin{array}{c}\text { Lulzbot TAZ } \\
4 \text { 3D printer }\end{array}$ & ABS Filament - & Ninjaflex - & PVA Filament - \\
& & & WHITE 3.0mm & FIRE red & NATURAL 3.0 mm \\
& reviewed & Well-reviewed & & \\
\hline Reason & Cost, Well- & Cost, & Cost, Durability & Cost, Viability & Dissolvable in water \\
& & & & \\
\hline Seller & NextEngine & Lulzbot & Filaments.ca & Fennel drive & Filaments.ca \\
\hline
\end{tabular}

Table 3: Materials Used for 3D Scanning and 3D printing 
Appendix B: 10 Trial Data

\begin{tabular}{|c|c|c|c|c|c|c|c|c|c|c|c|c|c|c|c|c|c|c|c|}
\hline \multicolumn{2}{|c|}{ Run1 } & \multicolumn{2}{|c|}{ Run2 } & \multicolumn{2}{|c|}{ Run3 } & \multicolumn{2}{|c|}{ Run4 } & \multicolumn{2}{|c|}{ Run5 } & \multicolumn{2}{|c|}{ Run6 } & \multicolumn{2}{|c|}{ Run7 } & \multicolumn{2}{|c|}{ Run8 } & \multicolumn{2}{|c|}{ Run9 } & \multicolumn{2}{|c|}{ Run10 } \\
\hline $\begin{array}{l}\text { Distance( } \\
\mathrm{mm} \text { ) }\end{array}$ & Force $(\mathrm{N})$ & $\begin{array}{l}\text { Distance( } \\
\mathrm{mm})\end{array}$ & Force(N) & $\begin{array}{l}\text { Distance( } \\
\mathrm{mm})\end{array}$ & Force $(\mathrm{N})$ & $\begin{array}{l}\text { Distance( } \\
\mathrm{mm})\end{array}$ & Force(N) & $\begin{array}{l}\text { Distance ( } \\
\mathrm{mm})\end{array}$ & Force(N) & $\begin{array}{l}\text { Distance( } \\
\mathrm{mm} \text { ) }\end{array}$ & Force(N) & $\begin{array}{l}\text { Distance( } \\
\mathrm{mm} \text { ) }\end{array}$ & Force(N) & $\begin{array}{l}\text { Distance( } \\
\mathrm{mm} \text { ) }\end{array}$ & Force(N) & $\begin{array}{l}\text { Distance } \\
\mathrm{mm} \text { ) }\end{array}$ & Force(N) & $\begin{array}{l}\text { Distance( } \\
\mathrm{mm} \text { ) }\end{array}$ & Force(N) \\
\hline 0.00 & 0.00 & $\quad 0.00$ & -0.03 & $\begin{array}{ll}3 & 0.00\end{array}$ & 0.00 & $\quad 0.00$ & 0.00 & $\quad 0.00$ & 0.00 & 0.00 & 0.00 & 0.00 & 0.00 & 0.00 & $\quad 0.00$ & 0.00 & 0.00 & 0.00 & 0.00 \\
\hline 0.00 & 0.00 & 0.00 & 0.00 & 0.00 & 0.00 & 0.00 & 0.00 & 0.00 & 0.00 & 0.00 & 0.00 & 0.00 & 0.00 & 0.00 & 0.00 & 0.00 & 0.00 & 0.00 & 0.00 \\
\hline 0.00 & 0.00 & 0.00 & 0.00 & 0.00 & 0.00 & 0.00 & 0.00 & 0.00 & 0.00 & 0.00 & 0.00 & 0.00 & 0.00 & 0.00 & 0.00 & 0.00 & 0.00 & 0.00 & 0.00 \\
\hline 0.00 & 0.00 & 0.00 & 0.00 & 0.00 & 0.00 & 0.00 & 0.00 & 0.00 & 0.00 & 0.00 & 0.00 & 0.00 & 0.00 & 0.00 & 0.00 & 0.00 & 0.00 & 0.00 & 0.00 \\
\hline 0.00 & 0.00 & 0.00 & 0.00 & 0.00 & 0.00 & 0.00 & 0.00 & 0.00 & 0.00 & 0.00 & 0.00 & 0.00 & 0.00 & 0.00 & 0.00 & 0.00 & 0.00 & 0.00 & 0.00 \\
\hline 0.15 & 0.00 & 0.10 & 0.00 & 0.10 & 0.00 & 0.10 & 0.00 & 0.10 & 0.00 & 0.10 & 0.00 & 0.10 & 0.00 & 0.10 & 0.00 & 0.05 & 0.00 & 0.10 & 0.00 \\
\hline 0.29 & 0.00 & 0.24 & 0.00 & 0.24 & 0.00 & 0.24 & 0.00 & 0.24 & 0.00 & 0.24 & 0.00 & 0.24 & 0.00 & 0.24 & 0.00 & 0.19 & 0.00 & 0.24 & 0.00 \\
\hline 0.44 & 0.00 & 0.39 & 0.00 & 0.39 & 0.00 & 0.39 & 0.26 & 0.39 & 0.00 & 0.34 & 0.00 & 0.39 & 0.00 & 0.39 & 0.00 & 0.34 & 0.16 & 0.39 & 0.00 \\
\hline 0.53 & 0.00 & 0.49 & 0.00 & 0.49 & 0.44 & 0.49 & 0.96 & 0.49 & 0.39 & 0.49 & 0.62 & 0.49 & 0.18 & 0.49 & 0.00 & 0.44 & 1.20 & 0.49 & 0.55 \\
\hline 0.68 & 0.70 & 0.63 & 0.70 & 0.63 & 1.20 & 0.63 & 2.03 & 0.63 & 1.20 & 0.63 & 1.53 & 0.63 & 1.12 & 0.63 & 0.52 & 0.58 & 2.16 & 0.63 & 1.43 \\
\hline 0.82 & 1.59 & 0.78 & 1.59 & 0.78 & 2.42 & 0.78 & 3.43 & 0.78 & 2.34 & 0.78 & 2.91 & 0.78 & 2.19 & 0.78 & 1.61 & 0.73 & 3.80 & 0.78 & 2.63 \\
\hline 0.97 & 3.04 & 0.92 & 3.04 & 0.92 & 4.29 & 0.92 & 5.02 & 0.87 & 3.41 & 0.92 & 4.60 & 0.92 & 3.49 & 0.87 & 3.02 & 0.87 & 5.25 & 0.92 & 4.24 \\
\hline 1.07 & 5.02 & 1.02 & 5.02 & 1.02 & 6.43 & 1.02 & 6.92 & 1.02 & 5.67 & 1.02 & 6.48 & 1.02 & 5.28 & 1.02 & 4.84 & 1.02 & 7.08 & 1.07 & 6.17 \\
\hline 1.21 & 7.60 & 1.16 & 7.31 & 1.16 & 8.90 & 1.16 & 9.52 & 1.16 & 8.09 & 1.16 & 9.18 & 1.16 & 7.99 & 1.16 & 7.10 & 1.12 & 9.37 & 1.16 & 8.64 \\
\hline 1.36 & 11.71 & 1.31 & 10.74 & 1.31 & 12.12 & 1.26 & 12.49 & 1.26 & 11.34 & 1.31 & 12.49 & 1.31 & 11.19 & 1.31 & 10.56 & 1.26 & 12.07 & 1.31 & 11.45 \\
\hline 1.50 & 14.57 & 1.46 & 13.50 & 1.46 & 14.49 & 1.46 & 14.70 & 1.46 & 13.76 & 1.46 & 14.62 & 1.46 & 13.79 & 1.41 & 13.40 & 1.41 & 13.53 & 1.46 & 13.29 \\
\hline 1.50 & 13.97 & 1.50 & 12.67 & 1.50 & 13.58 & 1.50 & 13.61 & 1.50 & 13.24 & 1.46 & 14.00 & 1.46 & 13.24 & 1.50 & 12.64 & 1.46 & 12.67 & 1.50 & 12.49 \\
\hline 1.46 & 8.58 & 1.46 & 7.91 & 1.46 & 8.14 & 1.41 & 8.30 & 1.41 & 7.83 & 1.46 & 8.69 & 1.41 & 8.27 & 1.41 & 7.67 & 1.41 & 8.14 & 1.46 & 7.80 \\
\hline 1.36 & 5.54 & 1.36 & 5.41 & 1.36 & 5.31 & 1.36 & 5.33 & 1.36 & 5.72 & 1.31 & 5.51 & 1.36 & 5.10 & 1.36 & 5.33 & 1.31 & 5.80 & 1.36 & 5.75 \\
\hline 1.36 & 4.71 & 1.31 & 4.60 & 1.31 & 4.16 & 1.31 & 4.73 & 1.31 & 5.05 & 1.26 & 4.60 & 1.31 & 4.40 & 1.31 & 4.50 & 1.31 & 4.99 & 1.36 & 5.02 \\
\hline 1.31 & 4.29 & 1.31 & 4.01 & 1.26 & 3.75 & 1.26 & 4.29 & 1.31 & 4.76 & 1.26 & 4.08 & 1.31 & 4.16 & 1.31 & 3.98 & 1.26 & 4.71 & 1.36 & 4.58 \\
\hline 1.31 & 3.36 & 1.26 & 3.28 & 1.26 & 3.10 & 1.26 & 3.28 & 1.26 & 3.51 & 1.26 & 3.30 & 1.26 & 3.33 & 1.26 & 3.30 & 1.26 & 3.46 & 1.31 & 3.54 \\
\hline 1.26 & 2.91 & 1.26 & 3.04 & 1.26 & 2.52 & 1.26 & 2.81 & 1.26 & 2.99 & 1.26 & 2.78 & 1.26 & 2.91 & 1.26 & 3.02 & 1.21 & 3.02 & 1.26 & 2.97 \\
\hline 1.26 & 2.50 & 1.26 & 2.47 & 1.21 & 2.00 & 1.21 & 2.32 & 1.21 & 2.37 & 1.21 & 2.37 & 1.26 & 2.55 & 1.26 & 2.55 & 1.21 & 2.55 & 1.26 & 2.52 \\
\hline 1.26 & 1.40 & 1.21 & 0.94 & 1.21 & 1.09 & 1.21 & 1.27 & 1.21 & 1.12 & 1.21 & 1.25 & 1.21 & 1.53 & 1.26 & 1.09 & 1.21 & 1.38 & 1.26 & 1.07 \\
\hline 1.16 & 0.00 & 1.16 & 0.00 & 1.12 & 0.00 & 1.12 & 0.00 & 1.12 & 0.00 & 1.12 & 0.00 & 1.16 & 0.00 & 1.16 & 0.00 & 1.12 & -0.03 & 1.12 & 0.00 \\
\hline 1.02 & 0.00 & 1.02 & 0.00 & 1.02 & 0.00 & 0.97 & 0.00 & 0.97 & 0.00 & 0.97 & 0.00 & 1.02 & 0.00 & 1.02 & 0.00 & 1.02 & 0.00 & 1.02 & 0.00 \\
\hline 0.92 & 0.00 & 0.87 & 0.00 & 0.87 & 0.00 & 0.87 & 0.00 & 0.87 & 0.00 & 0.87 & 0.00 & 0.87 & 0.00 & 0.87 & 0.00 & 0.87 & 0.00 & 0.87 & 0.00 \\
\hline 0.78 & 0.00 & 0.78 & 0.00 & 0.73 & 0.00 & 0.73 & 0.00 & 0.73 & 0.00 & 0.73 & 0.00 & 0.78 & 0.00 & 0.73 & 0.00 & 0.73 & 0.00 & 0.73 & 0.00 \\
\hline 0.63 & 0.00 & 0.63 & 0.00 & 0.58 & 0.00 & 0.58 & 0.00 & 0.58 & 0.00 & 0.58 & 0.00 & 0.63 & 0.00 & 0.63 & 0.00 & 0.58 & 0.00 & 0.63 & 0.00 \\
\hline 0.49 & 0.00 & 0.49 & 0.00 & 0.49 & 0.00 & 0.44 & 0.00 & 0.44 & 0.00 & 0.49 & 0.00 & 0.39 & 0.00 & 0.49 & 0.00 & 0.44 & 0.00 & 0.49 & -0.03 \\
\hline 0.39 & 0.00 & 0.34 & 0.00 & 0.34 & 0.00 & 0.34 & 0.00 & 0.34 & 0.00 & 0.34 & 0.00 & 0.39 & 0.00 & 0.34 & 0.00 & 0.34 & 0.00 & 0.39 & 0.00 \\
\hline 0.24 & 0.00 & 0.24 & 0.00 & 0.24 & 0.00 & 0.19 & 0.00 & 0.19 & 0.00 & 0.19 & 0.00 & 0.24 & 0.00 & 0.24 & 0.00 & 0.19 & 0.00 & 0.19 & 0.00 \\
\hline
\end{tabular}

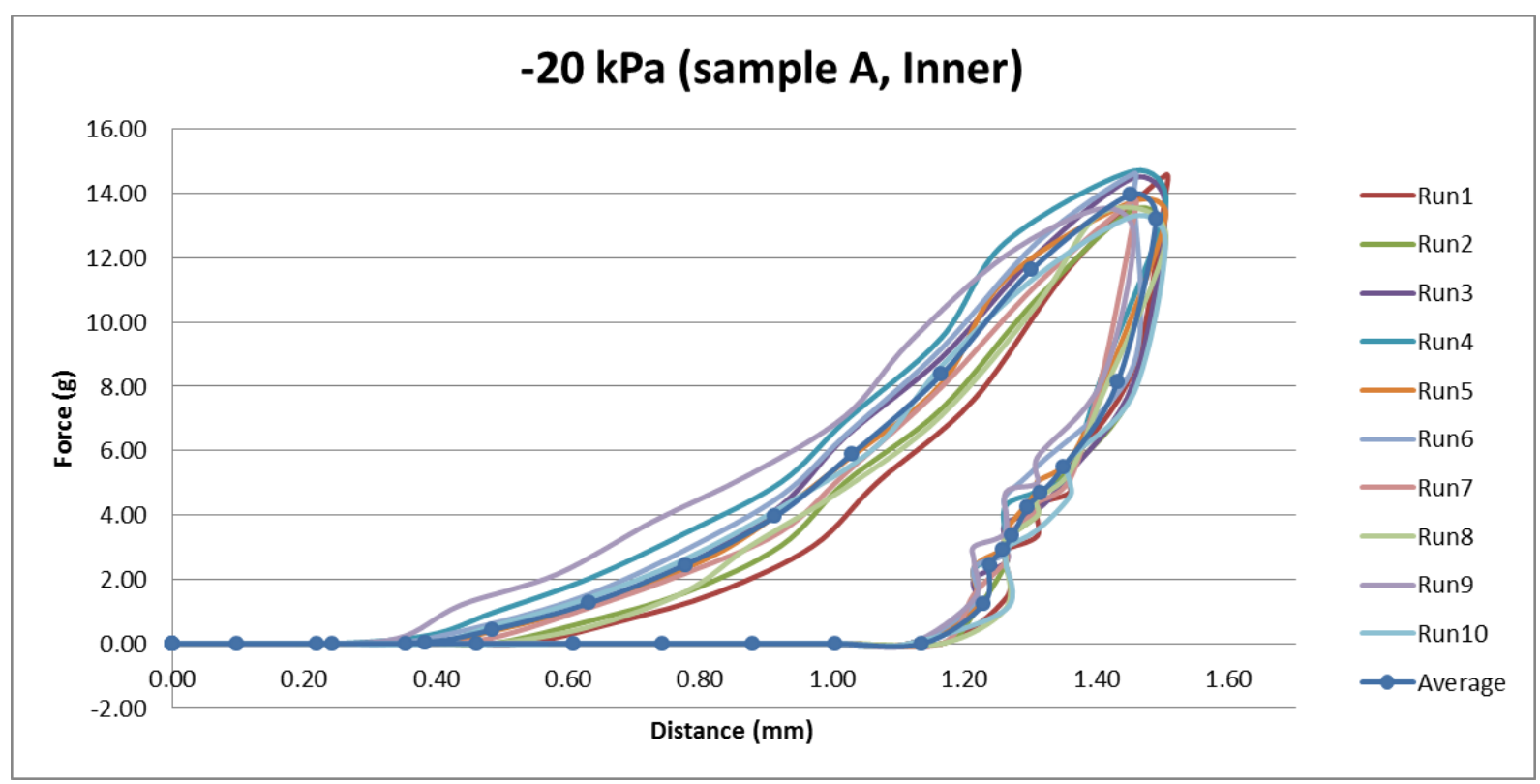




\begin{tabular}{|c|c|c|c|c|c|c|c|c|c|c|c|c|c|c|c|c|c|c|c|c|}
\hline \multirow{3}{*}{$\begin{array}{l}\text { R } \\
\text { Distance( } \\
\mathrm{mm})\end{array}$} & un1 & \multicolumn{3}{|c|}{ Run2 } & \multicolumn{2}{|c|}{ Run3 } & \multicolumn{2}{|c|}{ Run4 } & \multicolumn{2}{|c|}{ Run5 } & \multicolumn{2}{|c|}{ Run6 } & \multicolumn{2}{|c|}{$\quad$ Run7 } & \multicolumn{2}{|c|}{ Run8 } & \multicolumn{2}{|c|}{ Run9 } & \multicolumn{2}{|c|}{ Run10 } \\
\hline & Force(N) & $\begin{array}{l}\text { Dista } \\
\mathrm{mm})\end{array}$ & & Force $(\mathrm{N})$ & $\begin{array}{l}\text { Distance( } \\
\mathrm{mm} \text { ) }\end{array}$ & Force(N) & $\begin{array}{l}\text { Distance( } \\
\mathrm{mm})\end{array}$ & Force(N) & $\begin{array}{l}\text { Distance( } \\
\mathrm{mm} \text { ) }\end{array}$ & Force(N) & $\begin{array}{l}\text { Distance( } \\
\mathrm{mm})\end{array}$ & Force(N) & $\begin{array}{l}\text { Distance ( } \\
\mathrm{mm} \text { ) }\end{array}$ & Force $(\mathrm{N})$ & $\begin{array}{l}\text { Distance( } \\
\mathrm{mm} \text { ) }\end{array}$ & Force $(\mathrm{N})$ & $\begin{array}{l}\text { Distance( } \\
\mathrm{mm})\end{array}$ & Force(N) & $\begin{array}{l}\text { Distance( } \\
\mathrm{mm})\end{array}$ & Force(N) \\
\hline & $\quad 0.0$ & & 0.00 & 0.00 & 0.00 & 0.00 & $0 \quad 0.00$ & $\begin{array}{ll}0 & 0.00\end{array}$ & 0.00 & $\quad 0.00$ & 0.00 & $0 \quad 0.00$ & 0.00 & $\quad 0.00$ & $\quad 0.00$ & 0.00 & $0 \quad 0.00$ & $\begin{array}{ll}0 & 0.00\end{array}$ & $0 \quad 0.00$ & 0.00 \\
\hline 0.00 & 0.0 & 000.00 & & 0.00 & 0.00 & 0.00 & 0.00 & 0.00 & 0.00 & 0.00 & 0.00 & 0.00 & 0.00 & 0.00 & 0.00 & 0.00 & 0.00 & 0.00 & 0.00 & 0.00 \\
\hline 0.00 & 0.0 & & 0.00 & 0.00 & 0.00 & 0.00 & 0.00 & 0.00 & 0.00 & 0.00 & 0.00 & 0.00 & 0.00 & 0.00 & 0.00 & 0.00 & 0.00 & 0.00 & 0.00 & 0.00 \\
\hline 0.00 & 0.0 & & 0.00 & 0.00 & 0.00 & 0.00 & 0.00 & 0.00 & 0.00 & 0.00 & 0.00 & 0.00 & 0.00 & 0.00 & 0.00 & 0.00 & 0.00 & 0.00 & 0.00 & 0.00 \\
\hline 0.00 & 0.0 & & 0.00 & 0.00 & 0.00 & 0.00 & 0.00 & 0.00 & 0.00 & 0.00 & 0.00 & 0.00 & 0.00 & 0.00 & 0.00 & 0.00 & 0.00 & 0.00 & 0.00 & 0.00 \\
\hline 0.10 & 0.0 & & 0.15 & 0.00 & 0.10 & 0.00 & 0.10 & -0.03 & 0.05 & 0.00 & 0.05 & 0.00 & 0.10 & 0.00 & 0.15 & 0.00 & 0.10 & 0.00 & 0.10 & 0.00 \\
\hline 0.24 & 0.0 & & 0.19 & 0.00 & 0.24 & 0.00 & 0.24 & 0.00 & 0.24 & 0.00 & 0.24 & 0.00 & 0.24 & 0.00 & 0.24 & 0.00 & 0.19 & 0.00 & 0.24 & 0.00 \\
\hline 0.34 & 0.0 & & 0.34 & 0.00 & 0.34 & 0.00 & 0.39 & 0.00 & 0.34 & 0.00 & 0.34 & 0.00 & 0.34 & 0.00 & 0.39 & 0.00 & 0.34 & 0.00 & 0.29 & 0.00 \\
\hline 0.49 & 0.1 & & 0.49 & 0.13 & 0.44 & 0.00 & 0.53 & 0.00 & 0.49 & 0.16 & 0.49 & 0.00 & 0.49 & 0.10 & 0.53 & 0.00 & 0.49 & 0.00 & 0.49 & 0.03 \\
\hline 0.63 & 0.8 & & 0.63 & 0.86 & 0.63 & 0.60 & 0.63 & 0.65 & 0.58 & 0.75 & 0.58 & 0.73 & 0.58 & 0.81 & 0.63 & 0.81 & 0.58 & 0.52 & 0.58 & 0.73 \\
\hline 0.78 & 1.8 & & 0.73 & 1.87 & 0.78 & 1.64 & 0.78 & 1.51 & 0.78 & 1.66 & 0.78 & 1.66 & 0.78 & 1.85 & 0.78 & 1.53 & 0.78 & 1.53 & 0.73 & 1.66 \\
\hline 0.87 & 3.1 & & 0.92 & 3.25 & 0.92 & 2.73 & 0.87 & 2.81 & 0.87 & 2.76 & 0.92 & 2.97 & 0.87 & 2.99 & 0.92 & 2.73 & 0.87 & 2.78 & 0.87 & 2.91 \\
\hline 1.07 & 4.8 & & 1.07 & 4.92 & 1.02 & 4.34 & 1.02 & 4.58 & 1.02 & 4.34 & 1.02 & 4.60 & 1.02 & 4.63 & 1.02 & 4.53 & 1.02 & 4.37 & 1.02 & 4.58 \\
\hline 1.16 & 7.2 & & 1.12 & 7.31 & 1.16 & 6.66 & 1.16 & 6.79 & 1.12 & 6.84 & 1.16 & 6.69 & 1.16 & 7.00 & 1.21 & 7.02 & 1.16 & 6.56 & 1.12 & 6.87 \\
\hline 1.31 & 10.2 & & 1.31 & 10.38 & 1.31 & 9.60 & 1.31 & 9.86 & 1.31 & 9.83 & 1.31 & 9.52 & 1.26 & 10.22 & 1.31 & 9.94 & 1.26 & 9.55 & 1.26 & 9.76 \\
\hline 1.46 & 12.5 & & 1.41 & 12.67 & 1.41 & 11.50 & 1.41 & 12.12 & 1.46 & 11.91 & 1.41 & 11.68 & 1.41 & 12.20 & 1.46 & 12.28 & 1.46 & 11.76 & 1.41 & 11.73 \\
\hline 1.46 & 11.5 & & 1.46 & 11.91 & 1.46 & 10.90 & 1.46 & 11.29 & 1.50 & 11.11 & 1.46 & 10.87 & 1.46 & 11.45 & 1.55 & 11.71 & 1.50 & 10.64 & 1.46 & 10.98 \\
\hline 1.46 & 7.2 & & 1.41 & 7.75 & 1.41 & 7.00 & 1.41 & 7.54 & 1.46 & 7.18 & 1.41 & 6.95 & 1.41 & 7.44 & 1.46 & 7.28 & 1.36 & 6.82 & 1.41 & 7.21 \\
\hline 1.36 & 6.1 & & 1.41 & 6.69 & 1.36 & 5.70 & 1.36 & 5.96 & 1.36 & 5.85 & 1.36 & 5.49 & 1.31 & 6.22 & 1.41 & 5.96 & 1.36 & 5.80 & 1.31 & 5.62 \\
\hline 1.31 & 5.6 & & 1.31 & 5.93 & 1.36 & 5.07 & 1.41 & 5.39 & 1.36 & 5.46 & 1.36 & 4.73 & 1.31 & 5.65 & 1.36 & 5.41 & 1.31 & 5.33 & 1.31 & 5.12 \\
\hline 1.31 & 4.5 & & 1.31 & 4.89 & 1.31 & 4.37 & 1.31 & 4.50 & 1.31 & 4.55 & 1.36 & 4.16 & 1.31 & 4.63 & 1.36 & 4.53 & 1.31 & 4.24 & 1.26 & 4.40 \\
\hline 1.31 & 3.5 & & 1.31 & 3.59 & 1.31 & 3.62 & 1.31 & 3.56 & 1.31 & 3.62 & 1.31 & 3.43 & 1.31 & 3.67 & 1.36 & 3.51 & 1.31 & 3.49 & 1.26 & 3.51 \\
\hline 1.31 & 2.9 & & 1.26 & 3.10 & 1.31 & 3.28 & 1.26 & 3.15 & 1.26 & 3.07 & 1.26 & 3.17 & 1.31 & 3.23 & 1.26 & 3.12 & 1.26 & 3.10 & 1.26 & 3.12 \\
\hline 1.26 & 2.6 & & 1.26 & 2.71 & 1.31 & 2.76 & 1.26 & 2.68 & 1.26 & 2.81 & 1.26 & 2.78 & 1.26 & 2.86 & 1.31 & 2.58 & 1.26 & 2.68 & 1.26 & 2.81 \\
\hline 1.21 & 0.7 & & 1.21 & 1.07 & 1.26 & 0.44 & 1.26 & 0.65 & 1.26 & 0.57 & 1.21 & 0.62 & 1.31 & 0.73 & 1.26 & 0.91 & 1.21 & 0.34 & 1.26 & 0.62 \\
\hline 1.07 & 0.0 & & 1.12 & 0.00 & 1.07 & 0.00 & 1.16 & 0.00 & 1.12 & 0.00 & 1.12 & 0.00 & 1.12 & 0.00 & 1.16 & 0.00 & 1.12 & 0.00 & 1.07 & 0.00 \\
\hline 1.02 & 0.0 & & 0.97 & 0.00 & 1.02 & 0.00 & 1.02 & 0.00 & 0.97 & 0.00 & 0.97 & 0.00 & 0.97 & 0.00 & 1.02 & -0.03 & 1.02 & 0.00 & 0.92 & 0.00 \\
\hline 0.82 & 0.0 & & 0.82 & 0.00 & 0.82 & 0.00 & 0.87 & 0.00 & 0.87 & 0.00 & 0.82 & 0.00 & 0.87 & 0.00 & 0.87 & 0.00 & 0.82 & 0.00 & 0.82 & 0.00 \\
\hline 0.73 & 0.0 & & 0.73 & 0.00 & 0.73 & 0.00 & 0.73 & 0.00 & 0.73 & 0.00 & 0.73 & 0.00 & 0.73 & 0.00 & 0.73 & 0.00 & 0.73 & 0.00 & 0.73 & 0.00 \\
\hline 0.58 & 0.0 & & 0.58 & 0.00 & 0.58 & -0.03 & 0.58 & 0.00 & 0.58 & 0.00 & 0.58 & 0.00 & 0.58 & 0.00 & 0.63 & 0.03 & 0.58 & 0.00 & 0.53 & 0.00 \\
\hline 0.44 & 0.0 & & 0.44 & 0.00 & 0.49 & 0.00 & 0. & 0.00 & 0. & 0.00 & 0. & 0.00 & 0.49 & 0.00 & 0.49 & 0.00 & 0.44 & 0.00 & 0.44 & 0.00 \\
\hline 0.29 & 0.0 & & 0.29 & 0.00 & 0.34 & 0.00 & 0.29 & 0.00 & 0.29 & 0.00 & 0.34 & 0.00 & 0.34 & 0.00 & 0.34 & 0.00 & 0.29 & 0.00 & 0.29 & 0.00 \\
\hline 0.19 & 0.0 & & 0.19 & 0.00 & 0.19 & 0.00 & 0.19 & 0.00 & 0.19 & 0.00 & 0.19 & 0.00 & 0.19 & 0.00 & 0.24 & 0.00 & 0.19 & 0.00 & 0.19 & 0.00 \\
\hline
\end{tabular}

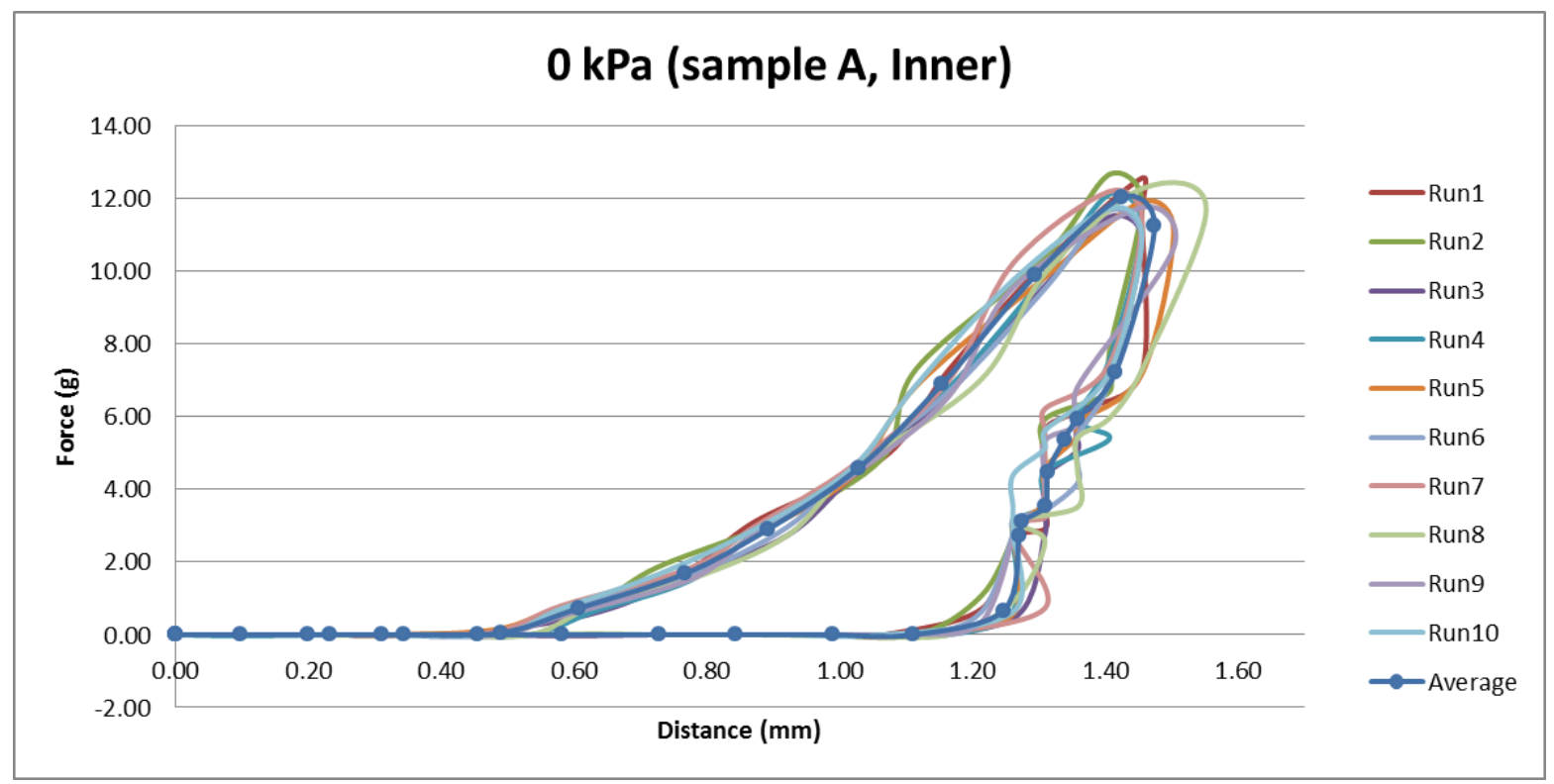




\begin{tabular}{|c|c|c|c|c|c|c|c|c|c|c|c|c|c|c|c|c|c|c|c|}
\hline \multicolumn{2}{|c|}{ Run1 } & \multicolumn{2}{|c|}{ Run2 } & \multicolumn{2}{|c|}{ Run3 } & \multicolumn{2}{|c|}{ Run4 } & \multicolumn{2}{|c|}{ Run5 } & \multicolumn{2}{|c|}{ Run6 } & \multicolumn{2}{|l|}{ Run7 } & \multicolumn{2}{|c|}{ Run8 } & \multicolumn{2}{|c|}{ Run9 } & \multicolumn{2}{|c|}{ Run10 } \\
\hline $\begin{array}{l}\text { Distance( } \\
\mathrm{mm} \text { ) }\end{array}$ & Force(N) & $\begin{array}{l}\text { Distance( } \\
\mathrm{mm} \text { ) }\end{array}$ & Force(N) & $\begin{array}{l}\text { Distance( } \\
\mathrm{mm})\end{array}$ & Force(N) & $\begin{array}{l}\text { Distance( } \\
\mathrm{mm})\end{array}$ & Force $(\mathrm{N})$ & $\begin{array}{l}\text { Distance( } \\
\mathrm{mm} \text { ) }\end{array}$ & rce(N) & $\begin{array}{l}\text { Distance( } \\
\mathrm{mm})\end{array}$ & Force $(\mathrm{N}) \quad \mathrm{D}$ & $\begin{array}{l}\text { Distance( } \\
\mathrm{mm} \text { ) }\end{array}$ & $\mathrm{ce}(\mathrm{N})$ & $\begin{array}{l}\text { Distance( } \\
\mathrm{mm})\end{array}$ & Eorce(N) & $\begin{array}{l}\text { Distance( } \\
\mathrm{mm} \text { ) }\end{array}$ & Force(N) & $\begin{array}{l}\text { Distance( } \\
\mathrm{mm})\end{array}$ & $\operatorname{arce}(\mathrm{N})$ \\
\hline 0.00 & $\quad 0.00$ & 0.00 & 0.00 & $0 \quad 0.00$ & 0.00 & 0.00 & $\quad 0.00$ & $\quad 0.00$ & 0.00 & $\quad 0.00$ & 0.00 & 0.00 & 0.00 & $\begin{array}{ll}0 & 0.00\end{array}$ & 0.00 & $\quad 0.00$ & 0.00 & $\quad 0.00$ & 0.03 \\
\hline 0.00 & $\quad 0.00$ & 0.00 & 0.00 & 0.00 & 0.00 & 0.00 & 0.00 & 0.00 & 0.00 & 0.00 & 0.00 & 0.00 & 0.00 & 0.00 & 0.00 & 0.00 & 0.00 & 0.00 & 0.00 \\
\hline 0.00 & 0.00 & 0.00 & 0.00 & 0.00 & 0.00 & 0.00 & 0.00 & 0.00 & -0.03 & 0.00 & 0.00 & 0.00 & 0.00 & 0.00 & 0.00 & 0.00 & 0.00 & 0.00 & 0.00 \\
\hline 0.00 & $\quad 0.00$ & 0.00 & 0.00 & 0.00 & 0.00 & 0.00 & 0.00 & 0.00 & 0.00 & 0.00 & 0.00 & 0.00 & 0.00 & 0.00 & 0.00 & 0.00 & 0.00 & 0.00 & 0.00 \\
\hline 0.05 & 0.00 & 0.00 & 0.00 & 0.00 & 0.00 & 0.00 & 0.00 & 0.00 & 0.00 & 0.05 & 0.00 & 0.00 & 0.00 & 0.00 & 0.00 & 0.00 & 0.00 & 0.00 & 0.00 \\
\hline 0.10 & 0.00 & 0.10 & 0.00 & 0.10 & 0.00 & 0.10 & 0.00 & 0.10 & 0.00 & 0.10 & 0.00 & 0.05 & 0.00 & 0.15 & 0.00 & 0.10 & 0.00 & 0.10 & 0.00 \\
\hline 0.24 & 0.00 & 0.19 & 0.00 & 0.24 & -0.03 & 0.24 & 0.00 & 0.24 & 0.00 & 0.24 & 0.00 & 0.19 & 0.00 & 0.24 & 0.00 & 0.24 & 0.00 & 0.24 & 0.00 \\
\hline 0.34 & 0.00 & 0.39 & 0.00 & 0.34 & 0.00 & 0.34 & 0.00 & 0.39 & 0.00 & 0.39 & 0.00 & 0.34 & 0.00 & 0.34 & 0.00 & 0.39 & 0.00 & 0.29 & 0.00 \\
\hline 0.49 & 0.00 & 0.49 & 0.00 & 0.53 & 0.00 & 0.53 & 0.00 & 0.53 & 0.00 & 0.49 & 0.00 & 0.44 & 0.00 & 0.49 & 0.00 & 0.44 & 0.00 & 0.49 & 0.00 \\
\hline 0.58 & 0.26 & 0.63 & 0.18 & 0.63 & 0.26 & 0.63 & 0.52 & 0.63 & 0.29 & 0.63 & 0.29 & 0.58 & 0.49 & 0.63 & 0.57 & 0.58 & 0.16 & 0.63 & 0.18 \\
\hline 0.78 & 1.22 & 0.78 & 0.94 & 0.73 & 1.22 & 0.78 & 1.27 & 0.78 & 1.14 & 0.78 & 1.14 & 0.73 & 1.14 & 0.78 & 1.33 & 0.73 & 0.70 & 0.73 & 1.07 \\
\hline 0.92 & 2.19 & 0.87 & 2.19 & 0.87 & 2.19 & 0.92 & 2.39 & 0.92 & 2.13 & 0.87 & 2.21 & 0.87 & 2.21 & 0.87 & 2.39 & 0.87 & 1.87 & 0.82 & 2.13 \\
\hline 1.02 & 3.69 & 1.02 & 3.77 & 1.02 & 3.69 & 1.07 & 3.98 & 1.02 & 3.64 & 1.02 & 3.59 & 0.97 & 3.62 & 1.02 & 3.75 & 0.97 & 3.33 & 1.02 & 3.59 \\
\hline 1.16 & 5.70 & 1.12 & 5.85 & 1.12 & 4.84 & 1.16 & 6.06 & 1.16 & 5.85 & 1.16 & 5.67 & 1.12 & 5.57 & 1.16 & 5.88 & 1.12 & 5.39 & 1.12 & 5.70 \\
\hline 1.26 & 8.48 & 1.31 & 8.58 & 1.26 & 7.78 & 1.31 & 8.97 & 1.31 & 8.90 & 1.31 & 8.82 & 1.26 & 8.27 & 1.26 & 8.64 & 1.2 & 8.19 & 1.26 & 8.53 \\
\hline 1.46 & 10.48 & 1.41 & 10.46 & 1.41 & 10.12 & 1.46 & 11.11 & 1.41 & 11.11 & 1.46 & 10.90 & 1.41 & 10.28 & 1.46 & 10.67 & 1.41 & 10.25 & 1.41 & 10.56 \\
\hline 1.50 & 9.83 & 1.46 & 9.91 & 1.46 & 9.31 & 1.50 & 10.51 & 1.50 & 10.41 & 1.50 & 10.17 & 1.46 & 9.50 & 1.50 & 9.99 & 1.41 & 9.55 & 1.46 & 9.96 \\
\hline 1.46 & 6.45 & 1.41 & 6.35 & 1.41 & 6.24 & 1.46 & 6.61 & 1.46 & 6.76 & 1.46 & 6.35 & 1.41 & 6.48 & 1.41 & 6.45 & 1.41 & 6.58 & 1.41 & 6.58 \\
\hline 1.36 & 5.65 & 1.36 & 5.12 & 1.36 & 4.84 & 1.36 & 5.54 & 1.41 & 5.39 & 1.41 & 5.54 & 1.3 & 5.51 & 1.3 & 5.25 & 1.3 & 5.41 & 1.36 & 5.72 \\
\hline 1.36 & 5.07 & 1.36 & 4.60 & 1.41 & 4.37 & 1.36 & 5.05 & 1.36 & 5.10 & 1.36 & 4.86 & 1.36 & 4.81 & 1.36 & 4.84 & 1.31 & 4.86 & 1.31 & 5.05 \\
\hline 1.31 & 4.19 & 1.31 & 4.06 & 1.31 & 3.80 & 1.36 & 4.01 & 1.36 & 4.11 & 1.36 & 4.01 & 1.31 & 4.01 & 1.31 & 3.95 & 1.31 & 4.01 & 1.36 & 4.19 \\
\hline 1.31 & 3.49 & 1.26 & 3.33 & 1.26 & 3.36 & 1.31 & 3.33 & 1.31 & 3.36 & 1.31 & 3.23 & 1.26 & 3.49 & 1.31 & 3.46 & 1.3 & 3.54 & 1.36 & 3.49 \\
\hline 1.31 & 3.07 & 1.26 & 2.94 & 1.31 & 3.02 & 1.31 & 3.04 & 1.31 & 2.91 & 1.26 & 2.97 & 1.31 & 3.02 & 1.31 & 3.10 & 1.2 & 3.10 & 1.26 & 3.04 \\
\hline 1.31 & 2.65 & 1.26 & 2.63 & 1.26 & 2.58 & & 2.60 & 1.26 & 2.29 & 1.26 & 2.47 & 1.26 & 2.55 & 1.31 & 2.68 & 1.26 & 2.76 & 1.26 & 2.60 \\
\hline 1.21 & 0.49 & 1.21 & 0.73 & 1.21 & 0.42 & 1.21 & 0.60 & 1.26 & 0.44 & 1.21 & 0.49 & 1.21 & 0.65 & 1.21 & 0.62 & 1.21 & 0.49 & 1.21 & 0.68 \\
\hline 1.12 & 0.00 & 1.16 & 0.00 & 1.12 & 0.00 & 1.12 & 0.00 & 1.07 & 0.00 & 1.16 & 0.00 & 1.07 & 0.00 & 1.07 & 0.00 & 1.1 & 0.00 & 1.12 & 0.00 \\
\hline 0.97 & 0.00 & 0.9 & 0.00 & 0.97 & 0.00 & & 0.00 & 0. & 0.00 & 1.0 & 0.00 & 0.9 & 0.00 & 0.97 & 0.00 & 0.9 & -0.03 & 0.97 & 0.00 \\
\hline 0.87 & 0.00 & 0.87 & 0.00 & 0.87 & 0.00 & 0.87 & -0.03 & 0.87 & 0.00 & 0.87 & 0.00 & 0.87 & 0.00 & 0.82 & 0.00 & 0.87 & 0.00 & 0.82 & 0.00 \\
\hline 0.73 & -0.03 & 0.73 & 0.00 & 0.68 & 0.00 & & 0.00 & 0.73 & 0.00 & 0.73 & 0.00 & 0.73 & 0.00 & 0.68 & 0.00 & 0.73 & 0.00 & 0.63 & 0.00 \\
\hline 0.58 & 0.00 & 0.58 & 0.00 & & 0.00 & & 0.00 & & 0.00 & 0. & 0.00 & 0.5 & 0.0 & 0.6 & 0.00 & & 0.00 & 0.53 & 0.00 \\
\hline 0.44 & 0.00 & 0.49 & 0.00 & 0.49 & 0.00 & 0.4 & 0.00 & 0.49 & 0.00 & 0.49 & 0.00 & 0.44 & -0.03 & 0.44 & 0.00 & 0.44 & 0.00 & 0.44 & 0.00 \\
\hline 0.34 & 0.00 & 0.34 & 0.00 & 0.53 & 0.00 & 0.34 & 0.00 & 0.34 & 0.00 & 0.34 & 0.00 & 0.29 & 0.00 & 0.29 & 0.00 & 0.34 & 0.00 & 0.29 & 0.00 \\
\hline 0.19 & 0.00 & 0.24 & 0.00 & 0.19 & 0.00 & 0.19 & 0.00 & 0.19 & 0.00 & 0.19 & 0.00 & 0.15 & 0.00 & 0.19 & 0.00 & 0.19 & 0.00 & 0.19 & 0.00 \\
\hline
\end{tabular}

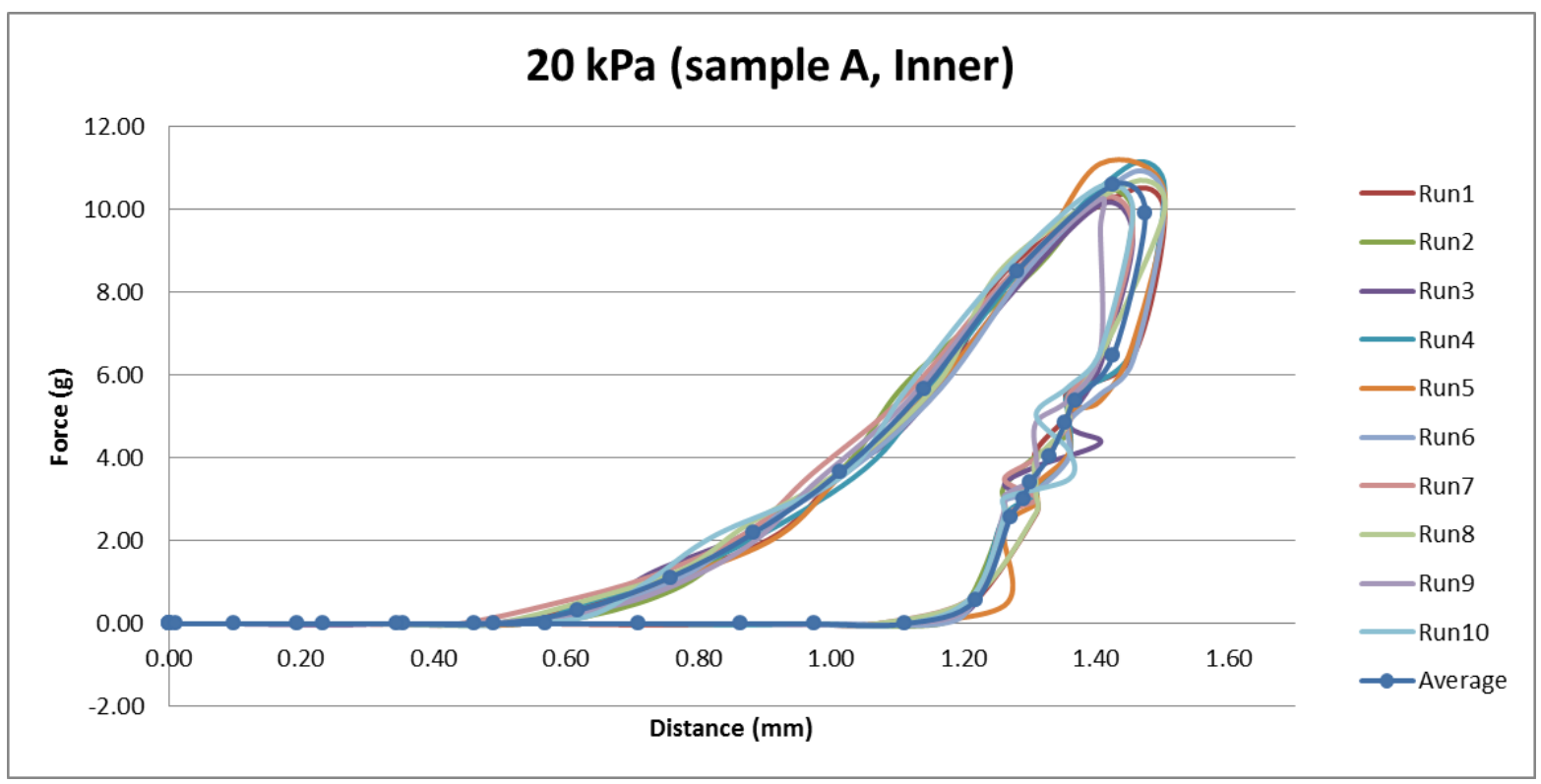



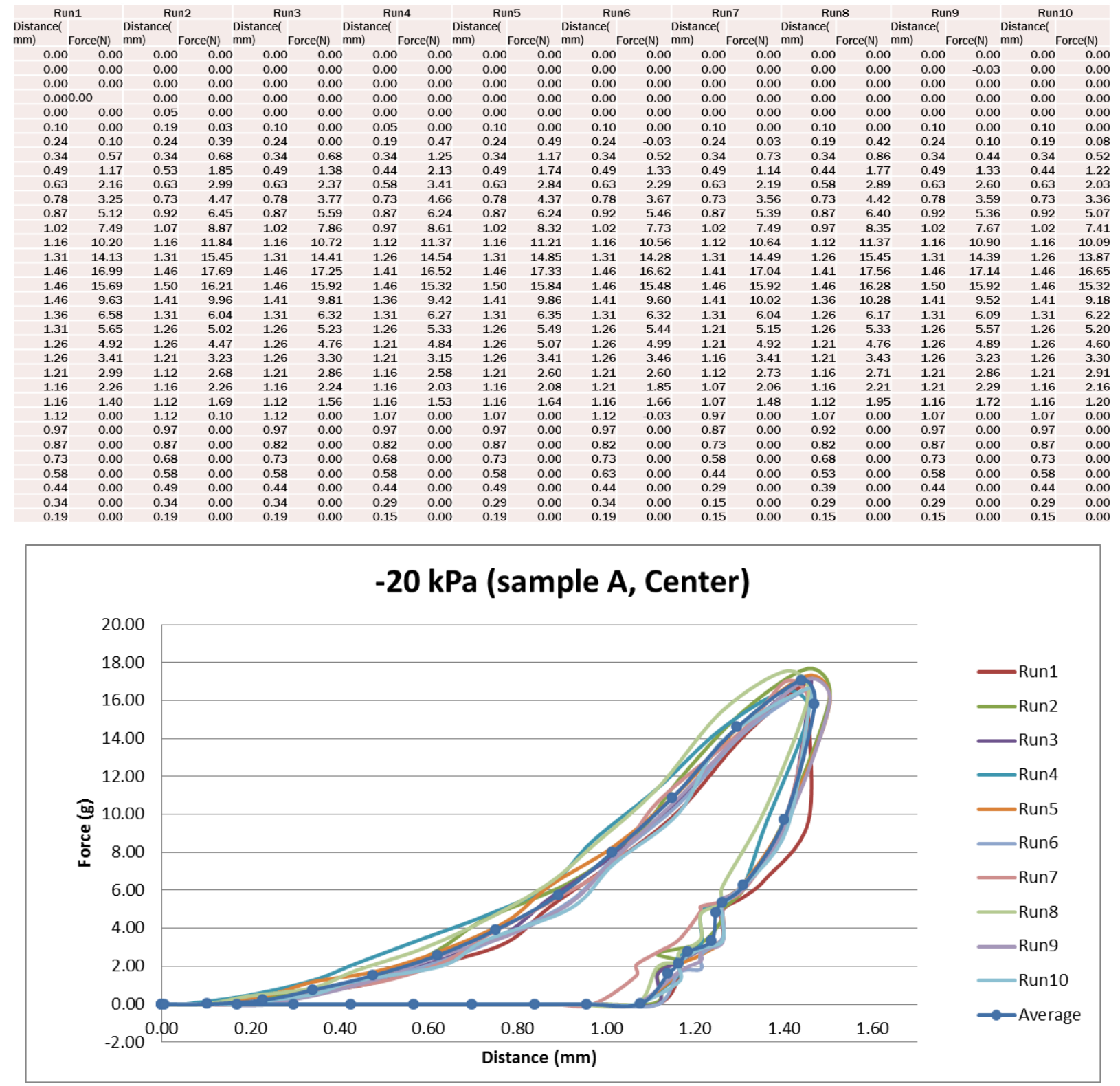


\begin{tabular}{|c|c|c|c|c|c|c|c|c|c|c|c|c|c|c|c|c|c|c|c|}
\hline \multicolumn{2}{|c|}{ Run1 } & \multicolumn{2}{|c|}{ Run2 } & \multicolumn{2}{|c|}{ Run3 } & \multicolumn{2}{|c|}{ Run4 } & \multicolumn{2}{|c|}{ Run5 } & \multicolumn{2}{|c|}{ Run6 } & \multicolumn{2}{|c|}{ Run7 } & \multicolumn{2}{|c|}{ Run8 } & \multicolumn{2}{|c|}{ Run9 } & \multicolumn{2}{|c|}{ Run10 } \\
\hline $\begin{array}{l}\text { Distance( } \\
\mathrm{mm} \text { ) }\end{array}$ & $\begin{array}{l}\text { Diste } \\
\mathrm{mm} \text { ) }\end{array}$ & $\begin{array}{l}\text { istance ( } \\
\mathrm{m} \text { ) }\end{array}$ & Force $(\mathrm{N})$ & $\begin{array}{l}\text { Distance } \\
\mathrm{mm} \text { ) }\end{array}$ & Force(N) & $\begin{array}{l}\text { Distance } \\
\mathrm{mm})\end{array}$ & Force(N) & $\begin{array}{l}\text { Distance( } \\
\mathrm{mm})\end{array}$ & Force(N) & $\begin{array}{l}\text { Distance } \\
\mathrm{mm})\end{array}$ & Force(N) & $\begin{array}{l}\text { Distance ( } \\
\mathrm{mm} \text { ) }\end{array}$ & Force(N) & $\begin{array}{l}\text { Distance } \\
\mathrm{mm})\end{array}$ & Force(N) & $\begin{array}{l}\text { Distance ( } \\
\mathrm{mm} \text { ) }\end{array}$ & Force(N) & $\begin{array}{l}\text { Distance( } \\
\mathrm{mm} \text { ) }\end{array}$ & $\operatorname{arce}(\mathrm{N})$ \\
\hline 0.00 & 0.00 & 0.00 & $\quad-0.03$ & $\begin{array}{ll}3 & 0.00\end{array}$ & 0.00 & 0.00 & 0.00 & $\begin{array}{ll}0 & 0.00\end{array}$ & 0.00 & $\begin{array}{ll}0 & 0.00\end{array}$ & 0.00 & $0 \quad 0.00$ & 0.00 & $\begin{array}{ll}0 & 0.00\end{array}$ & 0.00 & $\begin{array}{ll}0 & 0.00\end{array}$ & 0.00 & $\quad 0.00$ & 0.00 \\
\hline 0.00 & 0.00 & 0.00 & 0.00 & 0.00 & 0.00 & 0.00 & 0.00 & 0.00 & 0.00 & 0.00 & 0.00 & 0.00 & 0.00 & 0.00 & 0.00 & 0.00 & 0.00 & 0.00 & 0.00 \\
\hline 0.00 & 0.000 .00 & & 0.00 & 0.00 & 0.00 & 0.00 & 0.00 & 0.00 & 0.00 & 0.00 & 0.00 & 0.00 & 0.00 & 0.00 & 0.00 & 0.00 & 0.00 & 0.00 & 0.00 \\
\hline 0.00 & 0.00 & 0.00 & 0.00 & 0.00 & 0.00 & 0.00 & 0.00 & 0.00 & 0.00 & 0.00 & 0.00 & 0.00 & 0.00 & 0.00 & 0.00 & 0.00 & 0.00 & 0.00 & 0.00 \\
\hline 0.00 & 0.00 & 0.00 & 0.00 & 0.00 & 0.00 & 0.00 & 0.00 & 0.00 & 0.00 & 0.00 & 0.00 & 0.00 & 0.00 & 0.00 & 0.00 & 0.00 & 0.00 & 0.00 & 0.00 \\
\hline 0.10 & 0.00 & 0.10 & 0.00 & 0.10 & -0.03 & 0.10 & 0.00 & 0.10 & 0.00 & 0.10 & 0.00 & 0.10 & 0.00 & 0.10 & 0.00 & 0.10 & -0.03 & 0.10 & 0.00 \\
\hline 0.24 & 0.00 & 0.24 & 0.00 & 0.24 & 0.00 & 0.24 & 0.00 & 0.24 & 0.00 & 0.24 & 0.00 & 0.24 & 0.00 & 0.24 & 0.00 & 0.24 & 0.00 & 0.24 & 0.00 \\
\hline 0.34 & 0.42 & 0.39 & 0.36 & 0.34 & 0.08 & 0.34 & 0.10 & 0.34 & 0.16 & 0.34 & 0.03 & 0.39 & 0.00 & 0.39 & 0.00 & 0.39 & 0.05 & 0.39 & 0.05 \\
\hline 0.49 & $\begin{array}{l}0.42 \\
1.14\end{array}$ & 0.49 & 1.20 & 0.49 & 0.55 & 0.49 & 0.68 & 0.49 & 0.75 & 0.49 & 0.57 & 0.53 & 0.44 & 0.49 & 0.52 & 0.49 & 0.55 & 0.49 & 0.49 \\
\hline 0.63 & 2.16 & 0.68 & 2.06 & 0.63 & 1.46 & 0.63 & 1.40 & 0.63 & 1.14 & 0.63 & 1.30 & 0.63 & 1.14 & 0.63 & 1.30 & 0.63 & 1.38 & 0.63 & 1.40 \\
\hline 0.78 & 3.04 & 0.78 & 2.99 & 0.78 & 2.32 & 0.78 & 2.39 & 0.73 & 2.21 & 0.78 & 2.24 & 0.78 & 2.26 & 0.78 & 2.42 & 0.78 & 2.21 & 0.78 & 2.26 \\
\hline 0.92 & 4.60 & 0.92 & 4.32 & 0.87 & 3.64 & 0.87 & 3.72 & 0.87 & 3.88 & 0.87 & 3.56 & 0.92 & 3.69 & 0.87 & 3.88 & 0.87 & 3.88 & 0.87 & 3.41 \\
\hline 1.02 & 6.56 & 1.02 & 6.40 & 1.02 & 5.70 & 1.02 & 5.75 & 1.02 & 5.67 & 1.02 & 5.57 & 1.07 & 5.41 & 1.02 & 5.59 & 1.02 & 5.59 & 1.02 & 5.49 \\
\hline $\begin{array}{l}1.02 \\
1.16\end{array}$ & 9.50 & $\begin{array}{l}1.02 \\
1.16\end{array}$ & 9.08 & $\begin{array}{l}1.02 \\
1.16\end{array}$ & 8.30 & $\begin{array}{l}1.02 \\
1.16\end{array}$ & 8.51 & $\begin{array}{l}1.02 \\
1.16\end{array}$ & 8.06 & $\begin{array}{l}1.02 \\
1.16\end{array}$ & 7.83 & 1.16 & $\begin{array}{l}3.41 \\
7.73\end{array}$ & 1.16 & 8.09 & $\begin{array}{l}1.02 \\
1.16\end{array}$ & 8.22 & $\begin{array}{l}1.02 \\
1.16\end{array}$ & 7.99 \\
\hline 1.31 & 12.80 & 1.31 & 12.36 & 1.26 & 11.52 & 1.31 & 12.10 & 1.31 & 11.42 & 1.31 & 11.11 & 1.31 & 10.98 & 1.31 & 11.34 & 1.31 & 11.52 & 1.31 & 11.21 \\
\hline 1.41 & 15.40 & 1.46 & 15.09 & 1.41 & 14.02 & 1.46 & 14.41 & 1.46 & 13.74 & 1.46 & 13.68 & 1.46 & 13.81 & 1.46 & 13.89 & 1.46 & 14.28 & 1.46 & 13.74 \\
\hline 1.46 & 14.49 & 1.50 & 14.00 & 1.46 & 13.32 & 1.50 & 13.66 & 1.46 & 12.93 & 1.46 & 12.88 & 1.50 & 12.59 & 1.50 & 12.72 & 1.46 & $\begin{array}{l}13.09 \\
\end{array}$ & 1.46 & 12.72 \\
\hline 1.46 & 8.69 & 1.41 & 8.12 & 1.41 & 7.67 & 1.41 & 7.73 & 1.41 & 7.57 & 1.41 & 7.34 & 1.46 & 7.47 & 1.46 & 7.70 & 1.41 & 7.65 & 1.41 & 7.75 \\
\hline $\begin{array}{l}1.40 \\
1.36\end{array}$ & $\begin{array}{l}6.05 \\
6.61\end{array}$ & $\begin{array}{l}1.41 \\
1.36\end{array}$ & 6.48 & $\begin{array}{l}1.41 \\
1.31\end{array}$ & 5.70 & $\begin{array}{l}1.41 \\
1.36\end{array}$ & 5.75 & $\begin{array}{l}1.41 \\
1.36\end{array}$ & 5.65 & $\begin{array}{l}1.41 \\
1.36\end{array}$ & 5.62 & $\begin{array}{l}1.40 \\
1.36\end{array}$ & $\begin{array}{l}1.41 \\
5.65\end{array}$ & $\begin{array}{l}1.40 \\
1.36\end{array}$ & 5.57 & $\begin{array}{l}1.41 \\
1.36\end{array}$ & 5.33 & $\begin{array}{l}1.41 \\
1.36\end{array}$ & 5.28 \\
\hline 1.31 & 5.91 & 1.31 & 5.51 & 1.31 & 4.84 & 1.31 & 4.97 & 1.31 & 5.10 & 1.31 & 4.97 & 1.36 & 4.66 & 1.31 & 4.71 & 1.31 & 4.55 & 1.31 & 4.58 \\
\hline 1.31 & 5.51 & 1.31 & 5.18 & 1.31 & 4.53 & 1.31 & 4.66 & 1.31 & 4.42 & 1.31 & 4.24 & 1.31 & 4.01 & 1.31 & 4.11 & 1.31 & 4.11 & 1.26 & 4.01 \\
\hline 1.26 & 3.23 & 1.26 & 3.15 & 1.26 & 3.07 & 1.26 & 3.07 & 1.26 & 3.10 & $\begin{array}{l}1.31 \\
1.26\end{array}$ & 3.04 & 1.31 & $\begin{array}{l}3.01 \\
3.10\end{array}$ & 1.31 & 3.23 & $\begin{array}{l}1.31 \\
1.26\end{array}$ & $\begin{array}{l}3.11 \\
3.04\end{array}$ & $\begin{array}{l}1.20 \\
1.26\end{array}$ & 3.23 \\
\hline 1.21 & 2.55 & 1.26 & 2.63 & 1.21 & 2.73 & 1.26 & 2.60 & 1.26 & 2.65 & 1.26 & 2.60 & 1.26 & 2.76 & 1.26 & 2.65 & 1.26 & 2.63 & 1.26 & 2.71 \\
\hline 1.21 & $\begin{array}{l}2.53 \\
2.08\end{array}$ & $\begin{array}{l}1.26 \\
1.21\end{array}$ & 2.19 & $\begin{array}{l}1.21 \\
1.21\end{array}$ & $\begin{array}{l}2.15 \\
2.16\end{array}$ & $\begin{array}{l}1.20 \\
1.21\end{array}$ & $\begin{array}{l}2.00 \\
2.13\end{array}$ & $\begin{array}{l}1.20 \\
1.21\end{array}$ & $\begin{array}{l}2.05 \\
2.37\end{array}$ & $\begin{array}{l}1.20 \\
1.21\end{array}$ & $\begin{array}{l}2.00 \\
2.16\end{array}$ & $\begin{array}{l}1.20 \\
1.26\end{array}$ & $\begin{array}{l}2.10 \\
2.06\end{array}$ & 1.21 & $\begin{array}{l}2.05 \\
2.06\end{array}$ & $\begin{array}{l}1.20 \\
1.26\end{array}$ & $\begin{array}{l}2.03 \\
2.16\end{array}$ & $\begin{array}{l}1.20 \\
1.21\end{array}$ & 2.11 \\
\hline 1.16 & 1.33 & 1.16 & 1.17 & 1.16 & 0.99 & 1.21 & 0.99 & 1.21 & 1.04 & 1.21 & 0.62 & 1.21 & 0.52 & 1.21 & 0.62 & 1.21 & 0.60 & 1.21 & 0.60 \\
\hline 1.07 & 0.00 & 1.12 & 0.00 & 1.07 & -0.03 & 1.12 & 0.00 & 1.12 & 0.00 & 1.12 & 0.00 & 1.12 & 0.00 & 1.12 & 0.00 & 1.12 & 0.00 & 1.12 & 0.00 \\
\hline 0.92 & 0.00 & 0.97 & 0.00 & 0.97 & 0.00 & 0.97 & 0.00 & 0.97 & 0.00 & 0.97 & 0.00 & 1.02 & 0.00 & 0.97 & 0.00 & 0.97 & -0.03 & 0.97 & 0.00 \\
\hline 0.82 & 0.00 & 0.87 & 0.00 & 0.82 & 0.00 & 0.82 & 0.00 & 0.82 & 0.00 & 0.87 & 0.00 & 0.87 & 0.00 & 0.87 & 0.00 & 0.82 & 0.00 & 0.87 & 0.00 \\
\hline 0.73 & 0.00 & 0.73 & 0.00 & 0.68 & 0.00 & $\begin{array}{l}0.82 \\
0.73\end{array}$ & 0.00 & 0.73 & 0.00 & $\begin{array}{l}0.81 \\
0.73\end{array}$ & 0.00 & 0.73 & 0.00 & 0.73 & 0.00 & 0.73 & 0.00 & 0.73 & 0.00 \\
\hline 0.58 & 0.00 & 0.58 & 0.00 & 0.58 & 0.00 & 0.58 & 0.00 & 0.58 & 0.00 & 0.58 & 0.00 & 0.63 & 0.00 & 0.58 & 0.00 & 0.58 & 0.00 & 0.58 & 0.00 \\
\hline $\begin{array}{l}0.58 \\
0.49\end{array}$ & 0.00 & $\begin{array}{l}0.58 \\
0.44\end{array}$ & 0.00 & $\begin{array}{l}0.38 \\
0.44\end{array}$ & $\begin{array}{l}0.00 \\
0.00\end{array}$ & $\begin{array}{l}0.58 \\
0.44\end{array}$ & 0.00 & $\begin{array}{l}0.38 \\
0.49\end{array}$ & 0.00 & $\begin{array}{l}0.58 \\
0.49\end{array}$ & 0.00 & $\begin{array}{l}0.63 \\
0.49\end{array}$ & 0.00 & $\begin{array}{l}0.58 \\
0.49\end{array}$ & 0.00 & $\begin{array}{l}0.58 \\
0.44\end{array}$ & 0.00 & $\begin{array}{l}0.38 \\
0.49\end{array}$ & 0.00 \\
\hline 0.29 & 0.00 & 0.29 & 0.00 & 0.29 & 0.00 & 0.34 & 0.00 & 0.34 & 0.00 & 0.34 & 0.00 & 0.34 & 0.00 & 0.34 & 0.00 & 0.34 & 0.00 & 0.34 & 0.00 \\
\hline 0.19 & 0.00 & $\begin{array}{l}0.19 \\
0.19\end{array}$ & 0.00 & $\begin{array}{l}0.29 \\
0.19\end{array}$ & 0.00 & $\begin{array}{l}0.34 \\
0.19\end{array}$ & 0.00 & $\begin{array}{l}0.34 \\
0.19\end{array}$ & 0.00 & $\begin{array}{l}0.34 \\
0.19\end{array}$ & 0.00 & $\begin{array}{l}0.34 \\
0.19\end{array}$ & 0.00 & $\begin{array}{l}0.34 \\
\end{array}$ & 0.00 & $\begin{array}{l}0.34 \\
0.19\end{array}$ & 0.00 & $\begin{array}{l}0.34 \\
0.19\end{array}$ & 0.00 \\
\hline
\end{tabular}

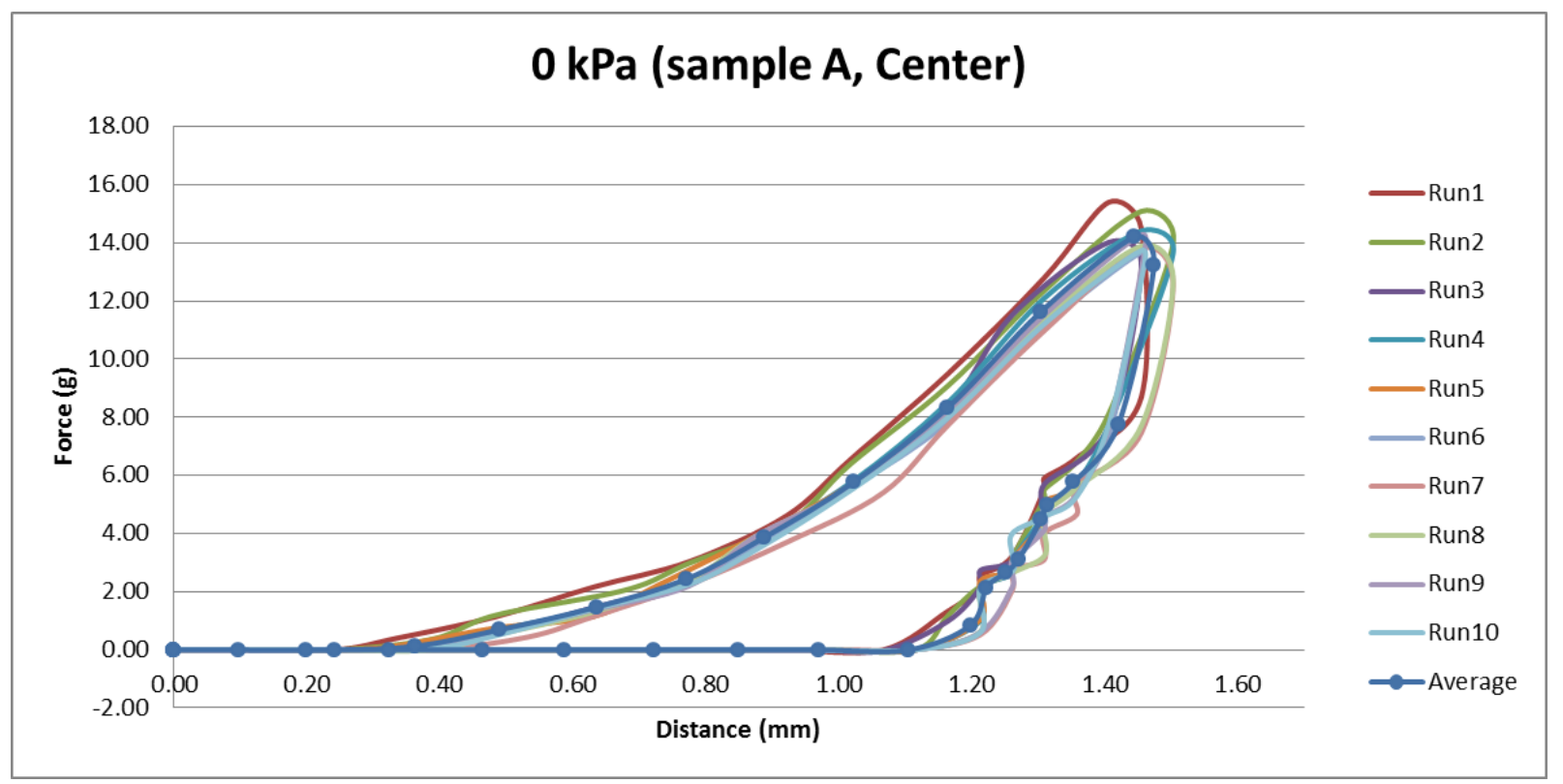




\begin{tabular}{|c|c|c|c|c|c|c|c|c|c|c|c|c|c|c|c|c|c|c|c|}
\hline \multicolumn{2}{|c|}{ Run1 } & \multicolumn{2}{|c|}{ Run2 } & \multicolumn{2}{|c|}{ Run3 } & \multicolumn{2}{|c|}{ Run4 } & \multicolumn{2}{|l|}{ Run5 } & \multicolumn{2}{|l|}{ Run6 } & \multicolumn{2}{|l|}{ Run7 } & \multicolumn{2}{|c|}{ Run8 } & \multicolumn{2}{|c|}{ Run9 } & \multicolumn{2}{|c|}{ Run10 } \\
\hline $\begin{array}{l}\text { Distancel } \\
\mathrm{mm} \text { ) }\end{array}$ & & $\begin{array}{l}\text { Distance( } \\
\mathrm{mm} \text { ) }\end{array}$ & $\begin{array}{l}\text { Dista } \\
\mathrm{mm} \text { ) }\end{array}$ & ances & orce $(N)$ & $\begin{array}{l}\text { Distance( } \\
\mathrm{mm} \text { ) }\end{array}$ & Force(N) & $\begin{array}{l}\text { Distance( } \\
\mathrm{mm} \text { ) }\end{array}$ & $\operatorname{rce}(\mathrm{N})$ & $\begin{array}{l}\text { Distance( } \\
\mathrm{mm} \text { ) }\end{array}$ & $\operatorname{rce}(\mathrm{N})$ & $\begin{array}{l}\text { Distance( } \\
\mathrm{mm} \text { ) }\end{array}$ & $\operatorname{ce}(\mathrm{N})$ & $\begin{array}{l}\text { Distance( } \\
\mathrm{mm})\end{array}$ & rce & $\begin{array}{l}\text { Distance( } \\
\mathrm{mm})\end{array}$ & & $\begin{array}{l}\text { Distance( } \\
\mathrm{mm})\end{array}$ & $\operatorname{rrce}(\mathrm{N})$ \\
\hline 0.00 & 0.00 & $\quad 0.00$ & -0.03 & 0.00 & 0.00 & $\quad 0.00$ & 0.00 & $\quad 0.00$ & 0.00 & $\quad 0.00$ & 0.00 & $\quad 0.00$ & 0.00 & 0.00 & 0.00 & 0.00 & 0.00 & $\quad 0.00$ & 0.00 \\
\hline 0.00 & 0.00 & 0.00 & 0.00 & 0.00 & 0.00 & 0.00 & 0.00 & 0.00 & 0.00 & 0.00 & 0.00 & 0.00 & 0.00 & 0.00 & 0.00 & 0.00 & 0.00 & 0.00 & 0.00 \\
\hline 0.00 & 0.00 & 0.00 & 0.000 .00 & & 0.00 & 0.00 & 0.00 & 0.00 & 0.00 & 0.00 & 0.00 & 0.00 & 0.00 & 0.00 & 0.00 & 0.00 & 0.00 & 0.00 & 0.00 \\
\hline 0.00 & 0.00 & 0.00 & 0.00 & 0.00 & 0.00 & 0.00 & 0.00 & 0.00 & 0.00 & 0.00 & 0.00 & 0.00 & 0.00 & 0.00 & 0.00 & 0.00 & 0.03 & 0.00 & 0.00 \\
\hline 0.00 & 0.00 & 0.00 & 0.00 & 0.00 & 0.00 & 0.00 & 0.00 & 0.00 & 0.00 & 0.00 & 0.00 & 0.00 & 0.00 & 0.00 & 0.00 & 0.00 & 0.00 & 0.00 & 0.00 \\
\hline 0.10 & 0.00 & 0.10 & 0.00 & 0.10 & 0.00 & 0.10 & 0.00 & 0.10 & 0.00 & 0.10 & 0.00 & 0.10 & 0.00 & 0.00 & 0.00 & 0.10 & 0.00 & 0.10 & 0.00 \\
\hline 0.24 & 0.00 & 0.24 & 0.00 & 0.24 & 0.00 & 0.24 & 0.00 & 0.24 & 0.00 & 0.24 & -0.03 & 0.24 & 0.00 & 0.00 & 0.00 & 0.24 & 0.00 & 0.24 & 0.00 \\
\hline 0.39 & 0.03 & 0.39 & 0.00 & 0.34 & 0.00 & 0.39 & 0.00 & 0.34 & 0.00 & 0.39 & 0.00 & 0.34 & -0.03 & 0.15 & 0.00 & 0.34 & 0.00 & 0.34 & 0.00 \\
\hline 0.49 & 0.36 & 0.49 & 0.08 & 0.49 & 0.36 & 0.49 & 0.34 & 0.53 & 0.29 & 0.49 & 0.21 & 0.49 & 0.31 & 0.24 & 0.00 & 0.49 & 0.10 & 0.49 & 0.10 \\
\hline 0.63 & 0.91 & 0.63 & 0.65 & 0.58 & 0.88 & 0.63 & 0.94 & 0.63 & 0.70 & 0.63 & 1.25 & 0.63 & 0.88 & 0.39 & 0.05 & 0.63 & 0.65 & 0.63 & 0.62 \\
\hline 0.78 & 1.53 & 0.73 & 1.74 & 0.73 & 1.77 & 0.73 & 1.74 & 0.78 & 1.72 & 0.78 & 1.80 & 0.78 & 1.38 & 0.53 & 0.44 & 0.78 & 1.53 & 0.78 & 1.53 \\
\hline 0.87 & 2.73 & 0.87 & 2.71 & 0.87 & 3.02 & 0.87 & 2.99 & 0.92 & 3.15 & 0.92 & 2.91 & 0.87 & 2.65 & 0.63 & 0.88 & 0.87 & 2.37 & 0.92 & 2.65 \\
\hline 1.02 & 4.63 & 1.02 & 4.53 & 1.02 & 4.47 & 1.02 & 4.47 & 1.02 & 4.66 & 1.07 & 4.84 & 1.02 & 4.37 & 0.78 & 1.85 & 1.02 & 3.95 & 1.07 & 4.06 \\
\hline 1.16 & 7.05 & 1.16 & 6.69 & 1.12 & 6.69 & 1.16 & 6.89 & 1.16 & 6.82 & 1.16 & 7.18 & 1.16 & 6.74 & 0.92 & 3.12 & 1.16 & 6.27 & 1.16 & 6.40 \\
\hline 1.31 & 10.07 & 1.26 & 9.60 & 1.31 & 9.76 & 1.26 & 9.91 & 1.31 & 9.89 & 1.31 & 10.22 & 1.26 & 9.55 & 1.07 & 4.84 & 1.31 & 9.26 & 1.31 & 9.26 \\
\hline 1.46 & 12.54 & 1.46 & 11.84 & 1.41 & 12.04 & 1.46 & 12.28 & 1.46 & 12.56 & 1.46 & 12.56 & 1.41 & 11.52 & 1.21 & 7.10 & 1.41 & 11.26 & 1.46 & 11.55 \\
\hline 1.50 & 11.52 & 1.46 & 11.21 & 1.46 & 10.93 & 1.46 & 11.29 & 1.46 & 11.26 & 1.50 & 11.81 & 1.46 & 10.80 & 1.31 & 10.04 & 1.46 & 10.33 & 1.50 & 10.38 \\
\hline 1.41 & 6.74 & 1.41 & 6.58 & 1.41 & 6.35 & 1.41 & 6.82 & 1.46 & 6.74 & 1.46 & 6.92 & 1.41 & 6.66 & 1.50 & 12.38 & 1.41 & 6.58 & 1.41 & 6.58 \\
\hline 1.36 & 5.25 & 1.31 & 5.18 & 1.36 & 5.02 & 1.36 & 5.25 & 1.36 & 5.18 & 1.36 & 5.41 & 1.36 & 4.99 & 1.50 & 11.52 & 1.36 & 5.10 & 1.36 & 5.39 \\
\hline 1.31 & 4.60 & 1.31 & 4.76 & 1.31 & 4.03 & 1.36 & 4.27 & 1.31 & 4.32 & 1.31 & 4.68 & 1.31 & 4.32 & 1.46 & 6.66 & 1.31 & 4.27 & 1.36 & 4.63 \\
\hline 1.31 & 4.16 & 1.31 & 3.80 & 1.26 & 3.64 & 1.31 & 3.93 & 1.31 & 3.72 & 1.31 & 4.27 & 1.31 & 3.88 & 1.36 & 4.99 & 1.26 & 3.56 & 1.36 & 3.72 \\
\hline 1.31 & 2.97 & 1.26 & 2.86 & 1.26 & 2.71 & 1.31 & 3.12 & 1.31 & 2.99 & 1.31 & 3.23 & 1.26 & 3.15 & 1.36 & 4.47 & 1.31 & 2.91 & 1.31 & 3.02 \\
\hline 1.26 & 2.47 & 1.26 & 2.68 & 1.21 & 2.52 & 1.26 & 2.68 & 1.26 & 2.78 & 1.26 & 2.86 & 1.26 & 2.63 & 1.31 & 4.06 & 1.26 & 2.45 & 1.26 & 2.76 \\
\hline 1.21 & 2.00 & 1.21 & 2.39 & 1.21 & 1.85 & 1.26 & 1.98 & 1.26 & 2.13 & 1.26 & 2.24 & 1.26 & 2.11 & 1.31 & 2.99 & 1.26 & 1.85 & 1.26 & 2.03 \\
\hline 1.21 & 0.62 & 1.21 & 0.39 & 1.21 & 0.65 & 1.21 & 0.65 & 1.26 & 0.39 & 1.26 & 0.88 & 1.21 & 0.47 & 1.26 & 2.58 & 1.21 & 0.13 & 1.26 & 0.26 \\
\hline 1.07 & 0.00 & 1.12 & 0.00 & 1.07 & 0.00 & 1.12 & 0.00 & 1.12 & 0.00 & 1.12 & -0.03 & 1.07 & 0.00 & 1.26 & 2.32 & 1.12 & 0.00 & 1.12 & 0.00 \\
\hline 0.97 & 0.00 & 0.97 & 0.00 & 0.97 & 0.00 & 0.97 & 0.00 & 0.97 & 0.00 & 1.02 & 0.00 & 0.97 & 0.00 & 1.26 & 0.49 & 0.97 & 0.00 & 0.97 & 0.00 \\
\hline 0.87 & -0.08 & 0.82 & 0.00 & 0.82 & 0.00 & 0.87 & 0.00 & 0.87 & 0.00 & 0.87 & 0.00 & 1.02 & 0.00 & 1.12 & 0.00 & 0.82 & 0.00 & 0.82 & 0.00 \\
\hline 0.73 & 0.00 & 0.73 & 0.00 & 0.68 & 0.00 & 0.73 & 0.00 & 0.73 & 0.00 & 0.73 & 0.00 & 0.68 & 0.00 & 1.02 & 0.00 & 0.68 & 0.00 & 0.73 & 0.00 \\
\hline 0.58 & -0.03 & 0.53 & 0.00 & 0.58 & 0.00 & 0.58 & 0.00 & 0.58 & 0.00 & 0.63 & 0.00 & 0.58 & 0.00 & 0.87 & 0.00 & 0.58 & 0.00 & 0.58 & 0.00 \\
\hline 0.44 & 0.00 & 0.44 & 0.00 & 0.44 & 0.00 & 0.49 & 0.00 & 0.44 & 0.00 & 0.49 & 0.00 & 0.44 & 0.00 & 0.73 & 0.00 & 0.44 & 0.00 & 0.44 & 0.00 \\
\hline 0.19 & 0.00 & 0.29 & 0.00 & 0.29 & -0.03 & 0.34 & 0.00 & 0.34 & 0.00 & 0.34 & 0.00 & 0.29 & 0.00 & 0.58 & 0.00 & 0.29 & 0.00 & 0.34 & 0.00 \\
\hline 0.19 & 0.00 & 0.19 & 0.00 & 0.19 & 0.00 & 0.19 & 0.00 & 0.19 & 0.00 & 0.24 & 0.00 & 0.19 & 0.00 & 0.49 & 0.00 & 0.19 & 0.00 & 0.19 & 0.00 \\
\hline
\end{tabular}

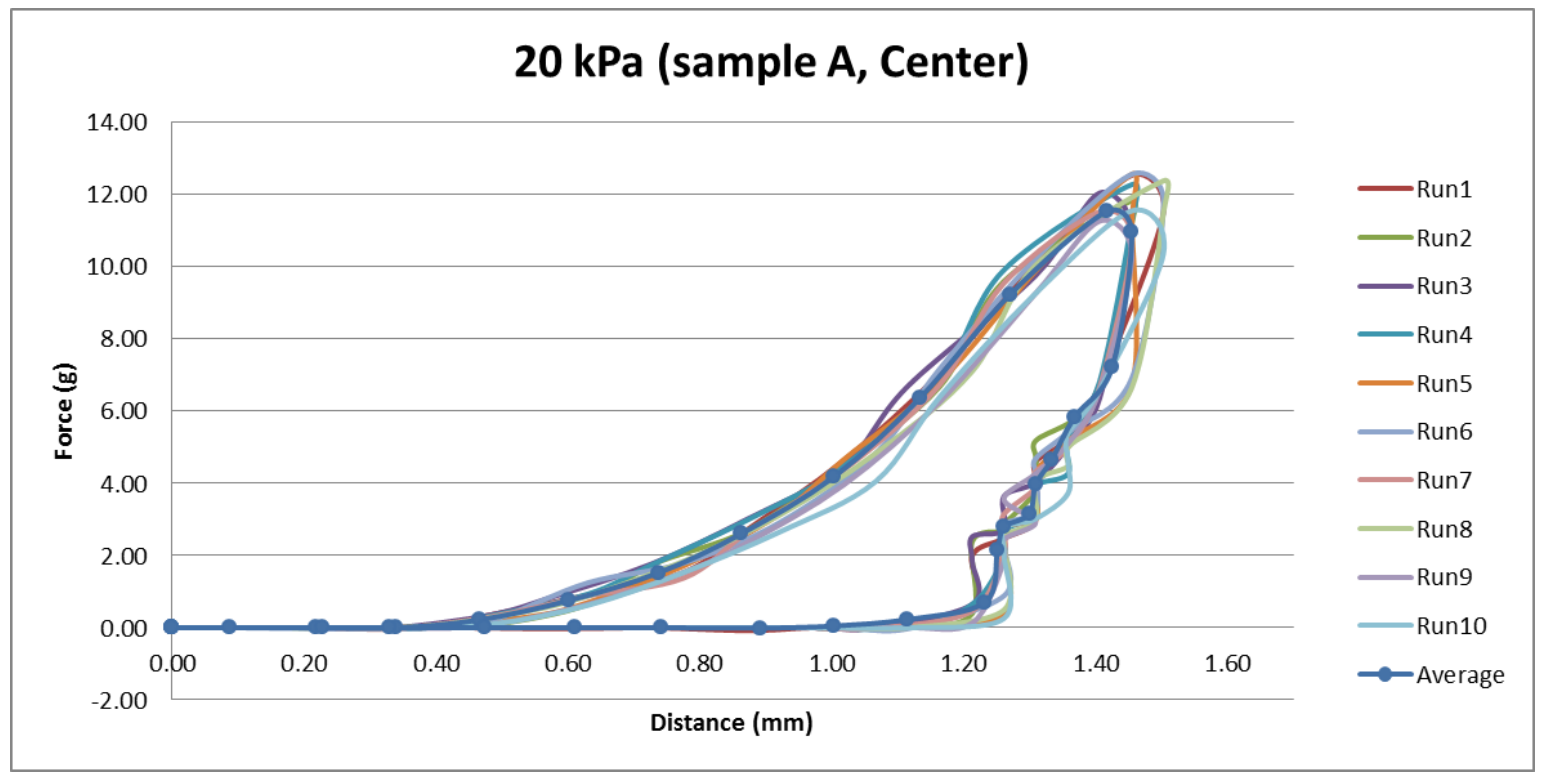




\begin{tabular}{|c|c|c|c|c|c|c|c|c|c|c|c|c|c|c|c|c|c|c|c|}
\hline \multicolumn{2}{|c|}{ Run1 } & \multicolumn{2}{|c|}{ Run2 } & \multicolumn{2}{|c|}{ Run3 } & \multicolumn{2}{|c|}{ Run4 } & \multicolumn{2}{|c|}{ Run5 } & \multicolumn{2}{|c|}{ Run6 } & \multicolumn{2}{|c|}{ Run7 } & \multicolumn{2}{|c|}{ Run8 } & \multicolumn{2}{|c|}{ Run9 } & \multicolumn{2}{|c|}{ Run10 } \\
\hline $\begin{array}{l}\text { Distance( } \\
\mathrm{mm} \text { ) }\end{array}$ & & $\begin{array}{l}\text { Distance( } \\
\mathrm{mm})\end{array}$ & Force(N) & $\begin{array}{l}\text { Distance( } \\
\mathrm{mm})\end{array}$ & Force(N) & $\begin{array}{l}\text { Distance( } \\
\mathrm{mm} \text { ) }\end{array}$ & Force(N) & $\begin{array}{l}\text { Distance( } \\
\mathrm{mm})\end{array}$ & Force(N) & $\begin{array}{l}\text { Distance( } \\
\mathrm{mm} \text { ) }\end{array}$ & Force(N) & $\begin{array}{l}\text { Distance( } \\
\mathrm{mm} \text { ) }\end{array}$ & Force(N) & $\begin{array}{l}\text { Distance ( } \\
\mathrm{mm} \text { ) }\end{array}$ & Force(N) & $\begin{array}{l}\text { Distance( } \\
\mathrm{mm})\end{array}$ & Force(N) & $\begin{array}{l}\text { Distance( } \\
\mathrm{mm})\end{array}$ & Force $(\mathrm{N})$ \\
\hline 0.00 & $0 \quad-0.03$ & 0.00 & $\quad 0.00$ & $0 \quad 0.00$ & $\begin{array}{ll}0 & 0.00\end{array}$ & 0.00 & 0.00 & 0.00 & $0 \quad 0.00$ & 0.00 & $\begin{array}{ll}0 & 0.00\end{array}$ & 0.00 & 0.00 & 0.00 & 0.00 & $\begin{array}{ll}0 & 0.00\end{array}$ & 0.00 & 0.00 & 0.00 \\
\hline 0.00 & 0.00 & 0.00 & 0.00 & 0.00 & 0.00 & 0.00 & 0.00 & 0.00 & 0.00 & 0.00 & 0.00 & 0.00 & 0.00 & 0.00 & 0.00 & 0.00 & 0.00 & 0.00 & 0.00 \\
\hline 0.00 & 0.00 & 0.00 & 0.00 & 0.00 & 0.00 & 0.00 & 0.00 & 0.00 & 0.00 & 0.00 & 0.00 & 0.00 & 0.00 & 0.00 & 0.00 & 0.00 & 0.00 & 0.00 & 0.00 \\
\hline 0.00 & 0.00 & 0.00 & 0.00 & 0.00 & 0.00 & 0.00 & 0.00 & 0.00 & 0.00 & 0.00 & 0.00 & 0.00 & 0.00 & 0.00 & 0.00 & 0.00 & 0.00 & 0.00 & 0.00 \\
\hline 0.00 & 0.00 & 0.00 & 0.00 & 0.00 & 0.00 & 0.00 & 0.00 & 0.00 & 0.00 & 0.00 & 0.00 & 0.00 & 0.00 & 0.00 & 0.00 & 0.00 & 0.00 & 0.00 & 0.00 \\
\hline 0.10 & 0.00 & 0.05 & 0.00 & 0.00 & 0.00 & 0.10 & 0.00 & 0.10 & 0.00 & 0.10 & 0.00 & 0.10 & 0.00 & 0.10 & 0.00 & 0.10 & 0.00 & 0.10 & 0.00 \\
\hline 0.24 & 0.00 & 0.19 & 0.00 & 0.10 & 0.00 & 0.24 & 0.00 & 0.24 & 0.00 & 0.24 & 0.00 & 0.24 & 0.00 & 0.24 & 0.00 & 0.24 & 0.00 & 0.24 & 0.00 \\
\hline 0.39 & 0.00 & 0.34 & 0.00 & 0.24 & 0.00 & 0.39 & 0.00 & 0.34 & 0.00 & 0.39 & 0.00 & 0.39 & 0.00 & 0.39 & 0.00 & 0.39 & 0.00 & 0.39 & 0.00 \\
\hline 0.49 & 0.00 & 0.44 & 0.16 & 0.34 & 0.00 & 0.49 & 0.10 & 0.49 & 0.29 & 0.49 & 0.34 & 0.49 & 0.00 & 0.49 & 0.00 & 0.49 & 0.00 & 0.68 & 0.00 \\
\hline 0.63 & 0.49 & 0.58 & 0.73 & 0.49 & 0.21 & 0.63 & 0.65 & 0.63 & 0.88 & 0.63 & 1.22 & 0.63 & 0.75 & 0.63 & 0.78 & 0.63 & 0.44 & 0.63 & 0.39 \\
\hline 0.78 & 1.56 & 0.73 & 1.40 & 0.63 & 1.07 & 0.78 & 1.46 & 0.78 & 1.82 & 0.78 & 2.37 & 0.78 & 1.72 & 0.78 & 1.59 & 0.78 & 1.12 & 0.78 & 1.09 \\
\hline 0.92 & 2.65 & 0.87 & 2.55 & 0.78 & 1.95 & 0.92 & 2.58 & 0.87 & 3.20 & 0.87 & 3.33 & 0.92 & 2.84 & 0.87 & 2.42 & 0.92 & 2.42 & 0.92 & 1.87 \\
\hline 1.02 & 4.11 & 1.02 & 3.95 & 0.92 & 3.04 & 1.02 & 3.98 & 1.02 & 4.79 & 1.02 & 4.71 & 1.07 & 4.50 & 1.02 & 3.88 & 1.02 & 3.69 & 1.02 & 3.25 \\
\hline 1.12 & 6.04 & 1.12 & 6.01 & 1.07 & 4.71 & 1.16 & 6.27 & 1.16 & 6.71 & 1.16 & 7.10 & 1.16 & 6.40 & 1.16 & 5.72 & 1.16 & 5.59 & 1.21 & 5.33 \\
\hline 1.31 & 8.90 & 1.26 & 8.56 & 1.21 & 6.89 & 1.31 & 8.87 & 1.26 & 9.65 & 1.31 & 10.15 & 1.31 & 9.21 & 1.31 & 8.84 & 1.31 & 8.04 & 1.31 & 7.47 \\
\hline 1.46 & 11.26 & 1.41 & 10.69 & 1.31 & 10.09 & 1.41 & 11.06 & 1.41 & 11.78 & 1.46 & 12.02 & 1.46 & 11.58 & 1.46 & 11.00 & 1.46 & 10.54 & 1.46 & 9.96 \\
\hline 1.46 & 10.33 & 1.41 & 9.96 & 1.46 & 11.94 & 1.46 & 10.33 & 1.46 & 10.90 & 1.50 & 11.26 & 1.50 & 10.69 & 1.50 & 9.86 & 1.50 & 9.37 & 1.50 & 9.13 \\
\hline 1.41 & 6.50 & 1.36 & 6.40 & 1.50 & 11.24 & 1.46 & 6.56 & 1.41 & 7.02 & 1.41 & 7.13 & 1.41 & 7.28 & 1.41 & 5.88 & 1.46 & 5.75 & 1.46 & 5.62 \\
\hline 1.36 & 5.57 & 1.36 & 5.51 & 1.46 & 7.02 & 1.36 & 5.36 & 1.36 & 6.14 & 1.36 & 5.72 & 1.41 & 6.14 & 1.36 & 4.58 & 1.41 & 4.63 & 1.41 & 4.60 \\
\hline 1.36 & 4.84 & 1.31 & 5.07 & 1.41 & 5.31 & 1.36 & 4.76 & 1.36 & 5.41 & 1.36 & 5.07 & 1.36 & 5.72 & 1.36 & 3.69 & 1.36 & 4.24 & 1.41 & 4.16 \\
\hline 1.36 & 3.82 & 1.36 & 4.03 & 1.36 & 4.76 & 1.36 & 4.06 & 1.36 & 4.08 & 1.36 & 4.21 & 1.36 & 4.24 & 1.36 & 3.43 & 1.36 & 3.51 & 1.36 & 3.59 \\
\hline 1.31 & 3.07 & 1.31 & 3.17 & 1.36 & 4.11 & 1.31 & 3.17 & 1.31 & 3.28 & 1.31 & 3.51 & 1.31 & 3.41 & 1.36 & 3.10 & 1.36 & 2.99 & 1.36 & 3.07 \\
\hline 1.31 & 2.89 & 1.26 & 2.58 & 1.31 & 3.30 & 1.31 & 2.68 & 1.26 & 2.73 & 1.26 & 2.84 & 1.31 & 2.86 & 1.36 & 2.60 & 1.36 & 2.68 & 1.36 & 2.52 \\
\hline 1.26 & 2.45 & 1.26 & 2.03 & 1.31 & 2.73 & 1.31 & 2.08 & 1.26 & 2.50 & 1.26 & 2.45 & 1.31 & 2.42 & 1.31 & 1.72 & 1.31 & 2.06 & 1.31 & 1.82 \\
\hline 1.26 & 0.00 & 1.21 & 0.00 & 1.26 & 2.37 & 1.26 & 0.05 & 1.21 & 0.05 & 1.26 & 0.23 & 1.26 & 0.03 & 1.26 & 0.00 & 1.26 & -0.03 & 1.26 & 0.00 \\
\hline 1.12 & 0.00 & 1.07 & 0.00 & 1.26 & 0.26 & 1.12 & 0.00 & 1.12 & 0.00 & 1.12 & 0.00 & 1.12 & -0.03 & 1.12 & 0.00 & 1.16 & 0.00 & 1.16 & 0.00 \\
\hline 1.02 & 0.00 & 0.97 & 0.00 & 1.12 & 0.00 & 0.97 & 0.00 & 0.97 & 0.00 & 1.02 & 0.00 & 1.02 & 0.00 & 0.97 & 0.00 & 1.02 & 0.00 & 1.02 & 0.00 \\
\hline 0.87 & 0.00 & 0.82 & 0.00 & 1.02 & 0.00 & 0.87 & 0.00 & 0.82 & 0.00 & 0.87 & 0.00 & 0.87 & 0.00 & 0.87 & 0.00 & 0.87 & 0.00 & 0.87 & 0.00 \\
\hline 0.73 & 0.00 & 0.68 & 0.00 & 0.92 & 0.00 & 0.73 & 0.00 & 0.73 & 0.00 & 0.73 & -0.03 & 0.78 & 0.03 & 0.73 & 0.00 & 0.73 & 0.00 & 0.78 & 0.00 \\
\hline 0.58 & 0.00 & 0.53 & 0.00 & 0.78 & 0.00 & 0.58 & 0.00 & 0.58 & 0.00 & 0.58 & 0.00 & 0.63 & 0.00 & 0.63 & 0.00 & 0.58 & 0.00 & 0.63 & 0.00 \\
\hline 0.44 & 0.00 & 0.44 & 0.00 & 0.63 & 0.00 & 0.49 & 0.00 & 0.44 & 0.00 & 0.49 & 0.00 & 0.49 & 0.00 & 0.49 & 0.00 & 0.49 & 0.00 & 0.49 & 0.00 \\
\hline 0.34 & 0.00 & 0.29 & 0.00 & 0.49 & 0.00 & 0.34 & 0.00 & 0.34 & 0.00 & 0.34 & 0.00 & 0.39 & 0.00 & 0.34 & 0.00 & 0.34 & 0.00 & 0.39 & 0.00 \\
\hline 0.19 & 0.00 & 0.15 & 0.00 & 0.34 & 0.00 & 0.19 & 0.00 & 0.19 & 0.00 & 0.19 & 0.00 & 0.19 & 0.00 & 0.19 & 0.00 & 0.24 & 0.00 & 0.24 & 0.00 \\
\hline
\end{tabular}

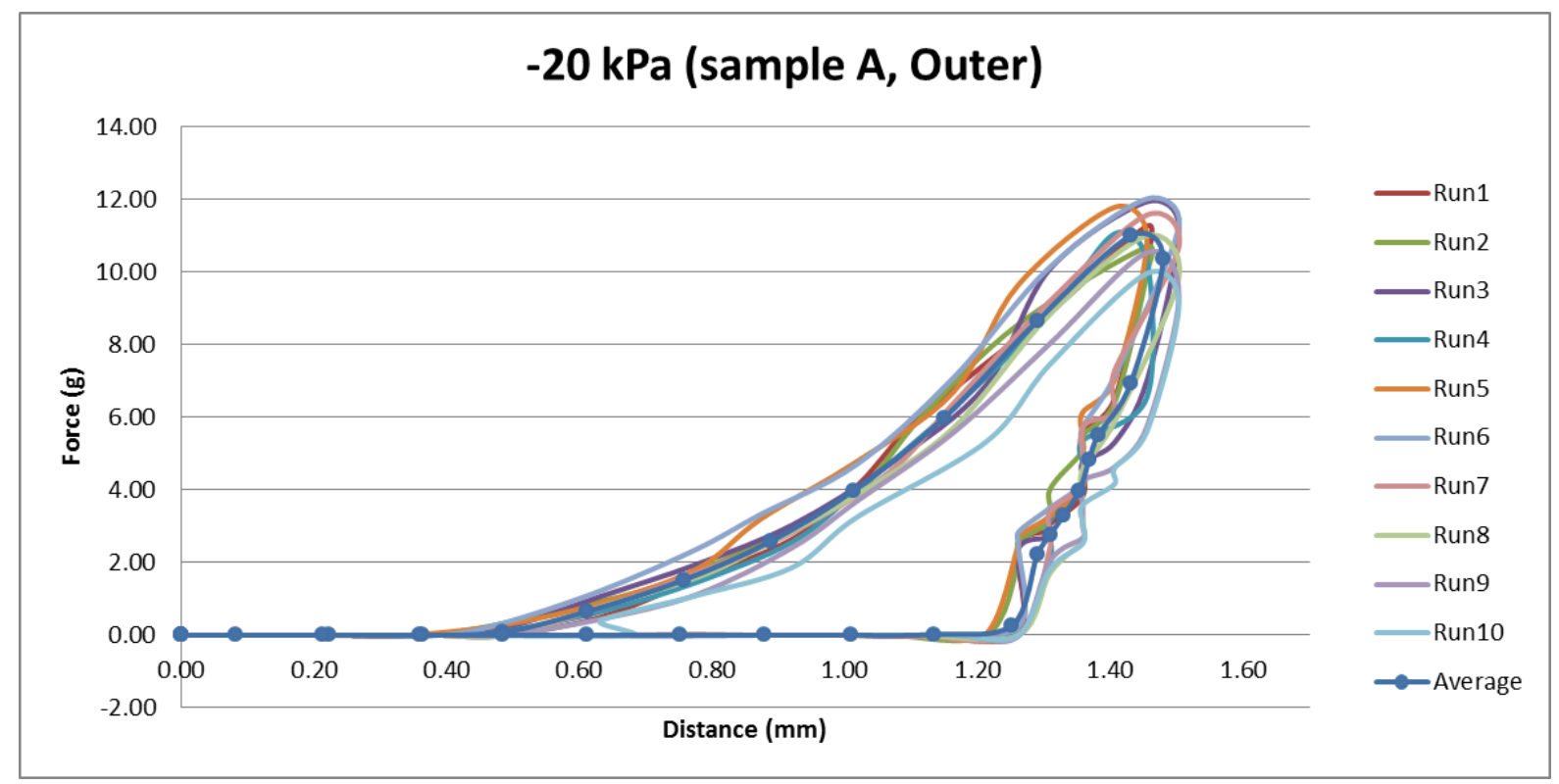




\begin{tabular}{|c|c|c|c|c|c|c|c|c|c|c|c|c|c|c|c|c|c|c|c|}
\hline \multicolumn{2}{|c|}{ Run1 } & \multicolumn{2}{|l|}{ Run2 } & \multicolumn{2}{|c|}{ Run3 } & \multicolumn{2}{|c|}{ Run4 } & \multicolumn{2}{|c|}{ Run5 } & \multicolumn{2}{|c|}{ Run6 } & \multicolumn{2}{|c|}{ Run7 } & \multicolumn{2}{|c|}{ Run8 } & \multicolumn{2}{|c|}{ Run9 } & \multicolumn{2}{|c|}{ Run10 } \\
\hline $\begin{array}{l}\text { Distance( } \\
\mathrm{mm} \text { ) }\end{array}$ & & $\begin{array}{l}\text { Distance( } \\
\mathrm{mm} \text { ) Force }\end{array}$ & & $\begin{array}{l}\text { Distance } \\
\mathrm{mm} \text { ) }\end{array}$ & Force(N) & $\begin{array}{l}\text { Distance( } \\
\mathrm{mm})\end{array}$ & Force(N) & $\begin{array}{l}\text { Distance } \\
\mathrm{mm})\end{array}$ & Force(N) & $\begin{array}{l}\text { Distance } \\
\mathrm{mm})\end{array}$ & Force(N) & $\begin{array}{l}\text { Distance( } \\
\mathrm{mm})\end{array}$ & $\operatorname{rce}(\mathrm{N})$ & $\begin{array}{l}\text { Distance( } \\
\mathrm{mm})\end{array}$ & $\operatorname{rce}(\mathrm{N})$ & $\begin{array}{l}\text { Distance( } \\
\mathrm{mm} \text { ) }\end{array}$ & orce(N) & $\begin{array}{l}\text { Distance( } \\
\mathrm{mm} \text { ) }\end{array}$ & $\operatorname{rrce}(\mathrm{N})$ \\
\hline 0.00 & 0.00 & 0.00 & 0.00 & $\begin{array}{l}0 \\
0.00\end{array}$ & 0.00 & $0 \quad 0.00$ & 0.00 & 0.00 & 0.00 & $0 \quad 0.00$ & 0.00 & $0 \quad 0.00$ & 0.00 & $0 \quad 0.00$ & 0.00 & 0.00 & 0.00 & $\quad 0.00$ & 0.00 \\
\hline 0.00 & 0.00 & 0.00 & 0.00 & 0.00 & 0.00 & 0.00 & 0.00 & 0.00 & 0.00 & 0.00 & 0.00 & 0.00 & 0.00 & 0.00 & 0.00 & 0.00 & 0.00 & 0.00 & 0.00 \\
\hline 0.00 & 0.00 & 0.000 .00 & & 0.00 & 0.00 & 0.00 & 0.00 & 0.00 & 0.00 & 0.00 & 0.00 & 0.00 & 0.00 & 0.00 & 0.00 & 0.00 & 0.00 & 0.00 & 0.00 \\
\hline 0.00 & 0.00 & 0.00 & 0.00 & 0.00 & 0.00 & 0.00 & 0.00 & 0.00 & 0.00 & 0.00 & 0.00 & 0.00 & 0.00 & 0.00 & 0.00 & 0.00 & 0.00 & 0.00 & 0.00 \\
\hline 0.00 & 0.00 & 0.00 & 0.00 & 0.00 & 0.00 & 0.05 & 0.00 & 0.00 & 0.00 & 0.00 & 0.00 & 0.00 & 0.00 & 0.00 & 0.00 & 0.00 & 0.00 & 0.00 & 0.00 \\
\hline 0.10 & 0.00 & 0.05 & 0.00 & 0.10 & 0.00 & 0.05 & 0.00 & 0.10 & 0.00 & 0.10 & 0.00 & 0.10 & 0.00 & 0.10 & 0.00 & 0.10 & 0.00 & 0.10 & 0.00 \\
\hline 0.24 & 0.00 & 0.19 & 0.00 & 0.24 & 0.00 & 0.19 & 0.00 & 0.24 & 0.00 & 0.24 & 0.00 & 0.24 & 0.00 & 0.24 & 0.00 & 0.24 & 0.00 & 0.24 & -0.03 \\
\hline 0.39 & 0.00 & 0.34 & 0.00 & 0.39 & -0.03 & 0.39 & 0.00 & 0.39 & 0.00 & 0.34 & 0.00 & 0.39 & 0.00 & 0.39 & 0.00 & 0.34 & 0.00 & 0.39 & 0.00 \\
\hline 0.49 & 0.00 & 0.44 & 0.00 & 0.49 & 0.05 & 0.49 & 0.00 & 0.49 & 0.00 & 0.49 & 0.00 & 0.49 & 0.00 & 0.49 & 0.00 & 0.49 & 0.00 & 0.49 & 0.00 \\
\hline 0.63 & 0.44 & 0.58 & 0.18 & 0.63 & 0.42 & 0.63 & 0.39 & 0.63 & 0.36 & 0.63 & 0.39 & 0.63 & 0.52 & 0.63 & 0.57 & 0.63 & 0.62 & 0.58 & 0.47 \\
\hline 0.78 & 1.40 & 0.73 & 0.94 & 0.78 & 1.33 & 0.73 & 1.20 & 0.78 & 1.22 & 0.78 & 1.12 & 0.78 & 1.27 & 0.78 & 1.09 & 0.78 & 1.25 & 0.78 & 1.14 \\
\hline 0.92 & 2.03 & 0.82 & 1.64 & 0.87 & 2.08 & 0.87 & 2.11 & 0.92 & 2.00 & 0.87 & 1.98 & 0.92 & 2.03 & 0.92 & 2.13 & 0.87 & 2.45 & 0.87 & 2.34 \\
\hline 1.02 & 3.25 & 1.02 & 2.91 & 1.02 & 3.33 & 1.02 & 3.46 & 1.07 & 3.38 & 1.02 & 3.43 & 1.07 & 3.28 & 1.02 & 3.62 & 1.02 & 3.75 & 1.02 & 3.56 \\
\hline 1.16 & 5.31 & 1.12 & 4.71 & 1.16 & 5.25 & 1.16 & 5.33 & 1.21 & 5.28 & 1.16 & 5.20 & 1.16 & 5.44 & 1.16 & 5.51 & 1.16 & 5.75 & 1.16 & 5.46 \\
\hline 1.31 & 8.30 & 1.26 & 6.84 & 1.31 & 8.19 & 1.26 & 7.88 & 1.31 & 7.86 & 1.31 & 7.80 & 1.31 & 8.06 & 1.31 & 8.14 & 1.26 & 8.35 & 1.31 & 8.14 \\
\hline 1.46 & 10.30 & 1.41 & 9.18 & 1.41 & 10.15 & 1.41 & 9.31 & 1.46 & 10.12 & 1.41 & 9.91 & 1.46 & 10.09 & 1.46 & 10.43 & 1.46 & 10.38 & 1.46 & 10.46 \\
\hline 1.50 & 9.63 & 1.46 & 8.38 & 1.46 & 9.47 & 1.46 & 8.92 & 1.50 & 9.29 & 1.50 & 9.16 & 1.50 & 9.21 & 1.46 & 9.55 & 1.46 & 9.81 & 1.50 & 9.55 \\
\hline 1.46 & 7.10 & 1.41 & 6.45 & 1.41 & 6.79 & 1.46 & 6.11 & 1.46 & 6.17 & 1.41 & 6.40 & 1.46 & 6.45 & 1.46 & 6.40 & 1.41 & 7.10 & 1.46 & 7.00 \\
\hline 1.41 & 6.17 & 1.41 & 5.88 & 1.41 & 5.80 & 1.36 & 4.86 & 1.41 & 5.20 & 1.41 & 5.31 & 1.41 & 5.23 & 1.41 & 5.20 & 1.36 & 6.17 & 1.41 & 6.04 \\
\hline 1.36 & 5.41 & 1.41 & 5.39 & 1.36 & 5.15 & 1.36 & 4.32 & 1.41 & 4.86 & 1.36 & 4.94 & 1.4 & 4.68 & 1.3 & 4.79 & 1.41 & 5.80 & 1.41 & 5.41 \\
\hline 1.41 & 3.98 & 1.36 & 3.98 & 1.36 & 4.01 & 1.36 & 3.67 & 1.41 & 3.77 & 1.36 & 3.90 & 1.41 & 3.69 & 1.36 & 3.82 & 1.36 & 4.21 & 1.41 & 4.16 \\
\hline 1.36 & 3.46 & 1.31 & 3.41 & 1.31 & 3.25 & 1.36 & 3.28 & 1.36 & 3.33 & 1.36 & 3.15 & 1.36 & 3.17 & 1.36 & 3.36 & 1.31 & 3.36 & 1.41 & 3.23 \\
\hline 1.31 & 3.04 & 1.31 & 2.91 & 1.31 & 2.97 & 1.31 & 2.68 & 1.36 & 2.58 & 1.31 & 2.58 & 1.36 & 2.86 & 1.36 & 2.60 & 1.31 & 2.86 & 1.31 & 2.89 \\
\hline 1.31 & 2.37 & 1.31 & 1.85 & 1.31 & 2.21 & 1.31 & 1.93 & 1.36 & 1.80 & 1.31 & 2.00 & 1.36 & 2.06 & 1.31 & 2.11 & 1.31 & 2.50 & 1.31 & 2.37 \\
\hline 1.26 & 0.00 & 1.21 & 0.00 & 1.26 & 0.00 & 1.26 & 0.00 & 1.26 & 0.05 & 1.21 & 0.00 & 1.26 & -0.03 & 1.26 & 0.00 & 1.26 & 0.13 & 1.26 & 0.10 \\
\hline 1.12 & 0.00 & 1.12 & 0.00 & 1.12 & 0.00 & 1.12 & 0.00 & 1.16 & -0.03 & 1.12 & 0.00 & 1.12 & 0.00 & 1.12 & 0.00 & 1.1 & 0.00 & 1.1 & 0.00 \\
\hline 1.02 & 0.00 & 0.97 & 0.0 & 1.02 & 0.00 & 1.02 & 0.00 & 1.02 & -0.03 & 0.97 & 0.00 & 1.02 & 0.00 & 1.02 & 0.00 & 1.02 & 0.00 & 1.02 & 0.00 \\
\hline 0.87 & 0.00 & 0.82 & 0.00 & 0.87 & 0.00 & 0.87 & 0.00 & 0.87 & 0.00 & 0.87 & 0.00 & 0.87 & 0.00 & 0.87 & 0.00 & 0.87 & 0.00 & 0.87 & 0.00 \\
\hline 0.78 & 0.00 & 0.73 & 0.00 & 0.78 & 0.00 & 0.73 & 0.00 & 0.73 & 0.00 & 0.73 & 0.00 & 0.73 & 0.00 & 0.73 & 0.00 & 0.73 & 0.00 & 0.73 & 0.00 \\
\hline 0.58 & 0.00 & 0.58 & 0.00 & 0.58 & 0.00 & 0.58 & 0.00 & & 0.00 & 0.58 & 0.00 & 0.63 & 0.00 & 0.63 & 0.00 & 0.63 & 0.00 & 0.58 & 0.00 \\
\hline 0.49 & 0.0 & 0. & 0. & 0. & & 0. & 0.00 & & 0.0 & 0. & 0.00 & 0.4 & 0.00 & 0.49 & 0.00 & 0.44 & 0.00 & 0.49 & 0.00 \\
\hline 0.34 & 0.00 & 0.34 & 0.00 & 0.39 & 0.00 & 0.34 & 0.00 & 0.39 & 0.00 & 0.34 & 0.00 & 0.39 & 0.00 & 0.34 & 0.00 & 0.34 & 0.00 & 0.34 & 0.00 \\
\hline 0.24 & 0.00 & 0.19 & 0.00 & 0.24 & 0.00 & 0.19 & 0.00 & 0.24 & 0.00 & 0.19 & 0.00 & 0.19 & 0.00 & 0.24 & 0.00 & 0.24 & 0.00 & 0.24 & 0.00 \\
\hline
\end{tabular}

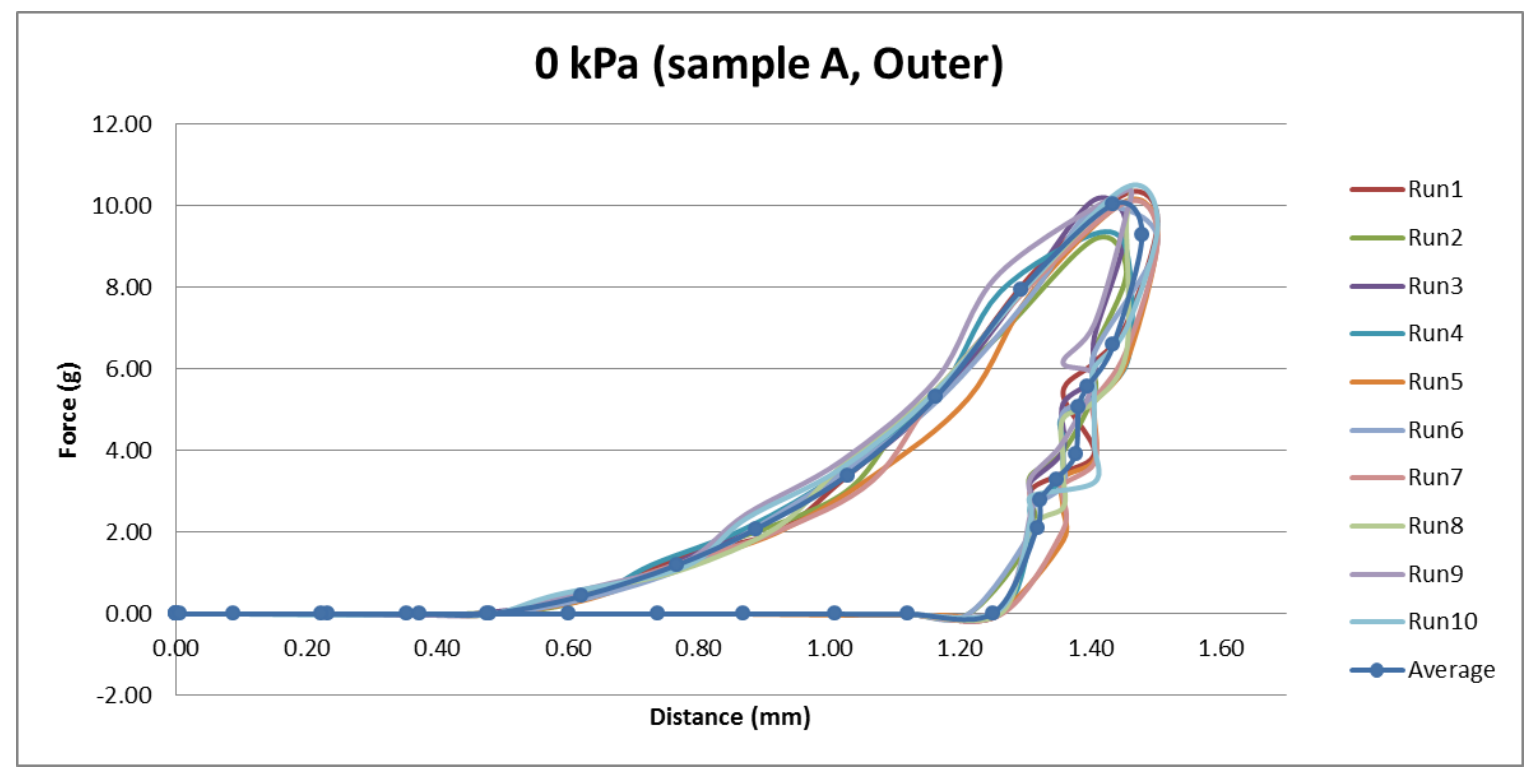




\begin{tabular}{|c|c|c|c|c|c|c|c|c|c|c|c|c|c|c|c|c|c|c|c|}
\hline & In1 & Ru & un2 & Ru & un3 & Ru & in 4 & Ru & un5 & Ru & un6 & Ru & in7 & Ru & In8 & Ru & In9 & Run & n10 \\
\hline $\begin{array}{l}\text { Distance } \\
\mathrm{mm})\end{array}$ & & $\begin{array}{l}\text { Distance } \\
\mathrm{mm} \text { ) }\end{array}$ & & $\begin{array}{l}\text { Distance( } \\
\mathrm{mm} \text { ) }\end{array}$ & & $\begin{array}{l}\text { Distance } \\
\mathrm{mm} \text { ) }\end{array}$ & & $\begin{array}{l}\text { Distance( } \\
\mathrm{mm} \text { ) }\end{array}$ & Force(N) & $\begin{array}{l}\text { Distance( } \\
\mathrm{mm} \text { ) }\end{array}$ & Force(N) & $\begin{array}{l}\text { Distance( } \\
\mathrm{mm} \text { ) }\end{array}$ & Force(N) & $\begin{array}{l}\text { Distance } \\
\mathrm{mm} \text { ) }\end{array}$ & Force(N) & $\begin{array}{l}\text { Distance } \\
\text { mm) }\end{array}$ & Force(N) & $\begin{array}{l}\begin{array}{l}\text { Distance( } \\
\mathrm{mm} \text { ) }\end{array} \\
\text { (1) }\end{array}$ & Force(N) \\
\hline 0.00 & $\quad 0.00$ & $\quad 0.00$ & 0.00 & 0.00 & 0.00 & $\quad 0.00$ & $\quad 0.00$ & 0.00 & 0.00 & $\quad 0.00$ & 0.00 & $\quad 0.00$ & 0.00 & $\begin{array}{ll}0 & 0.00\end{array}$ & 0.00 & $\begin{array}{l}0 \quad 0.00 \\
\end{array}$ & 0.00 & $\begin{array}{ll}0 & 0.00\end{array}$ & 0.00 \\
\hline 0.00 & 0.00 & 0.00 & 0.00 & 0.00 & 0.00 & 0.00 & 0.00 & 0.00 & 0.00 & 0.00 & 0.00 & 0.00 & 0.00 & 0.00 & 0.00 & 0.00 & 0.00 & 0.00 & 0.00 \\
\hline 0.00 & 0.00 & 0.00 & 0.00 & 0.00 & 0.00 & 0.00 & 0.00 & 0.00 & 0.00 & 0.00 & 0.00 & 0.00 & 0.00 & 0.00 & 0.00 & 0.00 & 0.00 & 0.00 & 0.00 \\
\hline 0.00 & 0.00 & 0.00 & 0.00 & 0.00 & 0.00 & 0.00 & 0.00 & 0.00 & 0.00 & 0.00 & 0.00 & 0.00 & 0.00 & 0.00 & 0.00 & 0.00 & 0.00 & 0.00 & 0.00 \\
\hline 0.00 & $\quad 0.00$ & 0.00 & 0.00 & 0.00 & 0.00 & 0.00 & 0.00 & 0.00 & 0.00 & 0.00 & 0.00 & 0.00 & 0.00 & 0.00 & 0.00 & 0.00 & 0.00 & 0.00 & 0.00 \\
\hline 0.10 & 0.00 & 0.10 & 0.00 & 0.10 & 0.00 & 0.10 & 0.00 & 0.10 & 0.00 & 0.10 & 0.00 & 0.10 & 0.00 & 0.05 & 0.00 & 0.10 & 0.00 & 0.10 & 0.00 \\
\hline 0.24 & 0.00 & 0.24 & 0.00 & 0.24 & 0.00 & 0.24 & 0.00 & 0.24 & 0.00 & 0.24 & 0.00 & 0.19 & 0.00 & 0.19 & 0.00 & 0.19 & 0.00 & 0.19 & 0.00 \\
\hline 0.34 & 0.00 & 0.39 & 0.00 & 0.34 & 0.00 & 0.34 & 0.00 & 0.39 & 0.00 & 0.39 & 0.00 & 0.39 & 0.00 & 0.29 & 0.00 & 0.34 & 0.00 & 0.34 & 0.00 \\
\hline 0.49 & 0.00 & 0.49 & 0.00 & 0.49 & 0.00 & 0.49 & 0.00 & 0.49 & 0.00 & 0.49 & 0.00 & 0.49 & 0.00 & 0.49 & 0.00 & 0.49 & 0.13 & 0.44 & 0.00 \\
\hline 0.63 & 0.00 & 0.63 & 0.39 & 0.63 & 0.36 & 0.63 & 0.26 & 0.63 & 0.31 & 0.63 & 0.39 & 0.63 & 0.44 & 0.58 & 0.52 & 0.63 & 0.55 & 0.58 & 0.52 \\
\hline 0.78 & 0.73 & 0.73 & 0.75 & 0.78 & 1.17 & 0.78 & 0.91 & 0.78 & 0.96 & 0.78 & 0.62 & 0.73 & 1.09 & 0.73 & 1.17 & 0.73 & 1.20 & 0.73 & 1.17 \\
\hline 0.87 & 1.48 & 0.87 & 1.66 & 0.92 & 2.00 & 0.87 & 1.87 & 0.92 & 1.93 & 0.87 & 1.64 & 0.87 & 2.21 & 0.87 & 2.00 & 0.87 & 2.16 & 0.87 & 1.95 \\
\hline 1.02 & 2.86 & 1.02 & 2.86 & 1.02 & 2.99 & 1.02 & 3.12 & 1.02 & 3.23 & 1.02 & 2.94 & 1.02 & 3.56 & 1.02 & 3.20 & 1.02 & 3.30 & 1.02 & 3.23 \\
\hline 1.16 & 4.58 & 1.16 & 4.63 & 1.16 & 4.89 & 1.16 & 4.89 & 1.16 & 4.81 & 1.16 & 4.55 & 1.16 & 5.25 & 1.16 & 5.05 & 1.12 & 5.20 & 1.16 & 4.81 \\
\hline 1.31 & 6.95 & 1.31 & 7.15 & 1.31 & 7.60 & 1.31 & 7.10 & 1.31 & 7.26 & 1.31 & 6.89 & 1.31 & 7.93 & 1.26 & 7.65 & 1.26 & 7.78 & 1.26 & 7.39 \\
\hline 1.41 & 8.90 & 1.46 & 9.26 & 1.46 & 9.50 & 1.46 & 9.08 & 1.46 & 9.18 & 1.41 & 8.77 & 1.41 & 9.86 & 1.46 & 9.65 & 1.46 & 9.65 & 1.41 & 9.16 \\
\hline 1.50 & 8.43 & 1.46 & 8.43 & 1.50 & 8.66 & 1.50 & 8.48 & 1.50 & 8.69 & 1.46 & 8.06 & 1.50 & 9.44 & 1.51 & 8.97 & 1.46 & 8.95 & 1.46 & 8.71 \\
\hline 1.46 & 6.71 & 1.46 & 5.96 & 1.46 & 6.35 & 1.41 & 5.98 & 1.46 & 6.27 & 1.46 & 5.98 & 1.46 & 6.37 & 1.41 & 6.53 & 1.41 & 6.50 & 1.46 & 6.50 \\
\hline 1.41 & 5.54 & 1.41 & 5.10 & 1.41 & 5.15 & 1.41 & 4.92 & 1.41 & 5.39 & 1.41 & 5.05 & 1.41 & 5.33 & 1.38 & 5.62 & 1.41 & 5.72 & 1.41 & 5.59 \\
\hline 1.41 & 4.94 & 1.41 & 4.40 & 1.36 & 4.34 & 1.36 & 4.37 & 1.41 & 4.79 & 1.41 & 4.34 & 1.41 & 4.89 & 1.38 & 5.02 & 1.41 & 5.15 & 1.41 & 4.97 \\
\hline 1.41 & 3.82 & 1.36 & 3.64 & 1.36 & 3.59 & 1.36 & 3.62 & 1.41 & 3.88 & 1.36 & 3.88 & 1.36 & 4.19 & 1.38 & 4.08 & 1.41 & 4.11 & 1.41 & 4.01 \\
\hline 1.36 & 3.41 & 1.36 & 3.36 & 1.36 & 3.25 & 1.31 & 3.04 & 1.36 & 3.41 & 1.36 & 3.28 & 1.36 & 3.54 & 1.31 & 3.51 & 1.31 & 3.46 & 1.36 & 3.51 \\
\hline 1.31 & 2.73 & 1.31 & 2.81 & 1.31 & 2.89 & 1.31 & 2.78 & 1.36 & 2.78 & 1.36 & 2.91 & 1.31 & 3.10 & 1.31 & 3.17 & 1.31 & 3.10 & 1.36 & 3.10 \\
\hline 1.31 & 1.90 & 1.31 & 1.90 & 1.31 & 2.13 & 1.31 & 2.00 & 1.31 & 2.11 & 1.31 & 1.87 & 1.31 & 2.29 & 1.31 & 2.34 & 1.31 & 2.34 & 1.31 & 2.29 \\
\hline 1.26 & 0.00 & 1.26 & 0.08 & 1.26 & 0.00 & 1.26 & 0.00 & 1.26 & 0.16 & 1.26 & 0.00 & 1.21 & 0.42 & 1.26 & 0.21 & 1.26 & 0.31 & 1.21 & 0.23 \\
\hline 1.12 & 0.00 & 1.16 & 0.00 & 1.12 & 0.03 & 1.07 & 0.00 & 1.12 & 0.00 & 1.12 & 0.00 & 1.12 & 0.00 & 1.12 & 0.00 & 1.12 & 0.00 & 1.16 & 0.00 \\
\hline 1.02 & 0.00 & 1.02 & 0.00 & 1.02 & 0.00 & 1.02 & 0.00 & 0.97 & 0.00 & 1.02 & 0.00 & 0.97 & 0.00 & 0.97 & 0.00 & 1.02 & 0.00 & 0.97 & -0.03 \\
\hline 0.87 & 0.00 & 0.87 & 0.00 & 0.87 & 0.00 & 0.87 & 0.00 & 0.87 & 0.00 & 0.87 & 0.00 & 0.87 & 0.00 & 0.82 & 0.00 & 0.87 & 0.00 & 0.87 & 0.00 \\
\hline 0.78 & 0.00 & 0.73 & 0.00 & 0.78 & 0.00 & 0.73 & 0.00 & 0.73 & 0.00 & 0.73 & 0.00 & 0.78 & 0.00 & 0.73 & 0.00 & 0.73 & 0.00 & 0.73 & 0.00 \\
\hline 0.58 & 0.00 & 0.63 & 0.00 & 0.63 & 0.00 & 0.58 & 0.03 & 0.63 & 0.00 & 0.63 & 0.00 & 0.58 & 0.00 & 0.58 & 0.00 & 0.58 & 0.00 & 0.58 & 0.00 \\
\hline 0.49 & 0.00 & 0.49 & 0.00 & 0.49 & 0.00 & 0.49 & 0.00 & 0.49 & 0.00 & 0.49 & 0.00 & 0.49 & 0.00 & 0.49 & 0.00 & 0.49 & 0.00 & 0.49 & 0.00 \\
\hline 0.34 & 0.03 & 0.39 & 0.00 & 0.34 & 0.00 & 0.34 & 0.00 & 0.34 & 0.00 & 0.34 & 0.00 & 0.34 & 0.00 & 0.34 & 0.00 & 0.34 & 0.00 & 0.34 & 0.00 \\
\hline 0.24 & 0.00 & 0.24 & 0.00 & 0.24 & 0.00 & 0.24 & 0.00 & 0.24 & 0.00 & 0.19 & 0.00 & 0.19 & 0.00 & 0.19 & 0.00 & 0.19 & 0.00 & 0.19 & 0.00 \\
\hline
\end{tabular}

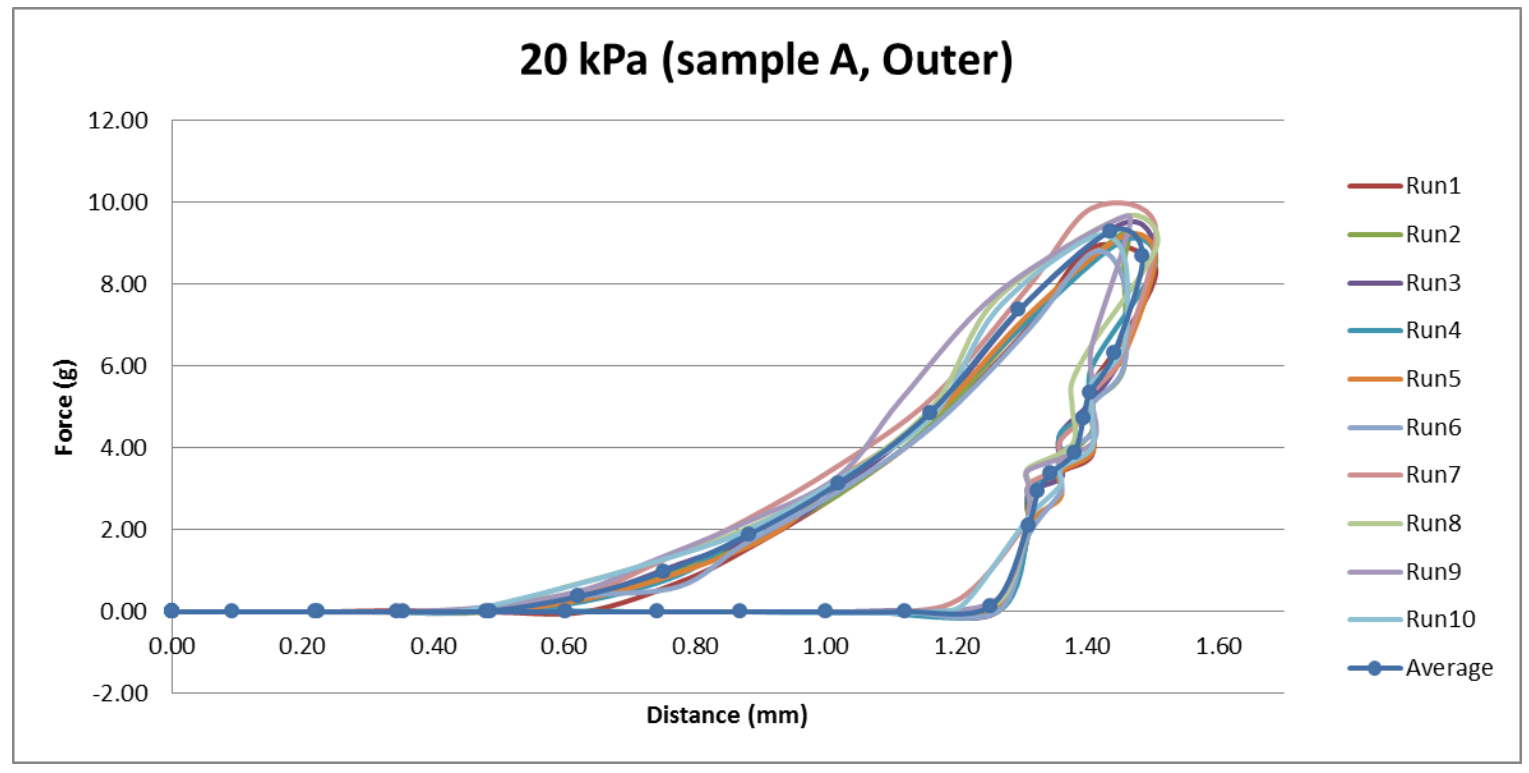




\begin{tabular}{|c|c|c|c|c|c|c|c|c|c|c|c|c|c|c|c|c|c|c|c|}
\hline Run & & Run & un2 & Rut & $\ln 3$ & & un 4 & & un5 & & un6 & Run & In7 & Run & & Run & in9 & Run1 & $\mathrm{n} 10$ \\
\hline $\begin{array}{l}\text { Distance( } \\
\mathrm{mm} \text { ) }\end{array}$ & & $\begin{array}{l}\text { Distance( } \\
\mathrm{mm} \text { ) }\end{array}$ & & $\begin{array}{l}\text { Distance( } \\
\mathrm{mm} \text { ) }\end{array}$ & & $\begin{array}{l}\text { Distance( } \\
\mathrm{mm} \text { ) }\end{array}$ & Force(N) & $\begin{array}{l}\text { Distance( } \\
\mathrm{mm} \text { ) }\end{array}$ & Force(N) & $\begin{array}{l}\text { Distance( } \\
\mathrm{mm} \text { ) }\end{array}$ & $\mathrm{D}$ & $\begin{array}{l}\text { Distance( } \\
\mathrm{mm} \text { ) }\end{array}$ & Force(N) & $\begin{array}{l}\text { Distance( } \\
\mathrm{mm} \text { ) }\end{array}$ & Force(N) & $\begin{array}{l}\text { Distance( } \\
\mathrm{mm})\end{array}$ & $\operatorname{rce}(\mathrm{N})$ & $\begin{array}{l}\text { Distancel } \\
\mathrm{mm} \text { ) }\end{array}$ & Force(N) \\
\hline $0.00^{\mathrm{F}}$ & $\quad 0.00$ & $0 \quad 0.00$ & 0.00 & 0.00 & 0.00 & $0^{m m)} 0.00$ & $0_{0}^{\text {Force }(\mathrm{N})}$ & $0^{m(m)} \quad 0.00$ & $0 \quad 0.00$ & 0.00 & 0.00 & 0.00 & 0.00 & 0.00 & 0.00 & 0.00 & 0.00 & mm) $0.00^{\mathrm{F}}$ & $\begin{array}{l}\text { Force(N) } \\
\quad 0.00\end{array}$ \\
\hline 0.00 & 0.00 & 0.00 & 0.00 & 0.00 & 0.00 & 0.00 & 0.00 & 0.00 & 0.00 & 0.00 & 0.00 & 0.00 & 0.00 & 0.00 & 0.00 & 0.00 & 0.00 & 0.00 & 0.00 \\
\hline 0.00 & 0.00 & 0.00 & 0.00 & 0.00 & 0.00 & 0.00 & 0.00 & 0.00 & 0.00 & 0.00 & 0.00 & 0.00 & 0.00 & 0.00 & 0.00 & 0.00 & 0.00 & 0.00 & 0.00 \\
\hline 0.00 & 0.00 & 0.00 & 0.00 & 0.00 & 0.00 & 0.00 & -0.02 & 0.00 & 0.00 & 0.00 & 0.00 & 0.00 & 0.00 & 0.00 & -0.02 & 0.00 & 0.00 & 0.00 & 0.00 \\
\hline 0.00 & 0.00 & 0.00 & 0.00 & 0.00 & 0.00 & 0.00 & 0.00 & 0.00 & 0.00 & 0.00 & 0.00 & 0.00 & 0.00 & 0.00 & -0.02 & 0.00 & 0.00 & 0.00 & 0.00 \\
\hline 0.05 & 0.00 & 0.10 & 0.00 & 0.10 & 0.00 & 0.10 & 0.00 & 0.10 & 0.00 & 0.10 & 0.00 & 0.10 & 0.00 & 0.10 & -0.02 & 0.10 & 0.00 & 0.10 & 0.00 \\
\hline 0.24 & 0.00 & 0.24 & 0.08 & 0.24 & -0.02 & 0.24 & 0.00 & 0.24 & 0.00 & 0.24 & 0.14 & 0.24 & 0.00 & 0.24 & 0.14 & 0.24 & 0.06 & 0.24 & 0.00 \\
\hline 0.34 & 0.35 & 0.39 & 0.60 & 0.39 & 0.39 & 0.39 & 0.33 & 0.34 & 0.29 & 0.34 & 0.64 & 0.39 & 0.35 & 0.39 & 0.70 & 0.34 & 0.59 & 0.39 & 0.35 \\
\hline 0.49 & 0.96 & 0.49 & 1.27 & 0.49 & 1.00 & 0.53 & 0.88 & 0.49 & 0.90 & 0.49 & 1.21 & 0.49 & 0.86 & 0.49 & 1.29 & 0.49 & 1.19 & 0.49 & 0.80 \\
\hline 0.63 & 1.64 & 0.63 & 2.15 & 0.63 & 1.78 & 0.63 & 1.60 & 0.63 & 1.54 & 0.63 & 2.07 & 0.63 & 1.56 & 0.63 & 2.11 & 0.63 & 2.03 & 0.63 & 1.56 \\
\hline 0.78 & 2.59 & 0.78 & 3.00 & 0.78 & 2.75 & 0.78 & 2.56 & 0.78 & 2.58 & 0.78 & 3.12 & 0.78 & 2.67 & 0.78 & 3.12 & 0.78 & 3.10 & 0.78 & 2.54 \\
\hline 0.92 & 3.88 & 0.92 & 4.25 & 0.92 & 4.02 & 0.92 & 3.65 & 0.92 & 3.71 & 0.92 & 4.41 & 0.92 & 3.79 & 0.92 & 4.19 & 0.87 & 4.31 & 0.92 & 3.63 \\
\hline 1.02 & 5.44 & 1.02 & 5.81 & 1.07 & 5.58 & 1.07 & 5.05 & 1.02 & 5.07 & 1.02 & 5.85 & 1.07 & 5.19 & 1.02 & 5.74 & 1.02 & 5.91 & 1.02 & 5.09 \\
\hline 1.16 & 7.28 & 1.16 & 7.65 & 1.16 & 7.39 & 1.16 & 6.81 & 1.16 & 6.95 & 1.16 & 7.49 & 1.16 & 7.04 & 1.16 & 7.57 & 1.16 & 7.65 & 1.16 & 6.83 \\
\hline 1.31 & 10.01 & 1.31 & 10.55 & 1.31 & 10.16 & 1.31 & 9.43 & 1.31 & 9.72 & 1.31 & 10.26 & 1.31 & 9.99 & 1.31 & 10.47 & 1.31 & 10.59 & 1.31 & 9.53 \\
\hline 1.41 & 12.29 & 1.46 & 13.05 & 1.46 & 12.52 & 1.46 & 11.70 & 1.46 & 12.12 & 1.46 & 12.36 & 1.46 & 12.45 & 1.46 & 12.76 & 1.46 & 12.52 & 1.46 & 11.92 \\
\hline 1.46 & 11.61 & 1.50 & 12.23 & 1.50 & 11.74 & 1.50 & 11.26 & 1.50 & 11.23 & 1.50 & 11.92 & 1.50 & 11.90 & 1.50 & 11.98 & 1.50 & 11.94 & 1.50 & 11.08 \\
\hline 1.41 & 6.87 & 1.46 & 7.35 & 1.46 & 6.78 & 1.46 & 6.51 & 1.46 & 6.85 & 1.46 & 7.20 & 1.46 & 7.20 & 1.46 & 7.37 & 1.46 & 7.39 & 1.41 & 6.72 \\
\hline 1.31 & 4.81 & 1.36 & 4.81 & 1.36 & 4.83 & 1.36 & 4.62 & 1.36 & 4.60 & 1.36 & 4.66 & 1.36 & 4.68 & 1.36 & 4.87 & 1.36 & 4.91 & 1.36 & 4.77 \\
\hline 1.31 & 4.06 & 1.31 & 4.22 & 1.31 & 4.20 & 1.31 & 4.18 & 1.31 & 4.04 & 1.31 & 4.12 & 1.31 & 4.06 & 1.31 & 4.14 & 1.31 & 4.27 & 1.31 & 4.16 \\
\hline 1.26 & 3.73 & 1.26 & 3.95 & 1.31 & 3.89 & 1.31 & 3.83 & 1.31 & 3.89 & 1.26 & 3.79 & 1.31 & 3.79 & 1.31 & 3.95 & 1.26 & 4.04 & 1.31 & 3.89 \\
\hline 1.26 & 3.50 & 1.26 & 3.58 & 1.26 & 3.54 & 1.31 & 3.50 & 1.26 & 3.52 & 1.26 & 3.52 & 1.26 & 3.48 & 1.26 & 3.66 & 1.26 & 3.60 & 1.26 & 3.58 \\
\hline 1.21 & 3.33 & 1.26 & 3.43 & 1.26 & 3.31 & 1.26 & 3.25 & 1.26 & 3.29 & 1.26 & 3.23 & 1.26 & 3.27 & 1.26 & 3.39 & 1.26 & 3.31 & 1.26 & 3.48 \\
\hline 1.21 & 2.93 & 1.26 & 3.12 & 1.26 & 3.00 & 1.26 & 3.12 & 1.26 & 3.04 & 1.26 & 2.96 & 1.26 & 3.06 & 1.26 & 2.91 & 1.21 & 3.04 & 1.26 & 3.00 \\
\hline 1.21 & 1.87 & 1.26 & 1.96 & 1.26 & 1.73 & 1.26 & 1.66 & 1.26 & 1.66 & 1.21 & 2.14 & 1.26 & 2.00 & 1.21 & 2.00 & 1.21 & 1.89 & 1.26 & 1.66 \\
\hline 1.12 & 0.42 & 1.12 & 0.65 & 1.12 & 0.37 & 1.12 & 0.35 & 1.12 & 0.54 & 1.16 & 0.75 & 1.12 & 0.54 & 1.12 & 0.60 & 1.12 & 0.73 & 1.12 & 0.50 \\
\hline 0.97 & 0.00 & 1.02 & 0.00 & 1.06 & 0.00 & 0.97 & 0.00 & 1.02 & 0.00 & 1.02 & 0.00 & 1.02 & 0.00 & 1.02 & 0.00 & 1.02 & 0.00 & 1.02 & 0.00 \\
\hline 0.87 & 0.00 & 0.87 & 0.00 & 0.87 & 0.00 & 0.87 & 0.00 & 0.87 & 0.00 & 0.92 & 0.00 & 0.87 & 0.00 & 0.87 & 0.00 & 0.87 & -0.02 & 0.87 & 0.00 \\
\hline 0.73 & 0.00 & 0.73 & 0.00 & 0.78 & 0.00 & 0.73 & 0.00 & 0.73 & 0.00 & 0.78 & 0.00 & 0.73 & -0.02 & 0.73 & 0.00 & 0.73 & -0.02 & 0.73 & 0.00 \\
\hline 0.58 & 0.00 & 0.63 & 0.0 & 0.63 & 0.0 & 0.63 & 0.00 & 0.58 & 0.00 & 0.63 & 0.00 & 0.63 & 0.00 & 0.63 & 0.00 & 0.58 & 0.00 & 0.58 & 0.00 \\
\hline 0.44 & 0.00 & 0.49 & 0.00 & 0.49 & 0.00 & 0.49 & 0.00 & 0.49 & 0.00 & 0.49 & 0.00 & 0.49 & 0.00 & 0.49 & 0.02 & 0.49 & 0.00 & 0.49 & 0.02 \\
\hline 0.24 & 0.00 & 0.34 & 0.00 & 0.39 & 0.00 & 0.34 & 0.00 & 0.34 & 0.00 & 0.39 & 0.00 & 0.39 & 0.00 & 0.39 & 0.00 & 0.34 & 0.00 & 0.34 & 0.00 \\
\hline 0.19 & 0.00 & 0.24 & 0.00 & 0.24 & 0.00 & 0.19 & 0.00 & 0.24 & 0.00 & 0.19 & 0.00 & 0.19 & 0.00 & 0.24 & 0.00 & 0.19 & 0.00 & 0.19 & 0.00 \\
\hline
\end{tabular}

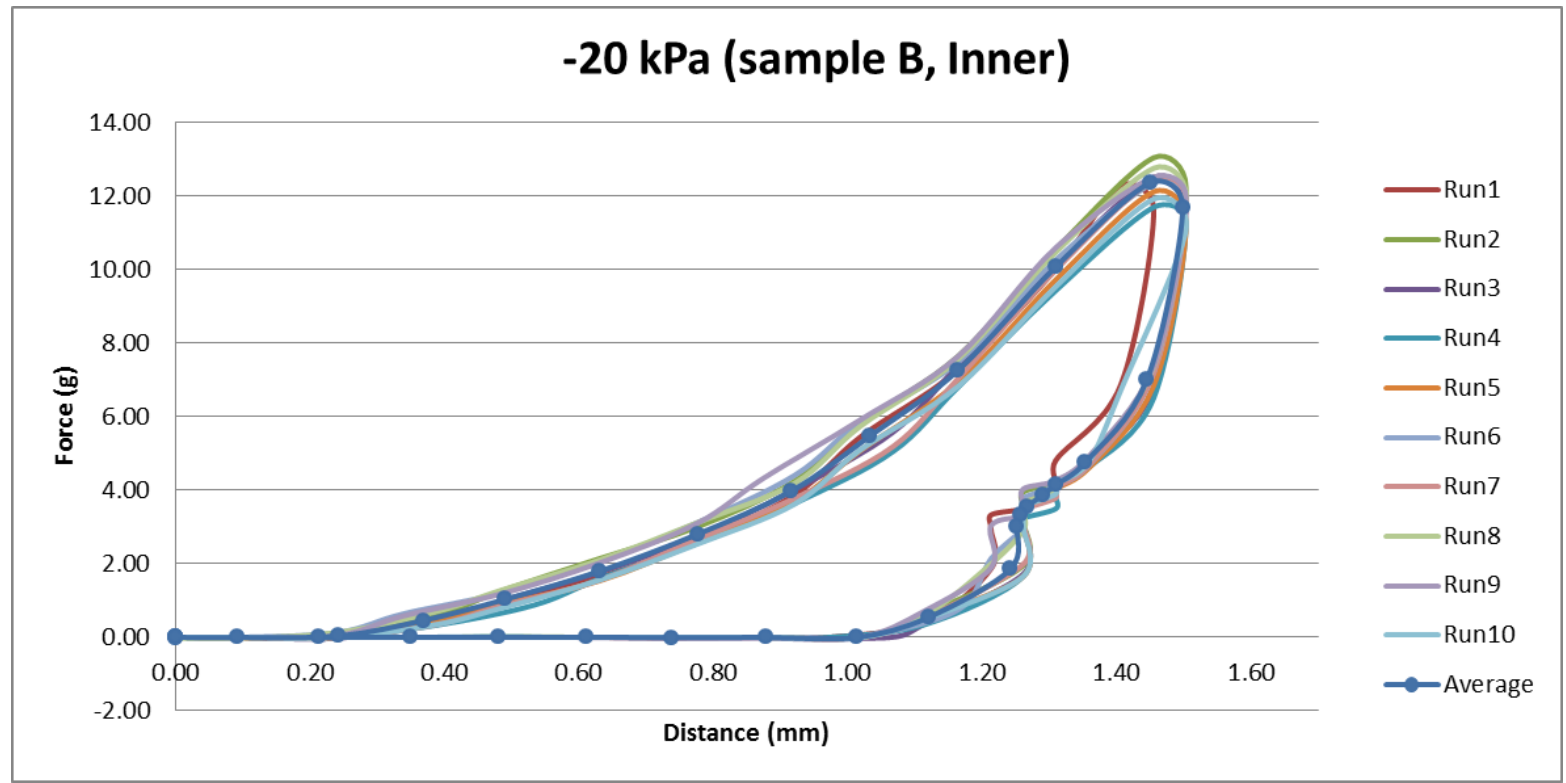




\begin{tabular}{|c|c|c|c|c|c|c|c|c|c|c|c|c|c|c|c|c|c|c|c|}
\hline Run & & Run & In2 & Run & in 3 & Rur & In 4 & & un5 & $\mathrm{Ru}$ & un6 & Ru & in7 & Rur & & Run & in9 & Run & n10 \\
\hline $\begin{array}{l}\text { Distance( } \\
\mathrm{mm})\end{array}$ & Force(N) & $\begin{array}{l}\text { Distance( } \\
\mathrm{mm} \text { ) }\end{array}$ & Force $(\mathrm{N})$ & $\begin{array}{l}\text { Distance( } \\
\mathrm{mm})\end{array}$ & Force(N) & $\begin{array}{l}\text { Distance( } \\
\mathrm{mm} \text { ) }\end{array}$ & Force(N) & $\begin{array}{l}\text { Distance( } \\
\mathrm{mm} \text { ) }\end{array}$ & Force(N) & $\begin{array}{l}\text { Distance( } \\
\mathrm{mm} \text { ) }\end{array}$ & Force(N) & $\begin{array}{l}\text { Distance( } \\
\mathrm{mm} \text { ) }\end{array}$ & Force(N) & $\begin{array}{l}\text { Distance( } \\
\mathrm{mm} \text { ) }\end{array}$ & Force(N) & $\begin{array}{l}\text { Distance( } \\
\mathrm{mm} \text { ) }\end{array}$ & Force(N) & $\begin{array}{l}\text { Distance( } \\
\mathrm{mm} \text { ) }\end{array}$ & Force(N) \\
\hline 0.00 & 0.00 & 0.00 & 0.00 & 0.00 & 0.00 & 0.00 & 0.00 & 0.00 & $\begin{array}{l}0 \\
0\end{array}$ & 0.00 & 0.00 & 0.00 & 0.00 & 0.00 & 0.00 & 0.00 & 0.00 & 0.00 & 0.00 \\
\hline 0.00 & 0.00 & 0.00 & 0.00 & 0.00 & 0.00 & 0.00 & 0.00 & 0.00 & 0.00 & 0.00 & 0.00 & 0.00 & 0.00 & 0.00 & 0.00 & 0.00 & 0.00 & 0.00 & 0.00 \\
\hline 0.00 & 0.00 & 0.00 & 0.00 & 0.00 & 0.00 & 0.00 & 0.00 & 0.00 & 0.00 & 0.00 & 0.00 & 0.00 & 0.00 & 0.00 & 0.00 & 0.00 & 0.00 & 0.00 & 0.00 \\
\hline 0.000 & 0.00 & 0.00 & 0.00 & 0.00 & 0.00 & 0.00 & 0.00 & 0.00 & 0.00 & 0.00 & 0.00 & 0.00 & 0.00 & 0.00 & 0.00 & 0.00 & 0.00 & 0.00 & 0.00 \\
\hline 0.00 & 0.00 & 0.00 & 0.00 & 0.00 & 0.00 & 0.00 & 0.00 & 0.00 & 0.00 & 0.00 & 0.00 & 0.00 & 0.00 & 0.00 & 0.00 & 0.00 & 0.00 & 0.00 & 0.00 \\
\hline 0.10 & 0.00 & 0.10 & 0.00 & 0.10 & 0.03 & 0.10 & 0.00 & 0.10 & 0.00 & 0.10 & 0.00 & 0.10 & 0.00 & 0.10 & 0.00 & 0.10 & 0.00 & 0.10 & 0.00 \\
\hline 0.24 & 0.00 & 0.24 & 0.00 & 0.24 & 0.00 & 0.24 & 0.00 & 0.24 & 0.00 & 0.24 & 0.00 & 0.19 & 0.00 & 0.24 & 0.00 & 0.24 & 0.00 & 0.24 & 0.00 \\
\hline 0.39 & 0.00 & 0.39 & 0.00 & 0.39 & 0.00 & 0.39 & 0.00 & 0.39 & 0.00 & 0.39 & 0.00 & 0.39 & 0.00 & 0.39 & 0.00 & 0.39 & 0.00 & 0.39 & 0.00 \\
\hline 0.49 & 0.00 & 0.49 & 0.00 & 0.49 & 0.00 & 0.49 & 0.00 & 0.49 & 0.00 & 0.49 & 0.00 & 0.49 & 0.00 & 0.49 & 0.00 & 0.49 & 0.00 & 0.49 & 0.00 \\
\hline 0.68 & 0.49 & 0.63 & 0.52 & 0.63 & 0.47 & 0.63 & 0.44 & 0.63 & 0.36 & 0.63 & 0.00 & 0.63 & 0.44 & 0.63 & 0.47 & 0.63 & 0.39 & 0.63 & 0.42 \\
\hline 0.78 & 1.30 & 0.78 & 1.20 & 0.78 & 1.27 & 0.78 & 1.35 & 0.78 & 1.20 & 0.78 & 0.49 & 0.78 & 1.17 & 0.78 & 1.30 & 0.78 & 1.12 & 0.78 & 1.38 \\
\hline 0.92 & 2.55 & 0.92 & 2.24 & 0.92 & 2.52 & 0.92 & 2.37 & 0.92 & 2.24 & 0.87 & 1.74 & 0.87 & 2.21 & 0.87 & 2.26 & 0.92 & 2.16 & 0.87 & 2.34 \\
\hline 1.07 & 4.01 & 1.02 & 3.67 & 1.07 & 4.06 & 1.07 & 3.88 & 1.02 & 3.64 & 1.07 & 3.36 & 1.07 & 3.64 & 1.02 & 3.69 & 1.02 & 3.59 & 1.02 & 3.59 \\
\hline 1.16 & 5.83 & 1.16 & 5.67 & 1.16 & 6.11 & 1.16 & 5.83 & 1.16 & 5.78 & 1.16 & 5.62 & 1.16 & 5.51 & 1.16 & 5.51 & 1.16 & 5.57 & 1.16 & 5.59 \\
\hline 1.31 & 8.53 & 1.31 & 8.30 & 1.31 & 8.82 & 1.31 & 8.53 & 1.31 & 8.56 & 1.31 & 8.82 & 1.31 & 8.27 & 1.31 & 8.30 & 1.31 & 8.32 & 1.31 & 8.14 \\
\hline 1.46 & 10.59 & 1.46 & 10.25 & 1.46 & 11.00 & 1.46 & 10.74 & 1.46 & 10.51 & 1.46 & 11.19 & 1.46 & 10.48 & 1.41 & 10.28 & 1.46 & 10.46 & 1.46 & 10.30 \\
\hline 1.50 & 9.76 & 1.50 & 9.44 & 1.50 & 10.02 & 1.50 & 9.81 & 1.46 & 9.83 & 1.50 & 10.25 & 1.50 & 9.76 & 1.50 & 9.78 & 1.50 & 9.91 & 1.46 & 9.55 \\
\hline 1.46 & 6.06 & 1.46 & 5.98 & 1.46 & 5.98 & 1.46 & 6.14 & 1.46 & 5.93 & 1.46 & 6.01 & 1.46 & 6.06 & 1.46 & 6.14 & 1.41 & 6.01 & 1.41 & 6.61 \\
\hline 1.36 & 4.63 & 1.36 & 4.81 & 1.36 & 4.92 & 1.41 & 4.84 & 1.36 & 4.68 & 1.36 & 4.89 & 1.36 & 4.68 & 1.36 & 4.89 & 1.41 & 4.92 & 1.41 & 5.49 \\
\hline 1.36 & 4.16 & 1.36 & 4.27 & 1.36 & 4.24 & 1.36 & 4.34 & 1.36 & 4.16 & 1.31 & 4.24 & 1.36 & 4.06 & 1.36 & 4.32 & 1.36 & 4.45 & 1.36 & 4.92 \\
\hline 1.36 & 3.93 & 1.36 & 3.75 & 1.36 & 3.69 & 1.31 & 3.82 & 1.31 & 3.69 & 1.31 & 3.77 & 1.31 & 3.75 & 1.31 & 3.80 & 1.36 & 3.77 & 1.36 & 4.08 \\
\hline 1.31 & 3.15 & 1.31 & 3.20 & 1.31 & 3.23 & 1.31 & 3.17 & 1.31 & 3.25 & 1.31 & 3.12 & 1.31 & 3.25 & 1.31 & 3.20 & 1.31 & 3.23 & 1.31 & 3.41 \\
\hline 1.31 & 2.84 & 1.31 & 2.73 & 1.31 & 3.02 & 1.31 & 2.91 & 1.31 & 2.84 & 1.26 & 2.89 & 1.31 & 2.89 & 1.31 & 2.89 & 1.31 & 2.91 & 1.31 & 2.89 \\
\hline 1.31 & 2.55 & 1.31 & 2.45 & 1.31 & 2.55 & 1.31 & 2.63 & 1.26 & 2.55 & 1.26 & 2.71 & 1.26 & 2.52 & 1.26 & 2.63 & 1.31 & 2.58 & 1.26 & 2.45 \\
\hline 1.26 & 1.01 & 1.26 & 0.78 & 1.26 & 0.83 & 1.26 & 0.81 & 1.26 & 0.88 & 1.26 & 0.78 & 1.26 & 0.81 & 1.26 & 0.86 & 1.26 & 0.83 & 1.26 & 0.83 \\
\hline 1.12 & $\begin{array}{r}1.01 \\
-0.03\end{array}$ & 1.16 & 0.00 & 1.12 & 0.00 & 1.16 & 0.00 & 1.12 & 0.00 & 1.12 & 0.00 & 1.12 & 0.00 & 1.16 & 0.00 & 1.12 & 0.00 & 1.12 & 0.00 \\
\hline 1.02 & 0.00 & 1.02 & 0.00 & 1.02 & 0.00 & 1.02 & 0.00 & 1.02 & 0.03 & 1.02 & 0.00 & 1.02 & 0.00 & 1.02 & 0.00 & 1.02 & 0.00 & 1.02 & 0.00 \\
\hline 0.87 & 0.00 & 0.87 & 0.00 & 0.87 & 0.00 & 0.87 & 0.00 & 0.87 & 0.00 & 0.87 & 0.00 & 0.87 & 0.00 & 0.87 & 0.00 & 0.87 & 0.00 & 0.87 & 0.00 \\
\hline 0.73 & -0.03 & 0.73 & 0.00 & 0.73 & 0.03 & 0.73 & 0.00 & 0.73 & 0.00 & 0.73 & 0.00 & 0.73 & 0.00 & 0.78 & 0.00 & 0.73 & 0.00 & 0.73 & 0.00 \\
\hline 0.63 & 0.00 & 0.63 & 0.00 & 0.63 & 0.03 & 0.63 & 0.00 & 0.58 & 0.00 & 0.58 & 0.00 & 0.58 & 0.00 & 0.58 & 0.00 & 0.58 & 0.00 & 0.58 & 0.00 \\
\hline 0.49 & 0.00 & 0.49 & 0.00 & 0.49 & 0.00 & 0.49 & 0.00 & 0.49 & 0.00 & 0.49 & 0.00 & 0.49 & 0.00 & 0.49 & 0.00 & 0.49 & 0.00 & 0.49 & 0.00 \\
\hline 0.34 & 0.00 & 0.39 & 0.00 & 0.34 & 0.00 & 0.34 & 0.00 & 0.34 & 0.00 & 0.34 & 0.00 & 0.34 & 0.00 & 0.39 & 0.00 & 0.34 & 0.00 & 0.34 & 0.00 \\
\hline 0.24 & 0.00 & 0.19 & 0.00 & 0.24 & 0.00 & 0.24 & 0.00 & 0.24 & 0.00 & 0.19 & 0.00 & 0.19 & 0.00 & 0.19 & 0.00 & 0.19 & 0.00 & 0.19 & 0.00 \\
\hline
\end{tabular}

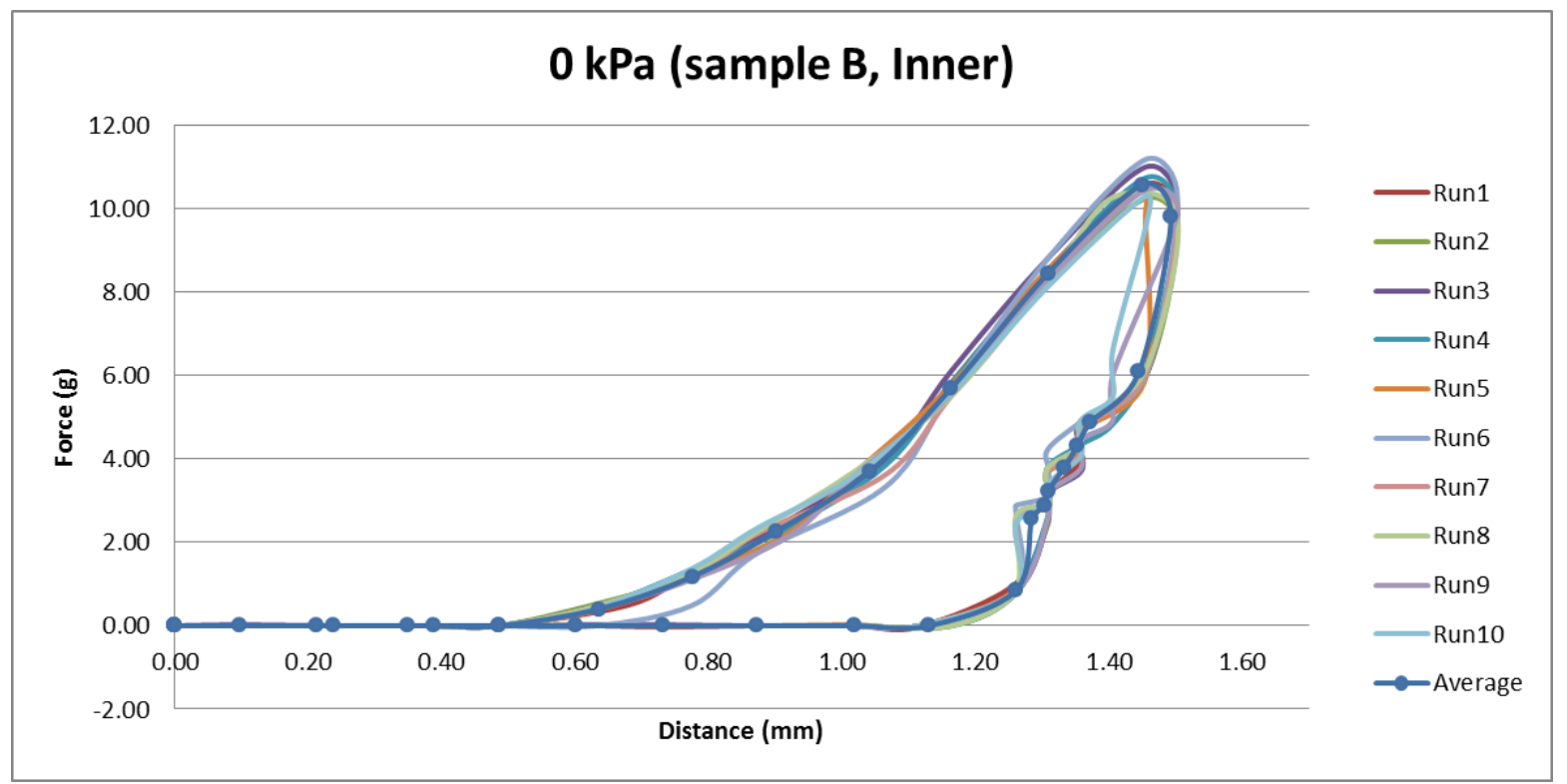



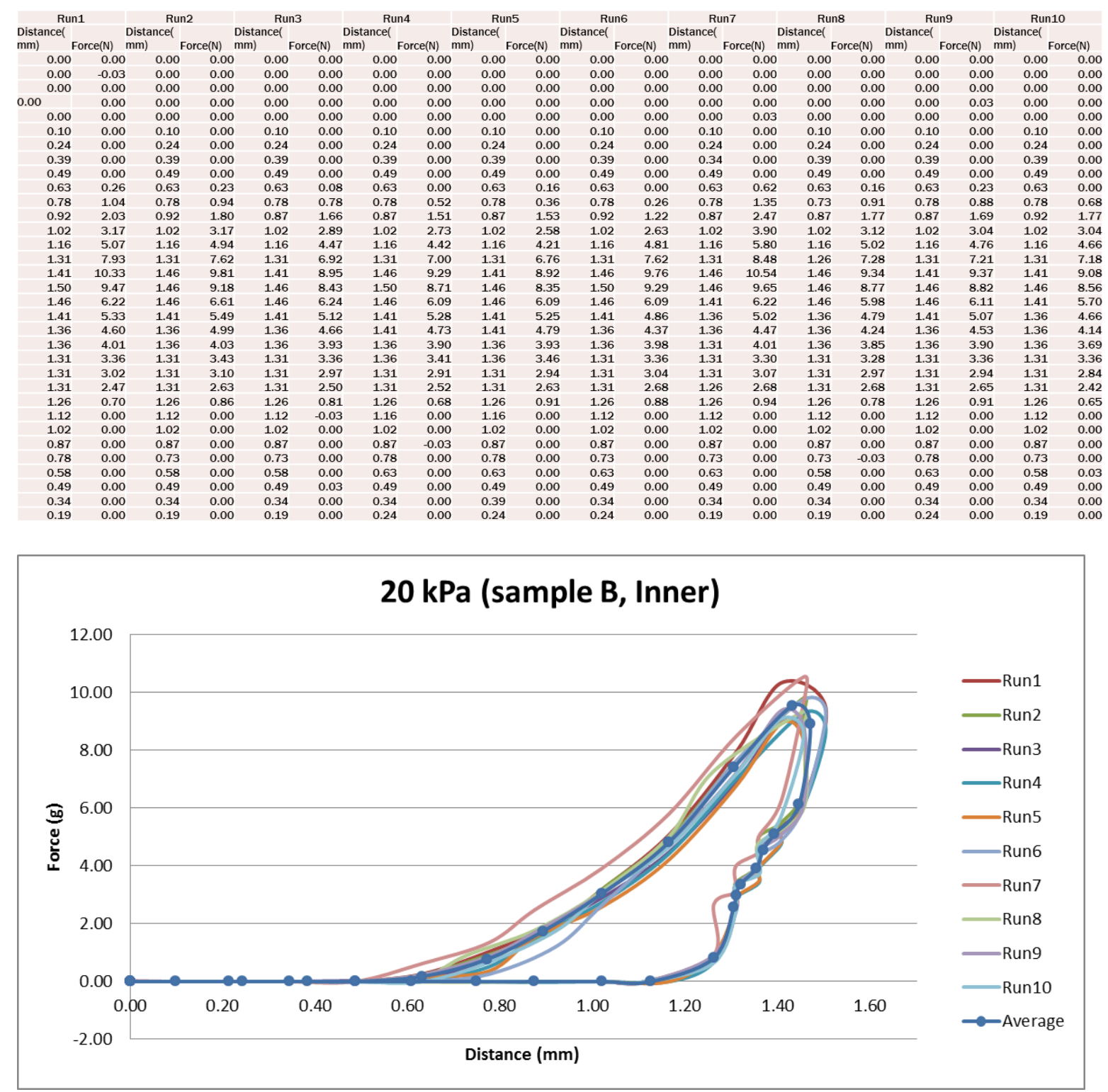


\begin{tabular}{|c|c|c|c|c|c|c|c|c|c|c|c|c|c|c|c|c|c|c|c|}
\hline \multirow{3}{*}{\multicolumn{2}{|c|}{$\begin{array}{l}\text { Run1 } \\
\text { Distancel } \\
\text { mm) Force(N) } \\
0.00 \quad 0.00\end{array}$}} & \multicolumn{2}{|c|}{ Run2 } & \multicolumn{2}{|c|}{ Run3 } & \multicolumn{2}{|c|}{$\begin{array}{r}\text { Run4 } \\
\text { r }\end{array}$} & \multicolumn{2}{|c|}{$\begin{array}{r}\text { Run5 } \\
\text { rista }\end{array}$} & \multicolumn{2}{|c|}{ Run6 } & \multicolumn{2}{|c|}{ Run7 } & \multicolumn{2}{|c|}{ Run8 } & \multicolumn{2}{|c|}{ Run9 } & \multicolumn{2}{|c|}{ Run10 } \\
\hline & & $\begin{array}{l}\text { Distance( } \\
\mathrm{mm} \text { ) }\end{array}$ & Force(N) $n$ & $\begin{array}{l}\text { Distance( } \\
\mathrm{mm} \text { ) }\end{array}$ & Force(N) & $\begin{array}{l}\text { Distance( } \\
\mathrm{mm} \text { ) }\end{array}$ & Force(N) & $\begin{array}{l}\text { Distance( } \\
\mathrm{mm})\end{array}$ & Force(N) & $\begin{array}{l}\text { Distance( } \\
\mathrm{mm})\end{array}$ & Force(N) & $\begin{array}{l}\text { Distance } \\
\mathrm{mm})\end{array}$ & Force $(\mathrm{N}$ & $\begin{array}{l}\text { Distance( } \\
\mathrm{mm} \text { ) }\end{array}$ & Force(N) & $\begin{array}{l}\text { Distance } \\
\mathrm{mm})\end{array}$ & Force(N) & $\begin{array}{l}\text { Distance } \\
\mathrm{mm} \text { ) }\end{array}$ & Force(N) \\
\hline & & $\begin{array}{ll}0 & 0.00\end{array}$ & $\begin{array}{ll}0 & 0.00\end{array}$ & 0.00 & $\begin{array}{ll}0 & 0.00\end{array}$ & 0.00 & $0 \quad 0.00$ & $\quad 0.00$ & 0.00 & $\quad 0.00$ & 0.00 & $\begin{array}{ll}0 & 0.00\end{array}$ & -0.03 & $\begin{array}{l}30.00 \\
0\end{array}$ & 0.00 & $\begin{array}{ll}0 & 0.00\end{array}$ & 0.00 & $0 \quad 0.00$ & 0.00 \\
\hline 0.00 & $\begin{array}{l}0 \quad 0.00 \\
\end{array}$ & 0.00 & 0.00 & 0.00 & 0.00 & 0.00 & 0.00 & 0.00 & 0.00 & 0.00 & 0.00 & 0.00 & 0.00 & 0.00 & 0.00 & 0.00 & 0.00 & 0.00 & 0.03 \\
\hline 0.00 & 0.00 & 0.00 & 0.00 & 0.00 & 0.00 & 0.00 & 0.00 & 0.00 & 0.00 & 0.00 & 0.00 & 0.00 & 0.00 & 0.00 & 0.00 & 0.00 & 0.00 & 0.00 & 0.00 \\
\hline 0.00 & 0.00 & 0.00 & 0.00 & 0.00 & 0.00 & 0.00 & 0.00 & 0.00 & 0.00 & 0.00 & 0.00 & 0.00 & 0.00 & 0.00 & 0.00 & 0.00 & 0.00 & 0.00 & 0.00 \\
\hline 0.00 & 0.00 & 0.00 & 0.00 & 0.00 & 0.00 & 0.00 & 0.00 & 0.00 & 0.00 & 0.00 & 0.00 & 0.00 & 0.00 & 0.00 & 0.00 & 0.00 & 0.00 & 0.00 & 0.00 \\
\hline 0.10 & 0.00 & 0.10 & 0.00 & 0.10 & 0.00 & 0.10 & 0.00 & 0.10 & 0.00 & 0.10 & 0.00 & 0.10 & 0.00 & 0.10 & 0.00 & 0.10 & 0.00 & 0.10 & 0.00 \\
\hline 0.24 & 0.00 & 0.24 & 0.05 & 0.24 & 0.05 & 0.24 & 0.05 & 0.24 & 0.05 & 0.24 & 0.00 & 0.24 & 0.00 & 0.24 & 0.00 & 0.24 & 0.13 & 0.24 & 0.05 \\
\hline 0.34 & 0.60 & 0.34 & 0.57 & 0.39 & 0.68 & 0.34 & 0.62 & 0.34 & 0.75 & 0.34 & 0.47 & 0.39 & 0.49 & 0.39 & 0.36 & 0.34 & 0.60 & 0.34 & 0.65 \\
\hline 0.49 & 1.17 & 0.49 & 1.38 & 0.49 & 1.40 & 0.49 & 1.27 & 0.49 & 1.48 & 0.49 & 1.20 & 0.49 & 1.04 & 0.53 & 1.14 & 0.49 & 1.30 & 0.49 & 1.27 \\
\hline 0.63 & 2.16 & 6 & 2.32 & 0.63 & 2.34 & 0.63 & 2.11 & 0.63 & 2.50 & 0.63 & 1.98 & 0.63 & 1.90 & 0.63 & 1.98 & 0.63 & 2.13 & 0.63 & 2.24 \\
\hline 0.78 & 3.20 & 0.78 & 3.43 & 0.78 & 3.49 & 0.78 & 3.23 & 0.78 & 3.67 & 0.78 & 3.10 & 0.82 & 2.99 & 0.78 & 3.07 & 0.82 & 3.28 & 0.78 & 3.15 \\
\hline 0.92 & 4.71 & 0.87 & 5.07 & 0.92 & 4.89 & 0.92 & 4.76 & 0.92 & 5.41 & 0.92 & 4.71 & 0.92 & 4.53 & 0.92 & 4.50 & 0.92 & 4.79 & 0.92 & 4.71 \\
\hline 1.02 & 6.82 & 1.02 & 7.21 & 1.02 & 6.87 & 1.02 & 6.69 & 1.02 & 7.70 & 1.02 & 6.92 & 1.07 & 6.76 & 1.07 & 6.56 & 1.07 & 6.95 & 1.07 & 6.71 \\
\hline 1.21 & 9.50 & 1.16 & 9.83 & 1.16 & 9.44 & 1.16 & 9.26 & 1.16 & 10.38 & 1.16 & 9.68 & 1.21 & 9.42 & 1.21 & 9.29 & 1.21 & 9.65 & 1.16 & 9.34 \\
\hline 1.31 & 12.90 & 1.31 & 13.27 & 1.31 & 12.72 & 1.31 & 12.64 & 1.31 & 13.87 & 1.31 & 13.03 & 1.31 & 12.64 & 1.31 & 12.70 & 1.31 & 12.80 & 1.31 & 12.54 \\
\hline 1.46 & 15.32 & 1.46 & 15.56 & 1.46 & 15.22 & 1.46 & 14.80 & 1.46 & 16.23 & 1.46 & 15.45 & 1.46 & 15.11 & 1.46 & 15.04 & 1.46 & 15.50 & 1.46 & 14.98 \\
\hline 1.50 & 14.31 & 1.50 & 14.52 & 1.50 & 14.28 & 1.50 & 13.92 & 1.50 & 15.27 & 1.50 & 14.36 & 1.50 & 14.20 & 1.50 & 14.18 & 1.50 & 14.46 & 1.50 & 14.02 \\
\hline 1.46 & 9.05 & 1.41 & 9.00 & 1.41 & 8.71 & 1.41 & 8.69 & 1.46 & 9.73 & 1.46 & 9.11 & 1.46 & 9.05 & 1.46 & 8.92 & 1.46 & 9.05 & 1.46 & 8.61 \\
\hline 1.36 & 5.98 & 1.31 & 6.24 & 1.36 & 6.71 & 1.31 & 5.83 & 1.36 & 6.27 & 1.36 & 6.01 & 1.36 & 5.91 & 1.36 & 6.11 & 1.36 & 6.01 & 1.36 & 5.72 \\
\hline 1.31 & 5.33 & 1.31 & 5.41 & 1.31 & 5.96 & 1.31 & 5.05 & 1.31 & 5.23 & 1.31 & 5.18 & 1.31 & 4.97 & 1.31 & 5.15 & 1.31 & 5.07 & 1.31 & 4.97 \\
\hline 1.31 & 4.81 & 1.26 & 4.94 & 1.31 & 5.49 & 1.26 & 4.60 & 1.26 & 4.71 & 1.26 & 4.60 & 1.31 & 4.55 & 1.2 & 4.73 & 1.26 & 4.55 & 1.26 & 4.42 \\
\hline 1.26 & 3.93 & 1.26 & 3.93 & 1.26 & 4.08 & 1.26 & 3.88 & 1.26 & 4.03 & 1.26 & 3.93 & 1.26 & 3.82 & 1.26 & 4.08 & 1.26 & 3.80 & 1.26 & 3.72 \\
\hline 1.26 & 3.56 & 1. & 3.67 & 1. & 3.56 & 1.26 & 3.46 & 1.21 & 3.62 & 1.21 & 3.59 & 1.26 & 3.51 & 1.26 & 3.56 & 1.26 & 3.49 & 1.21 & 3.43 \\
\hline 1.21 & 3.20 & 1.21 & 3.28 & 1.21 & 3.17 & 1.26 & 3.17 & 1.21 & 3.23 & 1.21 & 3.20 & 1.21 & 3.15 & 1.26 & 3.07 & 1.21 & 3.25 & 1.21 & 3.07 \\
\hline 1.21 & 2.42 & 1.21 & 2.42 & 1.21 & 2.03 & 1.21 & 2.21 & 1.21 & 2.84 & 1.21 & 2.26 & 1.21 & 2.13 & 1.21 & 2.03 & 1.21 & 2.19 & 1.21 & 2.21 \\
\hline 1.12 & 0.68 & 1.12 & 0.73 & 1. & 0.57 & 1.12 & 0.65 & 1.12 & 0.96 & 1.12 & 0.73 & 1.1 & 0.6 & 1.1 & 0.6 & 1.12 & 0. & 1.12 & 0.44 \\
\hline 1.02 & 0.00 & 0.97 & 0.00 & 0.97 & 0.00 & 0.9 & 0.00 & 1.02 & 0.03 & 0.97 & 0.00 & 1.02 & 0.00 & 0.97 & 0.00 & 0.97 & 0.00 & 0.97 & 0.00 \\
\hline 0.87 & 0.00 & 0.87 & 0.00 & 0.82 & 0.00 & 0.87 & 0.00 & 0.92 & 0.00 & 0.87 & 0.00 & 0.87 & 0.00 & 0.87 & 0.00 & 0.87 & 0.00 & 0.87 & 0.00 \\
\hline 0.73 & 0.00 & 0.73 & 0.00 & 0.73 & 0.00 & 0.73 & 0.00 & 0.78 & 0.00 & 0.73 & 0.00 & 0.73 & 0.00 & 0.73 & 0.00 & 0.73 & 0.00 & 0.73 & 0.00 \\
\hline 0.58 & 0.00 & & 0.00 & & 0.00 & 0.53 & 0.0 & 0. & 0.00 & 0.5 & 0.00 & 0.5 & 0.00 & 0.5 & 0.00 & 0.58 & 0.00 & 0.58 & 0.00 \\
\hline 0.49 & 0.00 & 0.49 & 0.00 & 0.49 & 0.00 & 0.44 & 0.00 & 0.49 & 0.00 & 0.49 & 0.00 & 0.49 & 0.00 & 0.49 & 0.00 & 0.49 & 0.00 & 0.44 & 0.00 \\
\hline 0.34 & 0.00 & 0.34 & 0.00 & 0.34 & 0.00 & 0.34 & 0.00 & 0.34 & 0.00 & 0.34 & 0.00 & 0.34 & 0.00 & 0.34 & 0.00 & 0.34 & 0.00 & 0.34 & 0.00 \\
\hline 0.19 & 0.00 & 0.19 & 0.00 & 0.19 & 0.00 & 0.19 & 0.00 & 0.24 & 0.00 & 0.19 & 0.00 & 0.24 & 0.00 & 0.24 & 0.00 & 0.24 & 0.00 & 0.19 & 0.00 \\
\hline
\end{tabular}

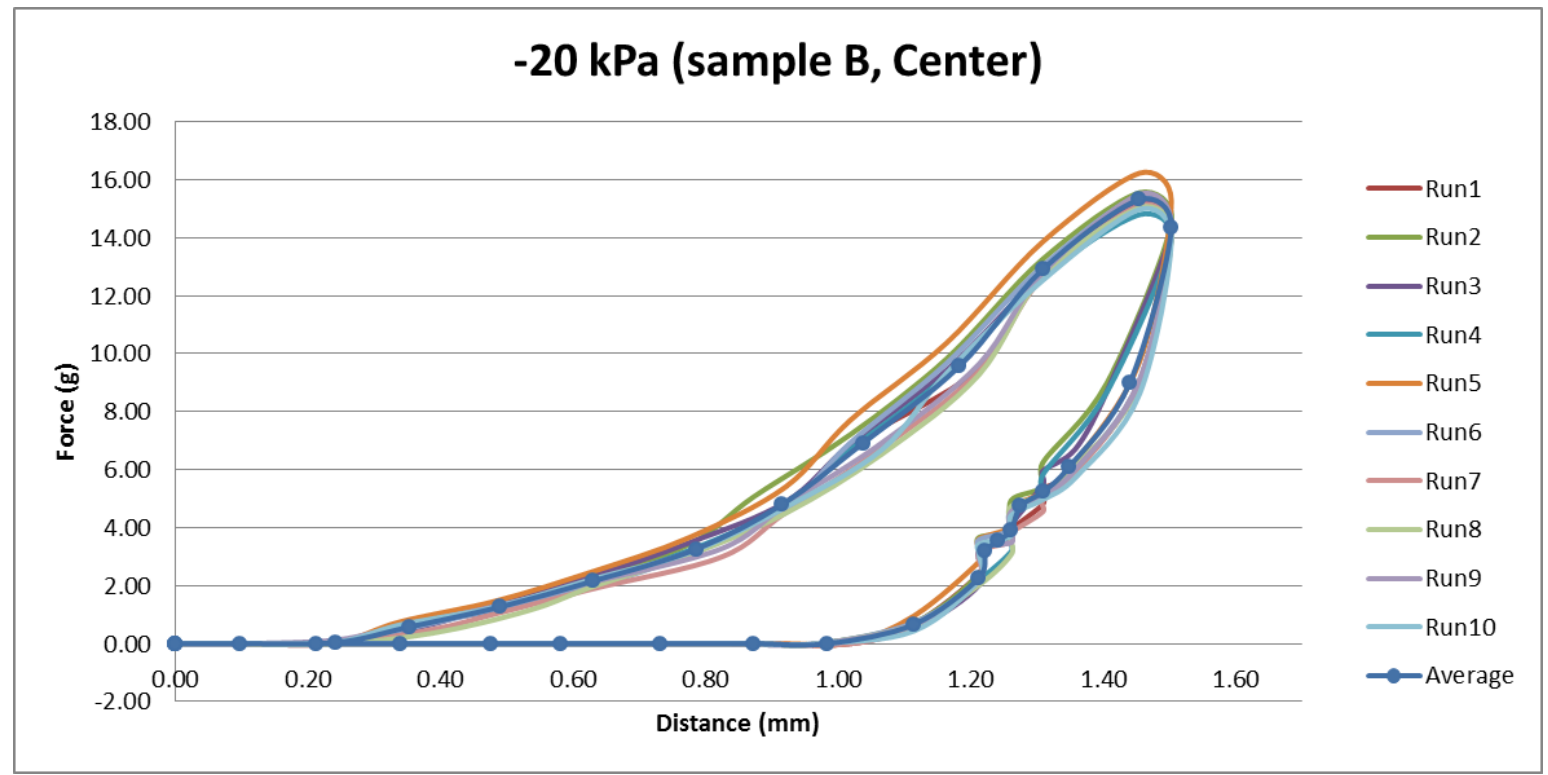




\begin{tabular}{|c|c|c|c|c|c|c|c|c|c|c|c|c|c|c|c|c|c|c|c|}
\hline \multicolumn{2}{|c|}{ Run1 } & \multicolumn{2}{|c|}{ Run2 } & \multicolumn{2}{|c|}{ Run3 } & \multicolumn{2}{|c|}{ Run4 } & \multicolumn{2}{|c|}{ Run5 } & \multicolumn{2}{|c|}{$\begin{array}{l}\text { Run6 } \\
\end{array}$} & \multicolumn{2}{|c|}{\begin{tabular}{|l|} 
Run7 \\
\end{tabular}} & \multicolumn{2}{|c|}{ Run8 } & \multicolumn{2}{|c|}{ Run9 } & \multicolumn{2}{|c|}{ Run10 } \\
\hline $\begin{array}{l}\text { Distance( } \\
\mathrm{mm} \text { ) }\end{array}$ & Force(N) & $\begin{array}{l}\text { Distance( } \\
\mathrm{mm} \text { ) }\end{array}$ & Force(N) & $\begin{array}{l}\text { Distance( } \\
\mathrm{mm} \text { ) }\end{array}$ & Force $(\mathrm{N})$ & $\begin{array}{l}\text { Distance( } \\
\mathrm{mm})\end{array}$ & Force(N) & $\begin{array}{l}\text { Distance( } \\
\mathrm{mm} \text { ) }\end{array}$ & Force(N) & $\begin{array}{l}\text { Distance( } \\
\mathrm{mm} \text { ) }\end{array}$ & Force(N) & $\begin{array}{l}\text { Distance( } \\
\mathrm{mm} \text { ) }\end{array}$ & Force(N) & $\begin{array}{l}\text { Distance } \\
\mathrm{mm} \text { ) }\end{array}$ & Force $(\mathrm{N}$ & $\begin{array}{l}\text { Distance( } \\
\mathrm{mm} \text { ) }\end{array}$ & Force(N) & $\begin{array}{l}\text { Distance( } \\
\mathrm{mm} \text { ) }\end{array}$ & Force(N) \\
\hline 0.00 & 0.00 & 0.00 & 0.00 & $0 \quad 0.00$ & 0.00 & 0.00 & 0.00 & 0.00 & 0.00 & 0.00 & 0.00 & 0.00 & 0.00 & $0 \quad 0.00$ & 0.00 & 0.00 & 0.00 & 0.00 & 0.00 \\
\hline 0.00 & 0.00 & 0.00 & 0.00 & 0.00 & 0.00 & 0.00 & 0.00 & 0.00 & 0.00 & 0.00 & 0.00 & 0.00 & 0.00 & 0.00 & 0.00 & 0.00 & 0.00 & 0.00 & 0.00 \\
\hline 0.00 & 0.00 & 0.00 & 0.00 & 0.00 & 0.00 & 0.00 & 0.00 & 0.00 & 0.00 & 0.00 & 0.00 & 0.00 & 0.00 & 0.00 & 0.00 & 0.00 & 0.00 & 0.00 & 0.00 \\
\hline 0.00 & 0.00 & 0.00 & 0.00 & 0.00 & 0.00 & 0.00 & 0.00 & 0.00 & 0.00 & 0.00 & 0.00 & 0.00 & 0.00 & 0.00 & 0.00 & 0.00 & 0.00 & 0.00 & 0.00 \\
\hline 0.00 & 0.00 & 0.00 & 0.00 & 0.00 & 0.00 & 0.00 & 0.00 & 0.00 & 0.00 & 0.00 & 0.00 & 0.00 & 0.00 & 0.00 & 0.00 & 0.00 & -0.03 & 0.00 & 0.00 \\
\hline 0.10 & 0.00 & 0.10 & 0.00 & 0.10 & 0.00 & 0.05 & 0.00 & 0.10 & 0.00 & 0.10 & 0.00 & 0.15 & -0.03 & 0.10 & 0.00 & 0.10 & 0.00 & 0.10 & 0.00 \\
\hline 0.24 & 0.00 & 0.24 & 0.00 & 0.24 & 0.00 & 0.24 & 0.00 & 0.24 & 0.00 & 0.19 & 0.00 & 0.29 & 0.00 & 0.24 & 0.00 & 0.24 & 0.00 & 0.24 & 0.00 \\
\hline 0.39 & 0.03 & 0.34 & 0.05 & 0.39 & 0.00 & 0.34 & 0.00 & 0.39 & 0.00 & 0.34 & 0.18 & 0.39 & 0.00 & 0.39 & 0.18 & 0.39 & 0.13 & 0.39 & 0.10 \\
\hline 0.49 & 0.57 & 0.49 & 0.75 & 0.49 & 0.62 & 0.49 & 0.57 & 0.49 & 0.29 & 0.49 & 0.83 & 0.53 & 0.39 & 0.49 & 0.81 & 0.49 & 0.68 & 0.49 & 0.70 \\
\hline 0.63 & 1.35 & 0.63 & 1.72 & 0.63 & 1.48 & .55 & 1.17 & 0.63 & 1.12 & 0.63 & 1.51 & 0.68 & 1.01 & 0.63 & 1.53 & 0.63 & 1.46 & 0.63 & 1.38 \\
\hline 0.78 & 2.11 & 0.78 & 2.73 & 0.78 & 2.55 & 0.78 & 2.19 & 0.78 & 2.00 & 0.73 & 2.50 & 0.82 & 2.00 & 0.78 & 2.42 & 0.78 & 2.21 & 0.78 & 2.16 \\
\hline 0.87 & 3.49 & 0.87 & 4.01 & 0.92 & 3.77 & 0.87 & 3.51 & 0.92 & 2.94 & 0.92 & 3.90 & 0.97 & 3.41 & 0.92 & 3.67 & 0.92 & 3.54 & 0.92 & 3.28 \\
\hline 1.02 & 5.28 & 1.02 & 5.70 & 1.02 & 5.46 & 1.02 & 4.97 & 1.07 & 4.45 & 1.02 & 5.78 & 1.12 & 4.99 & 1.0 & 5.33 & 1.0 & 5.23 & 1.02 & 4.94 \\
\hline 1.16 & 7.34 & 1.16 & 7.96 & 1.16 & 7.83 & 1.16 & 7.26 & 1.16 & 6.69 & 1.16 & 8.12 & 1.21 & 7.47 & 1.16 & 7.75 & 1.16 & 7.52 & 1.16 & 7.23 \\
\hline 1.26 & 10.25 & 1.31 & 11.08 & 1.31 & 10.90 & 1.26 & 10.33 & 1.31 & 9.89 & 1.31 & 11.00 & 1.36 & 10.74 & 1.31 & 10.82 & 1.31 & 10.72 & 1.31 & 10.46 \\
\hline 1.46 & 12.54 & 1.50 & 13.19 & 1.46 & 13.35 & 1.41 & 12.93 & 1.46 & 12.36 & 1.46 & 13.42 & 1.50 & 13.45 & 1.46 & 13.42 & 1.46 & 13.14 & 1.46 & 13.14 \\
\hline $\begin{array}{l}1.46 \\
1.46\end{array}$ & $\begin{array}{l}12.74 \\
11.76\end{array}$ & $\begin{array}{l}1.50 \\
1.50\end{array}$ & $\begin{array}{l}12.19 \\
12.46\end{array}$ & $\begin{array}{l}1.40 \\
1.46\end{array}$ & $\begin{array}{l}13.35 \\
12.46\end{array}$ & $\begin{array}{l}1.41 \\
1.46\end{array}$ & 11.99 & $\begin{array}{l}1.40 \\
1.50\end{array}$ & $\begin{array}{l}12.56 \\
11.58\end{array}$ & $\begin{array}{l}.40 \\
1.46\end{array}$ & $\begin{array}{l}12.467 \\
1.6\end{array}$ & $\begin{array}{l}1.50 \\
1.55\end{array}$ & $\begin{array}{l}13.45 \\
12.64\end{array}$ & $\begin{array}{l}1.40 \\
1.50\end{array}$ & $\begin{array}{l}15.42 \\
12.67\end{array}$ & $\begin{array}{l}1.40 \\
1.50\end{array}$ & $\begin{array}{l}13.14 \\
12.46\end{array}$ & $\begin{array}{l}1.40 \\
1.50\end{array}$ & 12.14 \\
\hline 1.41 & 6.84 & 1.41 & 7.57 & 1.46 & 7.44 & 1.41 & 7.15 & 1.46 & 6.92 & 1.41 & 7.60 & 1.46 & 7.65 & 1.46 & 7.36 & 1.46 & 7.36 & 1.46 & 7.18 \\
\hline 1.36 & 5.15 & 1.36 & 5.62 & 1.36 & 5.31 & 1.31 & 5.15 & 1.36 & 5.10 & 1.36 & 5.72 & 1.41 & 5.67 & 1.36 & 5.28 & 1.36 & 5.28 & 1.36 & 5.10 \\
\hline 1.31 & 4.66 & 1.31 & 5.12 & 1.31 & 4.68 & 1.31 & 4.50 & 1.36 & 4.50 & 1.31 & 5.07 & 1.36 & 4.76 & 1.31 & 4.76 & 1.31 & 4.71 & 1.31 & 4.63 \\
\hline 1.31 & 4.24 & & 4.66 & 1.31 & 4.37 & 1.26 & 4.11 & & 4.27 & 1.31 & 4.60 & 1.36 & 4.32 & 1.31 & 4.40 & 1.31 & 4.29 & 1.31 & 4.32 \\
\hline 1.31 & 3.38 & 1.26 & $\begin{array}{l}3.009 \\
\end{array}$ & 1.26 & 3.67 & 1.26 & 3.56 & 1.31 & 3.46 & 1.26 & 3.54 & 1.31 & 3.67 & 1.3 & $\begin{array}{l}3.40 \\
3.67\end{array}$ & 1.31 & 3.64 & 1.31 & 3.72 \\
\hline 1.26 & 3.12 & 1.26 & 3.25 & & 3.30 & 1. & 3.28 & 1. & 3.10 & 1.26 & 3.28 & 1.3 & 3.30 & 1. & 3.30 & 1.2 & 3.33 & 1.31 & 3.33 \\
\hline $\begin{array}{l}1.20 \\
1.26\end{array}$ & 2.84 & 1.26 & 2.81 & 1.26 & 2.86 & 1.21 & 2.78 & 1.26 & 2.76 & 1.26 & $\begin{array}{l}2.20 \\
2.99\end{array}$ & 1.31 & 2.86 & 1.26 & 2.97 & 1.31 & 3.02 & 1.26 & 3.07 \\
\hline 1.26 & 1.27 & 1.21 & 1.56 & 1.26 & 1.61 & 1.21 & 1.38 & 1.26 & 1.27 & 1.21 & 1.59 & 1.26 & 1.27 & 1.2 & 1.66 & 1.2 & 1.59 & 1.26 & 1.48 \\
\hline 1.12 & 0.00 & 1.12 & 0.23 & $\begin{array}{l}1.12 \\
1.12\end{array}$ & 0.16 & 1.1 & 0.03 & 1.12 & 0.05 & 1.12 & 0.16 & 1.16 & 0.03 & 1.1 & 0.29 & 1.1 & 0.36 & 1.12 & 0.16 \\
\hline 1.02 & 0.00 & 0.97 & 0.00 & 1.02 & 0.00 & 0.97 & 0.00 & 1.02 & 0.00 & 1.02 & 0.00 & 1.07 & 0.00 & 1.02 & 0.00 & 1.02 & 0.00 & 0.97 & 0.00 \\
\hline 0.87 & 0.00 & 0.87 & 0.00 & $\begin{array}{l}0.02 \\
0.87\end{array}$ & 0.00 & 0.87 & 0.00 & 0.87 & 0.00 & 0.87 & 0.00 & 0.92 & 0.00 & 0.87 & 0.00 & 0.87 & 0.00 & 0.87 & 0.00 \\
\hline 0.73 & 0.00 & 0.73 & 0.00 & & -0.03 & & 0.00 & & 0.00 & 0.73 & 0.00 & 0.82 & 0.00 & & 0.00 & 0.7 & 0.00 & 0.73 & -0.03 \\
\hline 0.58 & 0.00 & & 0.00 & & 0.00 & & 0.00 & & -0.03 & 0.5 & 0.0 & 0. & 0.00 & 0 & 0.0 & 0.63 & 0.00 & 0.63 & 0.00 \\
\hline 0.44 & 0.00 & 0.44 & 0.00 & 0.49 & 0.00 & 0.49 & 0.00 & 0.49 & 0.00 & 0.44 & 0.00 & 0.49 & 0.00 & 0.49 & 0.00 & 0.49 & 0.00 & 0.49 & 0.00 \\
\hline 0.00 & 0.00 & 0.00 & 0.00 & 0.00 & 0.00 & 0.00 & 0.00 & $\begin{array}{l}0.40 \\
0.00\end{array}$ & 0.00 & 0.00 & 0.00 & 0.00 & 0.00 & $\begin{array}{l}0.43 \\
0.00\end{array}$ & 0.00 & 0.00 & 0.00 & 0.00 & 0.00 \\
\hline 0.00 & 0.00 & 0.00 & 0.00 & 0.00 & 0.00 & 0.00 & 0.00 & 0.00 & 0.00 & 0.00 & 0.00 & 0.00 & 0.00 & 0.00 & 0.00 & 0.00 & 0.00 & 0.00 & 0.00 \\
\hline
\end{tabular}

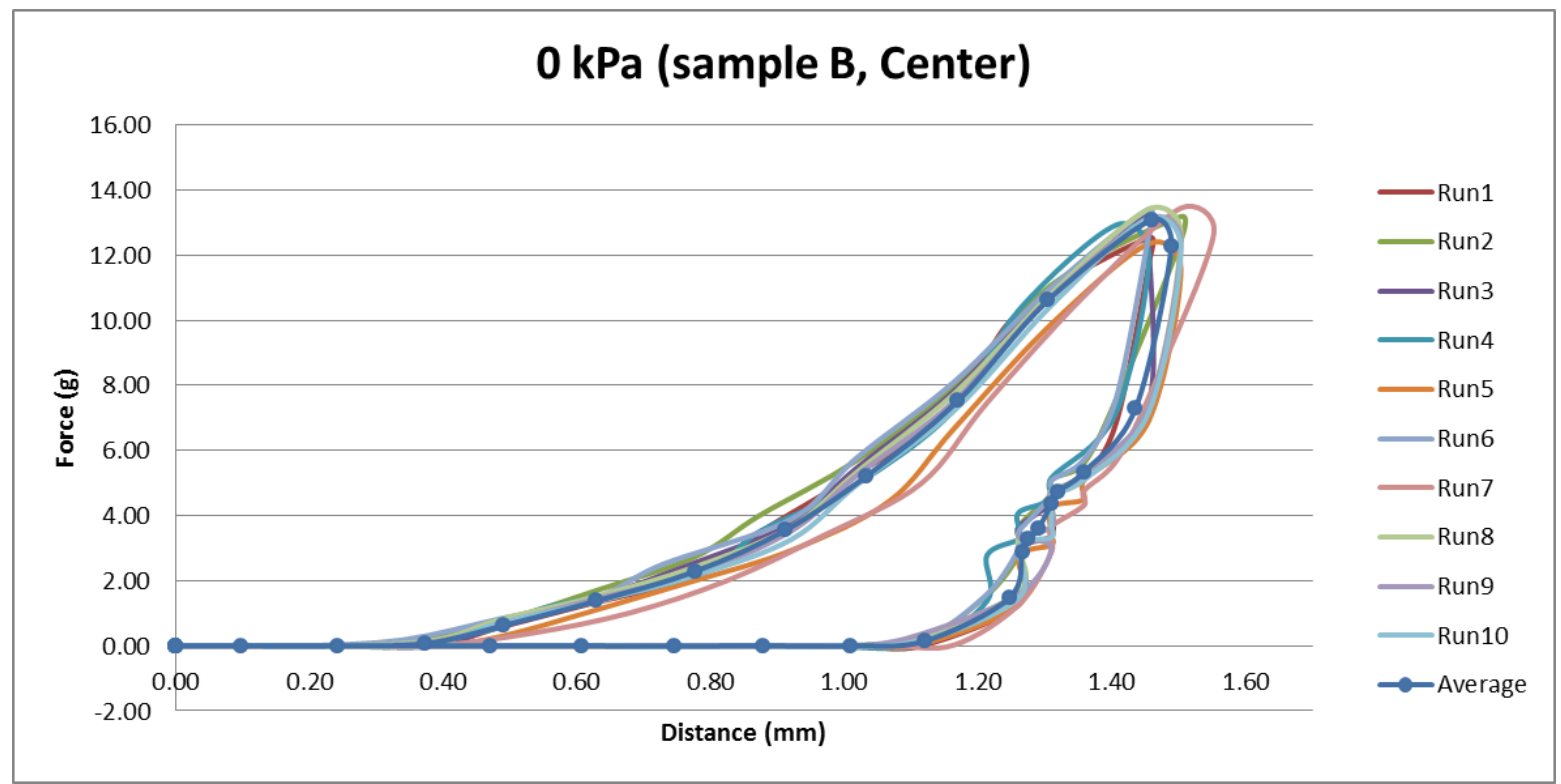




\begin{tabular}{|c|c|c|c|c|c|c|c|c|c|c|c|c|c|c|c|c|c|c|c|}
\hline \multicolumn{2}{|c|}{ Run1 } & \multicolumn{2}{|c|}{ Run2 } & \multicolumn{2}{|c|}{ Run3 } & \multicolumn{2}{|c|}{ Run4 } & \multicolumn{2}{|c|}{ Run5 } & \multicolumn{2}{|c|}{ Run6 } & \multicolumn{2}{|c|}{ Run7 } & \multicolumn{2}{|c|}{ Run8 } & \multicolumn{2}{|c|}{ Run9 } & \multicolumn{2}{|c|}{ Run10 } \\
\hline $\begin{array}{l}\text { Distance( } \\
\mathrm{mm} \text { ) }\end{array}$ & $\begin{array}{ll} & \text { Dis } \\
\text { Force(N) } & \mathrm{mm}\end{array}$ & $\begin{array}{l}\text { istance( } \\
\mathrm{nm} \text { ) }\end{array}$ & Force(N) & $\begin{array}{l}\text { Distance( } \\
\mathrm{mm} \text { ) }\end{array}$ & Force(N) & $\begin{array}{l}\text { Distance( } \\
\mathrm{mm} \text { ) }\end{array}$ & Force(N) & $\begin{array}{l}\text { Distance( } \\
\mathrm{mm})\end{array}$ & Force(N) & $\begin{array}{l}\text { Distance( } \\
\mathrm{mm})\end{array}$ & Force(N) & $\begin{array}{l}\text { Distance( } \\
\mathrm{mm} \text { ) }\end{array}$ & Force(N) & $\begin{array}{l}\text { Distance( } \\
\mathrm{mm})\end{array}$ & Force(N) & $\begin{array}{l}\text { Distance( } \\
\mathrm{mm})\end{array}$ & Force(N) & $\begin{array}{l}\text { Distance( } \\
\mathrm{mm})\end{array}$ & Force(N) \\
\hline 0.00 & $0 \quad 0.00$ & 0.00 & 0.00 & $\begin{array}{l}0 \\
0\end{array}$ & $0 \quad 0.00$ & $\quad 0.00$ & 0.00 & $\begin{array}{ll}0 & 0.00\end{array}$ & 0.00 & 0.00 & -0.03 & $\begin{array}{l}3 \quad 0.00 \\
0\end{array}$ & 0.00 & $\begin{array}{ll}0 & 0.00\end{array}$ & 0.00 & $\begin{array}{l}0 \quad 0.00 \\
0\end{array}$ & $\begin{array}{ll}0 & 0.00\end{array}$ & 0.00 & 0.00 \\
\hline 0.00 & 0.00 & 0.00 & 0.00 & 0.00 & 0.00 & 0.00 & 0.00 & 0.00 & 0.00 & 0.00 & 0.00 & 0.10 & 0.00 & 0.00 & 0.00 & 0.00 & 0.00 & 0.00 & 0.03 \\
\hline 0.00 & 0.00 & 0.00 & 0.00 & 0.00 & 0.00 & 0.00 & 0.00 & 0.00 & 0.00 & 0.00 & 0.00 & 0.00 & 0.00 & 0.00 & 0.00 & 0.00 & 0.00 & 0.00 & 0.00 \\
\hline 0.00 & 0.00 & 0.00 & 0.00 & 0.00 & 0.00 & 0.00 & 0.00 & 0.00 & 0.00 & 0.00 & 0.00 & 0.00 & 0.00 & 0.00 & 0.00 & 0.00 & 0.03 & 0.00 & 0.00 \\
\hline 0.00 & 0.00 & 0.00 & 0.00 & 0.00 & 0.00 & 0.00 & 0.00 & 0.00 & 0.00 & 0.00 & 0.00 & 0.00 & 0.00 & 0.00 & 0.00 & 0.00 & 0.00 & 0.00 & 0.00 \\
\hline 0.10 & 0.00 & 0.10 & 0.00 & 0.10 & 0.03 & 0.10 & 0.00 & 0.10 & 0.00 & 0.10 & 0.00 & 0.10 & 0.00 & 0.10 & 0.00 & 0.10 & 0.00 & 0.10 & 0.00 \\
\hline 0.24 & 0.00 & 0.24 & 0.00 & 0.24 & 0.00 & 0.24 & 0.00 & 0.24 & 0.00 & 0.19 & 0.00 & 0.24 & 0.00 & 0.24 & 0.00 & 0.24 & 0.00 & 0.24 & 0.00 \\
\hline 0.39 & 0.000 .3 & & 0.00 & 0.39 & 0.00 & 0.39 & 0.00 & 0.39 & 0.00 & 0.34 & 0.00 & 0.39 & 0.00 & 0.39 & 0.00 & 0.39 & 0.00 & 0.39 & 0.00 \\
\hline 0.49 & 0.21 & 0.44 & 0.05 & 0.49 & 0.10 & 0.49 & 0.00 & 0.49 & 0.05 & 0.49 & 0.00 & 0.49 & 0.03 & 0.49 & 0.00 & 0.49 & 0.08 & 0.49 & 0.08 \\
\hline 0.63 & 0.96 & 0.63 & 0.62 & 0.63 & 0.55 & 0.63 & 0.60 & 0.63 & 0.60 & 0.63 & 0.52 & 0.63 & 0.70 & 0.63 & 0.65 & 0.63 & 0.73 & 0.58 & 0.73 \\
\hline 0.78 & 1.93 & 0.73 & 1.33 & 0.78 & 1.30 & 0.73 & 1.33 & 0.73 & 1.40 & 0.73 & 1.33 & 0.78 & 1.48 & 0.73 & 1.09 & 0.78 & 1.56 & 0.73 & 1.43 \\
\hline 0.92 & 3.02 & 0.92 & 2.34 & 0.87 & 2.21 & & 2.19 & 0.92 & 2.45 & 0.87 & 2.32 & & 2.52 & 0.87 & 2.39 & 0.87 & 2.68 & 0.87 & 2.47 \\
\hline 1.02 & 4.60 & 1.02 & 3.62 & 1.02 & 3.62 & 1.02 & 3.56 & 1.02 & 3.85 & 1.02 & 3.77 & 1.02 & 4.08 & 1.02 & 3.88 & 1.02 & 4.16 & 1.02 & 3.93 \\
\hline 1.16 & 6.61 & 1.16 & 5.54 & 1.16 & 5.65 & 1.16 & 5.54 & 1.16 & 5.85 & 1.12 & 5.46 & 1.16 & 5.96 & 1.16 & 5.93 & 1.16 & 6.11 & 1.16 & 6.04 \\
\hline 1.31 & 9.57 & 1.26 & 8.32 & 1.31 & 8.43 & 1.26 & 8.25 & 1.31 & 8.64 & 1.26 & 8.04 & 1.31 & 8.82 & 1.31 & 8.58 & 1.31 & 8.95 & 1.26 & 9.13 \\
\hline 1.46 & 11.42 & 1.41 & 10.56 & 1.46 & 10.51 & 1.41 & 10.64 & 1.46 & 11.03 & 1.41 & 10.41 & 1.46 & 11.21 & 1.41 & 11.03 & 1.41 & 11.32 & 1.41 & 11.47 \\
\hline 1.50 & 10.56 & 1.46 & 9.55 & 1.46 & 9.83 & 1.46 & 9.52 & 1.50 & 10.22 & 1.46 & 9.52 & 1.46 & 10.38 & 1.46 & 10.35 & 1.46 & 10.77 & 1.46 & 10.77 \\
\hline 1.41 & 5.88 & 1.41 & 5.62 & 1.41 & 5.78 & 1.41 & 5.96 & 1.41 & 5.96 & 1.41 & 5.72 & 1.41 & 6.30 & 1.41 & 6.24 & 1.41 & 6.63 & 1.41 & 6.92 \\
\hline 1.36 & 4.40 & 1.3 & 4.58 & 1.36 & 4.42 & 1.36 & 4.97 & 1.36 & 4.79 & 1.36 & 4.71 & 1.36 & 5.05 & 1.36 & 5.10 & 1.36 & 5.07 & 1.36 & 5.98 \\
\hline 1.31 & 3.88 & 1.36 & 3.93 & 1.36 & 3.95 & 1.36 & 4.29 & 1.31 & 4.21 & 1.31 & 4.34 & 1.31 & 4.55 & 1.31 & 4.66 & 1.31 & 4.58 & 1.36 & 5.25 \\
\hline 1.31 & 3.54 & 1.31 & 3.54 & 1.31 & 3.59 & 1.31 & 3.67 & 1.31 & 3.62 & 1.31 & 3.72 & 1.31 & 3.85 & 1.31 & 4.06 & 1.31 & 4.11 & 1.31 & 4.27 \\
\hline 1.31 & 2.97 & 1.31 & 3.02 & 1.26 & 3.15 & 1.31 & 3.12 & 1.31 & 3.07 & 1.31 & 3.12 & 1.31 & 3.28 & 1.26 & 3.30 & 1.31 & 3.41 & 1.26 & 3.54 \\
\hline 1.26 & 2.50 & 1.31 & 2.84 & 1.31 & 2.76 & 1.31 & 2.99 & 1.26 & 2.81 & 1.26 & 2.89 & 1.31 & 2.99 & 1.2 & 2.91 & 1.2 & 2.99 & 1.36 & 3.28 \\
\hline 1.26 & 2.19 & 1.26 & 2.47 & & 2.37 & 1.26 & 2.45 & 1.26 & 2.68 & 1.26 & 2.65 & 1.26 & 2.68 & 1.2 & 2.73 & 1.2 & 2.65 & 1.26 & 2.86 \\
\hline 1.21 & 0.26 & 1.26 & 0.65 & 1.21 & 0.68 & 1.26 & 0.62 & 1.26 & 0.81 & 1.21 & 0.73 & 1.26 & 0.78 & 1.21 & 0.96 & 1.26 & 1.09 & 1.26 & 1.07 \\
\hline 1.12 & 0.00 & 1.12 & 0.00 & 1.12 & 0.00 & 1.16 & 0.00 & 1.12 & 0.00 & 1.12 & 0.00 & 1.12 & 0.00 & 1.12 & 0.00 & 1.12 & 0.00 & 1.12 & 0.00 \\
\hline 0.97 & 0.00 & 0.97 & 0.00 & & -0.03 & 1.0 & 0.00 & 1.02 & 0.00 & 0.97 & 0.00 & 1.02 & 0.00 & 0.97 & 0.00 & 0.9 & 0.00 & 0.97 & 0.00 \\
\hline 0.87 & 0.00 & 0.87 & -0.03 & 0.82 & -0.03 & 0.87 & 0.00 & 0.87 & 0.00 & 0.87 & 0.00 & 0.87 & 0.00 & 0.82 & 0.00 & 0.87 & 0.00 & 0.82 & 0.00 \\
\hline 0.73 & 0.00 & 0.73 & 0.00 & 0.73 & 0.00 & 0.73 & 0.00 & 0.73 & 0.00 & 0.73 & 0.00 & 0.73 & 0.00 & 0.73 & 0.00 & 0.73 & 0.00 & 0.73 & 0.00 \\
\hline 0.58 & 0.00 & 0.58 & 0.00 & & 0.00 & & 0.00 & 0.58 & 0.00 & & 0.00 & 0.58 & 0.00 & 0.58 & 0.00 & 058 & 0.00 & 0.58 & 0.00 \\
\hline 0.49 & 0.00 & 0.49 & 0.00 & 0.44 & 0.00 & 0.44 & 0.0 & 0.49 & 0.00 & 0.49 & 0.00 & 0.44 & 0.00 & 0.44 & 0.00 & 0.44 & 0.00 & 0.44 & 0.00 \\
\hline 0.34 & 0.00 & 0.34 & 0.00 & 0.34 & 0.00 & 0.34 & 0.00 & 0.34 & 0.00 & 0.34 & 0.00 & 0.34 & 0.00 & 0.34 & 0.00 & 0.34 & 0.00 & 0.34 & 0.00 \\
\hline 0.19 & 0.00 & 0.19 & 0.00 & 0.19 & 0.00 & 0.19 & 0.00 & 0.24 & 0.00 & 0.19 & 0.00 & 0.19 & 0.00 & 0.19 & 0.03 & 0.19 & 0.00 & 0.19 & 0.00 \\
\hline
\end{tabular}

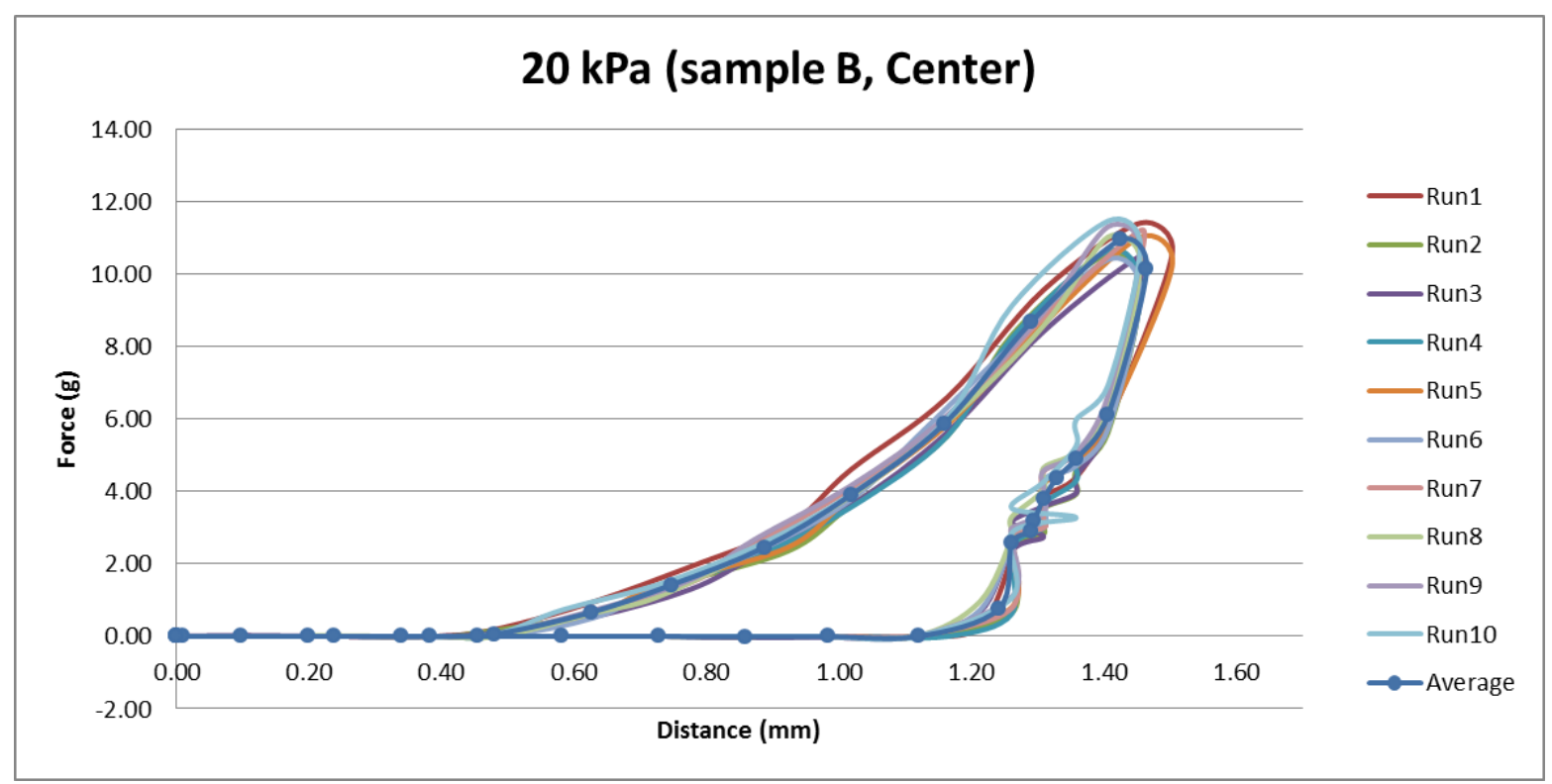




\begin{tabular}{|c|c|c|c|c|c|c|c|c|c|c|c|c|c|c|c|c|c|c|c|}
\hline \multirow{2}{*}{\multicolumn{2}{|c|}{ Run1 }} & \multicolumn{2}{|c|}{ Run2 } & \multicolumn{2}{|c|}{ Run3 } & \multicolumn{2}{|c|}{ Run4 } & \multicolumn{2}{|c|}{ Run5 } & \multicolumn{2}{|c|}{ Run6 } & \multicolumn{2}{|c|}{ Run7 } & \multicolumn{2}{|c|}{ Run8 } & \multicolumn{2}{|c|}{ Run9 } & \multicolumn{2}{|c|}{ Run10 } \\
\hline & & Distance( & & Distance( & & Distance( & & Distance( & & Distance( & & Distance( & & Distance( & & Distance( & & Distancel & \\
\hline & & & Force(N) & $\mathrm{mm}) \quad \mathrm{F}$ & Force(N) & $\mathrm{mm})$ & Force(N) & & Force $(\mathrm{N}) \quad \mathrm{n}$ & & Force $(\mathrm{N}) \quad \mathrm{n}$ & & Force(N) & & & & Force(N) n & & Force(N) \\
\hline 0.00 & 0.00 & $\quad 0.00$ & $0 \quad 0.00$ & $0 \quad 0.00$ & 0.00 & $\begin{array}{ll}0 & 0.00\end{array}$ & $\quad 0.00$ & $\quad 0.00$ & $\quad 0.00$ & $\quad 0.00$ & $\begin{array}{ll}0 & 0.00\end{array}$ & 0.00 & $\begin{array}{ll}0 & 0.00\end{array}$ & $\begin{array}{ll}0 & 0.00\end{array}$ & 0.00 & $\begin{array}{ll}0 & 0.00\end{array}$ & 0.00 & $\begin{array}{ll}0 & 0.00\end{array}$ & 0.00 \\
\hline 0.00 & 0.00 & 0.00 & 0.00 & 0.00 & 0.00 & 0.00 & 0.00 & 0.00 & 0.00 & 0.00 & 0.00 & 0.00 & -0.03 & 0.00 & 0.00 & 0.00 & -0.03 & 0.00 & 0.00 \\
\hline 0.00 & 0.00 & 0.00 & 0.00 & 0.00 & 0.00 & 0.00 & 0.00 & 0.00 & 0.00 & 0.00 & 0.00 & 0.00 & 0.00 & 0.00 & 0.00 & 0.00 & 0.00 & 0.00 & 0.00 \\
\hline 0.00 & 0.00 & 0.00 & 0.00 & 0.00 & 0.00 & 0.00 & 0.00 & 0.00 & 0.00 & 0.00 & 0.00 & 0.00 & 0.00 & 0.00 & 0.00 & 0.00 & 0.00 & 0.00 & 0.00 \\
\hline 0.00 & 0.00 & 0.00 & 0.00 & 0.00 & 0.00 & 0.00 & 0.00 & 0.00 & 0.00 & 0.00 & 0.00 & 0.00 & 0.00 & 0.00 & 0.00 & 0.00 & 0.00 & 0.00 & 0.00 \\
\hline 0.10 & 0.00 & 0.05 & 0.00 & 0.10 & 0.00 & 0.10 & 0.00 & 0.10 & 0.00 & 0.10 & 0.00 & 0.10 & 0.00 & 0.10 & 0.00 & 0.10 & 0.00 & 0.10 & 0.00 \\
\hline 0.24 & 0.00 & 0.19 & 0.00 & 0.19 & 0.00 & 0.19 & 0.00 & 0.24 & 0.00 & 0.24 & 0.00 & 0.24 & 0.00 & 0.24 & 0.00 & 0.24 & 0.00 & 0.24 & 0.00 \\
\hline 0.39 & 0.13 & 0.34 & 0.00 & 0.34 & 0.00 & 0.34 & 0.00 & 0.34 & 0.00 & 0.39 & 0.00 & 0.34 & 0.00 & 0.39 & 0.00 & 0.34 & 0.00 & 0.34 & 0.00 \\
\hline 0.49 & 0.81 & 0.44 & 0.39 & 0.49 & 0.57 & 0.49 & 0.10 & 0.49 & 0.03 & 0.49 & 0.49 & 0.49 & 0.21 & 0.49 & 0.29 & 0.49 & 0.08 & 0.49 & 0.16 \\
\hline 0.63 & 1.43 & 0.58 & 1.09 & 0.58 & 1.30 & 0.63 & 0.78 & 0.58 & 0.52 & 0.63 & 1.20 & 0.58 & 0.81 & 0.63 & 0.81 & 0.63 & 0.73 & 0.63 & 0.83 \\
\hline 0.78 & 2.34 & 0.73 & 1.93 & 0.73 & 2.21 & 0.78 & 1.61 & 0.73 & 1.43 & 0.78 & 2.16 & 0.73 & 1.51 & 0.78 & 1.72 & 0.73 & 1.56 & 0.73 & 1.51 \\
\hline 0.92 & 3.41 & 0.87 & 2.84 & 0.87 & 3.30 & 0.87 & 2.84 & 0.87 & 2.32 & 0.87 & 3.36 & 0.87 & 2.60 & 0.92 & 2.65 & 0.87 & 2.60 & 0.87 & 2.47 \\
\hline 1.07 & 4.89 & 1.02 & 4.14 & 0.97 & 4.42 & 1.02 & 4.06 & 1.02 & 3.69 & 1.02 & 4.92 & 1.02 & 4.14 & 1.07 & 4.19 & 1.02 & 3.98 & 1.02 & 4.03 \\
\hline 1.21 & 6.79 & 1.16 & 5.78 & 1.16 & 6.11 & 1.12 & 5.80 & 1.16 & 5.54 & 1.16 & 6.84 & 1.16 & 6.11 & 1.16 & 6.11 & 1.16 & 5.98 & 1.16 & 5.96 \\
\hline 1.31 & 8.84 & 1.26 & 7.91 & 1.26 & 8.19 & 1.26 & 7.73 & 1.31 & 7.75 & 1.31 & 9.29 & 1.31 & 8.61 & 1.31 & 8.61 & 1.31 & 8.35 & 1.31 & 8.48 \\
\hline 1.46 & $\begin{array}{r}10.07 \\
\end{array}$ & 1.41 & 9.44 & 1.41 & 9.39 & 1.41 & 8.84 & 1.41 & 9.29 & 1.46 & $\begin{array}{r}10.87 \\
\end{array}$ & 1.46 & 10.38 & 1.46 & 10.56 & 1.41 & $\begin{array}{r}0.04 \\
\end{array}$ & 1.41 & 9.99 \\
\hline 1.50 & 9.47 & 1.46 & 8.82 & 1.46 & 8.61 & 1.46 & 8.06 & 1.46 & 8.51 & 1.50 & 10.17 & 1.50 & 9.94 & 1.50 & 9.76 & 1.50 & 9.13 & 1.50 & 9.47 \\
\hline 1.46 & 6.30 & 1.41 & 6.14 & 1.41 & 6.32 & 1.41 & 5.91 & 1.41 & 6.01 & 1.46 & 6.56 & 1.41 & 6.35 & 1.46 & 6.22 & 1.46 & 6.22 & 1.41 & 6.45 \\
\hline 1.41 & 5.31 & 1.36 & 5.23 & 1.36 & 5.57 & 1.36 & 5.18 & 1.36 & 5.15 & 1.41 & 5.49 & 1.36 & 5.36 & 1.41 & 5.36 & 1.41 & 5.18 & 1.41 & 5.41 \\
\hline 1.36 & 4.76 & 1.36 & 4.79 & 1.36 & 5.02 & 1.36 & 4.68 & 1.36 & 4.66 & 1.36 & 5.05 & 1.36 & 4.94 & 1.36 & 4.76 & 1.36 & 4.68 & 1.36 & 4.81 \\
\hline 1.36 & 4.50 & 1.36 & 4.32 & 1.36 & 4.45 & 1.36 & 4.29 & 1.36 & 4.27 & 1.36 & 4.55 & 1.36 & 4.53 & 1.36 & 4.45 & 1.36 & 4.32 & 1.36 & 4.50 \\
\hline 1.36 & 4.19 & 1.31 & 4.11 & 1.36 & 4.03 & 1.36 & 4.03 & 1.36 & 4.11 & 1.36 & 4.34 & 1.36 & 4.19 & 1.36 & 4.21 & 1.36 & 4.08 & 1.36 & 4.16 \\
\hline 1.36 & 3.85 & 1.31 & 3.85 & 1.31 & 3.77 & 1.31 & 3.82 & 1.31 & 3.77 & 1.31 & 3.98 & 1.31 & 3.90 & 1.36 & 3.90 & 1.36 & 3.77 & 1.31 & 3.95 \\
\hline 1.36 & 3.23 & 1.31 & 3.23 & 1.31 & 2.97 & 1.31 & 2.86 & 1.31 & 2.55 & 1.31 & 3.28 & 1.31 & 3.17 & 1.31 & 3.20 & 1.36 & 2.81 & 1.31 & 3.02 \\
\hline 1.26 & 0.91 & 1.26 & 0.88 & 1.26 & 0.57 & 1.21 & 0.42 & 1.26 & 0.47 & 1.26 & 0.81 & 1.26 & 0.73 & 1.26 & 0.83 & 1.26 & 0.57 & 1.26 & 0.73 \\
\hline 1.16 & 0.00 & 1.16 & 0.00 & 1.12 & 0.00 & 1.12 & 0.00 & 1.12 & 0.00 & 1.12 & 0.00 & 1.12 & 0.00 & 1.16 & 0.00 & 1.12 & 0.00 & 1.12 & 0.00 \\
\hline 1.02 & 0.00 & 1.02 & 0.00 & 0.97 & -0.03 & 0.97 & 0.00 & 1.02 & 0.00 & 1.02 & 0.00 & 1.02 & 0.00 & 1.02 & 0.00 & 1.02 & 0.00 & 1.02 & 0.00 \\
\hline 0.87 & 0.00 & 0.87 & 0.00 & 0.87 & 0.00 & 0.82 & 0.00 & 0.87 & 0.00 & 0.87 & 0.00 & 0.87 & 0.00 & 0.87 & 0.00 & 0.87 & 0.00 & 0.87 & 0.00 \\
\hline $\begin{array}{l}0.01 \\
0.78\end{array}$ & 0.00 & 0.78 & 0. & 0.73 & $\begin{array}{l}-0.03 \\
-\end{array}$ & $\begin{array}{l}0.02 \\
0.73\end{array}$ & 0.00 & 0.73 & 0.00 & 0.73 & 0.00 & 0.73 & 0.00 & 0.78 & 0.00 & 0.73 & 0.00 & 0.73 & 0.00 \\
\hline 0.63 & 0.00 & 0.63 & 0.00 & 0.58 & 0.00 & 0.58 & 0.00 & 0.58 & 0.00 & 0.63 & 0.00 & 0.58 & 0.00 & 0.63 & 0.00 & 0.63 & 0.00 & 0.58 & 0.00 \\
\hline 0.53 & 0.00 & 0.49 & 0.00 & 0.49 & 0.00 & 0.49 & 0.00 & 0.49 & 0.00 & 0.49 & 0.00 & 0.49 & 0.00 & 0.49 & 0.00 & 0.49 & 0.00 & 0.49 & 0.00 \\
\hline 0.39 & 0.00 & 0.34 & 0.00 & 0.34 & 0.00 & 0.34 & 0.00 & 0.34 & 0.00 & 0.34 & 0.00 & 0.34 & 0.00 & 0.39 & 0.00 & 0.34 & 0.00 & 0.34 & 0.00 \\
\hline 0.24 & 0.00 & 0.24 & 0.00 & 0.15 & 0.00 & 0.19 & 0.00 & 0.19 & 0.00 & 0.24 & 0.00 & 0.19 & 0.00 & 0.24 & 0.00 & 0.24 & 0.00 & 0.24 & 0.00 \\
\hline
\end{tabular}

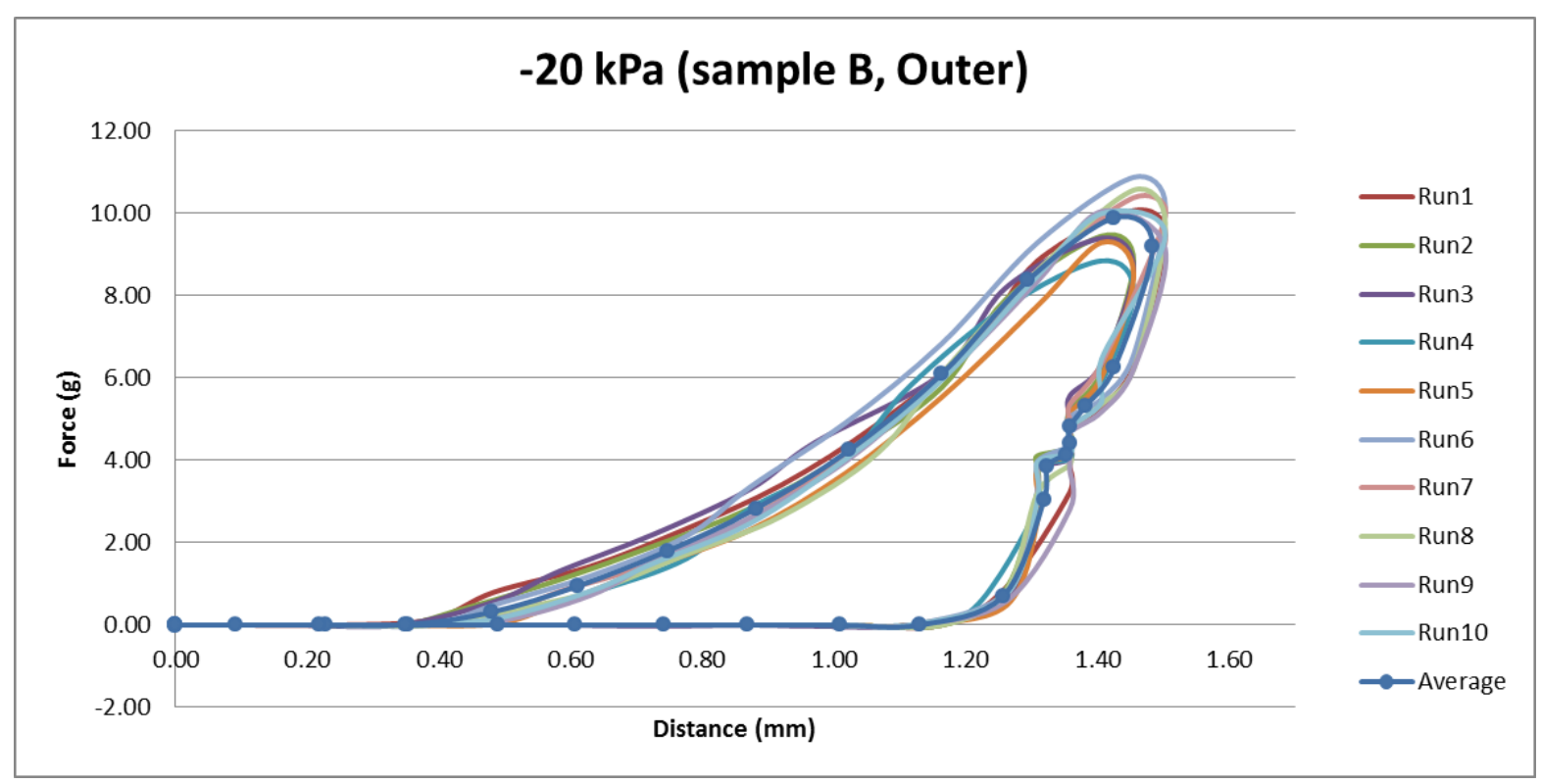




\begin{tabular}{|c|c|c|c|c|c|c|c|c|c|c|c|c|c|c|c|c|c|c|c|}
\hline \multirow{2}{*}{\multicolumn{2}{|c|}{$\begin{array}{l}\text { Run1 } \\
\text { Distance( }\end{array}$}} & \multicolumn{2}{|c|}{ Run2 } & \multicolumn{2}{|c|}{ Run3 } & \multicolumn{2}{|c|}{ Run4 } & \multicolumn{2}{|c|}{ Run5 } & \multicolumn{2}{|c|}{ Run6 } & \multicolumn{2}{|c|}{ Run7 } & \multicolumn{2}{|c|}{ Run8 } & \multicolumn{2}{|c|}{ Run9 } & \multicolumn{2}{|c|}{ Run10 } \\
\hline & & $\begin{array}{l}\text { Distancel } \\
\mathrm{mm})\end{array}$ & Force(N) & $\begin{array}{l}\text { Distancel } \\
\mathrm{mm})\end{array}$ & Force(N) & $\begin{array}{l}\text { Distancel } \\
\mathrm{mm})\end{array}$ & Force(N) & $\begin{array}{l}\text { Distancel } \\
\mathrm{mm} \text { ) }\end{array}$ & Force(N) & $\begin{array}{l}\text { Distance( } \\
\mathrm{mm} \text { ) }\end{array}$ & Force(N) & $\begin{array}{l}\text { Distance( } \\
\mathrm{mm} \text { ) }\end{array}$ & Force(N) & $\begin{array}{l}\text { Distance( } \\
\mathrm{mm} \text { ) }\end{array}$ & Force(N) & $\begin{array}{l}\text { Distance( } \\
\mathrm{mm} \text { ) }\end{array}$ & Force(N) & $\begin{array}{l}\text { Distance( } \\
\mathrm{mm} \text { ) }\end{array}$ & Force(N) \\
\hline 0.00 & 0.00 & 0.00 & $\begin{array}{lll}0 & 0.00\end{array}$ & 0.00 & $\begin{array}{lll}0 & 0.00\end{array}$ & 0.00 & $\begin{array}{lll}0 & 0.00\end{array}$ & $0 \quad 0.00$ & $\quad 0.00$ & 0.00 & $\begin{array}{lll}0 & 0.00\end{array}$ & $0 \quad 0.00$ & $\begin{array}{ll}0 & 0.00\end{array}$ & 0.00 & $\begin{array}{ll}0 & 0.00\end{array}$ & 0.00 & $\begin{array}{ll}0 & 0.00\end{array}$ & $0 \quad 0.00$ & $\begin{array}{lll}0 & 0.00\end{array}$ \\
\hline 0.00 & 0.00 & 0.00 & 0.00 & 0.00 & 0.00 & 0.00 & 0.00 & 0.00 & 0.00 & 0.00 & 0.00 & 0.00 & 0.00 & 0.00 & 0.02 & 0.00 & 0.00 & 0.00 & 0.00 \\
\hline 0.00 & 0.00 & 0.00 & 0.00 & 0.00 & 0.00 & 0.00 & 0.00 & 0.00 & 0.00 & 0.00 & 0.00 & 0.00 & 0.00 & 0.00 & 0.00 & 0.00 & 0.00 & 0.00 & 0.02 \\
\hline 0.00 & -0.02 & 0.00 & 0.00 & 0.00 & 0.00 & 0.00 & 0.00 & 0.00 & 0.00 & 0.00 & 0.00 & 0.00 & 0.00 & 0.00 & 0.00 & 0.00 & 0.02 & 0.00 & 0.00 \\
\hline 0.00 & 0.00 & 0.00 & 0.00 & 0.00 & 0.00 & 0.00 & 0.00 & 0.00 & -0.02 & 0.00 & 0.00 & 0.00 & 0.00 & 0.00 & 0.00 & 0.05 & 0.00 & 0.00 & 0.00 \\
\hline 0.10 & 0.00 & 0.05 & 0.00 & 0.10 & -0.02 & 0.10 & 0.00 & 0.10 & -0.02 & 0.15 & 0.00 & 0.10 & 0.00 & 0.10 & 0.00 & 0.19 & 0.00 & 0.00 & 0.00 \\
\hline 0.24 & 0.00 & 0.19 & 0.00 & 0.19 & 0.00 & 0.24 & 0.00 & 0.24 & 0.00 & 0.29 & 0.00 & 0.24 & 0.00 & 0.24 & 0.00 & 0.34 & 0.00 & 0.29 & 0.00 \\
\hline 0.34 & 0.00 & 0.34 & 0.00 & 0.34 & 0.00 & 0.39 & 0.00 & 0.34 & 0.00 & 0.39 & 0.02 & 0.34 & 0.00 & 0.34 & 0.00 & 0.44 & 0.03 & 0.39 & -0.02 \\
\hline 0.49 & 0.00 & 0.49 & 0.00 & 0.49 & 0.00 & 0.49 & 0.00 & 0.44 & 0.00 & 0.53 & 0.00 & 0.49 & 0.00 & 0.49 & 0.00 & 0.53 & 0.00 & 0.53 & 0.00 \\
\hline 0.63 & 0.00 & 0.58 & 0.00 & 0.58 & 0.00 & 0.63 & 0.00 & 0.58 & 0.00 & 0.68 & 0.00 & 0.58 & 0.31 & 0.63 & 0.00 & 0.73 & 0.00 & 0.68 & 0.00 \\
\hline 0.73 & 0.00 & 0.68 & 0.00 & 0.68 & 0.08 & 0.73 & 0.47 & 0.68 & 0.28 & 0.78 & 0.56 & 0.68 & 0.39 & 0.73 & 0.46 & 0.83 & 0.60 & 0.78 & 0.47 \\
\hline 0.83 & 0.55 & 0.78 & 0.72 & 0.78 & 0.30 & 0.83 & 0.71 & 0.78 & 0.54 & 0.88 & 0.87 & 0.78 & 0.67 & 0.83 & 0.71 & 0.93 & 0.91 & 0.88 & 0.75 \\
\hline 0.93 & 1.32 & 0.88 & 1.60 & 0.88 & 1.02 & 0.93 & 1.60 & 0.88 & 1.36 & 0.98 & 1.88 & 0.88 & 1.52 & 0.93 & 1.56 & 1.03 & 1.98 & 0.98 & 1.66 \\
\hline 1.03 & 2.26 & 0.98 & 2.63 & 0.98 & 2.01 & 1.03 & 2.66 & 0.98 & 2.38 & 1.08 & 2.94 & 0.98 & 2.47 & 1.03 & 2.62 & 1.13 & 3.22 & 1.08 & 2.68 \\
\hline 1.26 & 6.44 & 1.26 & 7.05 & 1.26 & 6.20 & 1.26 & 7.33 & 1.26 & 6.72 & 1.36 & 7.84 & 1.31 & 6.63 & 1.31 & 7.05 & 1.36 & 7.45 & 1.36 & 7.49 \\
\hline 1.41 & 7.91 & 1.41 & 8.17 & 1.41 & 8.03 & 1.41 & 8.73 & 1.41 & 8.24 & 1.50 & 9.08 & 1.46 & 8.03 & 1.46 & 8.29 & 1.50 & 8.59 & 1.50 & 9.08 \\
\hline 1.46 & 7.19 & 1.46 & 7.63 & 1.46 & 7.52 & 1.46 & 8.05 & 1.46 & 7.82 & 1.50 & 8.36 & 1.50 & 7.42 & 1.50 & 7.80 & 1.55 & 8.13 & 1.55 & 8.38 \\
\hline 1.41 & 4.87 & 1.41 & 5.36 & 1.41 & 4.89 & 1.41 & 5.71 & 1.41 & 5.27 & 1.46 & 5.36 & 1.46 & 5.60 & 1.46 & 5.74 & 1.50 & 5.55 & 1.50 & 5.20 \\
\hline 1.36 & 4.21 & 1.36 & 4.47 & 1.36 & 3.98 & 1.36 & 4.82 & 1.36 & 4.28 & 1.41 & 4.45 & 1.41 & 4.52 & 1.41 & 4.94 & 1.46 & 4.57 & 1.41 & 4.35 \\
\hline 1.36 & 3.70 & 1.36 & 4.12 & 1.31 & 3.68 & 1.36 & 4.40 & 1.31 & 3.82 & 1.41 & 4.05 & 1.41 & 4.19 & 1.41 & 4.40 & 1.41 & 3.96 & 1.41 & 4.05 \\
\hline 1.36 & 3.39 & 1.36 & 3.82 & 1.31 & 3.42 & 1.36 & 4.03 & 1.31 & 3.54 & 1.41 & 3.84 & 1.36 & 3.77 & 1.36 & 4.07 & 1.41 & 3.75 & 1.41 & 3.68 \\
\hline 1.31 & 3.14 & 1.31 & 3.56 & 1.31 & 3.14 & 1.31 & 3.70 & 1.31 & 3.25 & 1.36 & 3.47 & 1.36 & 3.61 & 1.36 & 3.68 & 1.36 & 3.54 & 1.41 & 3.32 \\
\hline 1.31 & 2.93 & 1.31 & 3.21 & 1.26 & 2.81 & 1.31 & 3.39 & 1.26 & 2.97 & 1.36 & 3.28 & 1.36 & 3.39 & 1.36 & 3.39 & 1.36 & 3.23 & 1.36 & 3.11 \\
\hline 1.31 & 2.25 & 1.31 & 2.36 & 1.26 & 2.29 & 1.31 & 2.62 & 1.26 & 2.48 & 1.36 & 2.88 & $\begin{array}{l}1.36 \\
\text { S }\end{array}$ & 2.48 & 1.31 & 2.74 & 1.36 & 2.74 & 1.36 & 2.62 \\
\hline 1.21 & 0.49 & 1.21 & 0.61 & 1.21 & 0.56 & 1.26 & 0.66 & 1.21 & 0.61 & 1.31 & 0.84 & 1.26 & 0.63 & 1.26 & 0.63 & 1.31 & 0.75 & 1.31 & 0.56 \\
\hline 1.12 & 0.00 & 1.12 & 0.00 & 1.07 & 0.00 & 1.12 & 0.00 & 1.12 & 0.00 & 1.16 & 0.00 & 1.16 & 0.00 & 1.12 & 0.00 & 1.31 & 0.00 & 1.16 & 0.00 \\
\hline 0.97 & 0.00 & 1.02 & 0.00 & 0.97 & 0.00 & 0.97 & 0.00 & 1.02 & 0.00 & 1.07 & 0.00 & 1.02 & 0.00 & 1.02 & -0.02 & 1.07 & 0.00 & 1.07 & 0.00 \\
\hline 0.87 & 0.00 & 0.87 & 0.00 & 0.82 & 0.00 & 0.87 & 0.00 & 0.87 & 0.00 & 0.92 & 0.00 & 0.92 & 0.00 & 0.92 & 0.00 & 0.92 & -0.02 & 0.92 & 0.00 \\
\hline 0.73 & 0.00 & 0.73 & -0.02 & 0.73 & 0.00 & 0.73 & 0.00 & 0.73 & 0.00 & 0.78 & 0.00 & 0.78 & 0.00 & 0.78 & 0.00 & 0.82 & 0.00 & 0.78 & 0.00 \\
\hline 0.63 & 0.00 & 0.58 & 0.00 & 0.58 & 0.00 & 0.63 & 0.00 & 0.63 & 0.00 & 0.68 & 0.00 & 0.63 & 0.00 & 0.63 & 0.00 & 0.68 & 0.00 & 0.63 & 0.00 \\
\hline 0.49 & 0.00 & 0.49 & 0.00 & 0.49 & 0.00 & 0.49 & 0.00 & 0.49 & 0.00 & 0.53 & 0.00 & 0.49 & 0.00 & 0.49 & 0.00 & 0.53 & 0.00 & 0.53 & 0.00 \\
\hline 0.34 & 0.00 & 0.34 & 0.00 & 0.29 & 0.00 & 0.34 & 0.00 & 0.34 & 0.00 & 0.39 & 0.00 & 0.39 & 0.00 & 0.39 & 0.00 & 0.44 & 0.00 & 0.39 & -0.02 \\
\hline 0.19 & 0.00 & 0.19 & 0.00 & 0.19 & 0.02 & 0.19 & 0.00 & 0.19 & 0.00 & 0.29 & 0.00 & 0.24 & 0.00 & 0.24 & 0.00 & 0.29 & 0.00 & 0.29 & 0.00 \\
\hline
\end{tabular}

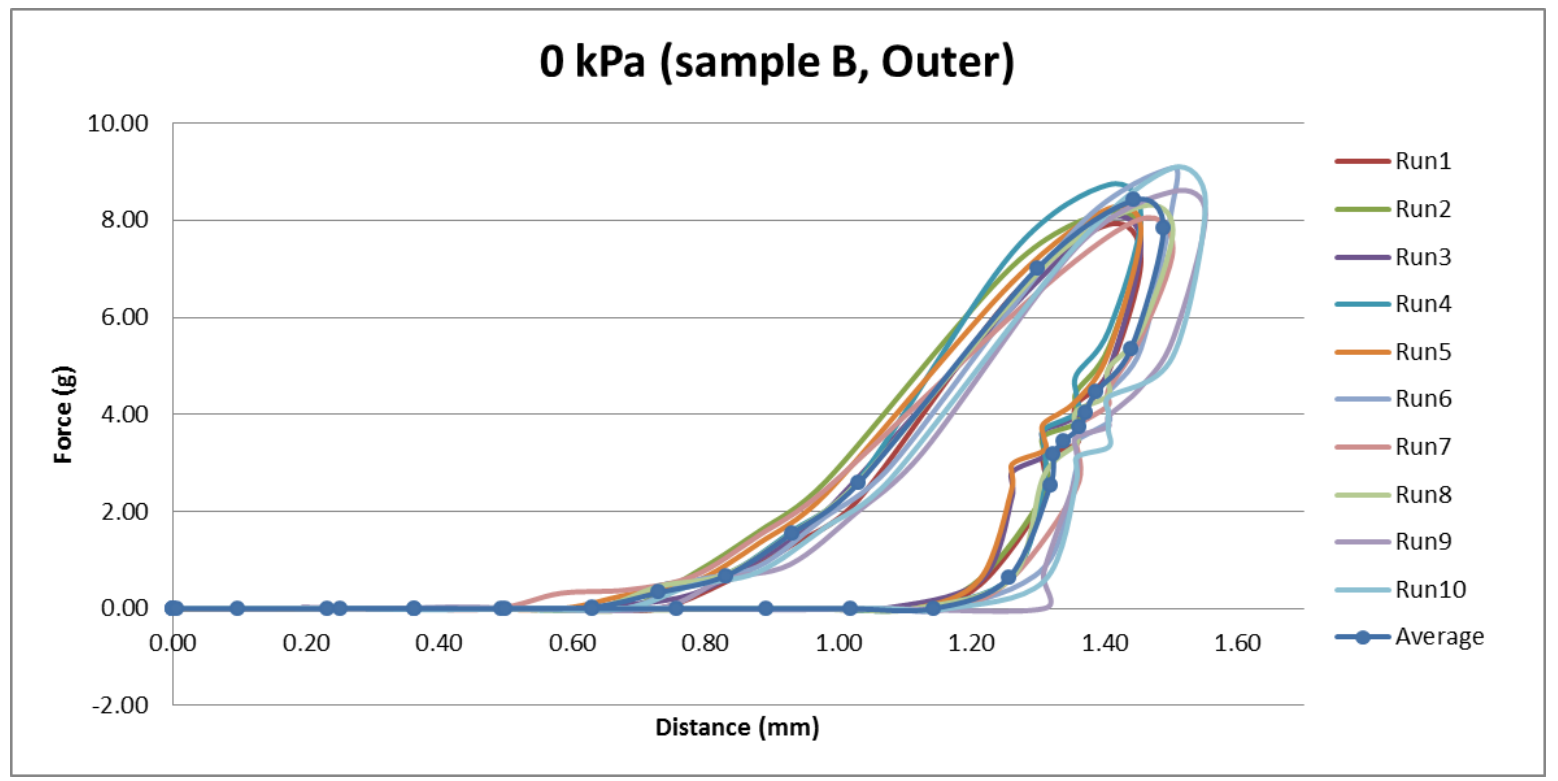




\begin{tabular}{|c|c|c|c|c|c|c|c|c|c|c|c|c|c|c|c|c|c|c|c|}
\hline \multicolumn{2}{|c|}{ Run1 } & \multicolumn{2}{|c|}{ Run2 } & \multicolumn{2}{|c|}{ Run3 } & \multicolumn{2}{|c|}{ Run4 } & \multicolumn{2}{|c|}{ Run5 } & \multicolumn{2}{|c|}{ Run6 } & \multicolumn{2}{|c|}{ Run7 } & \multicolumn{2}{|c|}{ Run8 } & \multicolumn{2}{|c|}{ Run9 } & \multicolumn{2}{|c|}{ Run10 } \\
\hline $\begin{array}{l}\text { Distance( } \\
\mathrm{mm} \text { ) }\end{array}$ & & $\begin{array}{l}\text { Distance( } \\
\mathrm{mm} \text { ) }\end{array}$ & Force(N) & $\begin{array}{l}\text { Distance( } \\
\mathrm{mm})\end{array}$ & Force(N) & $\begin{array}{l}\text { Distance( } \\
\mathrm{mm} \text { ) }\end{array}$ & Force(N) & $\begin{array}{l}\text { Distancel } \\
\mathrm{mm} \text { ) }\end{array}$ & Force(N) & $\begin{array}{l}\text { Distance( } \\
\mathrm{mm})\end{array}$ & Force(N) & $\begin{array}{l}\text { Distance( } \\
\mathrm{mm} \text { ) }\end{array}$ & rce $(\mathrm{N})$ & $\begin{array}{l}\text { Distance( } \\
\mathrm{mm})\end{array}$ & $\operatorname{rrce}(\mathrm{N})$ & $\begin{array}{l}\text { Distance( } \\
\mathrm{mm} \text { ) }\end{array}$ & $\operatorname{orce}(\mathrm{N})$ & $\begin{array}{l}\text { Distance( } \\
\mathrm{mm})\end{array}$ & rce(N) \\
\hline 0.00 & 0.00 & $\quad 0.00$ & $\begin{array}{ll}0 & 0.00\end{array}$ & $\begin{array}{ll}0 & 0.00\end{array}$ & 0.00 & $\quad 0.00$ & $\begin{array}{l}0 \\
0.00\end{array}$ & 0.00 & $\begin{array}{ll}0 & 0.00\end{array}$ & $\begin{array}{ll}0 & 0.00\end{array}$ & 0.00 & $\quad 0.00$ & 0.00 & $\quad 0.00$ & 0.00 & $\begin{array}{ll}0 & 0.00\end{array}$ & 0.00 & $\begin{array}{ll}0 & 0.00\end{array}$ & 0.00 \\
\hline 0.00 & 0.00 & 0.00 & 0.00 & 0.00 & 0.00 & 0.00 & 0.00 & 0.00 & 0.00 & 0.00 & 0.00 & 0.00 & 0.00 & 0.00 & 0.00 & 0.00 & 0.00 & 0.00 & 0.00 \\
\hline 0.00 & 0.00 & 0.00 & 0.00 & 0.00 & 0.00 & 0.00 & 0.00 & 0.00 & 0.00 & 0.00 & 0.00 & 0.00 & 0.00 & 0.00 & 0.00 & 0.00 & 0.00 & 0.00 & 0.00 \\
\hline 0.00 & 0.00 & 0.00 & 0.00 & 0.00 & 0.00 & 0.00 & 0.00 & 0.00 & 0.00 & 0.00 & 0.00 & 0.00 & 0.00 & 0.00 & 0.00 & 0.00 & 0.00 & 0.00 & 0.00 \\
\hline 0.00 & 0.00 & 0.00 & 0.00 & 0.00 & 0.00 & 0.00 & 0.00 & 0.00 & 0.00 & 0.00 & 0.00 & 0.00 & 0.00 & 0.00 & 0.00 & 0.00 & 0.00 & 0.00 & 0.00 \\
\hline 0.10 & 0.00 & 0.00 & 0.00 & 0.10 & 0.00 & 0.10 & 0.00 & 0.10 & 0.00 & 0.10 & 0.00 & 0.10 & 0.00 & 0.10 & 0.00 & 0.10 & 0.00 & 0.10 & 0.00 \\
\hline 0.24 & 0.00 & 0.10 & 0.00 & 0.24 & 0.00 & 0.24 & 0.00 & 0.24 & 0.00 & 0.24 & 0.00 & 0.24 & 0.00 & 0.24 & 0.00 & 0.24 & 0.00 & 0.19 & 0.00 \\
\hline 0.39 & 0.00 & 0.24 & 0.00 & 0.39 & 0.00 & 0.39 & 0.00 & 0.39 & 0.00 & 0.34 & 0.00 & 0.39 & 0.00 & 0.39 & 0.00 & 0.39 & 0.00 & 0.34 & 0.00 \\
\hline 0.49 & 0.00 & 0.34 & 0.00 & 0.49 & 0.00 & 0.49 & 0.00 & 0.49 & 0.00 & 0.49 & 0.00 & 0.49 & 0.02 & 0.49 & 0.00 & 0.49 & 0.05 & 0.49 & 0.02 \\
\hline 0.58 & 0.10 & 0.49 & 0.00 & 0.63 & 0.06 & 0.63 & 0.04 & 0.63 & 0.10 & 0.63 & 0.09 & 0.58 & 0.12 & 0.63 & 0.11 & 0.63 & 0.17 & 0.63 & 0.16 \\
\hline 0.73 & 0.23 & 0.58 & 0.10 & 0.73 & 0.21 & 0.78 & 0.21 & 0.73 & 0.22 & 0.73 & 0.18 & 0.73 & 0.29 & 0.78 & 0.25 & 0.78 & 0.34 & 0.78 & 0.30 \\
\hline 0.92 & 0.43 & 0.73 & 0.24 & 0.92 & 0.36 & 0.87 & 0.40 & 0.87 & 0.40 & 0.87 & 0.36 & 0.87 & 0.47 & 0.87 & 0.43 & 0.87 & 0.54 & 0.87 & 0.51 \\
\hline 1.02 & 1.76 & 0.87 & 1.04 & 1.02 & 1.35 & 1.02 & 1.44 & 1.02 & 1.57 & 1.02 & 1.44 & 1.02 & 1.73 & 1.02 & 1.60 & 1.02 & 1.99 & 1.02 & 1.94 \\
\hline 1.16 & 3.82 & 1.02 & 2.48 & 1.16 & 3.22 & 1.16 & 3.28 & 1.16 & 3.51 & 1.16 & 3.30 & 1.16 & 3.84 & 1.16 & 3.57 & 1.16 & 4.23 & 1.16 & 4.08 \\
\hline 1.31 & 6.58 & 1.16 & 4.50 & 1.31 & 5.76 & 1.31 & 5.64 & 1.31 & 6.09 & 1.31 & 5.81 & 1.26 & 6.39 & 1.31 & 6.09 & 1.31 & 6.93 & 1.31 & 6.70 \\
\hline 1.46 & 8.63 & 1.31 & 6.80 & 1.46 & 7.74 & 1.46 & 7.46 & 1.46 & 7.66 & 1.50 & 7.39 & 1.46 & 8.13 & 1.46 & 7.96 & 1.46 & 8.72 & 1.46 & 8.58 \\
\hline 1.50 & 7.91 & 1.46 & 7.96 & 1.50 & 7.04 & 1.46 & 6.99 & 1.50 & 7.07 & 1.50 & 6.97 & 1.46 & 7.46 & 1.50 & 7.36 & 1.50 & 8.16 & 1.50 & 8.06 \\
\hline 1.46 & 5.31 & 1.50 & 7.59 & 1.46 & 5.04 & 1.46 & 5.14 & 1.46 & 5.14 & 1.46 & 5.09 & 1.46 & 5.36 & 1.41 & 5.36 & 1.41 & 5.66 & 1.46 & 5.78 \\
\hline 1.41 & 4.45 & 1.46 & 5.29 & 1.41 & 4.45 & 1.41 & 4.42 & 1.41 & 4.45 & 1.41 & 4.52 & 1.41 & 4.57 & 1.41 & 4.67 & 1.41 & 4.79 & 1.41 & 5.04 \\
\hline 1.41 & 4.10 & 1.41 & 4.52 & 1.41 & 4.20 & 1.41 & 4.10 & 1.41 & 4.03 & 1.36 & 4.18 & 1.36 & 4.28 & 1.36 & 4.30 & 1.36 & 4.42 & 1.41 & 4.50 \\
\hline 1.36 & 3.78 & 1.41 & 4.10 & 1.41 & 3.81 & 1.36 & 3.68 & 1.36 & 3.73 & 1.41 & 3.73 & 1.36 & 4.03 & 1.36 & 3.93 & 1.36 & 4.03 & 1.36 & 4.23 \\
\hline 1.36 & 3.61 & 1.36 & 3.81 & 1.36 & 3.41 & 1.41 & 3.51 & 1.36 & 3.53 & 1.36 & 3.56 & 1.36 & 3.63 & 1.3 & 3.76 & 1.36 & 3.78 & 1.31 & 3.93 \\
\hline 1.36 & 3.19 & 1.36 & 3.51 & 1.36 & 3.14 & 1.36 & 3.21 & 1.36 & 3.26 & 1.36 & 3.29 & 1.36 & 3.36 & 1.3 & 3.53 & 1.3 & 3.51 & 1.36 & 3.63 \\
\hline 1.36 & 2.25 & 1.36 & 3.29 & 1.36 & 2.03 & 1.36 & 1.93 & 1.36 & 1.88 & 1.36 & 2.03 & 1.36 & 2.52 & 1.36 & 2.22 & 1.36 & 2.62 & 1.36 & 2.97 \\
\hline 1.26 & 0.35 & 1. & 2.32 & 1.2 & 0.20 & 1.26 & 0.07 & 1.26 & 0.22 & 1.26 & 0.27 & 1.2 & 0.57 & 1.2 & 0.30 & 1.2 & 0.47 & 1.26 & 0.77 \\
\hline 1.16 & 0.00 & 1.26 & 0.35 & 1.16 & 0.00 & 1.16 & 0.00 & 1.16 & 0.00 & 1.12 & 0.00 & 1.12 & 0.00 & 1.16 & 0.00 & 1.16 & 0.00 & 1.16 & 0.00 \\
\hline 1.02 & 0.00 & 1.16 & 0.00 & 1.02 & 0.00 & 1.02 & 0.00 & 1.02 & 0.00 & 0.97 & 0.00 & 1.02 & 0.00 & 0.97 & 0.00 & 1.02 & 0.00 & 1.02 & 0.00 \\
\hline 0.92 & 0.00 & 1.02 & 0.00 & 0.92 & 0.00 & 0.87 & 0.00 & 0.87 & 0.00 & 0.87 & 0.00 & 0.87 & 0.00 & 0.82 & 0.00 & 0.87 & 0.00 & 0.92 & 0.00 \\
\hline 0.78 & 0.00 & 0.92 & 0.00 & 0.78 & -0.02 & 0.78 & 0.00 & 0.78 & 0.00 & 0.73 & 0.00 & 0.73 & 0.00 & 0.73 & 0.00 & 0.73 & 0.00 & 0.73 & 0.00 \\
\hline 0.63 & 0.00 & 0.78 & 0.00 & 0.63 & 0.00 & 0.63 & 0.00 & 0.58 & 0.00 & 0.58 & 0.00 & 0.63 & 0.00 & 0.58 & 0.00 & 0.63 & 0.00 & 0.63 & 0.00 \\
\hline 0.49 & 0.00 & 0.63 & 0.00 & 0.49 & 0.00 & 0.49 & 0.00 & 0.49 & 0.00 & 0.49 & 0.00 & 0.49 & 0.00 & 0.44 & 0.00 & 0.49 & 0.00 & 0.49 & 0.00 \\
\hline 0.39 & 0.00 & 0. & 0.0 & 0.3 & 0.00 & 0 . & 0. & $0 . c$ & 0. & 0.3 & 0.00 & 0.34 & -0.02 & 0.2 & 0.00 & 0.3 & 0.02 & 0.39 & 0.00 \\
\hline 0.24 & 0.00 & 0.39 & 0.00 & 0.24 & 0.00 & 0.19 & 0.00 & 0.00 & 0.00 & 0.24 & 0.00 & 0.19 & 0.00 & 0.19 & -0.02 & 0.24 & 0.00 & 0.24 & 0.00 \\
\hline 0.49 & 0.00 & 0.24 & 0.00 & 0.97 & 0.00 & 0.97 & 0.00 & 0.00 & 0.00 & 0.97 & 0.00 & 0.97 & 0.00 & 0.00 & 0.00 & 0.97 & 0.00 & 0.97 & 0.00 \\
\hline
\end{tabular}

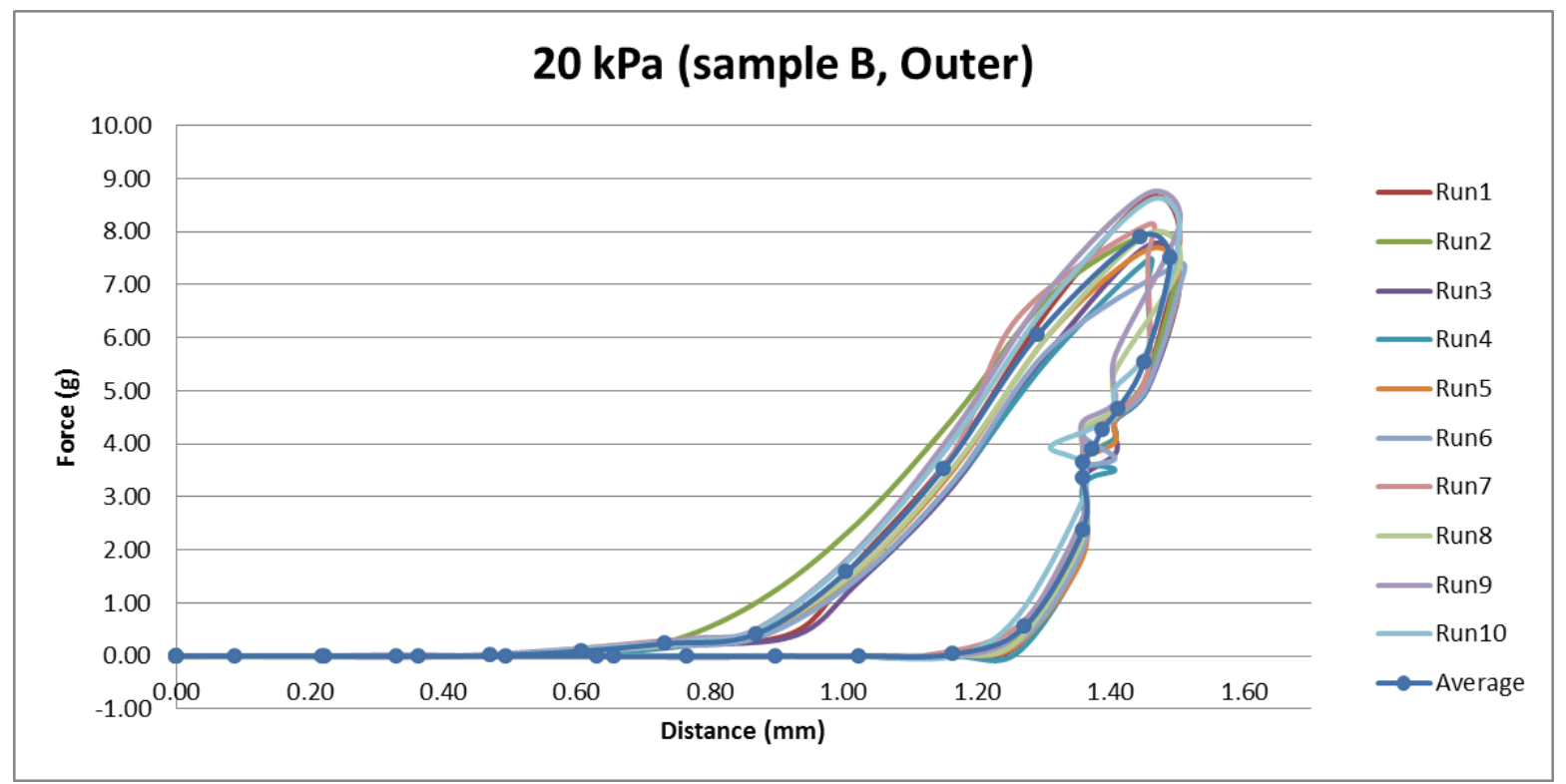




\section{References}

1. Nyengidiki TK. (2008). The incompetent cervix. Online. Septemter $27^{\text {th }}, 2015$ [http://www.scribd.com/doc/6587108/The-Incompetent-Cervix-2

2. Laughon, S. K., Zhang, J., Grewal, J., Sundaram, R., Beaver, J., \& Reddy, U. M. (2012). Induction of labor in a contemporary obstetric cohort. American Journal of Obstetrics and Gynecology, 206(6).

3. Wing, D. A. (2010). Induction of Labor. Protocols for High-Risk Pregnancies An EvidenceBased Approach, 140-147.

4. Smith, J. (2013). A simplified cervix model in response to induction balloon in pre-labour. Theor Biol Med Model Theoretical Biology and Medical Modelling, 10(1), 58.

5. Smith, J.A. Atwell, K.A. El-Falou and Leshchenko, A. (2012) Active Cervix Phantom for Labour Induction Training, IEEE Healthcare Innovation Conference: Translational Engineering in Health and Medicine, Houston, TX, USA,

6. Buchmann, E., \& Libhaber, E. (2007). Accuracy of cervical assessment in the active phase of labour. BJOG: An International Journal of Obstetrics \& Gynaecology, 114(7), 833-837.

7. Peisner, D. B., \& Rosen, M. G. (1986). Transition from latent to active labor. Obstetrics and Gynecology, 68, 448-451.

8. Sharf, Y., Farine, D., Batzalel, M., Megel, Y., Shenhav, M., Jaffa, A., \& Barnea, O. (2007). Continuous monitoring of cervical dilatation and fetal head station during labor. Medical Engineering \& Physics, 29(1), 61-71.

9. Hockaday, L. A., Kang, K. H., Colangelo, N. W., Cheung, P. Y., Duan, B., Malone, E., . . . Butcher, J. T. (2012). Rapid 3D printing of anatomically accurate and mechanically heterogeneous aortic valve hydrogel scaffolds. Biofabrication, 4(3), 035005.

10. Martinez, R. V., Branch, J. L., Fish, C. R., Jin, L., Shepherd, R. F., Nunes, R. M., . . . Whitesides, G. M. (2012). Robotic Tentacles with Three-Dimensional Mobility Based on Flexible Elastomers. Adv. Mater. Advanced Materials, 25(2), 205-212.

11. Satria, S. Wen, L.J, Samantha, C.W.T. (2015). Portable Amphibious Spherical Rolling Robot with Live-Streaming Capability for Ground and Aquatic Deployment, IRC-SET 2015.

12. Cheney, N., Maccurdy, R., Clune, J., \& Lipson, H. (2013). Unshackling evolution. Proceeding of the Fifteenth Annual Conference on Genetic and Evolutionary Computation Conference - GECCO '13. 
13. Cho, K., Koh, J., Kim, S., Chu, W., Hong, Y., \& Ahn, S. (2009). Review of manufacturing processes for soft biomimetic robots. International Journal of Precision Engineering and Manufacturing Int. J. Precis. Eng. Manuf., 10(3), 171-181.

14. Hiller, J., \& Lipson, H. (2012). Automatic Design and Manufacture of Soft Robots. IEEE Trans. Robot. IEEE Transactions on Robotics, 28(2), 457-466.

15. Iams, J. (2003). Prediction and early detection of preterm labor. Obstetrics \& Gynecology, 101(2), 402-412.

16. Leppert, P. C. (1995). Anatomy and Physiology of Cervical Ripening. Clinical Obstetrics and Gynecology, 38(2), 267-279.

17. Danforth, DN. (1947) The fiborous nature of the human cervix and its relation to the isthmic segment in gravid and nongravid uteri. Am J Obstet Gynecol. 53(4): 541—557.

18. Danforth, DN. (1983). The morphology of the human cervix. Clin Obstet Gynecol. 26(1): $7-13$.

19. Yu, S. Y., Tozzi, C. A., Babiarz, J., \& Leppert, P. C. (1995). Collagen Changes in Rat Cervix in Pregnancy--Polarized Light Microscopic and Electron Microscopic Studies. Experimental Biology and Medicine, 209(4), 360-368.

20. Ledger, W., \& Witting, W. (1972). The Use Of A Cervical Dilatation Graph In The Management Of Primigravidae In Labour. BJOG: An International Journal of Obstetrics and Gynaecology BJOG:An International Journal of O\&G, 79(8), 710-714.

21. Friedman, E. A. (1955). Primigravid Labor. Obstetrics \& Gynecology, 6(6), 567-589.

22. Friedman, E. A., \& Kroll, B. H. (1969). Computer Analysis Of Labour Progression. BJOG: An International Journal of Obstetrics and Gynaecology BJOG:An International Journal of O\&G, 76(12), 1075-1079.

23. Friedman, E. A. (1967) Labor Clinical Evaluation and Management. New York:Meredith

24. Schulman, H., and Ledger, W. J. (1964): Obstetrics and Gynecology, 23, 442.

25. Bishop, Edward H. (1964). "Pelvic Scoring for Elective Induction". Obstetrics \& Gynecology 24 (2): 266-268. PMID 14199536.

26. Bujold, E., Blackwell, S. C., Hendler, I., Berman, S., Sorokin, Y., \& Gauthier, R. J. (2004). Modified Bishop's score and induction of labor in patients with a previous cesarean delivery. American Journal of Obstetrics and Gynecology, 191(5), 1644-1648.

27. Myers, K., Paskaleva, A., House, M., \& Socrate, S. (2008). Mechanical and biochemical properties of human cervical tissue. Acta Biomaterialia, 4(1), 104-116. 
28. Iams, J. D., Goldenberg, R. L., Meis, P. J., Mercer, B. M., Moawad, A., Das, A., . . Roberts, J. M. (1996). The Length of the Cervix and the Risk of Spontaneous Premature Delivery. New England Journal of Medicine N Engl J Med, 334(9), 567-573.

29. Monitoring the Effacement of the Uterine Cervix by Transperineal Sonography: A new Perspective. (1995). Journal of Diagnostic Medical Sonography, 11(6), 335-336.

30. Mattei A (1855) : Essai sur l'accouchement physiologique. Paris, France: Victor Masson;.

31. Storer HR (1870): Thirtieth regular meeting march 15. J Gynaecol Soc Boston, 3(3):153-165. [Reported by Horatio R. Storer, Secretary]

32. Aveling JH (1872): On dilatation of the Cervix Uteri by Bougie. Brit Med J, 2(622):577-578.

33. Moleti, C. A. (2009). Trends and Controversies in Labor Induction. MCN, The American Journal of Maternal/Child Nursing, 34(1), 40-47.

34. Arsenijević S, Cakic N (2004): Instrument for fluid injection and dilation probe for implantation in body cavities. European Patent No.1299146;27 Available at http://www.google. com/patents/EP1299146B1,

35. Cromi, A., Ghezzi, F., Agosti, M., Serati, M., Uccella, S., Arlant, V., \& Bolis, P. (2011). Is transcervical Foley catheter actually slower than prostaglandins in ripening the cervix? A randomized study. American Journal of Obstetrics and Gynecology, 204(4).

36. Guinn, D. A., Davies, J. K., Jones, R. O., Sullivan, L., \& Wolf, D. (2004). Labor induction in women with an unfavorable Bishop score: Randomized controlled trial of intrauterine Foley catheter with concurrent oxytocin infusion versus Foley catheter with extra-amniotic saline infusion with concurrent oxytocin infusion. American Journal of Obstetrics and Gynecology, 191(1), 225-229.

37. Phillips, J. (1920). The Induction Of Premature Labour:. The Lancet, 196(5067), 741-743.

38. Veyre JF, Laumosne J, Mavel A, Feldman JP, Pelikan P, Michiels Y (1974): Le ballon de Boissard: antiquité ou moyen moderne de déclenchement.

Revue Francaise de Gynecologie et d'obstetrique, 69(10): 535-539.

39. Mei-Dan, E., Walfisch, A., Suarez-Easton, S., \& Hallak, M. (2012). Comparison of two mechanical devices for cervical ripening: A prospective quasi-randomized trial. J Matern Fetal Neonatal Med Journal of Maternal-Fetal and Neonatal Medicine, 25(6), 723-727.

40. Summers, L. (1997). Methods of cervical ripening and labor induction. Journal of NurseMidwifery, 42(2), 71-85. 
41. McGurk, M., Amis, A. A., Potamianos, P., \& Goodger, N. M. (1997). Rapid prototyping techniques for anatomical modelling in medicine. Annals of The Royal College of Surgeons of England, 79(3), 169-174.

42. Kim, S., Laschi, C., \& Trimmer, B. (2013). Soft robotics: A bioinspired evolution in robotics. Trends in Biotechnology, 31(5), 287-294.

43. Shepherd, R. F., Ilievski, F., Choi, W., Morin, S. A., Stokes, A. A., Mazzeo, A. D., . . . Whitesides, G. M. (2011). Multigait soft robot. Proceedings of the National Academy of Sciences, 108(51), 20400-20403.

44. Bartlett, N. W., Tolley, M. T., Overvelde, J. T., Weaver, J. C., Mosadegh, B., Bertoldi, K., . . . Wood, R. J. (2015). A 3D-printed, functionally graded soft robot powered by combustion. Science, 349(6244), 161-165.

45. Gynecological Model Obstetrical Childbirth Obstetric Models Simulators Manikins,Maternal 800-686-5232. (n.d.). Retrieved October 20, 2015, from http://www.chiropractictools.com/gynecological_models.php

46. Hodges, S., Taylor, S., Villar, N., Scott, J., \& Helmes, J. (2013). Exploring physical prototyping techniques for functional devices using .NET gadgeteer. Proceedings of the 7th International Conference on Tangible, Embedded and Embodied Interaction - TEI '13.

47. Gurau, V., \& Armstrong-Koch, T. (2015). Further Improvements of an End-Effector for Robotic Assembly of Polymer Electrolyte Membrane Fuel Cells. Energies, 8(9), 9452-9463.

48. Luk, Michelle; Jung, Kim et al (2014). A Novel Cervical Model for Use in Obstetrics Simulation Training. Unpublished Manuscript. Ryerson University.

49. David Didur (2014), First meeting July $10^{\text {th }}, 2014$. Think2Thing, 483 Bay Street, 105N, Toronto M5G 2C9 